\title{
Agronomic approaches in yield and quality stability of high oleic sunflowers (Helianthus annuus L.)
}

\author{
to obtain the Ph. D. degree \\ in the Faculty of Agricultural Sciences, \\ Georg-August-University Göttingen, Germany
}

presented by

\author{
Burcin Dilci \\ born in Ankara, Turkey
}


D 7

1. Name of referee: Prof. Dr. Jörg M. Greef

2. Name of co-referee: Prof. Dr. Elke Pawelzik

Date of dissertation: 23.10.2008 


\section{"Nothing shocks me}

I'm a scientist." 


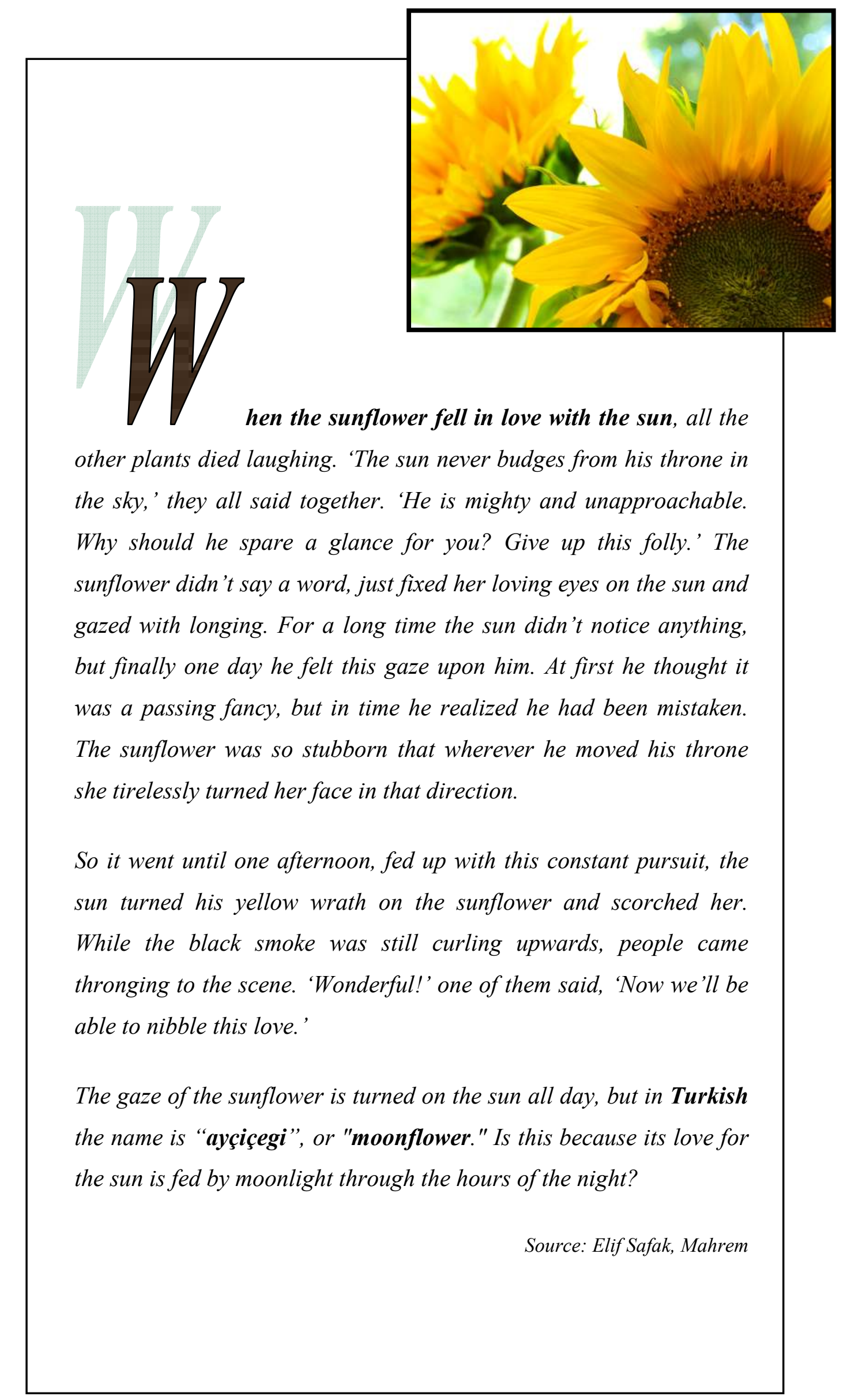




\section{LIST OF ABBREVIATIONS}

$\mathrm{BBCH}$ : Biologische Bundesanstalt,Bundessortenamt and CHemical industry BTH: $\quad$ Benzo $(1,2,3)$ thiadiazole-7-carbothioic acid S-methyl-ester

CULTAN: Controlled Uptake Long Term Ammonium Nutrition

HO: $\quad$ High Oleic

IR: $\quad$ Induced Resistance

$\mathrm{N}: \quad$ Nitrogen

PGPR: $\quad$ Plant Growth-Promoting Rhizobacteria

ppm: $\quad$ parts per million

SAR: $\quad$ Systematic Acquired Resistance

TSW: $\quad$ Thousand Seed Weight

UAN: $\quad$ Urea Ammonium Nitrate

UAN-N: $\quad$ Urea Ammonium Nitrate with Nitrification inhibitor

UAS: $\quad$ Urea Ammonium Sulfate 


\section{TABLE OF CONTENT}

\section{INTRODUCTION}

1.1 Sunflowers (Helianthus annuus L.) 1

1.2 High oleic (HO) sunflowers (Helianthus annuus L.) 1

1.3 Expanding HO sunflower production area in Germany leading studies 3

1.4 Cultivation of HO sunflowers under climatic conditions of central Europe

Critical points at sowing and early growing stages

Importance of variety selection

Fungal diseases and their control

Control of Sclerotinia and Botrytis diseases

1.5 Alternative agricultural approaches in $\mathrm{HO}$ sunflower cultivation

Induced resistance and Acibenzolar-S-methyl (BTH)

Injection of ammonium based liquid fertilizer

Mikro-Vital

1.6 Objectives

\section{Material AND Methods}

2.1 FieLD EXPERIMENTS

2.1.1 Experimental sites

2.1.2 Weather Data

2.1.3 Plant Material

2.1.4 Applications 
2.1.4.1 Fungicide application

2.1.4.2 The plant activator $\mathrm{BION}^{\circledR} \quad 18$

2.1.4.3 Ammonium based liquid fertilization $\quad 19$

2.1.4.4 Mikro-Vital applications $\quad 21$

2.1.5 Field evaluation and data collection 22

2.1.6 Chemical analysis 23

2.1.7 Statistical analysis 24

2.2 GReENHOUSE EXPERIMENTS 25

\section{RESULTS}

3.1. LOCATION AND VARIETY EFFECT

3.1.1 Changes in achene yield 27

3.1.2 Changes in oil content and composition 28

3.1.3 Changes in fungal infection rate 29

3.1.4 Interactions and correlations between the experimental factors 30

3.2 Agricultural applications 31

3.2.1 Effect of fungicide treatment 32

3.2.2 Effect of BTH seed treatment 35

3.2.3 Effect of Bion ${ }^{\circledR}$ leaf spray application $\quad 40$

3.2.4 Effect of ammonium based liquid fertilization 54

3.2.5 Effect of ammonium based liquid fertilization method in combination with Bion ${ }^{\circledR}$ application $\quad 63$

3.2.6 Effect of Mikro-Vital 72

3.3 SUGAR CONTENT AND SUGAR COMPOSITION OF THE PLANT PARTS

3.3.1 Total sugar content 77

$\begin{array}{ll}3.3 .2 \text { Fructose } & 77\end{array}$

$\begin{array}{ll}3.3 .3 \text { Glucose } & 78\end{array}$

$\begin{array}{lll}3.3 .4 \text { Sucrose } & 79\end{array}$

3.3.5 Other water soluble carbohydrates 82 


\section{Discussion}

4.1 Achene and oil yield of HO sunflowers 83

4.1.1 Influence of environment and location 84

$\begin{array}{ll}4.1 .2 \text { Influence of genotype } & 87\end{array}$

4.1.3 Fungal diseases and their influence 88

$\begin{array}{lll}4.1 .4 & \text { Fungicide application } & 89\end{array}$

$\begin{array}{lll}4.2 & \text { Alternative agricultural approaches } & \mathbf{9 0}\end{array}$

4.2.1 The plant activator $\mathrm{BTH}\left(\mathrm{BION}^{\circledR}\right) \quad 90$

4.2.2 Ammonium based liquid fertilization 95

4.2.3 Combination of $\mathrm{BION}^{\circledR}$ and Ammonium Fertilization 97

$\begin{array}{ll}\text { 4.2.4 Mikro-Vital } & 98\end{array}$

4.3 Sugars content of sunflower plant parts 101

$\begin{array}{ll}\text { 4.3.1 Role of sugars in fungal infections } & 101\end{array}$

$\begin{array}{ll}\text { 4.3.2 Dynamics of sugars in the plant } & 101\end{array}$

5 CONCLUSION 105

6 SUMMARY 107

7 ZUSAMMENFASSUNG $\quad 109$

8 REFERENCES 113

9 APPENDIX 129

$\begin{array}{lr}\text { ACKNOWLEDGMENT } & 149\end{array}$

$\begin{array}{ll}\text { CURRICUlum VITAE } & 151\end{array}$ 


\section{INTRODUCTION}

\subsection{Sunflowers (Helianthus annuus L.)}

Sunflower (Helianthus annuus L.) is, together with soybean, rapeseed and peanut, one of the most important annual crops in the world grown for edible oil. Helianthus is a genus in the tribe Heliantheae of the Compositae family. Helianthus annuus L. is a native of North America. Its introduction to Europe was made through Spain. Although this crop was originated in subtropical and temperate zones, through selective breeding, it has been made highly adaptable, especially to dry and warm temperate regions.

\subsection{High oleic (HO) sunflowers (Helianthus annuus L.)}

Regular sunflower oil is characterized by its high content of the essential linoleic acid (C18:2). Through conventional breeding techniques, a high oleic sunflower type has been developed. The high oleic sunflower oil is in appearance very similar to regular sunflower oil. The seed's oil content is around 50 percent, which is similar to the conventional sunflower. However, the fatty acid profile of the high oleic sunflower oil differs quite dramatically from conventional sunflower oil. The HO sunflower oil contains over $80 \%$ oleic acid (C18:1), whereas the regular sunflower oils oleic acid content is around $20 \%$ (Figure 1.1).

In comparison to the other oleic acid sources, the high oleic sunflower oil contains the highest amount of the monounsaturated fat levels (Table 1.1). Typically, HO sunflower oil contains 82 percent oleic acid, 9 percent linoleic acid, and 9 percent 
saturated fatty acids. In human nutrition, the fatty acid composition can be an important benefit to consider. In non-food applications, it is more a necessity to extinguish the unwanted fatty acids.

Regular Sunflower Oil

HO Sunflower Oil

\section{$20-25 \% \quad 60 \%$}

$80-92 \%$
$15-20 \%$

$5-9 \% \quad 9 \%$

nonounsaturated fatty acids Eolyunsaturated fatty acids Saturated fatty acids

Figure 1.1: Comparison between fatty acid composition of regular and $\mathrm{HO}$ sunflower oils.

For many applications, high oleic sunflowers provide an excellent raw material directly from the field. Primarily, no further cost intensive processes for the $\mathrm{HO}$ sunflower oil, like distillation, crystallization or hydrogenation, are necessary. At the moment, mostly used oleic acid source for the industry are beef tallow and palm oleine. Besides higher levels of oleic acid, HO sunflower provides remarkable advantages, such as neutral smell, minimal coloring, lower melting point, or higher purity, over the traditional oleic acid sources (Käb, 2001).

Table 1.1: Fatty acid composition of different oleic acid sources. * $F A=$ Fatty Acid

\begin{tabular}{|c|c|c|c|c|c|c|}
\hline Oleic acid source & $\begin{array}{l}\frac{0}{U} \\
\frac{4}{0} \\
\frac{0}{0} \overline{0} \\
\frac{0}{0}\end{array}$ & 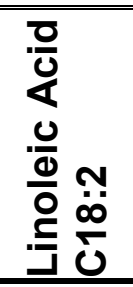 & 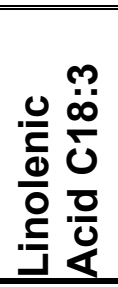 & 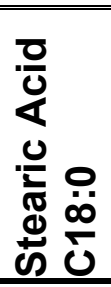 & 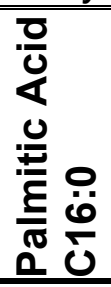 & 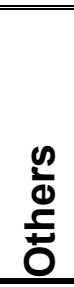 \\
\hline HO-Sunflower Oil & $80-92$ & $3-10$ & 0 & 2 & 4 & 1 \\
\hline HO-Rapeseed Oil & $75-85$ & $6-11$ & 3 & $1-2$ & 4 & 1.7 \\
\hline HO-Soybean Oil & $75-82$ & $2-5$ & $2-5$ & $3-5$ & $6-10$ & 0.7 \\
\hline HO-Safflower Oil & $75-85$ & $14-16$ & 0.3 & 1 & 5 & 0.7 \\
\hline Olive Oil & $73-78$ & $9-11$ & 0.5 & $3-5$ & 10 & 0.7 \\
\hline 00-Rapeseed Oil & $55-60$ & $19-22$ & 10 & $1-2$ & 4.5 & $2-3$ \\
\hline Palm Oil & $36-40$ & $11-12$ & 0.4 & 4.4 & 39.8 & $1-2$ \\
\hline Tallow (Fat) & $36-40$ & $4-5$ & 0.7 & 20 & 26 & 11 \\
\hline Tallow-Oleine $\left(\mathrm{FA}^{*}\right)$ & $60-70$ & $8-12$ & 1 & 1.5 & $3-5$ & 13 \\
\hline Palm Oleine $\left(\mathrm{FA}^{*}\right)$ & $47-50$ & $13-14$ & 0.3 & 3.2 & 31.5 & 2.1 \\
\hline
\end{tabular}

Source: Käb, 2001, Gülzower Fachgespräche, Band 19 
The high oleic sunflower plant needs similar growing conditions as conventional sunflowers. Nevertheless, there are some minor differences in cultivation of this type. The high oleic sunflower plants need a two weeks longer vegetation period. The seed yield potential of high oleic type is in general slightly lower than the regular type. Late ripening varieties give higher seed yield, but therefore are under higher risk of getting infected by the late fungal diseases.

\subsection{Expanding HO sunflower production area in Germany - leading studies}

The largest production area for high oleic sunflower appears in USA with 100,000 ha HO sunflower cultivation annually, followed by France $(30,000-50,000$ ha/year) and is primarily for the food industry. In Germany, sunflower oil with high oleic acid content used mainly in oleo-chemical industry. Production area showed an increasing trend in 2001-2002 up to 7-8 thousand ha in Germany. However it is still a less important oil plant in comparison to rape seed and linseed production. The main reason for this low interest in $\mathrm{HO}$ sunflower production from the farmers' point of view is the yield instability which is mostly related to the agricultural constraints and lack of know-how.

Crop Science Institute of Federal Agricultural Research Centre (FAL) in Braunschweig coordinated two previous projects with the object to secure yield and increase HO sunflower production in Germany. The first "model" project was promoted by Federal Ministry of Food, Agriculture and Consumer Protection (BMELV) in order to encourage $\mathrm{HO}$ sunflower production under the title "Expanding HO sunflower production in Germany" in 1997-2000. The aim of the project was to expand the production area and to develop new markets for the high oleic sunflower oil by targeting good prices for the high quality oil which shall attract the sunflower producers (Schlüter, 2001). In deed, the production area was significantly increased in 1998 and 1999 in correlation with the higher prices. However, price decrease in high oleic sunflower oil in 2000 caused a dramatic reduction in production area. The model project also showed that production risk caused by inconstant yields is also an important reason for the lack of interest from producer's point of view. Project coordinator Dr. Schlüter points at 3 important aspects in $\mathrm{HO}$ sunflower production to be improved. A fast quality measurement method, well adopted varieties, and stabile yield through agricultural measures. 
The second project on $\mathrm{HO}$ sunflowers coordinated by the Crop Science Institute was partially promoted by UFOP in 1998-2000 under the title "Yield security in HO sunflowers through agricultural measures". The main objective of this project was to stabilize the grain yield which is mainly affected by the insect and fungal disease attacks as well as the late ripening behaviour of $\mathrm{HO}$ sunflowers. On the field, driving through paths were established to be able to apply the fungicide at the late vegetation period.

\subsection{Cultivation of HO sunflowers under climatic conditions of central Europe} Environmental effects

Sunflower is a C3 plant and adapts best to the temperate. It requires adequate light, has tolerance to both cold and high temperatures that contributes to sunflower's adaptation in different environments (Robinson, 1978). However, in general, sunflowers grow best in dry and warm regions where sum of temperature reaches $1500-1700^{\circ} \mathrm{C}$ in the cultivation period (Hugger, 1989). Its characteristics make the sunflowers suitable to the southern Europe climatic conditions. Sunflower's adaptation decreases northwards starting from central Europe, which includes northern Germany.

Sunflower is classified as a very sensitive crop to environmental influences (Diepenbrock, 1995). Environmental factors affect the yield and quality traits of sunflower seeds (Ahmad, 2001). Yield parameters such as number of full achenes and the achene weight (Rawson et al., 1984) as well as the oil yield (Dompert and Beringer, 1976) react negatively to high temperature (above $30^{\circ} \mathrm{C}$ ). Temperature is also the main environmental factor affecting oil quality (Tremolieres et al., 1982). It is also reported in $\mathrm{HO}$ sunflowers that environmental factors, especially the soil characteristics, are the determining factors in grain yield (Vetter, 1996). HO type sunflowers have a comparable yield potential to the commercial type sunflowers (Müller-Sämann et al., 2003). However, mainly climatic factors hinder its production in cooler temperate climate zones including Germany. In contrast to the main sunflower production regions in subtropical or Mediterranean zones, main constraint in Germany, regarding climatic factors, is the cold and wet weather conditions during germination and late maturing. Therefore its cultivation in Germany is considered to 
be problematic (Graf et al., 1999) and stabilizing seed yield and quality are the main objectives to the agricultural practices. Furthermore, high temperatures are necessary for high oil and oleic acid yield (Reinbrecht, 2003).

\section{Critical points at sowing and early plant development stages}

Actual $\mathrm{HO}$ sunflower varieties germinate satisfactory only above $10^{\circ} \mathrm{C}$ soil temperature, although studies showed that there are inbred lines that germinate already at $8^{\circ} \mathrm{C}$ (Rühl, 2003). Cultivars germinating at low temperatures with rapid seedling development play an important role in stable yield achievement in $\mathrm{HO}$ sunflower production. Early germinated young plants (at 6-8 leave stage) react very sensitive to frost (Mielke, 2002) and therefore the yield accumulation stays risk. Wet and cold weather conditions also at the end of vegetation period in autumn increase the risk of diseases caused by fungal pathogens. The fact that $\mathrm{HO}$ sunflower varieties ripen in average 14 days later than the regular ones underlines the importance of early sowing time.

\section{Importance of variety selection}

Choice of correct $\mathrm{HO}$ sunflower hybrids is an extremely important factor for securing high yields. Following properties are to be considered in variety selection for oil-type sunflower production in Germany; high grain yield potential, high oil percentage, high oleic and low stearic acid content, disease resistance, early maturation (Hugger, 1989; Müller-Sämann et al., 2003).

Commercially, there are two types of $\mathrm{HO}$ sunflower varieties available in Germany representing different oleic acid levels of the oil seed. The seed oil of $80+\mathrm{HO}$ sunflower varieties contains over 80 percent oleic acid, whereas the $90+$ varieties achieve over 90 percent oleic acid (UFOP, 2003).

\section{Fungal diseases and their control}

The most important fungal diseases of sunflowers in Germany are Sclerotinia sclerotiorum (Lib.) de Bary, often called the "white mold" fungus, and Botrytis cinerea (Schlüter and Rühl, 1999). Sclerotinia disease is spread over all climate zones (Masirevic and Gulya, 1992; Porter and Clarke, 1992; Kedera, 1997; Leite et al., 
2000; Huguet and Heiland, 2000) and can infect any part of the plant at any growth stage regardless of the weather conditions (Gulya et al., 1997). Sclerotinia fungus has a wide range of species including rape seed, tobacco, soybean, several vegetable and leguminous species as well as of herbs (Hugger, 1989; Kandel, 2006). Predominantly three diseases, Sclerotinia wilt, middle stalk rot and head rot, are recognized in the field (Nelson, 2000). Sclerotinia wilt is caused by soilborne fungal bodies, so called "sclerotia", that infect primarily the plant roots and penetrates directly into the stem. This type of infection occurs only at high sclerotia intensity in the soil and primarily is a result of not adequate crop rotation (Hugger, 1989).

Sclerotinia head rot and mid-stem infections are caused by airborne ascospores of fungus produced by carpogenic germination of sclerotia under saturated soil moisture conditions (Rashid, 2004). Stalk rot usually appears in the middle or upper portion of the stalk while head rot often starts as spots on the receptacle (Kandel, 2000). Both infections can result complete death of the plant. Sclerotinia head and stalk rot occur mainly in cold and wet regions (Hoffmann and Schmutterer, 1999) and are the most common infection type in central Europe (Schuster, 1993; Schöber-Butin et al., 1999). Sunflowers are most susceptible to Sclerotinia head rot from full flowering until beginning of ripening (Duncan et al., 2003). It causes reductions in yield components (Gulya et al., 1989) and oil content as well as composition (Lazar et al., 1986, Chahal et al, 1988).

Botrytis cinerea, also called "gray mould", is a fungus disease which infects a wide range of annual and perennial plants. It causes infections on several parts of the plant such as flower parts, leaves, buds, shoots, seedlings and fruits (Schuster, 2007; Hugger, 1989). Botrytis can attack the plant at any growth stage; however it preferably infects sunflowers through the conidia (infectious spores) at the end of flowering and ripening which causes the highest yield losses (Hugger, 1989; LfL, 2006) as well as reduction in oil quality (CETIOM, 1989). Wet or humid weather is highly favourable for the spread of the disease and therefore appears mostly in humid autumn (Dieraurer, 2000). Botrytis disease occurs more intensively in humid areas of Northern Germany, but its damage on plants is less than of Sclerotinia diseases (Hoffmann and Schmutterer, 1999; Schöber-Butin et al., 1999). 


\section{Control of Sclerotinia and Botrytis diseases}

Conventional measures against Sclerotinia diseases include chemical control, disease resistance by breeding, and cultural control (Bardin and Huang, 2000) such as suitable crop rotation and selection of adequate production location (Mielke, 2002). A 3-6 year of cultivation pause can significantly reduce the sclerotia intensity in the soil (Termorshuizen, 2002; Mielke, 2002). By choosing early maturing cultivars and/or early sowing date, early ripening of the sunflower heads in cold and wet autumn in temperate climates can be enhanced and thus head and stem rot of sclerotinia can be reduced (Clarke et al., 1992; Slatter, 1992). The level of resistance to Sclerotinia (Feng, 2006) and Botrytis in actual sunflower hybrids is inadequate. Some resistance to Sclerotinia wilt was observed among various inbred lines (Huang, 1980) and hybrids (Huang, 1980; Rashid and Dedio, 1992). Also some inbred lines with a high level of resistance to Sclerotinia head rot could be identified in high oleic sunflowers (Rönicke et al., 2005). Yet the level of resistance to Sclerotinia in current sunflower hybrids is inadequate (Feng et al, 2007). To date no complete sclerotinia resistance is known in cultivated sunflower, although quantitative reactions against $S$. sclerotiorum have been described (Tourvieille de Labrouhe et al. 1996, Degener et al. 1998, 1999, Hahn 2002).

The chemical control of Botrytis by Dichlofluanide or Thiophanatmethyl+Maneb, if sprayed at beginning of flowering, is successful only to some extend (Zimmer and Hoes, 1978). Selecting early maturing cultivars and/or early sowing might help preventing Botrytis attack (LfL, 2000). Suitable crop rotation and selection of suitable production location is suggested as a control method also against Bortytis (Hoffmann and Schmutterer, 1999).

There is no fungicide registered for control of fungal diseases on sunflower in Germany. Folicur ${ }^{\circledR}$ is a broad spectrum fungicide with special strength against Sclerotinia but shall also effect on Botrytis (Bayer, 2004). Commonly it is recommended in oil seed rape cultivation. It is reported by the producer that besides disease control, it shows also useful growth regulatory effects in rape by its use in autumn. 


\subsection{Alternative agricultural approaches in HO sunflower cultivation}

Sunflowers cultivation in Germany is associated with number of constraints affecting its yield and oil quality. Unsuitable weather conditions have influence on yield and quality factors directly or indirectly through heavy fungal susceptibility. Since yield and quality reduction due to fungal disease damage takes the first place in production constraints, it is important to screen potential disease control measures. Lack of registered fungicides against fungal diseases in sunflower makes the disease control even more problematic. Currently, biocontrol agents inducing systematic acquired resistance (SAR) in order to provide a wide range of control mechanism against diseases are a main object of research worldwide. Alternatively, a bacterial mixture as soil treatment is being tested with the aim of achieving healthy and high yielding stands in Europe. Furthermore, a $\mathrm{N}$ fertilization method based on the injection of an ammonium based solution is also being discussed by researchers with the aim of optimal plant nutrition from cultivation and economical point of view as well as achieving healthy stands.

\section{Systematic acquired resistance (SAR) by Acibenzolar-S-methyl (BTH)}

The biological phenomenon "induced resistance" (IR) has been introduced as an alternative or a complementary crop health management approach for conventional protection methods. The IR is in its broadest sense the control of a wide range of microorganisms like fungal pathogens or pests by activation of genetically programmed plant defence mechanisms (Kogel and Langen, 2005). In most plants, low levels of a pathogen inoculum naturally trigger a resistance response - much like the human body's immune system mobilizes to fight a disease (Syngenta, 2001). This resistance may be expressed locally at the site of inoculation (local resistance) or it can also be triggered throughout the whole plant which is called "systematic acquired resistance" abbreviated as SAR (Sticher et al, 1997). SAR can be induced in plants by synthetic chemical agents (Malamy et al., 1990; Zeller et al., 2002). Several biocontrol agents have been shown to induce resistance in the plant (Baysal, 2001). A chemical with the property of inducing resistance systematically is the benzo $(1,2,3)$ thiadiazole-7-carbothioic acid S-methyl Ester (acibenzolar-S-methyl) which is also often called BTH commercialized under the trade mark Bion $尺$ (Kessmann et al., 1996). 
Bion $\circledast$, is a selective, systemic compound used for the disease control in many crops by activating the plant's natural resistance mechanisms. It induces host plant resistance and has no direct activity against target pathogens. Resistance inducing agent Bion ${ }^{\circledR}$ is a product of the company Syngenta. Induced resistance derived by BTH was reported against several fungal diseases (Kessmann et al., 1994; Ruess et al., 1995; Oostendorp et al., 1996; Baysal, 2001) in different plants (Benhamou, 1998; Huang, 2000; Soylu, 2003), but only some in sunflowers (Buschmann, 2002; Fan, 2003; Prats et al., 2002). Zeller (1999) reported high decrease in fire blight disease rate by the plant activator Bion $\AA$ in pear fruit. In sunflowers, BTH provides good protection against Plasmopara helianti (Tosi, 1999) and against Orobanche cumana (Sauerborn, 2001). BTH was also effective controlling Sclerotinia disease in soybean (Dann, 1998).

\section{Injection of ammonium based liquid fertilizer}

In conventional broadcast fertilization, mineral nitrogen is applied to the soil surface primarily in form of nitrate in number of splits. The broadcast nitrate fertilization associates with some ecological and economical disadvantages. Fertilization has to be repeated during the vegetation period depending on the $\mathrm{N}$ demand of the plant which leads to physical damage of the plant leaves as well as the soil. Nitrogen applied as $\mathrm{NH} 3$ is rather instable in the complete soil profile. $\mathrm{N}$ losses occur easily through leaching, denitrification, and votalization accompanied with environmental and atmospheric pollution, as well as economical losses (Sommer, 1992, 2001; Kücke, 2001).

An alternative fertilization method was developed by Prof.Dr. K. Sommer in order to overcome the disadvantages of conventional fertilization method. In contrast to the broadcast application of $\mathrm{N}$ fertilizers, in this alternative method ammonium based fertilizer solution is placed by injection locally to the root zone. Subsurface placement of the liquid fertilizer method is called CULTAN (Controlled Uptake Long Term Ammonium Nutrition) in Germany. The nitrogen nutrition source for the plants by this method is mainly ammonium instead of nitrate as common application form. Ammonium is reported to be the "better" nitrogen form for crops, if applied correctly 
(Sommer and Mertz, 1974). Principally, ammonium based solution is injected in liquid form 4-10 cm deep, depending on the crop, into the soil and forms a high concentrated spot. The plant roots create a dense root-net around this ammonium hotspot (Kücke, 2006). Only a part of the plant roots are directly in contact with the spots at the surface of the ammonium deposits due to its phytotoxicity, and can take up the nitrogen throughout the vegetation period as needed (Sommer, 2001). Thus, the total required nitrogen for the crop can be applied in one treatment which will also prevent losses through leaching and nitrification (Sommer, 1992).

This plant nutrition method shall also lead to more yielding and vital plants in addition to its ecological benefit by mainly hindering nitrate leaching and reducing plant nutrition costs. In response to liquid fertilizer injection, cereals shows in general similar or high grain yield in comparison to the conventional broadcast fertilization (Sommer and Fischer, 1993; Weimar, 2001). Yield increases with this alternative fertilization method were reported for potato (Weimar, 2001; Schumacher, 2001), as well as for winter wheat and winter barley (Kücke, 2001). Blanke and Bacher (1999) indicated reduction in any pathogen infection potential due to the increase in light reflectance in cabbage.

\section{Mikro-Vital}

Recently, a new bacterial fertilizer, called "Mikro-Vital", has been developed by Hungarian researchers. The Mikro-Vital is a liquid product consisting nitrogen and phophorus mobilizer bacteria. This bacterial mixture contains 50\% Pseudomonas, 25\% Azotobacter and 25\% Azospirillum strains. These microorganisms in part transfer $\mathrm{N}$ from the air into the soil in a form that is usable by plants; an average of 60 $\mathrm{kg} \mathrm{N}$ per hectares depending on the type of the soil and the vegetal residue of peduncle and mobilize the phosphorus absorbed between the crystal-lattices of the soil (180 mg P/kg soil depending on the type of the soil) and they make it available for the plant (BIO-NAT Kft, 2005). In parallel, other bacteria stocks decompose the organic surpluses in the soil and increase the quantity of the soil's organic colloids, the ability of providing nourishment, the capacity of water, the volume of interstice, the airiness, and decrease the solidness of the soil. It is reported by the producer that it additionally provides a disinfection effect with an increase of the fertilizer 
concentration. It was also proven by the producer that it disinfects the sclerotia of Sclerotinia sclerotiorum in the soil and decreases the infection level of Fusarium ssp. There is still on-going research on Mikro-Vital in Europe, but only limited information and research results are available until now. Nevertheless, the product is commercially available on the market since 1997 and widely used by farmers in Hungary.

\subsection{Objectives}

Unstable yield and oil quality as well as fungal disease susceptibility under central European climatic conditions are the main constraints for the $\mathrm{HO}$ sunflower production. Correct agricultural approach selection plays the most important role in order to stabilize the yield and quality. An integrated project financed by the Agency of Renewable Resources (FNR) was initiated in 2003 to identify plant production measures to extend the production area of $\mathrm{HO}$ sunflowers in Germany. In this respect, it is essential to screen alternative agricultural approaches that ensure stable kernel and oil yield, desired oil composition, and secure healthy plant development in the predominantly wet autumn, since $\mathrm{HO}$ sunflowers mature late under central European climatic conditions.

Research objectives of this project are as following;

a) Determine how different locations representing different climatic conditions for sunflower production affect $\mathrm{HO}$ sunflower yield and quality,

b) Screen the potential of different $\mathrm{HO}$ sunflower varieties representing different maturity classes at two locations in Germany,

c) Examine alternative agronomic approaches in order to achieve stable yield and oil quality as well as to reduce fungal disease severity. The following alternative applications will be focused on:

- In order to screen any possible effect of fungicides on HO sunflowers, a representative fungicide, Folicur $\AA$ is tested

As an alternative disease control method, the resistance inducing agent, BTH, commercially known as Bion ${ }^{\circledR}$, is examined under field and greenhouse conditions to figure out its effect on $\mathrm{HO}$ sunflowers, 
- A bacterial mixture, Mikro-Vital, as soil treatment is tested in order to screen its effectiveness as plant nutrition and soil disinfection method against soil-borne fungal infections

- Injection of ammonium based liquid fertilizer instead of conventional broadcast fertilization, is tested for its efficacy as plant nutrition method and/or for its ability to promote more vital stands.

d) Explain the development of the fungal pathogens by screening sugar content of the plant parts during the late vegetation period, since fungal pathogens use sugar as the main nutrition source in the plant. 


\section{2}

\section{MATERIAL AND METHODS}

\subsection{FIELD EXPERIMENTS}

A preliminary field experiment was conducted with three replications in 2002 on the experimental fields of the Federal Agricultural Research Centre (FAL) at Braunschweig. The aim of the preliminary experiment was to figure out, whether or not selected agricultural approaches in this study have potential in stabilizing yield and oil quality of $\mathrm{HO}$ sunflowers. The preliminary experiments consisted of two experimental fields that were located $100 \mathrm{~m}$ apart from each other. Soil properties of both fields were very similar. On the Field-1 Galega officinalis L. (Leguminosae) was grown in 2000 followed by maize in 2001. Rye, lupine and grass was grown on the Field-2 in 2000 and maize in 2001.

The main field experiments were established at two locations, at Braunschweig (north Germany) and at Eckartsweier (south Germany). The different variants were set up in 3 (2003) or 4 (2004-2005) replications.

All experiments were conducted in randomized block design with $2.5 \mathrm{~m} \times 8.0 \mathrm{~m}$ plots. Number of replications as well as sowing and harvest dates is given in Table 2.1. All plots except of the liquid fertilizer experiments were supplied by $60 \mathrm{~kg} \mathrm{~N} / \mathrm{ha}$ at Braunschweig and $80 \mathrm{~kg} \mathrm{~N} / \mathrm{ha}$ at Eckartsweier. In order to avoid losses through bird attack, the plots were covered with polyester mashes at the onset of fruit development (Figure 2.1). 
Table 2.1: Sowing and harvest dates in the field experiments.

\begin{tabular}{|c|c|c|c|c|c|}
\hline Field experiments & Year & $\begin{array}{l}\text { Experimental } \\
\text { site }\end{array}$ & *Rep. & $\begin{array}{r}\text { Sowing } \\
\text { date }\end{array}$ & $\begin{array}{r}\text { Harvest } \\
\text { date }\end{array}$ \\
\hline Preliminary experiments & 2002 & Braunschweig & 3 & 08.May & $1-20$ Oct \\
\hline \multirow[t]{4}{*}{ Main experiments } & 2003 & $\begin{array}{l}\text { Braunschweig } \\
\text { Eckartsweier }\end{array}$ & 3 & $\begin{array}{r}\text { 28-29 April } \\
29 \text { April }\end{array}$ & $\begin{array}{r}\text { 8-19 Sept } \\
09 \text { Sept }\end{array}$ \\
\hline & 2004 & Braunschweig & 4 & 28-29 April & 8-19 Sept \\
\hline & & Eckartsweier & & 29 April & 09 Sept \\
\hline & 2005 & $\begin{array}{l}\text { Braunschweig } \\
\text { Eckartsweier }\end{array}$ & 4 & $\begin{array}{l}25 \text { April } \\
11 \text { May }\end{array}$ & $\begin{array}{r}\text { 4-13 Sept } \\
27 \text { Sept }\end{array}$ \\
\hline
\end{tabular}

${ }^{*}$ Rep: Replications

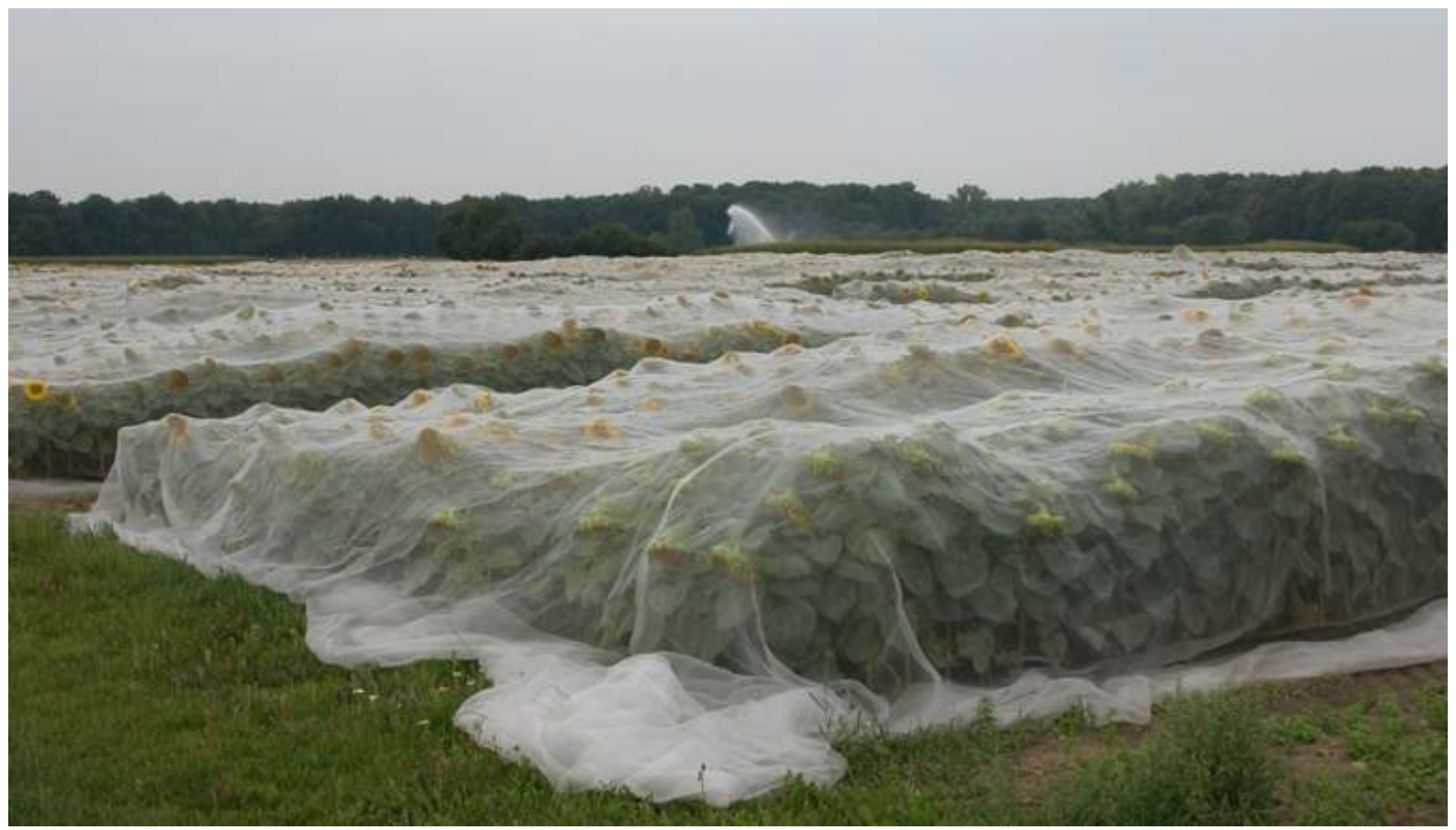

Figure 2.1: HO sunflower fields covered with nets at fruit development stage against bird attack.

\subsubsection{Experimental sites}

The experimental fields of the FAL at Braunschweig $\left(52^{\circ} 17^{`} \mathrm{~N}\right.$ latitude, $10^{\circ} 26^{\circ} \mathrm{E}$ longitude, $80 \mathrm{~m}$ altitude) represent, from climatic point of view, a marginal site for sunflower cultivation with sandy loam soil.

Additional field trials were conducted at a location in Southern Germany, at Eckartsweier ( $48^{\circ} 7^{\circ} \mathrm{N}$ latitude, $7^{\circ} 50^{\circ} \mathrm{E}$ longitude, $140 \mathrm{~m}$ altitude) on a silty loam soil. The field experiments at Eckartsweier were established and managed by the State Plant Breeding Institute of University of Hohenheim in Stuttgart. 


\subsubsection{Weather Data}

Braunschweig: Climatic data of the experimental site Braunschweig were obtained from the Agronomical Research Centre Station of the German National Meteorological Service within FAL. Uncommon heavy rainfall was recorded in 2002 while it was extraordinary warm and dry in 2003 (Figure 2.2). The highest monthly rainfall in 2002 was recorded in July $(225 \mathrm{~mm}$ ) which corresponds the mid-vegetation period for $\mathrm{HO}$ sunflowers in Europe. The highest value for total monthly rainfall in 2003 was achieved in September with $94 \mathrm{~mm}$. In comparison to the first two years, 2004 and 2005 were moderate years with most rain at the end of the vegetation period and relatively higher air temperature. The highest total monthly rainfall for 2004 and 2005 was 116 and 80 mm, respectively, in both cases in July.

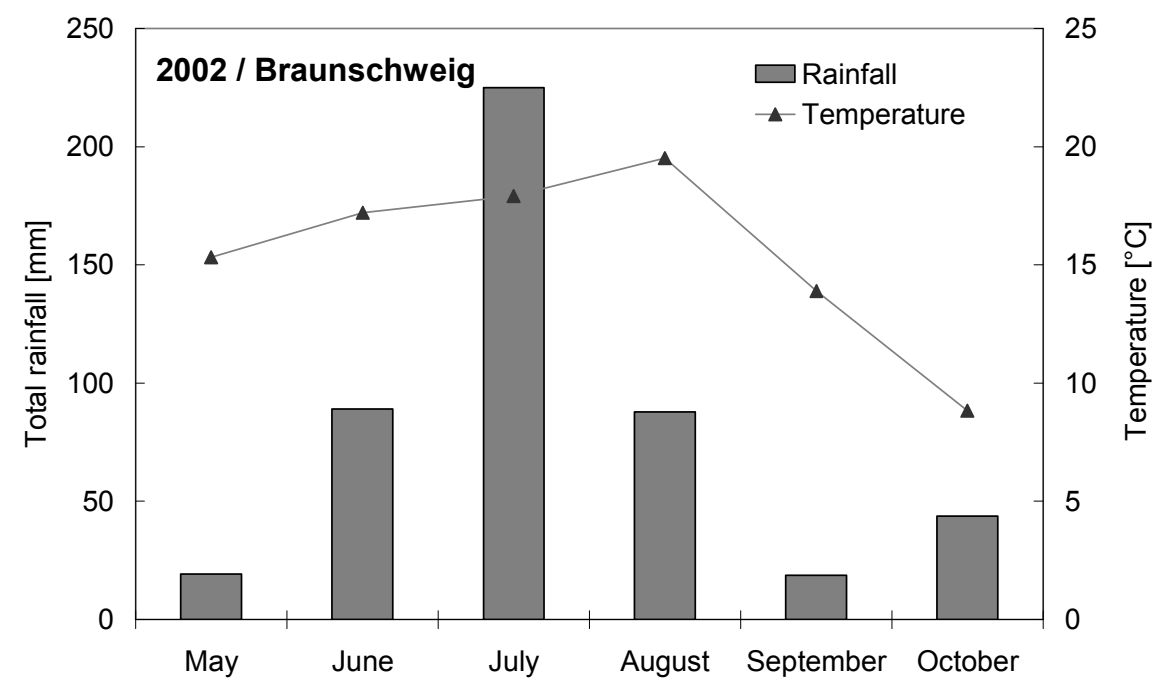

Figure 2.2: Monthly total rainfall and average air temperature at Braunschweig during vegetation period in 2002.

Eckartsweier: Generally, 2003 was a moderate year at the beginning (May-July) and drier at the late vegetation period (August-September) at Eckartsweier (Figure 2.3). Total monthly rainfall for this period was $63.4,44.5,92.7,31.4$ and 36.1 for May, June, July, August and September 2003, respectively. 2004 showed in comparison to 2003 slightly higher rainfall with $287 \mathrm{~mm}$ in total. However, the highest precipitation was recorded later in the vegetation period in August. 2005 was the wettest year with $320 \mathrm{~mm}$ in total during the whole vegetation period. 


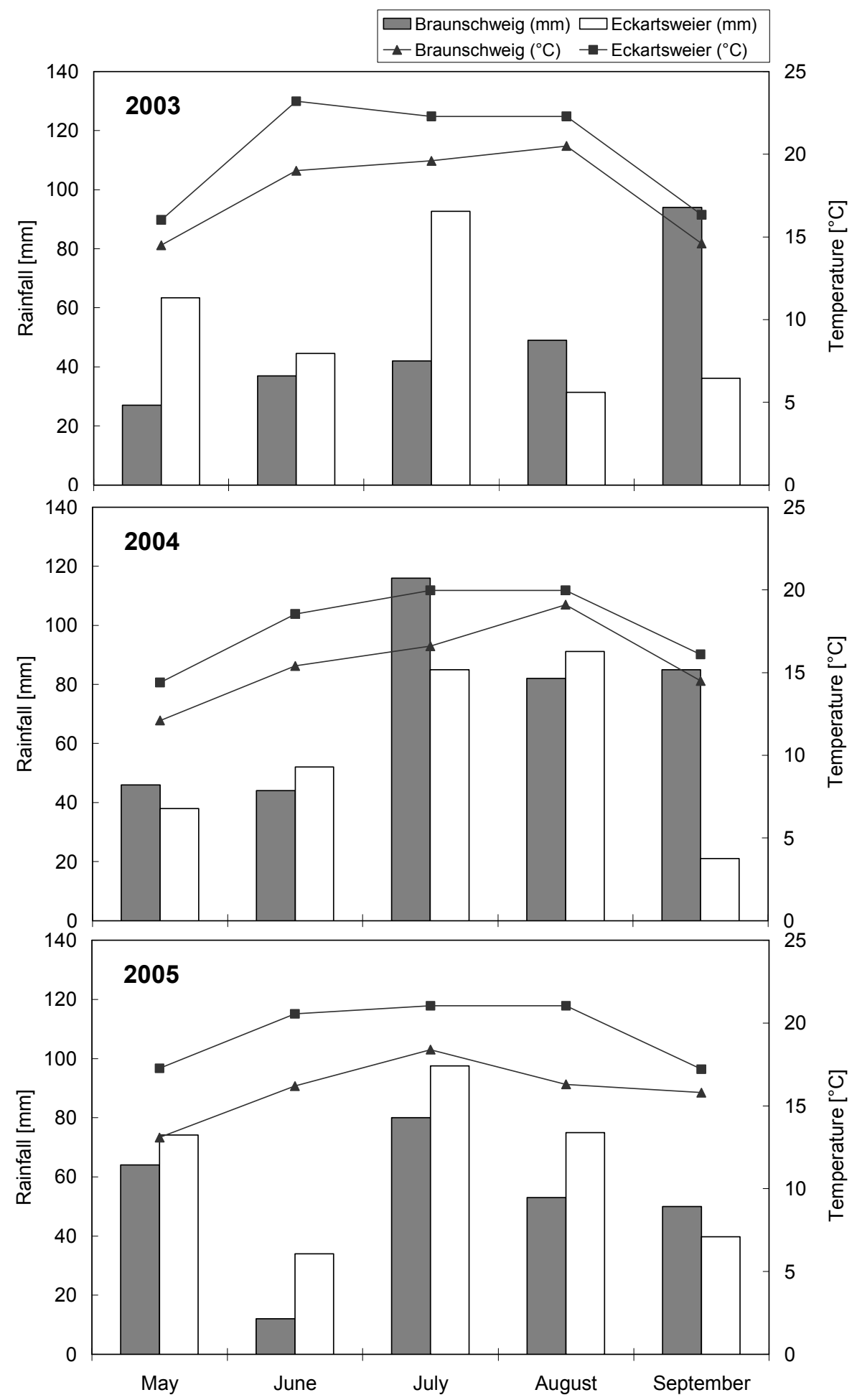

Figure 2.3: Monthly total rainfall and average air temperature at Braunschweig and Eckartsweier during vegetation period in 2003-2005. 


\subsubsection{Plant Material}

Three HO-sunflower varieties, Aurasol (Monsanto), Olsavil (Pioneer) and PR64H61 (Pioneer), representing different ripening classes, were used for the study. All varieties selected for this study have around $90 \%$ oleic acid. "Olsavil" is a late ripening variety with the highest oleic acid content. It presents high and stable yield, long plant height, high oil content, and good tolerance against diseases. "PR64H41" belongs to the mid-ripening class with high oil yield, short plant height and also good tolerance against diseases. The variety PR64H61 from Pioneer was used in the preliminary experiment instead of PR64H41. "Aurasol", the only variety from Monsanto, is also mid-early type with moderate plant height. It was reported by the seed producer Dekalb that Aurasol shows very good resistance against fungal attacks especially against head sclerotinia and botrytis.

\subsubsection{Applications}

The resistance inducing product Bion ${ }^{\circledR}$, ammonium based liquid fertizer injection and bacterial mixture Mikro-Vital were tested on three HO-sunflower varieties. All applications were compared to untreated and conventionally fertilized (60kg N/ha) control plots. A fungicide application with Folicur ${ }^{\circledR}$ from Bayer was also tested in all experimental years. Each application included different concentrations of the treatment medium as well as different application times, which are explained in detail in corresponding sub-chapters. Application times are presented as $\mathrm{BBCH}$ codes, which are shown in Figure 2.4.

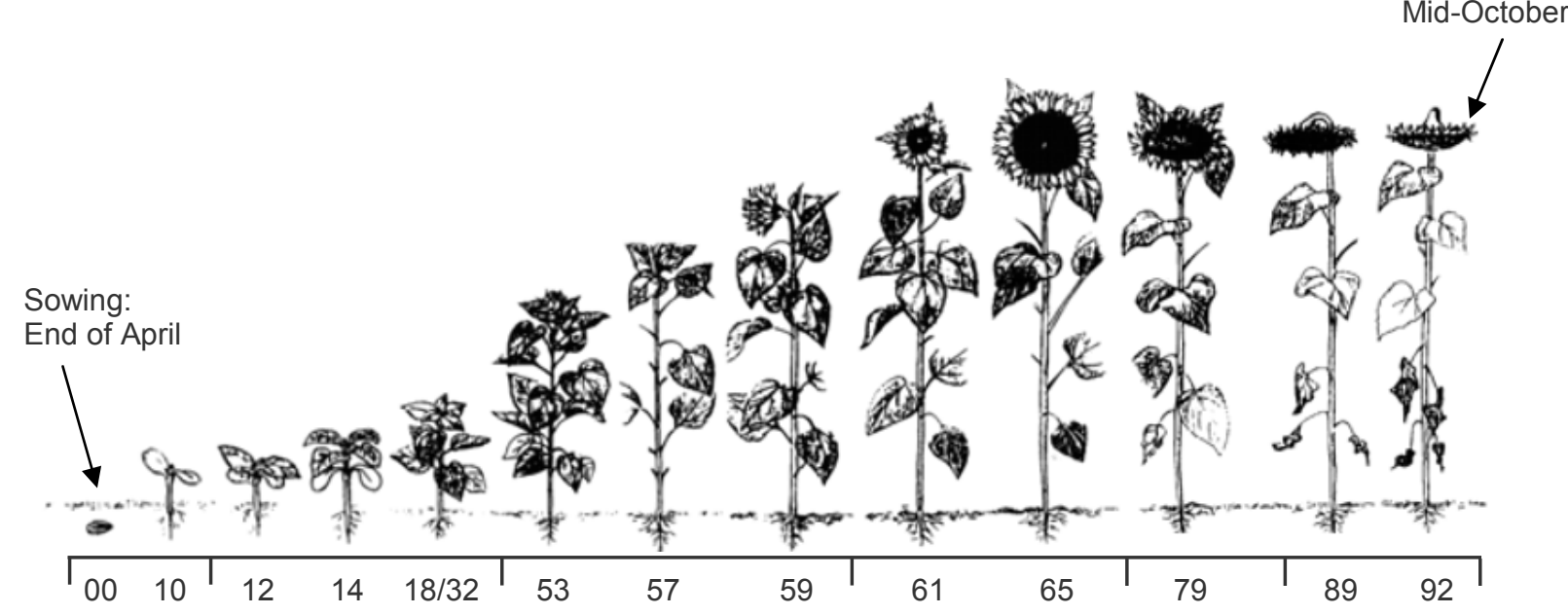

Figure 2.4: Phenological growth stages of sunflower and corresponding $\mathrm{BBCH}$ identification keys (Source: BBA, 2001). 


\subsubsection{Fungicide application}

The foliar fungicide tebuconazole (Folicur ${ }^{\circledR}$, a.i. $430 \mathrm{~g} / \mathrm{l}$, Bayer) was applied $1 \mathrm{~L} / \mathrm{ha}$ concentration with a conventional fungicide sprayer at full flowering stage (BBCH 65) on conventionally fertilized (60 kg N/ha) plots.

\subsubsection{Plant activator Bion ${ }^{\circledR}$}

Benzo $(1,2,3)$ thiadiazole-7-carbothioic acid S-methyl-ester (BTH) formulated as Bion $^{\circledR}$ was obtained from the company Syngenta, Basel, Switzerland. It was applied as seed treatment as well as foliar spray. Treatment of HO sunflower seeds were done by using beer as sticking agent. Bion ${ }^{\circledR}$ as foliar spray application was carried out with a conventional crop sprayer. Five different developmental stages were chosen for application time; emergence (BBCH-Code 09), 6 leaves unfolded $(\mathrm{BBCH}$ Code 16), inflorescence emergence ( $\mathrm{BBCH}$-Code 51), full flowering (BBCH-Code $65)$, and end of flowering ( $\mathrm{BBCH}-\mathrm{Code} 69)$. The plants were sprayed with a water suspension of Bion ${ }^{\circledR}$ at following concentrations: 10, 125 and 250 ppm, prepared from a wettable formulation containing $50 \%(\mathrm{w} / \mathrm{w})$ active ingredient. Application scheme for the plant activator, which differed in the four experimental years, is listed in the Table 2.2 in detail.

Table 2.2: Application scheme of the plant activator Bion ${ }^{\circledR}$ in the field experiments.

\begin{tabular}{|c|c|c|c|c|}
\hline \multirow[b]{2}{*}{ METHOD } & \multirow[b]{2}{*}{ YEAR } & \multirow[b]{2}{*}{ Doses } & \multicolumn{2}{|c|}{ APPLICATION TIME } \\
\hline & & & DESCRIPTION & CODE \\
\hline Bion $^{\circledR}$ Seed Treatment & $2002-2005$ & $\begin{array}{r}25 \mathrm{ppm} \\
250 \mathrm{ppm}\end{array}$ & & \\
\hline Bion $^{\circledR}$ Foliar Application & 2002 & $\begin{array}{r}\text { 10ppm } \\
\text { 125ppm } \\
\text { 250ppm }\end{array}$ & $\begin{array}{l}\text { inflorescence } \\
\text { emergence } \\
\text { full flowering }\end{array}$ & $\begin{array}{l}\mathrm{BBCH}-51 \\
\mathrm{BBCH}-65\end{array}$ \\
\hline & 2003 & $\begin{array}{l}\text { 10ppm } \\
\text { 125ppm } \\
250 p p m\end{array}$ & $\begin{array}{l}\text { emergence } \\
6 \text { leaves unfolded } \\
\text { inflorescence } \\
\text { emergence } \\
\text { full flowering } \\
\text { end of flowering }\end{array}$ & $\begin{array}{l}\mathrm{BBCH}-09 \\
\mathrm{BBCH}-16 \\
\mathrm{BBCH}-51 \\
\mathrm{BBCH}-65 \\
\mathrm{BBCH}-69\end{array}$ \\
\hline & 2004 & $\begin{array}{r}10 \mathrm{ppm} \\
125 \mathrm{ppm}\end{array}$ & $\begin{array}{l}\text { emergence } \\
6 \text { leaves unfolded } \\
\text { full flowering }\end{array}$ & $\begin{array}{l}\mathrm{BBCH}-09 \\
\mathrm{BBCH}-16 \\
\mathrm{BBCH}-65\end{array}$ \\
\hline & 2005 & $\begin{array}{r}10 p p m \\
125 p p m\end{array}$ & $\begin{array}{l}\text { emergence } \\
6 \text { leaves unfolded } \\
\text { full flowering }\end{array}$ & $\begin{array}{l}\mathrm{BBCH}-09 \\
\mathrm{BBCH}-16 \\
\mathrm{BBCH}-65\end{array}$ \\
\hline
\end{tabular}




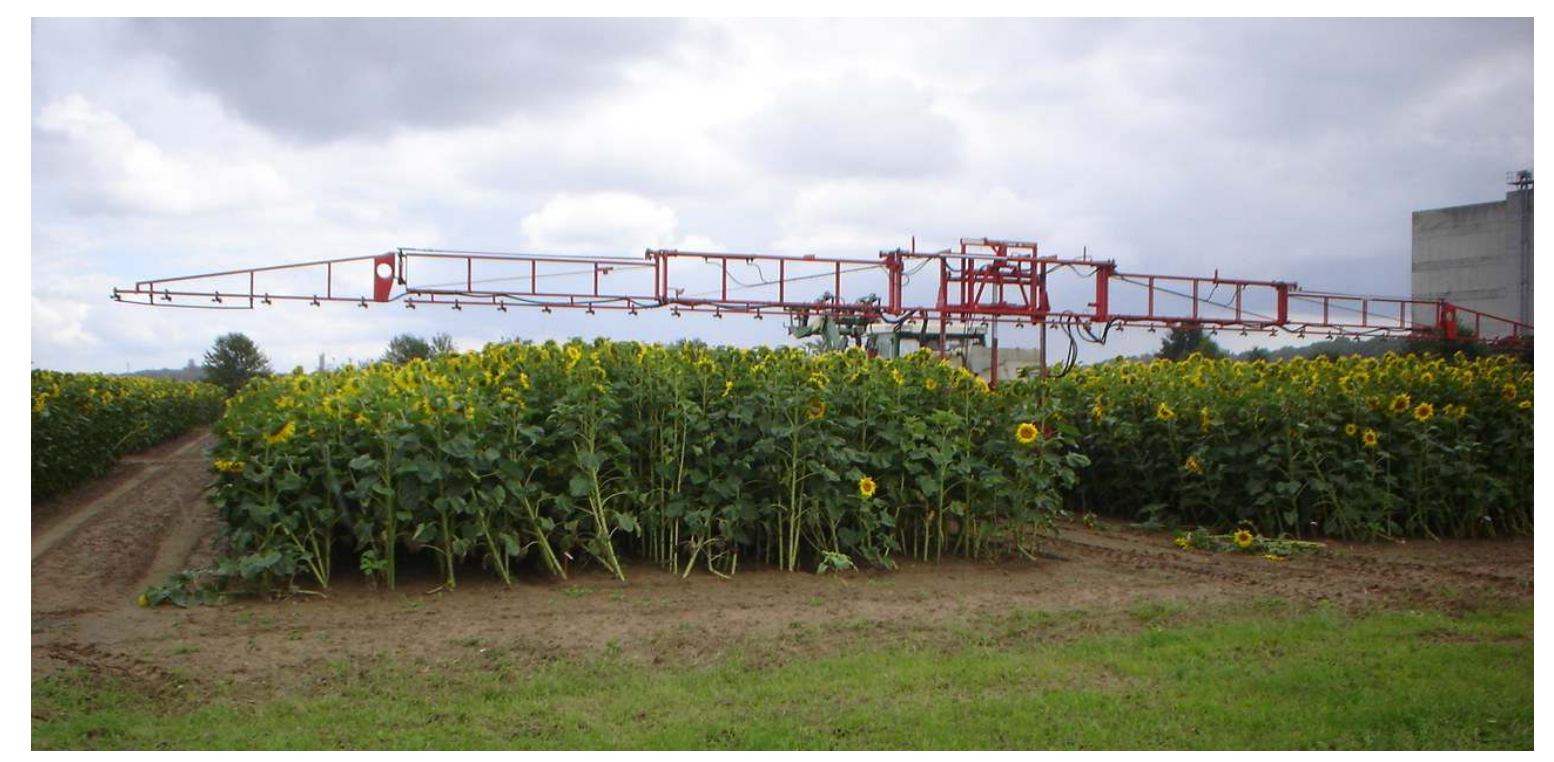

Figure 2.5: Application of the plant activator as foliar spraying on $\mathrm{HO}$ sunflower plots with crop sprayer at full flowering stage (BBCH 65)

\subsubsection{Ammonium based liquid fertilization}

The alternative fertilization method, injection of a ammonium based liquid fertilizer, also called CULTAN "Controlled Uptake Long Term Ammonium Nutrition" was investigated for 3 years during this study. In the preliminary experiments, two available approaches were tested to apply the ammonium based liquid fertilizer to the soil. The first approach was "surface application" of the liquid fertilizer, in which the fertilizer solution is between the rows brought to the soil with special pipes that were pulled over the surface of the field. The second method is based on injection of the ammonium solution into the soil with "point injector" carrying wheels (Figure 2.6a). In the main field experiments from 2003 to 2004, an improved "closed-band-injection" of liquid fertilization was used (Figure 2.5b). In this method, ammonium solution was placed around $12 \mathrm{~cm}$ deep below the surface on a continuous line and immediately covered with soil.

The detailed application scheme for this liquid fertilizer application and its combination with Bion ${ }^{\circledR}$ is listed in Table 2.3. Plants were supplied with liquid fertilizer as three different concentrated solutions; urea ammonium nitrate (UAN), urea ammonium nitrate with nitrification inhibitor (UAN-N) and urea ammonium sulfate (UAS). Different nitrogen concentrations were selected for this study based on the 
recommendations in conventional practices. Regarding soil property at the experimental site Braunschweig, $60 \mathrm{~kg} \mathrm{~N} /$ ha fertilizer solution is recommended. In the preliminary experiments, which was carried out only at Braunschweig, three $\mathrm{N}$ concentrations were tested, recommended $\mathrm{N}$ amount (60 kg/ha), $20 \%$ reduced $\mathrm{N}$ amount (48 kg/ha), and $20 \%$ increased $\mathrm{N}$ amount $(72 \mathrm{~kg} / \mathrm{ha})$. In the main field experiments, $20 \%$ increased $\mathrm{N}$ amount was excluded from the application scheme. In Eckartsweier, recommended $\mathrm{N} / \mathrm{ha}$ is $80 \mathrm{~kg}$. Regarding the recommendation for this site, two $\mathrm{N}$ levels, $80 \mathrm{~kg} / \mathrm{ha}$ and $64 \mathrm{~kg} / \mathrm{ha}$, were tested in liquid fertilizer applications.

(a)

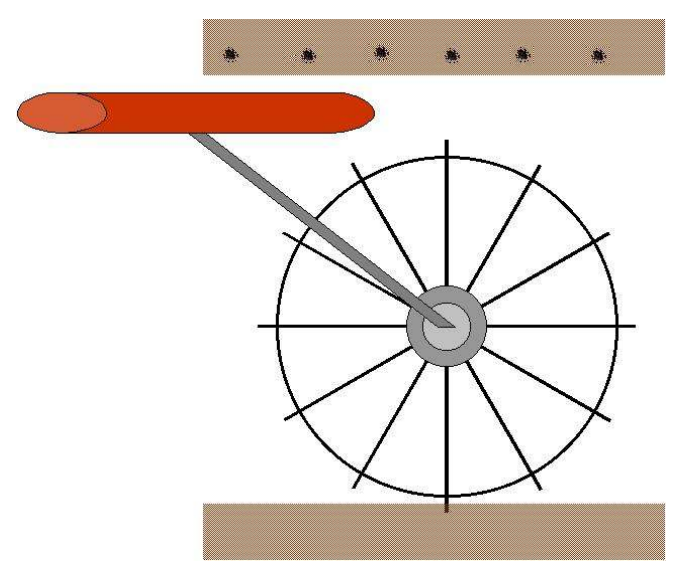

(b)

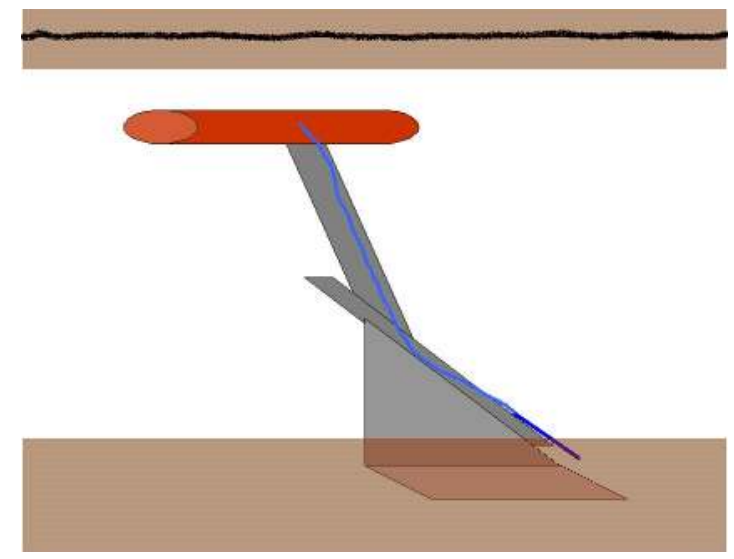

Figure 2.6: Two different methods for injection of the liquid fertilizer (a) the point injection (b) closed-band injection.

Table 2.3: Application scheme of the liquid fertilization method in the field experiments.

\begin{tabular}{|c|c|c|c|c|c|}
\hline \multirow[b]{2}{*}{ METHOD } & \multirow[b]{2}{*}{ YEAR } & \multirow[b]{2}{*}{ SOLUTION } & \multirow[b]{2}{*}{ N/HA } & \multicolumn{2}{|c|}{ APPLICATION TIME } \\
\hline & & & & DESCRIPTION & CODE \\
\hline Surface application & 2002 & UAN & $\begin{array}{l}48 \mathrm{~kg} \\
60 \mathrm{~kg} \\
72 \mathrm{~kg}\end{array}$ & emergence & $\mathrm{BBCH}-09$ \\
\hline Point Injection & 2002 & UAN & $\begin{array}{l}48 \mathrm{~kg} \\
60 \mathrm{~kg} \\
72 \mathrm{~kg}\end{array}$ & emergence & ВBCH-09 \\
\hline \multicolumn{2}{|c|}{ Closed-band-injection 2003} & $\begin{array}{l}\text { UAN } \\
\text { UAN-N } \\
\text { UAS }\end{array}$ & $\begin{array}{l}48 \mathrm{~kg} \\
60 \mathrm{~kg}\end{array}$ & $\begin{array}{l}6 \text { leaves unfolded } \\
\text { stem elongation }\end{array}$ & $\begin{array}{l}\mathrm{BBCH}-16 \\
\mathrm{BBCH}-30\end{array}$ \\
\hline \multicolumn{2}{|c|}{ Closed-band-injection 2004} & $\begin{array}{l}\text { UAN } \\
\text { UAN-N } \\
\text { UAS }\end{array}$ & $48 \mathrm{~kg}$ & 6 leaves unfolded & $\mathrm{BBCH}-16$ \\
\hline
\end{tabular}


Additionally to the liquid fertilization methods, its combination with the plant activator Bion ${ }^{\circledR}$ was included to the experiments in 2003. UAN (48 $\mathrm{kg} \mathrm{N} / \mathrm{ha}$ ) was mixed with Bion $^{\circledR}$ and injected to the soil, offering the plant activator to be taken by the plant roots. In the first year of this combination, the plant activator was mixed to the liquid fertilizer solution in 4 different concentrations: 250, 500, 1000, and 2000 ppm at BBCH16 (Table 2.4). In 2004, only the two lower $\mathrm{N}$ concentrations were applied since the higher concentrations were economically not reasonable. But therefore the mixed solution was tested additionally at a late growth stage $(\mathrm{BBCH}-30$ : beginning of stem elongation)

Table 2.4: Application scheme of liquid fertilization including Bion ${ }^{\circledR}$ in the field experiments.

\begin{tabular}{lccll}
\hline \hline & & & \multicolumn{2}{c}{ APPLICATION TIME } \\
\cline { 3 - 4 } METHOD & YEAR & Bion $^{\circledR}$ Doses & DESCRIPTION & CODE \\
\hline UAN + Bion ${ }^{\circledR}$ & 2003 & $250 \mathrm{ppm}$ & 6 leaves unfolded & BBCH-16 \\
(Closed-band-injection) & $500 \mathrm{ppm}$ & & \\
& & $1000 \mathrm{ppm}$ & & \\
& $2000 \mathrm{ppm}$ & & \\
& 2004 & $250 \mathrm{ppm}$ & 6 leaves unfolded & BBCH-16 \\
& $500 \mathrm{ppm}$ & stem elongation & BBCH-30 \\
\hline \hline
\end{tabular}

\subsubsection{Mikro-Vital applications}

The bacterial mixture Mikro-Vital consists of three microorganisms (Pseudomonas, Azotobacter, Azospirillum), and is available at the company Bio-Nat Kft. in Hungary. According to the recommendation by the company, 1 liter Mikro-Vital per hectare was diluted into 400 liters water before application to the soil. Mikro-Vital solution was sprayed over the prepared soil just before sowing, and immediately mixed $5-6 \mathrm{~cm}$ deep into the soil in 2003 to 2005. In addition to the Mikro-Vital application, its combination with the plant activator Bion ${ }^{\circledR}$ was tested in 2004 and 2005. In these plots, the soil was treated with Mikro-Vital solution prior to seeding and foliar treated with 125 ppm Bion ${ }^{\circledR}$ at 6 leaves stage $(\mathrm{BBCH} 16)$. 
Table 2.4: Application scheme of the liquid fertilization and Bion ${ }^{\circledR}$ combination in the field experiments.

\begin{tabular}{|c|c|c|c|c|}
\hline \multirow[b]{2}{*}{ METHOD } & \multirow[b]{2}{*}{ YEAR } & \multirow[b]{2}{*}{ CONCENTRATION } & \multicolumn{2}{|c|}{ APPLICATION TIME } \\
\hline & & & DESCRIPTION & CODE \\
\hline Mikro-Vital & $2003-2005$ & 1L/ha & at soil preparation & - \\
\hline Mikro-Vital+ Bion $^{\circledR}$ & $2004-2005$ & $\begin{array}{l}\text { 1L/ha + } \\
\text { 125ppm }\end{array}$ & 6 leaves unfolded & $\mathrm{BBCH}-16$ \\
\hline
\end{tabular}

\subsubsection{Field evaluation and data collection}

Evaluation of the fungal infection by the pathogens Sclerotinia and Botrytis was carried out 3-4 times in 2-3 weeks intervals starting from beginning of the flowering and until the end of vegetation period just before harvest. Number of plants of three rows showing any infection symptom was recorded and calculated as percent per plot.

All samples were harvested per hand. Grain yield was determined on total harvested heads, calculated as $\mathrm{dt} / \mathrm{ha}$ and adjusted for $9 \%$ seed moisture. Yield related traits (Table 2.5) were determined on 20 plants standing next to each other in the middle row of the plots.

Table 2.5: Evaluated parameters in the evaluation for the field experiments

\begin{tabular}{ll}
\hline \multicolumn{1}{c}{ PARAMETER } & DESCRIPTION \\
\hline Fungal infection rate [\%] & \% infected plants in a plot \\
\hline Yield related traits & Calculated on plot yield (9\% seed moisture) \\
Grain yield [dt/ha] & $\begin{array}{l}\text { Averaged on } 20 \text { plants in middle row } \\
\text { Averaged on 20 plants in middle row } \\
\text { Plant height [cm] } \\
\text { Head diameter [cm] } \\
\text { Thousand seed weight [g] (TSW) } \\
\text { harvested seeds }\end{array}$ \\
\hline Oil quality parameters & $\begin{array}{l}\text { Evaluated on representative samples from total } \\
\text { Oil content [\%] }\end{array}$ \\
Oleic acid [\%] & \\
Linoleic acid [\%] & \\
Stearic acid [\%] & \\
\hline Sugar componed seeds \\
Fructose [\%] & Averaged on 10 selected plants in a plot \\
Glucose [\%] & \\
Sucrose [\%] & \\
Rest soluble carbohydrates [\%] & \\
\hline \hline
\end{tabular}


For the oil content and fatty acid analysis, seeds from total harvest plots were mixed, and representative samples were taken. For sugar analysis, additional plots were established. 10 plants per plot were harvested, segmented, and analyzed for sugar content and components.

\subsubsection{Chemical analysis}

\section{Oil analysis}

Sample preparation: Harvested seeds were mixed, ground with an herb mill and stored cold. $300 \mathrm{mg}$ per sample was weighted into the centrifuge glass tubes for the analyses. $3 \mathrm{ml}$ petroleum benzene (boiling point $40-60^{\circ} \mathrm{C}$ ) was added to the tubes, closed with a lid. The samples were extracted for $20 \mathrm{~min}$ in an ultrasound bath and then centrifuged (Sonorex Super Digital 10P). $1 \mathrm{ml}$ of the surface liquid were pipetted and transferred to a reaction tube. $20 \mu \mathrm{l}$ sodium methylate (diluted in $1.7 \mathrm{ml} 2 \mathrm{~mol} / \mathrm{l}$ methanol; $\mathrm{CH}_{3} \mathrm{ONa}$ is as $5.4 \mathrm{~mol} / \mathrm{l}$ commercially available) was added to the tube for deesterification and shaken for $15 \mathrm{sec}$. After a minimum of 15 min of incubation time, water free calcium chloride was added with the point of a spatula and shaken. The surface liquid was transferred into the glass vials and made ready for gas chromatography (GC) analysis.

Analysis: The fatty acid spectrum was determined using a HP 5890 Series II plus gas chromatograph fitted with an automatic sampler (HP 7673) for a split-type injection $\left(280^{\circ} \mathrm{C}\right)$, a flame ionisation detector $(\mathrm{FID})$ at $270^{\circ} \mathrm{C}$ and an isotherm oven $\left(220^{\circ} \mathrm{C}\right)$. The GC was equipped with a $30 \mathrm{~m}$ AT-Silar capillary column (Alltech, $0.25 \mathrm{~mm}$ I.D., $0.25 \mu \mathrm{m}$ film thickness. No.: 13855). $40 \mathrm{ml} / \mathrm{min}$ nitrogen $\left(\mathrm{N}_{2}\right)$ was used as carrier gas.

\section{Soluble sugar analysis}

Sample preparation: 5 plants per plot of the variety Aurasol in 2002 were hand harvested within the border rows of the control plots. In 2003, 10 plants per plot of all three studied varieties were also hand harvested in additionally established plots. 3 sampling dates in 2002 (118, 145 and 159 days after sowing) and 5 sampling dates in 2003 (66, 79, 86, 109 days after sowing) were selected. Since there were both green and ripe plants 159 days after sowing in 2002, those were analyzed separately. Plants were cut into segments of a length of $30 \mathrm{~cm}$ starting from the 
bottom. Each segment was cut vertically into a half and than horizontally into small peaces. The sunflower head was separated to four parts as receptacle centre, inner and outer disc and the seeds (Figure 2.7). The three head parts were also cut in small peaces. The samples were packed in plastic bags and immediately stored at $20{ }^{\circ} \mathrm{C}$. For the analysis, samples were freeze-dried and ground to fine powder.
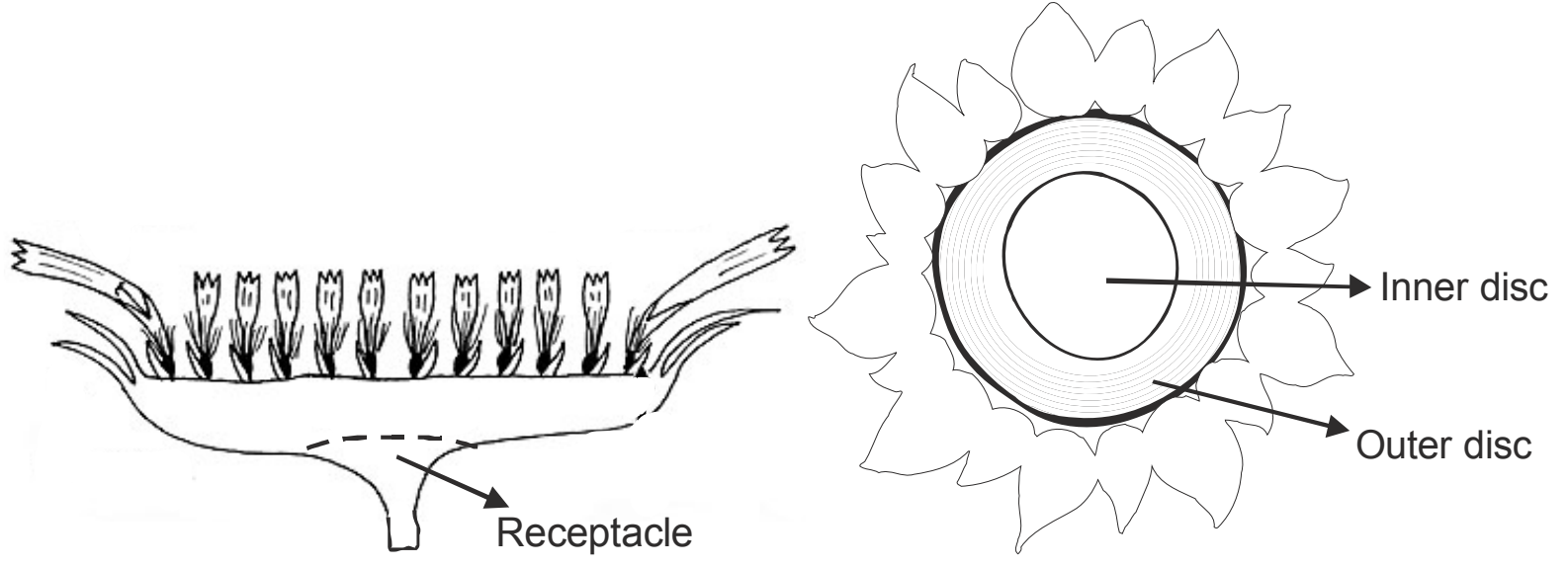

Figure 2.7: Sunflower head parts used for sugar analysis.

Analysis: Fructose, glucose, sucrose, and the rest water soluble carbohydrates were analyzed. $1.00 \mathrm{~g}$ per sample was weighted into $50 \mathrm{ml}$ flasks. Distilled water was added to about $50 \%$ volume, shaken for an hour to dissolve free sugars and filled up to $50 \mathrm{ml}$ level. The mixture was filtered and the filtrate was poured into vial bottles. Sugar analysis was done by using an isocratic High Performance Liquid Chromatography (HPLC) of Kontron Instruments with a column Rezex RPM (300 x $7.8 \mathrm{~mm}$, Phenomenex) and RI-detection (ERMA ERC-7512) with distilled water as solvent at a flow rate of $0.6 \mathrm{ml} / \mathrm{min}$ at $60^{\circ} \mathrm{C}$ temperature.

\subsubsection{Statistical analysis}

All statistical analyses were done by the General Linear Model (GLM) procedures of the Statistical Analysis System (SAS) software version 8.1 (SAS Institute, 1999). All yield and quality parameters as well as the fungal infection rate data were analyzed separately for years and sites, as the concentration and the application time of the treatments differed. Differences between treatments were detected by the least significant difference based on a Tukey Kramer's Honestly Significant Different (HSD) test at the $\mathrm{P}<0.05$ probability level. 


\subsection{GREENHOUSE EXPERIMENTS}

Additional to the field trials, an experiment was established in 2003 in order to evaluate the effect of Bion ${ }^{\circledR}$ on Sclerotinia sclerotiorum infection under greenhouse conditions. 125 ppm Bion ${ }^{\circledR}$ was tested as seed treatment and foliar application at two growth stages $(\mathrm{BBCH} 12$ and $\mathrm{BBCH} 16)$. Ten pots with a single plant of the varieties Aurasol and Olsavil were used per treatment. The greenhouse conditions were maintained at $14 \mathrm{~h}$ daylight, $20 \pm 3^{\circ} \mathrm{C}$ day and $13 \pm 1^{\circ} \mathrm{C}$ night temperatures. The plants were irrigated as needed.

The test of Bertrand and Tourvieille (1987) was modified to determine the reaction of sunflowers to artificial infection by Sclerotinia. At five different growth stages, with 2 weeks intervals, starting from the first leaf pair stage, the third fully grown leaf from the top was infected with Sclerotinia inoculum (Figure 2.8). The Sclerotinia culture was supplied by the State Plant Breeding Institute Research Station in Eckartsweier. One $\mathrm{cm}^{2}$ was cut from the culture and placed at the extremity of the leaf. The mycelium was fixed with tape to the leaf. In order to keep the inoculum in a humid atmosphere, sprayed with about $10 \mathrm{ml}$ water and covered with a transparent plastic bag. For data recording, the plants were observed periodically after inoculation for leaf lesions, diseased stems and the number of infected or dead plants.
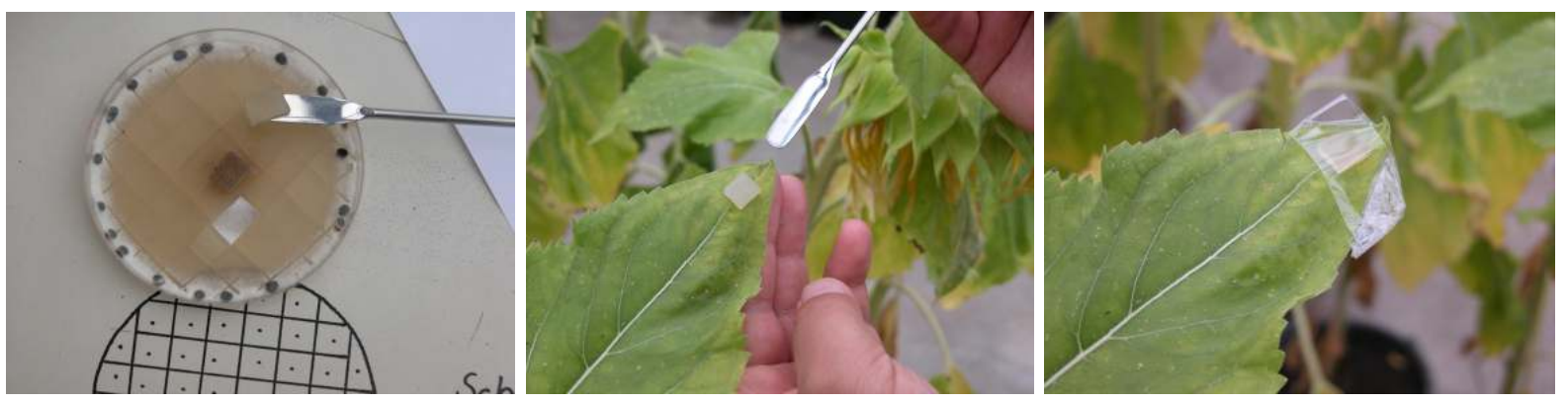

Figure 2.8: Artificial infection of the fully grown leaf with Sclerotinia inoculum. 


\section{RESULTS}

\subsection{LOCATION AND VARIETY EFFECT}

The locations of the main field experiments represent two different climatic conditions for sunflower production in Germany. The three selected high oleic sunflower varieties represent three different ripening classes. In the following subchapters, their influence on achene yield, oil content and fungal infection rate are presented.

\subsubsection{Changes in achene yield}

The highest yield (34.4 dt/ha at $9 \%$ seed moisture) throughout the mean of all varieties was achieved at Eckartsweier in dry and warm year 2003 (Table 3.1a). Achene yield was higher at Eckartsweier than at Braunschweig in 2003 and 2004, however it was only significant in 2004. In contrast to the first two years, achene yield was significantly lower at Eckartsweier by nearly $20 \%$ in 2005.

No significant difference in achene yield between the varieties was observed in 2003, although the yield showed a tendency to increase from late to early ripening varieties. Late ripening variety Olsavil showed the lowest achene yields in all study years in comparison to the other the varieties. Achene yield of Olsavil was significantly lower in 2004 (24.0 dt/ha) in comparison to the variety PR64H41 (29.3 dt/ha), and in 2005 (24.6 dt/ha) in comparison to Aurasol (31.3 dt/ha). The mid-early variety Aurasol showed higher achene yield in comparison to the moderate ripening variety PR64H41 and late ripening variety Olsavil, in 2003 and 2005. Achene yield of variety Aurasol decreased in the relatively cooler and wet year 2004. 
Table 3.1: Mean differences for achene yield (dt/ha) in 2003-2005 between the locations (a) and the varieties (b)

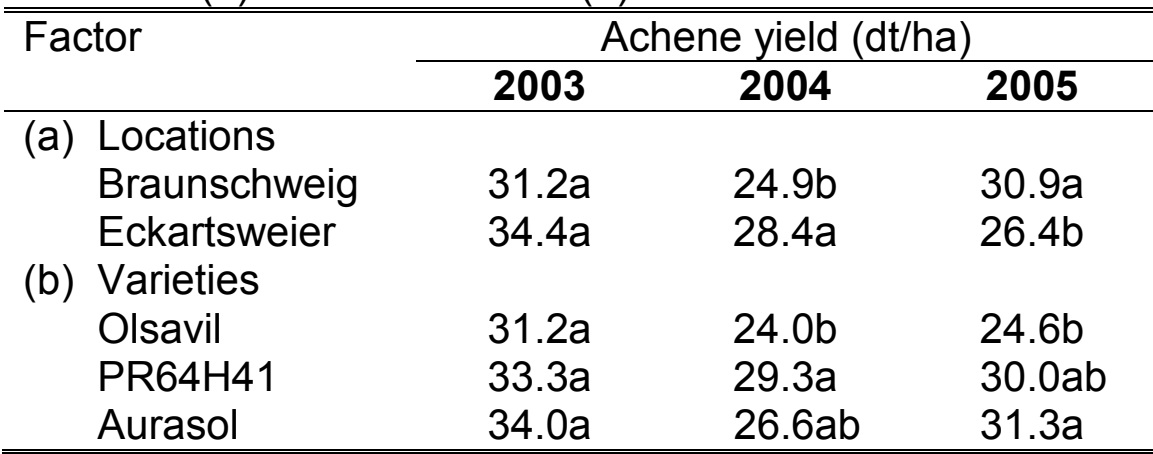

For locations and varieties, values in a column with different letters are significantly different at $P>0.05$

Achene yield of all three varieties was for each experimental site as average of three study years is presented in Table 3.2. According to the differences in mean values, Olsavil showed lower achene yield at both experimental sites. Significant difference in yield between Olsavil and the other two varieties was observed only at Braunschweig. Olsavil showed with $24.3 \mathrm{dt} / \mathrm{ha}$ the lowest achene yield in comparison to $30.9 \mathrm{dt} / \mathrm{ha}$ in PR64H41 and $30.3 \mathrm{dt} / \mathrm{ha}$ in Aurasol. Similar results were also observed at Eckartsweier. Olsavil showed the lowest but the difference was negligible yield with $27.1 \mathrm{dt} / \mathrm{ha}$ in comparison to $29.8 \mathrm{dt} / \mathrm{ha}$ in PR64H41 and 29.5 $\mathrm{dt} / \mathrm{ha}$ in Aurasol.

Table 3.2: Mean differences for achene yield (dt/ha) between the two locations across all varieties

\begin{tabular}{lcc}
\hline \hline & \multicolumn{2}{c}{ Achene yield (dt/ha) } \\
\cline { 2 - 3 } & Braunschweig & Eckartsweier \\
\hline Olsavil & $24.3 \mathrm{~b}$ & $27.1 \mathrm{a}$ \\
PR64H41 & $30.9 \mathrm{a}$ & $29.8 \mathrm{a}$ \\
Aurasol & $30.3 \mathrm{a}$ & $29.5 \mathrm{a}$ \\
\hline \hline
\end{tabular}

Values in a column with different letters are significantly different at $P>0.05$

\subsubsection{Changes in oil content and composition}

The most important quality parameters in $\mathrm{HO}$ sunflower are the oil content of the seeds and the fatty acid composition of the oil. Changes in oil content in dependence on the compared locations (a) and HO sunflower varieties (b) in the different study years are presented in Table 3.3. At the two experimental sites, the oil content varied between 49.3 \% (Braunschweig, 2003) and $51.8 \%$ (Eckartsweier, 2005) throughout the experimental years. In 2003, oil content was lower at Braunschweig than at 
Eckartsweier. Nearly no difference in oil content at the different study locations was detected in 2004. Similar to the results in 2003, oil content at Braunschweig with 49.7 \% was lower than at Eckartsweier with $51.8 \%$ in 2005. Significant difference in oil content between two experimental sites was only observed in this last study year.

Oil content significantly differed between the varieties. In 2003, the variety Aurasol showed slightly higher oil content with $51.2 \%$ in comparison to PR64H41 with 50.7 $\%$ and Olsavil with $49.1 \%$. In contrast, Aurasol showed significantly lower oil content in 2004 with $49.7 \%$ in comparison to Olsavil with $51.5 \%$, whereas $50.2 \%$ oil was observed in PR64H41. Also in 2005, Aurasol showed with 49.5 \%, significantly lower oil content in comparison to the other two varieties.

Table 3.3: Mean differences for oil content (\%) in 2003-2005 between the locations (a) and the varieties (b)

\begin{tabular}{|c|c|c|c|c|}
\hline & \multicolumn{3}{|c|}{ Oil content (\%) } \\
\hline & & 2003 & 2004 & 2005 \\
\hline (a) & Locations & & & \\
\hline & Braunschweig & $49.3 a$ & $50.6 a$ & $49.7 b$ \\
\hline (b) & $\begin{array}{l}\text { Eckartsweier } \\
\text { Varieties }\end{array}$ & $51.3 a$ & $50.3 a$ & $51.8 a$ \\
\hline & Olsavil & $49.1 \mathrm{a}$ & $51.5 a$ & $50.9 a b$ \\
\hline & PR64H41 & $50.7 a$ & $50.1 \mathrm{ab}$ & $51.9 a$ \\
\hline & Aurasol & $51.2 a$ & $49.7 b$ & $49.5 b$ \\
\hline
\end{tabular}

$\overline{\text { For locations and varieties, values in a column with different letters }}$ are significantly different at $P>0.05$

\subsubsection{Changes in fungal infection rate}

Fungal infection rate was calculated as the percentage of infected plants of the total number of plants irrespective of the fungal pathogen. Only $1.6 \%$ fungal infection rate at Braunschweig and $1.5 \%$ at Eckartsweier was observed in 2003 (Table 3.4a). In contrast, much higher fungal infection rates were observed in 2004. The average fungal infection rate at Braunschweig with $87.3 \%$ was double as high as at Eckartsweier (40.7\%). In opposite, fungal infections were significantly higher at Eckartsweier than at Braunschweig in 2005. Infection rate at Braunschweig was 7.6 $\%$ in comparison to $57.9 \%$ at Eckartsweier.

All varieties showed nearly no fungal infection in 2003 (Table 3.4b). In contrast, highest infection rates in the main field experiments were observed in 2004 in all 
three varieties. The late ripening variety Olsavil, with $56.9 \%$ in 2004 and $29.9 \%$ in 2005, showed lower infection rates in comparison to the two other varieties. PR64H41 showed the highest infection rate with $69.6 \%$, in 2004 and $37.8 \%$ in 2005 in comparison to the other varieties. Aurasol presented similar results like $\mathrm{PR} 64 \mathrm{H} 41$ with $65.6 \%$ infection rate in 2004 and $30.5 \%$ in 2005. However, the differences in fungal infection rate were in no case significant.

Table 3.4: Mean differences for fungal infection rate (\%) in 2003-2005 between the locations (a) and the varieties (b)

\begin{tabular}{|c|c|c|c|}
\hline & \multicolumn{3}{|c|}{ Fungal infection rate (\%) } \\
\hline & 2003 & 2004 & 2005 \\
\hline (a) Locations & & & \\
\hline Braunschweig & $1.6 a$ & $87.3 a$ & $7.6 b$ \\
\hline $\begin{array}{l}\text { Eckartsweier } \\
\text { (b) Varieties }\end{array}$ & $1.5 a$ & $40.7 b$ & $57.9 a$ \\
\hline Olsavil & $2.9 a$ & $56.9 a$ & $29.9 a$ \\
\hline PR64H41 & $1.0 a$ & $69.5 a$ & $37.8 a$ \\
\hline Aurasol & $0.7 a$ & $65.6 a$ & $30.5 a$ \\
\hline
\end{tabular}

$\overline{\text { For locations and varieties, values in a column with different letters }}$ are significantly different at $P>0.05$

\subsubsection{Interactions and correlations between the experimental factors}

Variance analysis showed that the achene yield was significantly influenced $(P<0.001)$ by experimental year as well as by variety (Table 3.5$)$. Achene yield was also significantly changed $(P<0.001)$ by location $x$ year interaction. The influence of location as well as its interaction with the variety on achene yield was negligible. Oil content was significantly affected $(P<0.01)$ by different locations but not by its interactions with other experimental factors. Oil content was also significantly influenced $(P<0.01)$ by year $x$ variety interaction. Fungal infection rate was significantly different in experimental years $(P<0.001)$ but it was not influenced by the factors location, variety or its interactions. Only location $x$ year interaction showed a significant effect $(P<0.001)$ on fungal infection rate. Fatty acid composition was significantly influenced $(P<0.001)$ by year, variety and its interaction. Location showed no significant influence fatty acid composition. However, its interaction with variety showed a significant effect $(P<0.01)$ on the oleic acid content. 
Table 3.5: Analysis of variance for factors location, year and variety

\begin{tabular}{lccccccc} 
& DF & $\begin{array}{c}\text { Achene } \\
\text { yield }\end{array}$ & $\begin{array}{c}\text { Oil } \\
\text { content }\end{array}$ & $\begin{array}{c}\text { Fungal } \\
\text { infection }\end{array}$ & $\begin{array}{c}\text { Oleic } \\
\text { acid }\end{array}$ & $\begin{array}{c}\text { Linoleic } \\
\text { acid }\end{array}$ & $\begin{array}{c}\text { Stearic } \\
\text { acid }\end{array}$ \\
\hline Location & 1 & $\mathrm{~ns}$ & $* *$ & $\mathrm{~ns}$ & $\mathrm{~ns}$ & $\mathrm{~ns}$ & $\mathrm{~ns}$ \\
Year & 2 & $* * *$ & $\mathrm{~ns}$ & $* * *$ & $* * *$ & $* * *$ & $* * *$ \\
Variety & 2 & $* * *$ & $\mathrm{~ns}$ & $\mathrm{~ns}$ & $* * *$ & $* * *$ & $* * *$ \\
Location ${ }^{*}$ Year & 2 & $* * *$ & $\mathrm{~ns}$ & $* * *$ & $\mathrm{~ns}$ & $\mathrm{~ns}$ & $* * *$ \\
Location*Variety & 2 & $\mathrm{~ns}$ & $\mathrm{~ns}$ & $\mathrm{~ns}$ & $* *$ & $*$ & $\mathrm{~ns}$ \\
Year*Variety & 4 & $\mathrm{~ns}$ & $* *$ & $\mathrm{~ns}$ & $* * *$ & $* *$ & $* *$ \\
Location*Year*Variety & 4 & $\mathrm{~ns}$ & $\mathrm{~ns}$ & $\mathrm{~ns}$ & $\mathrm{~ns}$ & $\mathrm{~ns}$ & $\mathrm{~ns}$ \\
Error & 42 & & & & & & \\
\hline \hline
\end{tabular}

${ }^{*},{ }^{* *},{ }^{* * *}$ Significant at the $0.05,0.01$ and 0.001 probability levels, respectively.

High correlation coefficients were revealed between the fungal infection rate and the achene yield as well as between the fatty acids (Table 3.6). The achene yield showed a significant $(P<0.001)$ negative correlation with the infection rate. Achene yield was also significant $(P<0.01)$ negatively correlated with the oleic acid percent but positively with the stearic acid percentage. There was a highly significant $(P<0.001)$ negative correlation between the oleic acid and the linoleic and stearic acid content. However linoleic and stearic acid was positively correlated.

Table 3.6: Pearson's correlation coefficients between selected yield and quality parameters

\begin{tabular}{llllll}
\hline \hline & \multicolumn{5}{c}{ Parameters $(\mathrm{N}=60)$} \\
\cline { 2 - 6 } & $\begin{array}{l}\text { Fungal } \\
\text { infection rate }\end{array}$ & $\begin{array}{l}\text { Achene } \\
\text { yield }\end{array}$ & Oil content & Oleic acid & Linoleic acid \\
\hline Achene yield & $-0.52^{* * *}$ & 1.00 & & & \\
Oil content & 0.13 & 0.01 & 1.00 & & \\
Oleic acid & 0.03 & $-0.38^{* *}$ & 0.07 & 1.00 & \\
Linoleic acid & 0.02 & $0.28^{*}$ & 0.04 & $-0.96^{* * *}$ & 1.00 \\
Stearic acid & -0.14 & $0.49^{* * *}$ & -0.22 & $-0.82^{* * *}$ & $0.65^{* * *}$ \\
\hline${ }^{*},{ }^{* *},{ }^{* * *}$ Significant at the $0.05,0.01$ and 0.001 probability levels, respectively.
\end{tabular}

\subsection{AgRicultuRAL APPLICATIONS}

Four different agricultural applications, a commercial fungicide, a commercial resistance inducing product, a new liquid fertilizer injection method, and a new bacterial fertilizer were tested under field conditions from 2002-2005. The field experiments of this study consisted of two parts;

1) The preliminary field experiments in 2002 at the marginal site Braunschweig

2) The main field experiments from 2003 to 2005 at two locations; Braunschweig and Eckartsweier. 


\subsubsection{Effect of fungicide treatment}

\section{Changes in fungal infection rate}

Effect of Folicur ${ }^{\circledR}$, applied at full flowering stage, on investigated agricultural parameters in 2002 is presented in Table A.4. Olsavil showed $100 \%$ fungal infection with and without fungicide application. Variety PR64H61 showed $86 \%$ infection with fungicide application in comparison to $80.2 \%$ infection in the control plot. Aurasol showed the lowest infection rates in comparison to the other two varieties with 40.7 $\%$ with control and $49.4 \%$ with fungicide treatment. Application of the fungicide did not reduce the infection rate of the three compared $\mathrm{HO}$ sunflower varieties significantly.

Figure 3.1 shows the fungal disease rates only for 2004 and 2005, since the infection rates in 2003 were much too low to show any considerable differences. At Braunschweig, infection rate varied from $79.0 \%$ (Fungicide/PR64H41) to $92.8 \%$ (Fungicide/Olsavil) in 2004. Fungicide application slightly decreased the fungal infection rate in varieties $\mathrm{PR} 64 \mathrm{H} 41$ and Aurasol, whereas it significantly increased the infection in Olsavil. Fungal infection rates in 2005 were, in comparison to the previous year, much lower. Infection rate ranged from $18.4 \%$ with fungicide application in Olsavil to $2.3 \%$ in untreated plots in Aurasol. All varieties showed a slight increase in fungal infection rate with the fungicide application, however without statistical significance.

At Eckartsweier, Olsavil showed the lowest fungal infection rates in 2004 with $29.5 \%$ and $26.8 \%$ in untreated control and fungicide applied plots, respectively. Fungicide application insignificantly reduced the fungal infection rate in all varieties. Similarly, Olsavil showed the lowest fungal infection rates also in 2005 with $47.5 \%$ and $40 \%$ in untreated control and fungicide applied plots, respectively. Fungicide application decreased infection rates in Olsavil and PR64H41; however, it was only significant in Olsavil. In contrast, an increase in infection rate was observed in PR64H41 with fungicide application. 

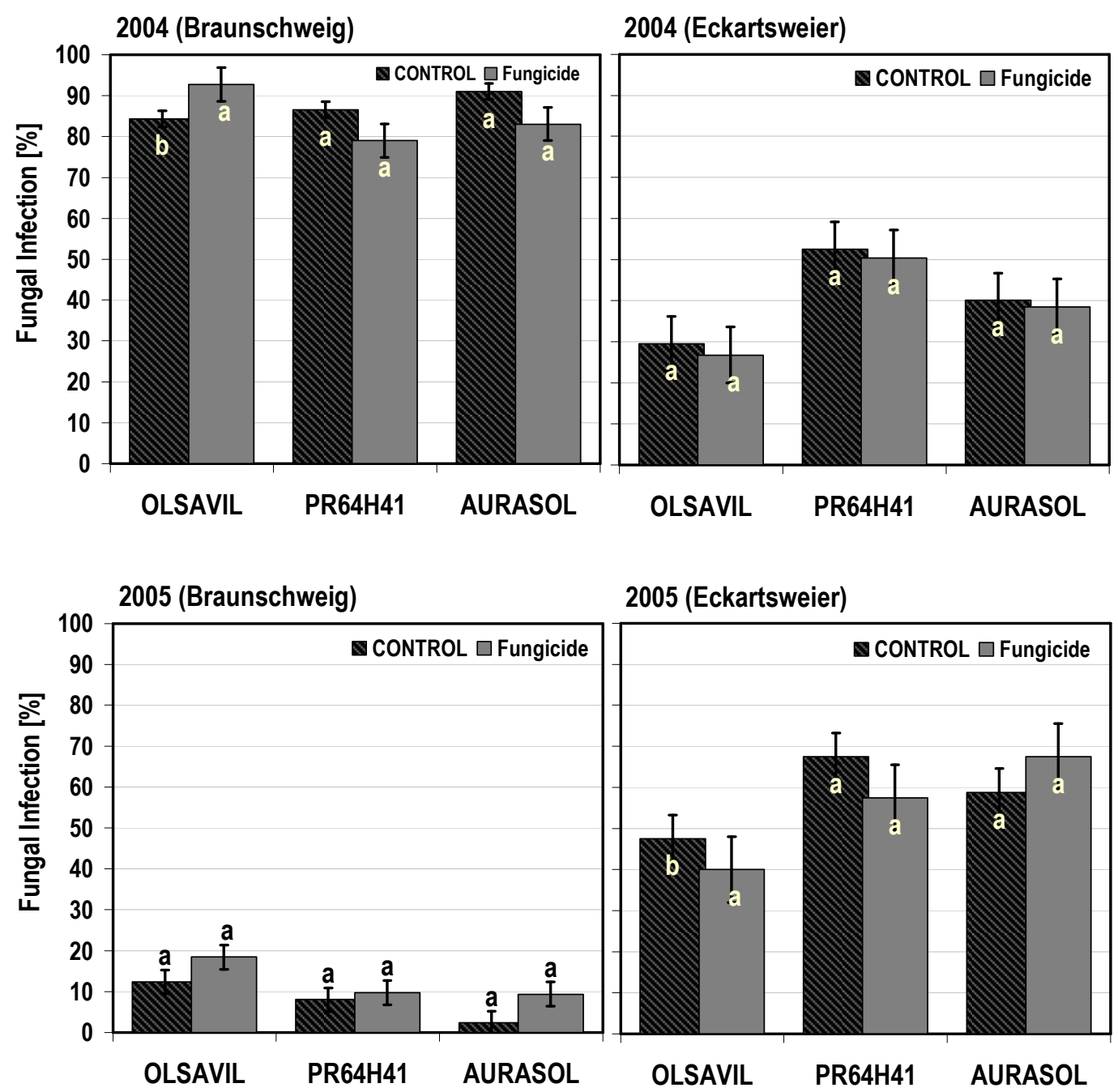

Figure 3.1: Effect of fungicide application on fungal infection rate by Sclerotinia and Botrytis (\%) at both experimental sites in 2004 and 2005.

\section{Changes in yield components}

Yield parameters were not significantly influenced by the fungicide application in 2002 (Table A.4). Table 3.7 shows achene yield of all three varieties at both experimental sites in 2003-2005. At Braunschweig, fungicide application led to a slight increase in achene yield in Olsavil in all experimental years. In contrast, achene yield of the varieties PR64H41 and Aurasol was decreased with fungicide application in comparison to the untreated control. Nevertheless, no significant difference by fungicide application was observed in achene yield.

At Eckartsweier, fungicide application caused a slight yield depression in the warm and dry year 2003. Achene yield was decreased on average by $30 \%$ in fungicide applied plots independent of the variety. Exclusively in this year, the yield reduction 
by the fungicide treatment in Olsavil was significant. In the following experimental years, achene yield was not influenced significantly by the fungicide treatment.

There was no significant effect on head diameter, plant height or thousand seeds weight by fungicide application in any year and at any site, and therefore data are not presented.

Table 3.7: Influence of fungicide application on achene yield (dt/ha) for all three $\mathrm{HO}$ sunflower varieties at both experiment sites in 2003-2005.

\begin{tabular}{lllllll}
\hline & \multicolumn{3}{c}{ BRAUNSCHWEIG } & \multicolumn{3}{c}{ ECKARTSWEIER } \\
& Olsavil & PR64H41 & Aurasol & Olsavil & PR64H41 Aurasol \\
\hline \multicolumn{1}{c}{2003} & & & & & & \\
Control & $28.7 \mathrm{a}$ & $31.3 \mathrm{a}$ & $33.7 \mathrm{a}$ & $33.7 \mathrm{a}$ & $35.4 \mathrm{a}$ & $34.2 \mathrm{a}$ \\
Fungicide & $30.6 \mathrm{a}$ & $30.5 \mathrm{a}$ & $31.0 \mathrm{a}$ & $23.7 \mathrm{~b}$ & $26.7 \mathrm{a}$ & $26.9 \mathrm{a}$ \\
Mean & 29.6 & 30.9 & 32.4 & 28.7 & 31.0 & 30.6 \\
LSD $_{0.05}^{\ddagger}$ & 6.0 & 15.6 & 17.4 & 9.0 & 11.6 & 15.1 \\
$\quad 2004$ & & & & & & \\
Control & $22.9 \mathrm{a}$ & $27.2 \mathrm{a}$ & $24.6 \mathrm{a}$ & $25.2 \mathrm{a}$ & $31.4 \mathrm{a}$ & $28.6 \mathrm{a}$ \\
Fungicide & $23.3 \mathrm{a}$ & $26.8 \mathrm{a}$ & $23.5 \mathrm{a}$ & $26.0 \mathrm{a}$ & $29.8 \mathrm{a}$ & $30.6 \mathrm{a}$ \\
Mean & 23.1 & 27.0 & 24.0 & 25.6 & 30.6 & 29.6 \\
LSD $_{0.05}^{\ddagger}$ & 2.0 & 5.7 & 3.8 & 6.9 & 5.9 & 8.1 \\
$\quad 2005$ & & & & & & \\
Control & $23.6 \mathrm{a}$ & $34.5 \mathrm{a}$ & $34.5 \mathrm{a}$ & $25.6 \mathrm{a}$ & $25.4 \mathrm{a}$ & $28.1 \mathrm{a}$ \\
Fungicide $_{\text {Mean }}$ & $24.4 \mathrm{a}$ & $34.1 \mathrm{a}$ & $33.0 \mathrm{a}$ & $25.8 \mathrm{a}$ & $25.9 \mathrm{a}$ & $29.4 \mathrm{a}$ \\
LSD $_{0.05}^{\ddagger}$ & 24.0 & 34.3 & 33.7 & 25.7 & 25.6 & 28.7 \\
\hline \hline
\end{tabular}

\section{Changes in quality components}

Quality parameters were not significantly influenced by the fungicide application in 2002 (Table A.4). At Braunschweig, oil content was in general not significantly changed with the fungicide application (Table 3.8). In 2003, only Olsavil showed a significant increase in oil content. Similarly, oleic, linoleic and stearic acid percentage in the oil was not significantly influenced with one exception of the variety PR64H41 in 2004. Only a slight increase in oleic acid was observed in PR64H41, which showed statistical significance.

Also at Eckartsweier, oil content of the $\mathrm{HO}$ sunflower seeds was not significantly influenced by treatment with Folicur ${ }^{\circledR}$. Only one exception was observed in 2004 in the variety Olsavil. Oil content of Olsavil was decreased from $51.5 \%$ to $50.1 \%$ by fungicide application. No significant change in oleic and linoleic acid content was 
observed at Eckartsweier. Nevertheless, the stearic acid percentage of all varieties showed a significant increase in 2003 with fungicide application in comparison to the untreated control.

Table 3.8: Influence of fungicide application on oil content and composition at both sites in 2003-2005.

\begin{tabular}{|c|c|c|c|c|c|c|c|c|}
\hline & \multicolumn{4}{|c|}{ BRAUNSCHWEIG } & \multicolumn{4}{|c|}{ ECKARTSWEIER } \\
\hline & $\begin{array}{c}\text { Oil } \\
\text { content } \\
(\%)\end{array}$ & $\begin{array}{l}\text { Oleic } \\
\text { acid } \\
(\%)\end{array}$ & $\begin{array}{l}\text { Linoleic } \\
\text { acid } \\
(\%)\end{array}$ & $\begin{array}{c}\text { Stearic } \\
\text { acid } \\
(\%)\end{array}$ & $\begin{array}{c}\text { Oil } \\
\text { content } \\
(\%)\end{array}$ & $\begin{array}{l}\text { Oleic } \\
\text { acid } \\
(\%)\end{array}$ & $\begin{array}{l}\text { Linoleic } \\
\text { acid } \\
(\%)\end{array}$ & $\begin{array}{c}\text { Stearic } \\
\text { acid } \\
(\%)\end{array}$ \\
\hline & \multicolumn{8}{|c|}{2003} \\
\hline \multicolumn{9}{|l|}{ Olsavil } \\
\hline Control & $46.8 b$ & $89.8 a$ & $2.8 \mathrm{a}$ & $2.0 \mathrm{a}$ & $51.4 a$ & $91.1 \mathrm{a}$ & $2.4 a$ & $1.7 b$ \\
\hline Fungicide & $48.1 \mathrm{a}$ & $89.9 a$ & $2.8 a$ & $1.9 a$ & $52.1 \mathrm{a}$ & $89.1 \mathrm{a}$ & $2.7 a$ & $2.4 a$ \\
\hline \multicolumn{9}{|l|}{ PR64H41 } \\
\hline Control & $50.0 a$ & $88.3 a$ & $3.6 a$ & $2.7 a$ & $50.6 a$ & $88.2 a$ & $4.2 a$ & $2.5 b$ \\
\hline Fungicide & $48.9 a$ & $88.7 a$ & $3.3 a$ & $2.7 a$ & $49.2 a$ & $86.8 a$ & $3.9 a$ & $3.4 a$ \\
\hline \multicolumn{9}{|l|}{ Aurasol } \\
\hline Control & $51.2 a$ & $88.7 a$ & $3.2 \mathrm{a}$ & $3.0 \mathrm{a}$ & $48.3 a$ & $87.8 a$ & $4.3 a$ & $2.8 b$ \\
\hline Fungicide & $49.5 a$ & $87.7 a$ & $3.7 a$ & $3.3 a$ & $47.2 a$ & $85.5 a$ & $4.9 a$ & $3.7 a$ \\
\hline & \multicolumn{8}{|c|}{2004} \\
\hline \multicolumn{9}{|l|}{ Olsavil } \\
\hline Control & $51.5 a$ & $91.7 a$ & $2.5 a$ & $1.4 a$ & $51.5 a$ & $91.4 a$ & $2.3 a$ & $1.8 a$ \\
\hline Fungicide & $52.1 \mathrm{a}$ & $91.8 a$ & $2.7 a$ & $1.4 a$ & $50.1 b$ & $91.6 a$ & $2.2 a$ & $1.7 a$ \\
\hline \multicolumn{9}{|l|}{ PR64H41 } \\
\hline Control & $50.4 a$ & $88.1 b$ & $4.7 a$ & $2.1 \mathrm{a}$ & $49.8 a$ & $85.9 a$ & $6.4 a$ & $2.8 a$ \\
\hline Fungicide & $50.1 a$ & $88.7 a$ & $4.1 \mathrm{a}$ & $2.2 a$ & $49.6 a$ & $87.3 a$ & $5.1 \mathrm{a}$ & $2.7 a$ \\
\hline \multicolumn{9}{|l|}{ Aurasol } \\
\hline Control & $49.8 a$ & $87.9 a$ & $4.4 a$ & $2.6 a$ & $49.6 a$ & $89.1 a$ & $3.5 a$ & $2.7 a$ \\
\hline Fungicide & $49.0 a$ & $88.2 a$ & $4.1 \mathrm{a}$ & $2.6 a$ & $49.9 a$ & $86.2 a$ & $6.0 \mathrm{a}$ & $2.9 a$ \\
\hline & \multicolumn{8}{|c|}{2005} \\
\hline \multicolumn{9}{|l|}{ Olsavil } \\
\hline Control & $49.1 a$ & $90.5 a$ & $3.7 a$ & $1.5 a$ & 52.7 & $90.9 a$ & $3.1 \mathrm{a}$ & $1.8 \mathrm{a}$ \\
\hline Fungicide & $49.0 a$ & $90.1 a$ & $3.9 a$ & $1.7 a$ & 52.6 & $90.7 a$ & $3.3 a$ & $1.8 a$ \\
\hline \multicolumn{9}{|l|}{ PR64H41 } \\
\hline Control & $50.8 a$ & $85.2 a$ & $7.2 \mathrm{a}$ & $2.9 a$ & 52.9 & $84.3 a$ & $8.1 \mathrm{a}$ & $2.8 a$ \\
\hline Fungicide & $51.9 a$ & $86.0 a$ & $6.6 a$ & $2.8 a$ & 53.1 & $84.2 a$ & $8.0 a$ & $3.0 a$ \\
\hline \multicolumn{9}{|l|}{ Aurasol } \\
\hline Control & $49.3 a$ & $84.9 a$ & $7.3 a$ & $3.2 \mathrm{a}$ & 49.7 & $86.6 a$ & $5.5 a$ & $3.3 a$ \\
\hline Fungicide & $49.9 a$ & $85.6 a$ & $6.6 a$ & $3.2 a$ & 50.7 & $86.2 a$ & $6.0 \mathrm{a}$ & $3.2 \mathrm{a}$ \\
\hline
\end{tabular}

\subsubsection{Effect of BTH seed treatment}

\section{Changes in fungal infection rate}

The plant activator was tested as seed treatment in two concentrations, 25 and 250 ppm BTH $\left(\right.$ Bion $\left.^{\circledR}\right)$ in the main experiments. Figure 3.2 presents the fungal infection 
rates at both locations, in 2004 and 2005. Evaluation of the fungal diseases in 2003 is not presented due to the low infection level in this first experimental year.
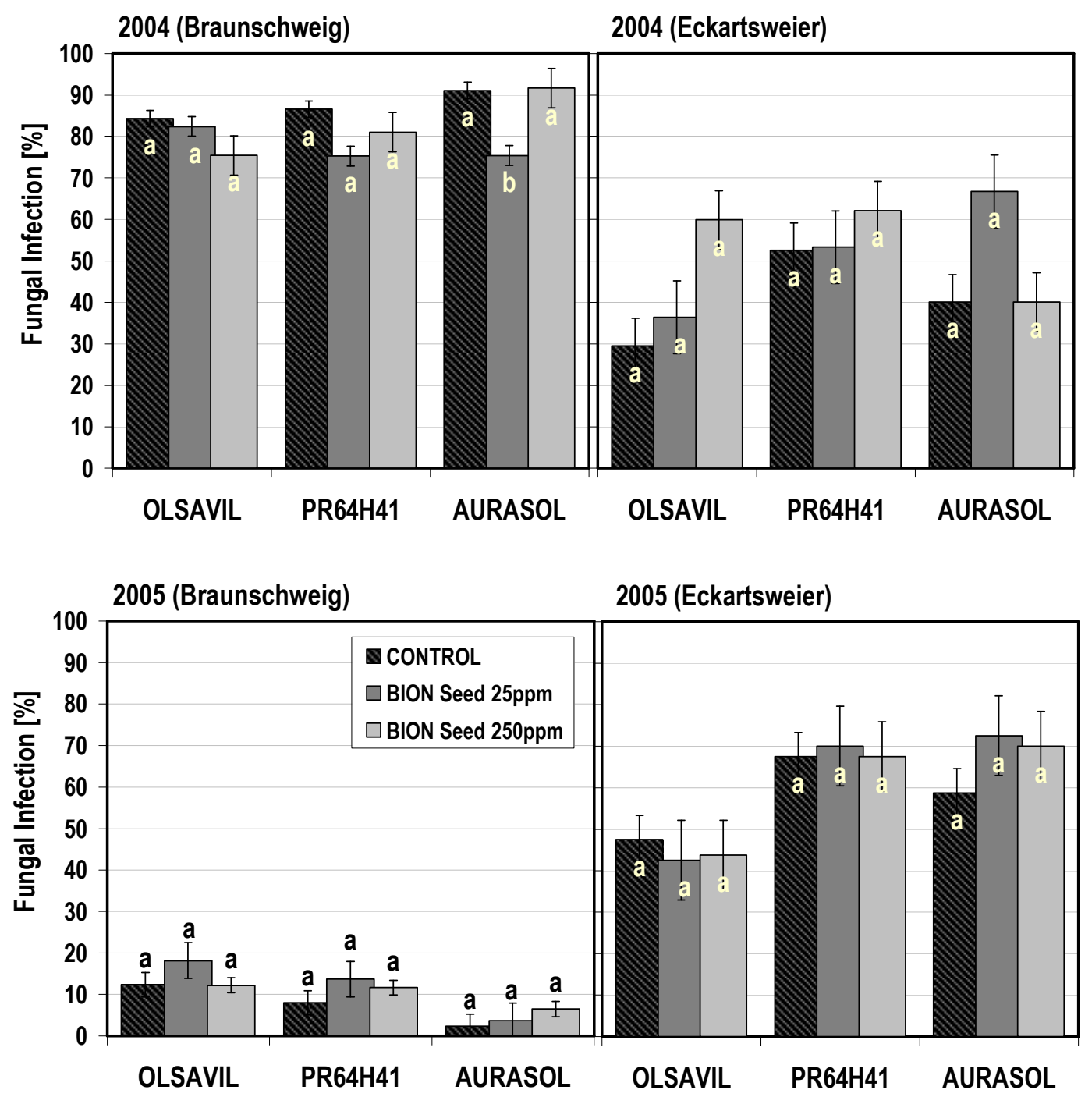

Figure 3.2: Influence of Bion ${ }^{\circledR}$ seed treatment on fungal infection by Sclerotinia and Botrytis (\%) at both experiment sites in 2004 and 2005.

The highest infection rates overall in the main experiments were observed at Braunschweig in 2004. Control plots showed $84.3 \%, 86.6 \%$ and $91.1 \%$ fungal infection for Olsavil, PR64H41, and Aurasol, respectively. Seed treatment with 25 ppm Bion ${ }^{\circledR}$ decreased the fungal infection rate in all varieties in this year. However, significant reduction in infection rate with fungicide application was only observed in variety Aurasol with $75.4 \%$ infection. Increasing Bion ${ }^{\circledR}$ concentration to $250 \mathrm{ppm}$ showed no significant effect on fungal infection rates. In general fungal disease rates 
were much lower in 2005 than in 2004, but no significant variation was observed between the two concentrations of Bion ${ }^{\circledR}$ seed treatment in any variety.

At Eckartsweier, 25 ppm Bion ${ }^{\circledR}$ seed treatment in Olsavil and Aurasol, as well as 250 ppm in variety Olsavil and PR64H41 caused a raise in fungal infection rate in 2004. In general fungal infection was not hindered by Bion ${ }^{\circledR}$ seed treatment independent of the two compared concentrations. Olsavil showed the lowest infection rates in 2005 with $47.5,42.5$ and $43.8 \%$ for control, 25 ppm and 250 ppm Bion ${ }^{\circledR}$ seed treatment respectively. Nevertheless, a significant effect of seed treatment on fungal infection rate was not observed at this experimental site.

\section{Changes in yield components}

The seed treatment by the plant activator was not tested at Eckartsweier in 2003. Achene yield of all varieties at both experimental sites in 2003-2004 are listed in the Table 3.14. Achene yield of all varieties was increased by Bion ${ }^{\circledR}$ seed treatment irrespective of the applied concentration in 2003 at Braunschweig (Table 3.9). The highest yield increase was observed with the variety $\mathrm{PR} 64 \mathrm{H} 41$, where the achene yield was raised from $31.3 \mathrm{dt} / \mathrm{ha}$ to $39.7 \mathrm{dt} /$ ha by $25 \mathrm{ppm}$ Bion ${ }^{\circledR}$ and to $40.1 \mathrm{dt} / \mathrm{ha}$ by 250 ppm Bion ${ }^{\circledR}$ seed treatment. In the following experimental years, no significant change in yield was observed at Braunschweig, except a slight statistically insignificant increase in Olsavil in 2004. Similarly, changes in achene yield at Eckartsweier were negligible.

Table 3.9: Influence of Bion ${ }^{\circledR}$ seed treatment on achene yield ( $\mathrm{dt} / \mathrm{ha}$ ) for all three varieties at both experimental sites.

\begin{tabular}{|c|c|c|c|c|c|c|}
\hline & \multicolumn{3}{|c|}{ BRAUNSCHWEIG } & \multicolumn{3}{|c|}{ ECKARTSWEIER } \\
\hline & Olsavil & PR64H41 & Aurasol & Olsavil & PR64H41 & Aurasol \\
\hline \multicolumn{7}{|l|}{2003} \\
\hline Control & $28.7 a$ & $31.3 a$ & $33.7 a$ & - & - & - \\
\hline Bion $^{\circledR}$-Seed 25ppm & $34.5 a$ & $39.7 a$ & $37.3 a$ & - & - & - \\
\hline Bion $^{\circledR}$-Seed 250 ppm & $30.9 a$ & $40.1 a$ & $36.7 a$ & - & - & - \\
\hline \multicolumn{7}{|l|}{2004} \\
\hline Control & $22.9 a$ & $27.2 \mathrm{a}$ & $24.6 a$ & $25.2 a$ & $31.4 a$ & $28.6 a$ \\
\hline Bion ${ }^{\circledR}$-Seed 25ppm & $22.2 a$ & $25.6 a$ & $24.4 a$ & $27.4 a$ & $28.7 a$ & $31.4 a$ \\
\hline Bion $^{\circledR}$-Seed 250 ppm & $24.5 a$ & $27.5 a$ & $22.5 a$ & $25.4 a$ & $29.9 a$ & $32.5 a$ \\
\hline \multicolumn{7}{|l|}{2005} \\
\hline Control & $23.6 a$ & $34.5 a$ & $34.5 a$ & $25.6 a$ & $25.4 a$ & $28.1 \mathrm{a}$ \\
\hline Bion $^{\circledR}$-Seed 25ppm & $26.4 a$ & $35.2 a$ & $34.6 a$ & $27.2 a$ & $26.0 a$ & $27.6 a$ \\
\hline Bion $^{\circledR}$-Seed 250ppm & $24.7 a$ & $34.9 a$ & $33.7 a$ & $25.4 a$ & $20.7 a$ & $27.8 a$ \\
\hline
\end{tabular}


The other yield parameters such as head diameter, thousand seed weight and plant height were not observed at Eckartsweier in any year. Head diameter was not significantly influenced by Bion ${ }^{\circledR}$ seed treatment in general at Braunschweig (Table 3.10). Only in 2003, it showed a slight tendency to increase with the Bion ${ }^{\circledR}$ application in all varieties except of 250 ppm Bion ${ }^{\circledR}$ seed treatment in Aurasol, where the head diameter decreased by $1 \mathrm{~cm}$ in comparison to the untreated control. Similarly, thousand seed weight of all varieties were increased in 2003. In contrast, it was not influenced by Bion $^{\circledR}$ seed treatment in the following experimental years. Nevertheless, no statistical change by Bion ${ }^{\circledR}$ application was observed in any year. Also plant height was raised by Bion ${ }^{\circledR}$ seed treatment in all varieties irrespective of the applied concentration in 2003 (Figure 3.3). However, no negligible change in plant height was observed in the following experimental years.

Table 3.10: Influence of Bion ${ }^{\circledR}$ seed treatment on head diameter and TSW of all three varieties at Braunschweig.

\begin{tabular}{|c|c|c|c|c|c|c|}
\hline & \multicolumn{3}{|c|}{ Head diameter $(\mathrm{cm})$} & \multicolumn{3}{|c|}{ Thousand seed weight $(\mathrm{g})$} \\
\hline & 2003 & 2004 & 2005 & 2003 & 2004 & 2005 \\
\hline \multicolumn{7}{|l|}{ Olsavil } \\
\hline Control & $13.35 a$ & $13.25 a$ & $13.90 \mathrm{a}$ & $40.22 a$ & $42.68 a$ & $44.03 a$ \\
\hline Bion $^{\circledR}$-Seed 25ppm & $14.80 \mathrm{a}$ & $12.70 \mathrm{a}$ & $13.30 \mathrm{a}$ & $42.55 a$ & $42.62 \mathrm{a}$ & $43.38 a$ \\
\hline Bion ${ }^{\circledR}-$ Seed 250ppm & $14.70 \mathrm{a}$ & $13.50 a$ & $13.33 a$ & $42.40 a$ & $43.54 a$ & $43.41 \mathrm{a}$ \\
\hline \multicolumn{7}{|l|}{ PR64H41 } \\
\hline Control & $11.75 a$ & $13.25 a$ & $13.08 a$ & $39.25 a$ & $40.19 a$ & $49.17 a$ \\
\hline Bion $^{\circledR}$-Seed 25ppm & $14.30 a$ & $13.15 a$ & $13.40 \mathrm{a}$ & $48.36 a$ & $39.34 a$ & $50.35 a$ \\
\hline Bion $^{\circledR}$-Seed 250ppm & $13.95 a$ & $13.45 a$ & $13.73 a$ & $44.35 a$ & $40.11 a$ & $52.48 a$ \\
\hline \multicolumn{7}{|l|}{ Aurasol } \\
\hline Control & $12.95 a$ & $12.28 \mathrm{a}$ & $12.50 \mathrm{a}$ & $44.62 a$ & $40.83 a$ & $46.21 \mathrm{a}$ \\
\hline Bion $^{\circledR}$-Seed 25ppm & $13.30 a$ & $12.45 a$ & $12.75 a$ & $48.06 a$ & $42.46 a$ & $47.31 \mathrm{a}$ \\
\hline Bion $^{\circledR}$-Seed 250ppm & $11.95 a$ & $12.13 a$ & $12.73 a$ & $46.85 a$ & $42.34 a$ & $49.13 a$ \\
\hline
\end{tabular}




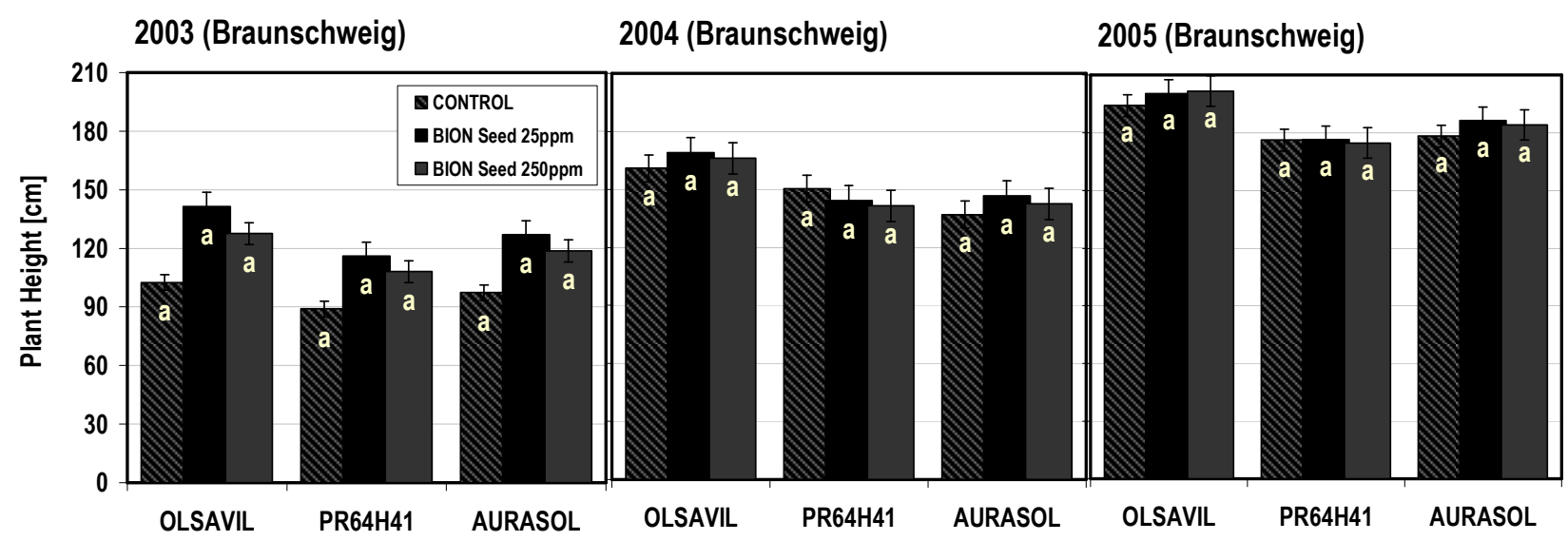

Figure 3.3: Influence of Bion $^{\circledR}$ seed treatment on plant height $(\mathrm{cm})$ at Braunschweig in 2003-2005.

\section{Changes in quality components}

Application of the plant activator Bion ${ }^{\circledR}$ as seed treatment showed in general no significant influence on oil content and composition at any site in the main experiments (Table A.5-8). A significant change in oil composition was only observed in 2005 at Braunschweig (Table 3.11). In variety PR64H41, 250 ppm Bion ${ }^{\circledR}$ seed treatment significantly decreased oleic acid content in comparison to the untreated control as well as to 25 ppm Bion ${ }^{\circledR}$ treatment, whereas it increased linoleic acid content. In contrast, Aurasol showed a slight increase in oleic acid content with the Bion ${ }^{\circledR}$ seed treatment irrespective of the applied concentration.

Table 3.11: Influence of Bion $^{\circledR}$ seed treatment on $\mathrm{HO}$ sunflower oil content and composition (\%) of all three varieties at Braunschweig in 2005.

\section{Oil content Oleic acid Linoleic acid Stearic acid}

\begin{tabular}{lcccc} 
& $(\mathbf{\%})$ & $\mathbf{( \% )}$ & $\mathbf{( \% )}$ & $\mathbf{( \% )}$ \\
\hline Olsavil & & & & \\
Control & $49.1 \mathrm{a}$ & $90.5 \mathrm{a}$ & $3.7 \mathrm{a}$ & $1.5 \mathrm{a}$ \\
Bion ${ }^{\circledR}$-Seed 25ppm & $47.4 \mathrm{a}$ & $90.2 \mathrm{a}$ & $4.0 \mathrm{a}$ & $1.5 \mathrm{a}$ \\
Bion ${ }^{\circledR}$-Seed 250ppm & $49.4 \mathrm{a}$ & $90.5 \mathrm{a}$ & $3.7 \mathrm{a}$ & $1.5 \mathrm{a}$ \\
PR64H61 & & & & \\
$\quad$ Control & $50.8 \mathrm{a}$ & $85.3 \mathrm{ab}$ & $7.2 \mathrm{~b}$ & $2.9 \mathrm{a}$ \\
Bion ${ }^{\circledR}$-Seed 25ppm & $50.8 \mathrm{a}$ & $85.4 \mathrm{a}$ & $7.3 \mathrm{~b}$ & $2.7 \mathrm{a}$ \\
Bion ${ }^{\circledR}$-Seed 250ppm & $51.9 \mathrm{a}$ & $83.8 \mathrm{~b}$ & $8.9 \mathrm{a}$ & $2.8 \mathrm{a}$ \\
Aurasol & & & & \\
Control & $49.3 \mathrm{a}$ & $84.9 \mathrm{a}$ & $7.3 \mathrm{a}$ & $3.2 \mathrm{a}$ \\
Bion ${ }^{\circledR}$-Seed 25ppm & $50.0 \mathrm{a}$ & $86.2 \mathrm{a}$ & $6.1 \mathrm{a}$ & $3.1 \mathrm{a}$ \\
Bion ${ }^{\circledR}$-Seed 250ppm & $50.2 \mathrm{a}$ & $86.1 \mathrm{a}$ & $6.2 \mathrm{a}$ & $3.1 \mathrm{a}$ \\
\hline \hline
\end{tabular}




\subsubsection{Effect of Bion ${ }^{\circledR}$ leaf spray application}

\section{Changes in fungal infection rate}

In 2002, plant activator Bion ${ }^{\circledR}$ was applied at inflorescence emergence (BBCH 51) and at full flowering stage (BBCH 65) in three concentrations, 10, 125 and 250 ppm. Fungal infection rate varied with application of Bion ${ }^{\circledR}$ depending on the variety (Figure 3.4). In general the late ripening variety Olsavil showed the least infection rate and lowest response to Bion ${ }^{\circledR}$ treatment. The highest fungal infection rates were detected in PR64H61 with over $60 \%$ infected plants in control and around $40 \%$ with applications of plant activator. The lowest infection rate $(38.5 \%)$ in PR64H61 was achieved by spraying Bion $^{\circledR}$ at inflorescence emergence stage in the lowest concentration of 10 ppm. The highest decrease in infection rate by Bion ${ }^{\circledR}$ application in 2002 was observed in the variety Aurasol. Fungal infection rate of Aurasol in control was $35 \%$, whereas it was less than $10 \%$ with Bion ${ }^{\circledR}$ applications irrespective of the application time and concentration. Even though, decrease in fungal infection rate was recorded with the plant activator treatment, these changes were statistically not significant.

The plant activator Bion $^{\circledR}$ as leaf treatment was tested in three different concentrations $(25,125$ and $250 \mathrm{ppm}$ ) and at five different application times (at BBCH growth stages 09, 16, 51, 65 and 69) in 2003 and only in two concentrations (10 and 125 ppm) and three application times (BBCH 09, $\mathrm{BBCH} 16$ an $\mathrm{BBCH} 65)$. Infection rate in 2003 was very low due to weather conditions at both sites and therefore any observed change in infection rate was negligible (Table A.9). The highest fungal infection rate, $10.3 \%$, was detected after 250 ppm Bion ${ }^{\circledR}$ leaf spraying at $\mathrm{BBCH} 69$ in $\mathrm{PR} 64 \mathrm{H} 41$ at Braunschweig. Significant increases in fungal infection rates were observed at Eckartsweier in $\mathrm{PR} 64 \mathrm{H} 41$ from $1 \%$ in the untreated control to $15.2 \%$ in plots. Where 10 ppm Bion ${ }^{\circledR}$ was applied at $\mathrm{BBCH} 16$. Aside of this exceptional high rate, all other values were below $10 \%$ at both sites.

The highest rate of fungal infections during the main experiments was reached in 2004 at Braunschweig. Figure 3.5 presents the changes in infection rate with spray application of the plant activator at Braunschweig in 2004. All varieties showed slight decrease in infection rate with 10 ppm $\mathrm{Bion}^{\circledR}$ applied at $\mathrm{BBCH} 09$ in comparison to the untreated control. An outstanding change was observed in Aurasol, where 
infection rate decreased in 125 ppm Bion ${ }^{\circledR}$ application at $\mathrm{BBCH} 65$ from $91 \%$ to 70 $\%$. However, none of the applications showed any significant change in fungal infection rate. Lower fungal infection rates were recorded in 2005 at Braunschweig in comparison to the previous experimental year (Figure A.2). The rates varied from 2.3 $\%$ in the control plots of Aurasol to $19.7 \%$ with 125 ppm Bion ${ }^{\circledR}$ applied at $\mathrm{BBCH} 65$ in Olsavil. In general, fungal infection rate showed a slight tendency to increase by Bion $^{\circledR}$ application. However, changes in infection rates were negligible and insignificant.
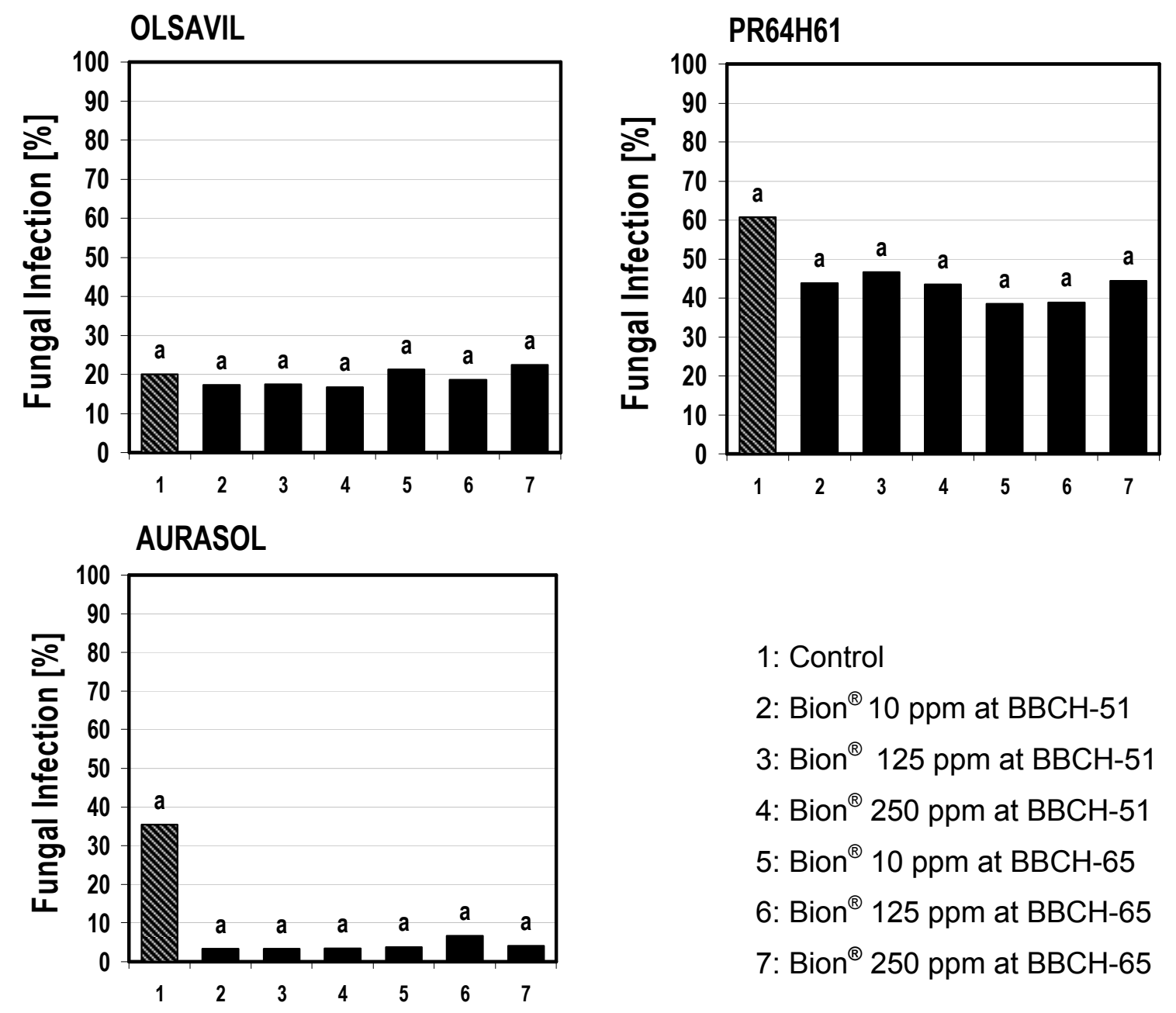
1: Control
2: $\mathrm{Bion}^{\circledR} 10 \mathrm{ppm}$ at $\mathrm{BBCH}-51$
3: Bion $^{\circledR} 125$ ppm at BBCH-51
4: $\mathrm{Bion}^{\circledR} 250$ ppm at $\mathrm{BBCH}-51$
5: Bion $^{\circledR} 10$ ppm at BBCH-65
6: Bion ${ }^{\circledR} 125$ ppm at $\mathrm{BBCH}-65$
7: Bion $^{\circledR} 250$ ppm at $\mathrm{BBCH}-65$

Figure 3.4: Influence of Bion ${ }^{\circledR}$ applications on fungal infection rate (\%) in all varieties at Braunschweig in 2002.

Fungal infection rate at Eckartsweier was in general lower than at Braunschweig in 2004. Infections varied from $21.0 \%$ (10 ppm Bion ${ }^{\circledR}$ at $\mathrm{BBCH} 09$ ) in Olsavil to $52.5 \%$ (control) in PR64H41 (Figure 3.6). Similar to the results at Braunschweig, $10 \mathrm{ppm}$ Bion $^{\circledR}$ sprayed at $\mathrm{BBCH} 09$ explicitly decreased the fungal infection rates in all varieties from $29.5 \%$ to $21 \%$ in Olsavil, from $52.5 \%$ to $33.1 \%$ in PR64H41, and 
from 40.1 to 27.3 in Aurasol. However, this decreasing effect of Bion ${ }^{\circledR}$ application at $\mathrm{BBCH} 09$ was not observed in 2005 at Eckartsweier (Figure A.3). In contrast to the infection rates in 2004, higher infection rates with an overall average of $56.1 \%$ were recorded at Eckartsweier in 2005. The fungal infection rates were slightly reduced in Olsavil and $\mathrm{PR} 64 \mathrm{H} 41$ with Bion ${ }^{\circledR}$ spraying irrespective of the application time and concentration. Nevertheless, the statistical evaluation showed no significant variation in infection rate between different applications in 2004.

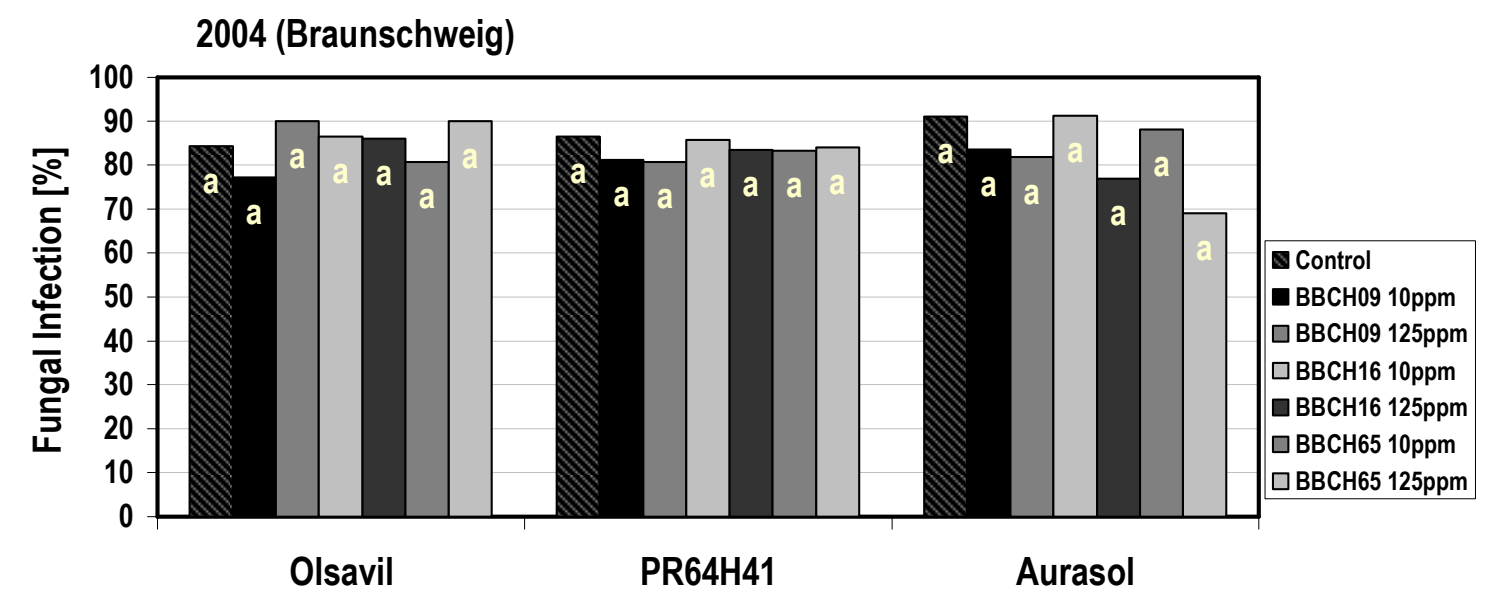

Figure 3.5: Influence of Bion $^{\circledR}$ leaf spray application on fungal infection rate (\%) at Braunschweig in 2004.

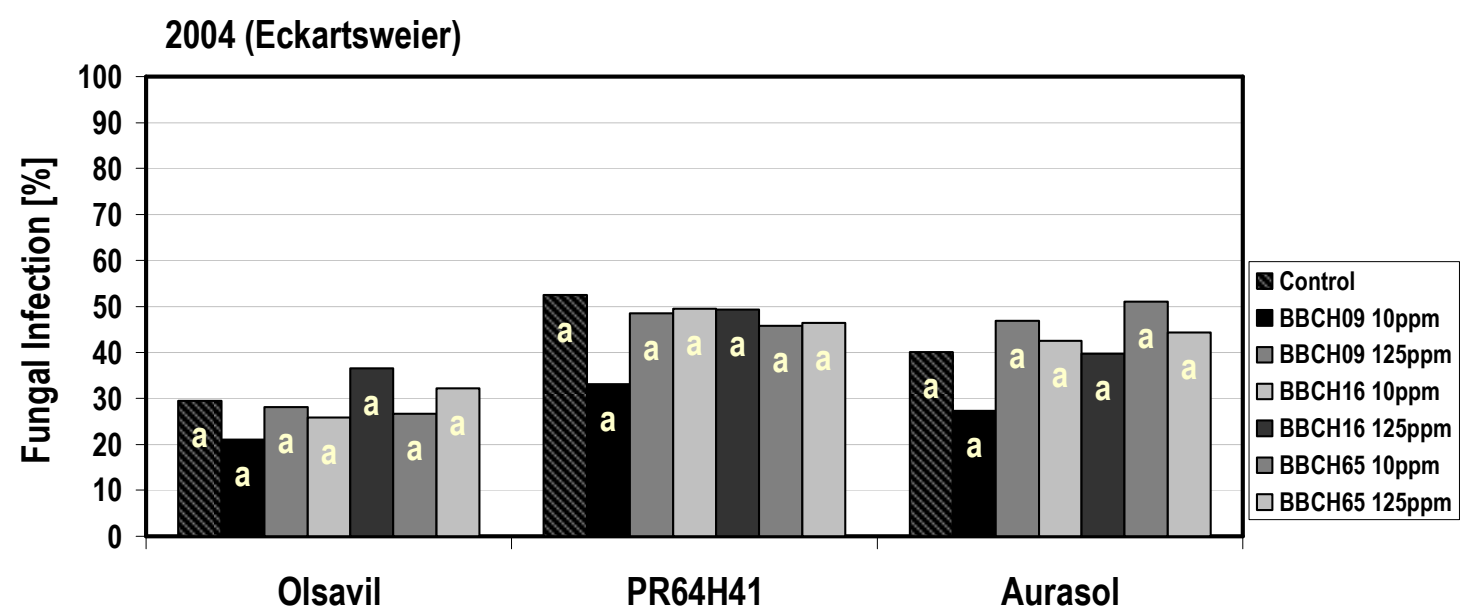

Figure 3.6: Influence of Bion ${ }^{\circledR}$ leaf spray application on fungal infection rate (\%) at Eckartsweier in 2004.

Figure 3.7 presents the fungal infection rate an average of three experimental years and the two sites with Bion ${ }^{\circledR}$ leaf application. Fungal infection rates after plant activator application were compared to the untreated control as well as to the fungicide application. Olsavil showed $34.7 \%$ fungal infection in control and $34.3 \%$ after fungicide application. Bion ${ }^{\circledR}$ spray applications, irrespective of the application 
time and concentration, did not show any significant change in infection rate. Fungal infection rates of PR64H41 were $42.3 \%$ in control and $41.6 \%$ with the fungicide application. Bion ${ }^{\circledR}$ spray applications showed in general slightly lower fungal infection with sclerotinia and botrytis. Only 10 ppm Bion ${ }^{\circledR}$ sprayed at $\mathrm{BBCH} 16$ stage showed slight increase in infection rate. Aurasol showed on average $36.3 \%$ fungal infection with untreated control. The infection rate was slightly increased by fungicide application to $40.6 \%$. All Bion ${ }^{\circledR}$ spray applications caused also an increase in infection rate in comparison to the control. Infection rates varied from $36.6 \%$ with 10 ppm Bion ${ }^{\circledR}$ applied at BBCH 09 to $42.9 \%$ with 125 ppm Bion ${ }^{\circledR}$ applied at BBCH 09.

In all three varieties, 10 ppm Bion ${ }^{\circledR}$ applied at early growth stage (BBCH 09) showed the lowest infection rate in average of the experimental years and the locations. However, none of the Bion ${ }^{\circledR}$ spray applications showed any significant change in fungal infection rate.

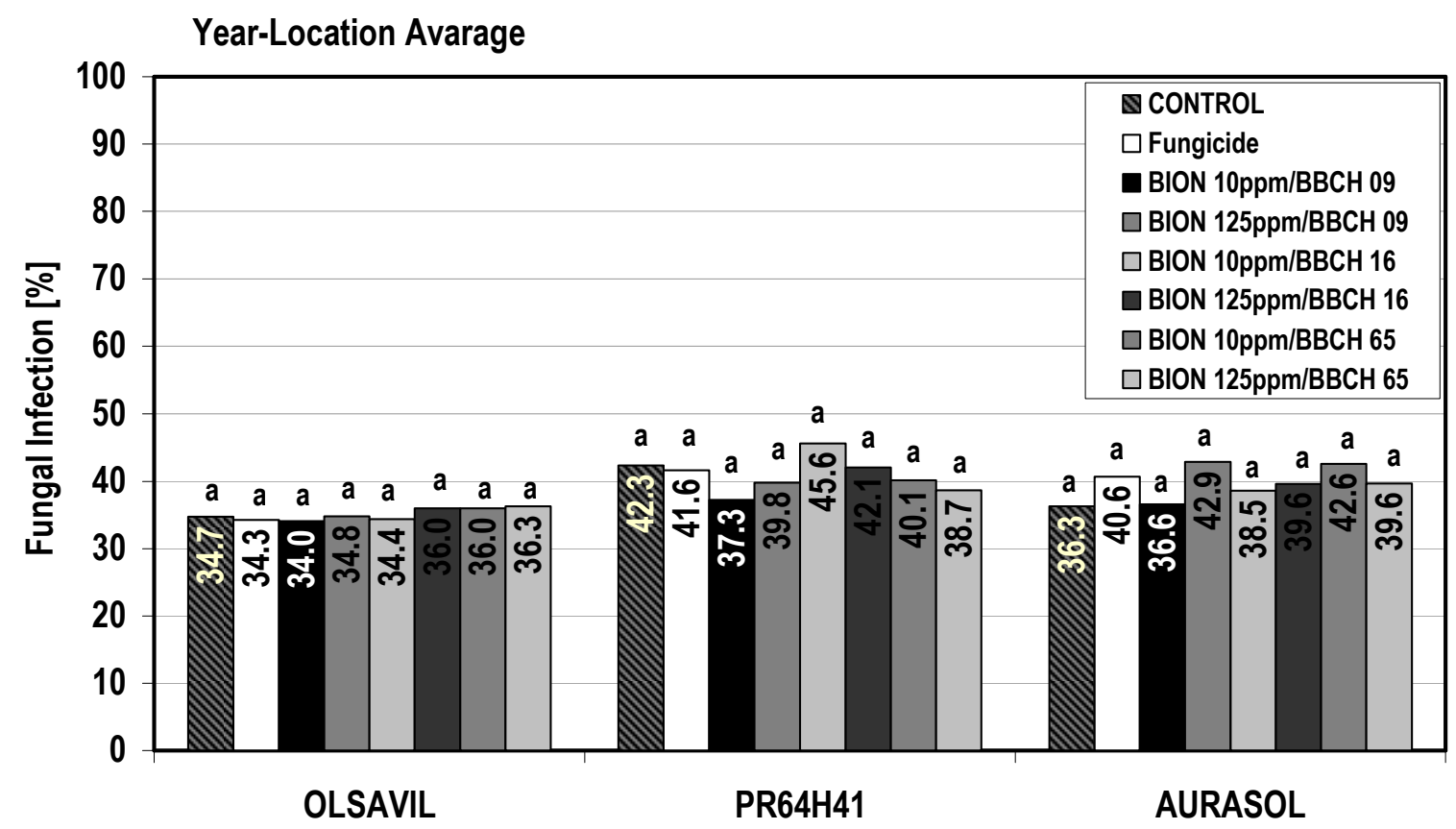

Figure 3.7: Influence of Bion ${ }^{\circledR}$ leaf spray application on fungal infection rate (\%) as average of both locations and all three main experimental years.

\section{Changes in yield components}

No significant variance was detected in any recorded yield parameter in 2002 (Table A.10-12). At both experimental sites, the most changes in yield were obtained in 2003 (Figure 3.8 and 9). Achene yield was increased with all Bion ${ }^{\circledR}$ applications 
irrespective of the application time and concentration in all varieties at Braunschweig. Especially Bion ${ }^{\circledR}$ applications at $\mathrm{BBCH} 09$ as well as at $\mathrm{BBCH} 65$ showed in general higher yield increase in comparison to the other Bion ${ }^{\circledR}$ applications. Nevertheless, significant increase in achene yield by Bion ${ }^{\circledR}$ applications was observed only in variety PR64H41. Achene yield was significantly increased by all Bion ${ }^{\circledR}$ applications irrespective of the application time and concentration in PR64H41.

On the contrary, achene yield was in general decreased in all varieties by the Bion ${ }^{\circledR}$ leaf spray applications at Eckartsweier in 2003. A significant change in achene yield was obtained, however, only in Olsavil. Exceptionally, $125 \mathrm{ppm}$ Bion ${ }^{\circledR}$ application at stage of BBCH 16 showed an outstanding higher achene yield of 38.9 t/ha. Also 250 ppm Bion ${ }^{\circledR}$ application at $\mathrm{BBCH} 65$, unlikely the other Bion ${ }^{\circledR}$ applications, showed with $34 \mathrm{dt} / \mathrm{ha}$ nearly the same achene yield as the control. All the other Bion ${ }^{\circledR}$ applications in Olsavil decreased the achene yield at this site. Nevertheless, significant reduction in yield was observed only by $10 \mathrm{ppm}$ Bion ${ }^{\circledR}$ application at $\mathrm{BBCH}$ 65. Achene yield of PR64H41 was decreased by all Bion ${ }^{\circledR}$ applications irrespective of the application time and concentration, but never significant. In contrast to the yield results at Braunschweig, Bion ${ }^{\circledR}$ application at $\mathrm{BBCH} 09$, irrespective of the applied concentration, showed the highest yield decrease in comparison to the other Bion ${ }^{\circledR}$ applications. A similar effect was also observed in Aurasol, where achene yield was decreased by all the three different concentrations of $\mathrm{Bion}^{\circledR}$ applied at $\mathrm{BBCH}$ 09. In opposite, applying the plant activator at the $\mathrm{BBCH} 16$ stage in all tested concentrations revealed slight increase in achene yield, where $10 \mathrm{ppm}$ Bion $^{\circledR}$ application showed the highest yield increase. Overall in variety Aurasol, changes in achene yield were negligible and not significant.

In the following experimental years 2004 and 2005, the variation in achene yield between the different Bion ${ }^{\circledR}$ applications was relatively smaller than in 2003 (Figure 3.10-11). At Braunschweig, nearly no change in yield was obtained by the Bion ${ }^{\circledR}$ applications in Olsavil in 2004, while all Bion ${ }^{\circledR}$ applications slightly increased the achene yield in 2005. The highest increase, in comparison to the other Bion ${ }^{\circledR}$ applications, was revealed by 125 ppm Bion ${ }^{\circledR}$ applied at $\mathrm{BBCH}$ 16. In $\mathrm{PR} 64 \mathrm{H} 41$, the yield was decreased with all Bion ${ }^{\circledR}$ applications in 2004, except of 10 ppm Bion ${ }^{\circledR}$ applied at $\mathrm{BBCH} 09$, where achene yield was raised from $27.2 \mathrm{dt} / \mathrm{ha}$ to $28.6 \mathrm{dt} / \mathrm{ha}$. In 
opposite, the yield was not changed by 10 ppm Bion ${ }^{\circledR}$ at $\mathrm{BBCH} 09$, but all the other Bion $^{\circledR}$ applications slightly increased the achene yield. However, changes in achene yield by Bion ${ }^{\circledR}$ leaf treatment were statistically not significant at Braunschweig.

At Eckartsweier, the yield of the variety Olsavil was not significantly changed by the Bion $^{\circledR}$ applications in 2004. In 2005, the yield was considerably changed only by Bion $^{\circledR}$ application at the growth stage $\mathrm{BBCH}$ 09. 10 ppm Bion ${ }^{\circledR}$ at this stage slightly increased the yield of Olsavil, whereas $125 \mathrm{ppm}$ applied at the same stage decreased the achene yield. The other Bion ${ }^{\circledR}$ applications showed only negligible changes in yield. In PR64H41, the achene yield was in general decreased in 2004 except of $10 \mathrm{ppm}$ at $\mathrm{BBCH} 09$ and $125 \mathrm{ppm}$ at $\mathrm{BBCH} 65$, where the achene yield was slightly increased. Only 10 ppm Bion ${ }^{\circledR}$ applied at $\mathrm{BBCH} 65$ showed a remarkable decrease in achene yield in 2005. 125 ppm Bion ${ }^{\circledR}$ at $\mathrm{BBCH} 65$ showed also in this experimental year a slight increase in yield. The achene yield of Aurasol was nearly not changed by any Bion ${ }^{\circledR}$ application in both experimental years. Overall, none of the Bion ${ }^{\circledR}$ applications significantly influenced the yield at Eckartsweier in 2004-2005.

Head diameter and thousand seed weight were recorded only at the site Braunschweig. Both parameters were in general increased with the spray applications of Bion ${ }^{\circledR}$ in 2003 but not in 2004-2005 (Table A.13-14). Head diameter of the variety Olsavil was raised by Bion ${ }^{\circledR}$ applications regardless of the application time and concentration, with the exception of all three applied Bion ${ }^{\circledR}$ concentrations at $\mathrm{BBCH}$ 69, where the head diameter was not influenced. Similarly, PR64H41 showed also an increase in head diameter by all the Bion ${ }^{\circledR}$ applications. This effect was not observed in the variety Aurasol. Although, some tendency of head diameter to increase by the Bion ${ }^{\circledR}$ applications was obtained, the changes in head diameter were statistically not significant. 

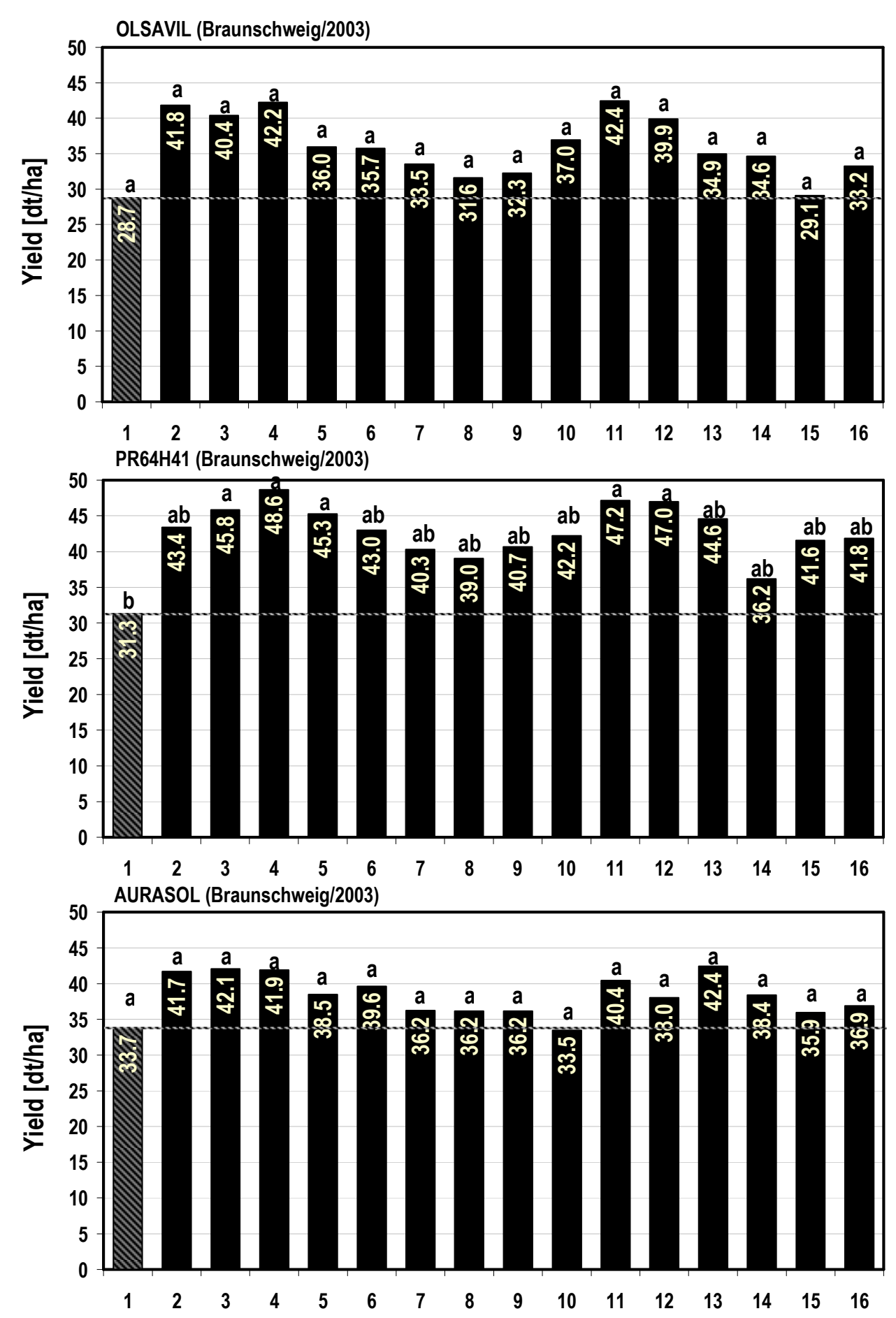

1: Control

2: $B$ ion ${ }^{\circledR} 10 \mathrm{ppm}$ at $\mathrm{BBCH}-09$

3: Bion ${ }^{\circledR} 125$ ppm at $\mathrm{BBCH}-09$

4: Bion ${ }^{\circledR} 250$ ppm at BBCH-09

5: Bion $^{\circledR} 10 \mathrm{ppm}$ at $\mathrm{BBCH}-16$

6: Bion ${ }^{\circledR} 125 \mathrm{ppm}$ at $\mathrm{BBCH}-16$

7: $\mathrm{Bion}{ }^{\circledR} 250 \mathrm{ppm}$ at $\mathrm{BBCH}-16$

8: $\mathrm{Bion}^{\circledR} 10 \mathrm{ppm}$ at $\mathrm{BBCH}-51$
9: $\mathrm{Bion}^{\circledR} 125 \mathrm{ppm}$ at $\mathrm{BBCH}-$ 10: Bion $^{\circledR} 250$ ppm at BBCH-1 11: Bion $^{\circledR} 10 \mathrm{ppm}$ at $\mathrm{BBCH}-65$ 12 Bion $^{\circledR} 125$ ppm at BBCH-65 13: $\operatorname{Bion}^{\circledR} 250$ ppm at BBCH-65 14: Bion $^{\circledR} 10$ ppm at $\mathrm{BBCH}-69$ 15: Bion $^{\circledR} 125$ ppm at $\mathrm{BBCH}-69$ 16: $\mathrm{Bion}^{\circledR} 250 \mathrm{ppm}$ at $\mathrm{BBCH}-69$

Figure 3.8: Influence of Bion $^{\circledR}$ leaf spray application on achene yield (dt/ha) at Braunschweig in 2003. 

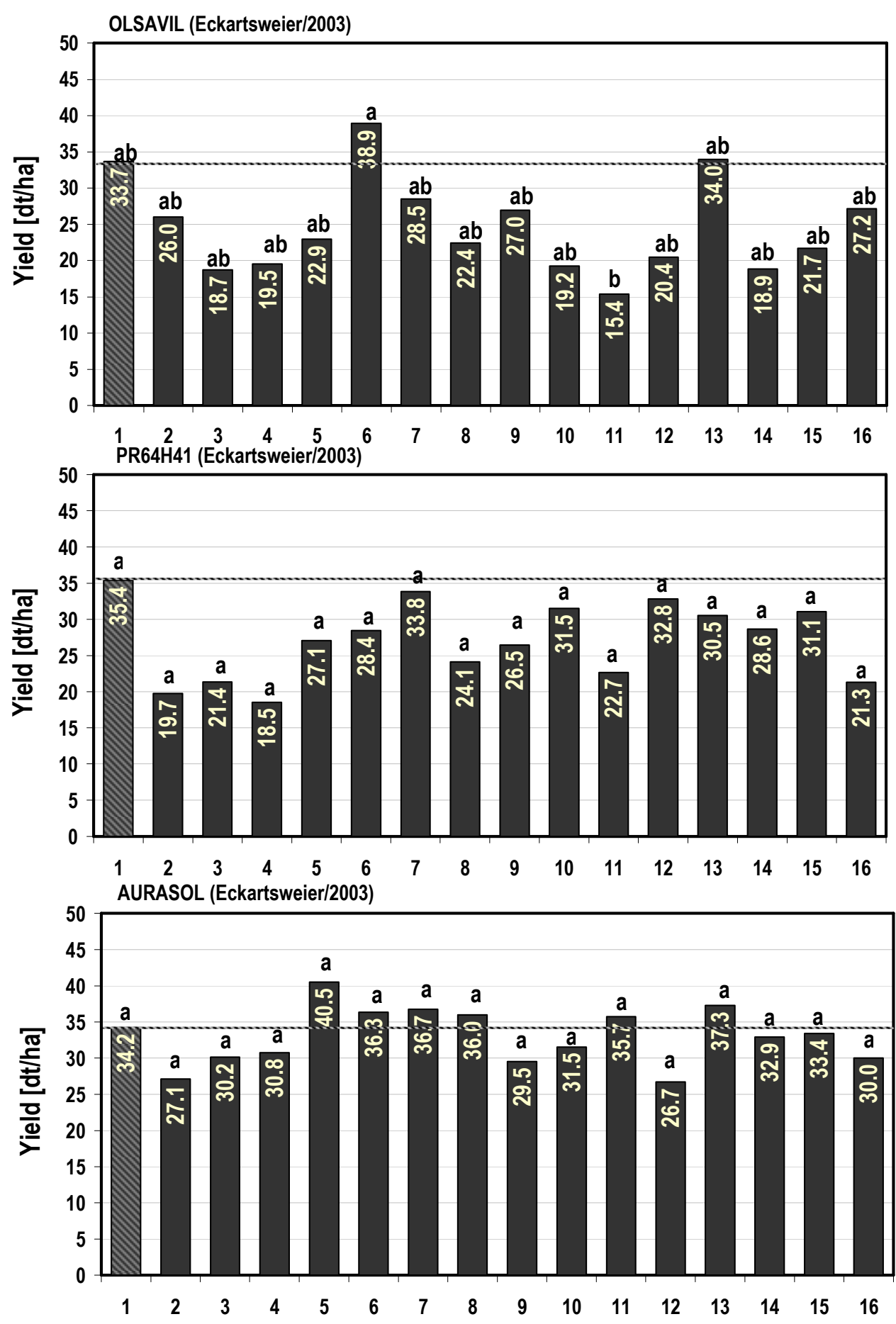

1: Control

2: Bion $^{\circledR} 0$ ppm at $\mathrm{BBCH}-09$

3: Bion $^{\circledR} 125$ ppm at $\mathrm{BBCH}-09$

4: $\mathrm{Bion}^{\circledR} 250$ ppm at $\mathrm{BBCH}-09$

5: $\mathrm{Bion}^{\circledR} 10 \mathrm{ppm}$ at $\mathrm{BBCH}-16$

6: $\mathrm{Bion}^{\circledR} 125 \mathrm{ppm}$ at $\mathrm{BBCH}-16$

7: Bion $^{\circledR} 250 \mathrm{ppm}$ at $\mathrm{BBCH}-16$

8: Bion $^{\circledR} 10$ ppm at $\mathrm{BBCH}-51$
9: Bion $^{\circledR} 125$ ppm at $\mathrm{BBCH}-51$

10: Bion $^{\circledR} 250$ ppm at BBCH-51

11: Bion $^{\circledR} 10 \mathrm{ppm}$ at $\mathrm{BBCH}-65$

12: Bion $^{\circledR} 125$ ppm at BBCH-65

13: $\operatorname{Bion}^{\circledR} 250$ ppm at BBCH-65

14: $\operatorname{Bion}^{\circledR} 10$ ppm at $\mathrm{BBCH}-69$

15: $\mathrm{Bion}^{\circledR} 125 \mathrm{ppm}$ at $\mathrm{BBCH}-69$

16: Bion $^{\circledR} 250$ ppm at $\mathrm{BBCH}-69$

Figure 3.9: Influence of Bion ${ }^{\circledR}$ leaf spray application on achene yield (dt/ha) at Eckartsweier in 2003 


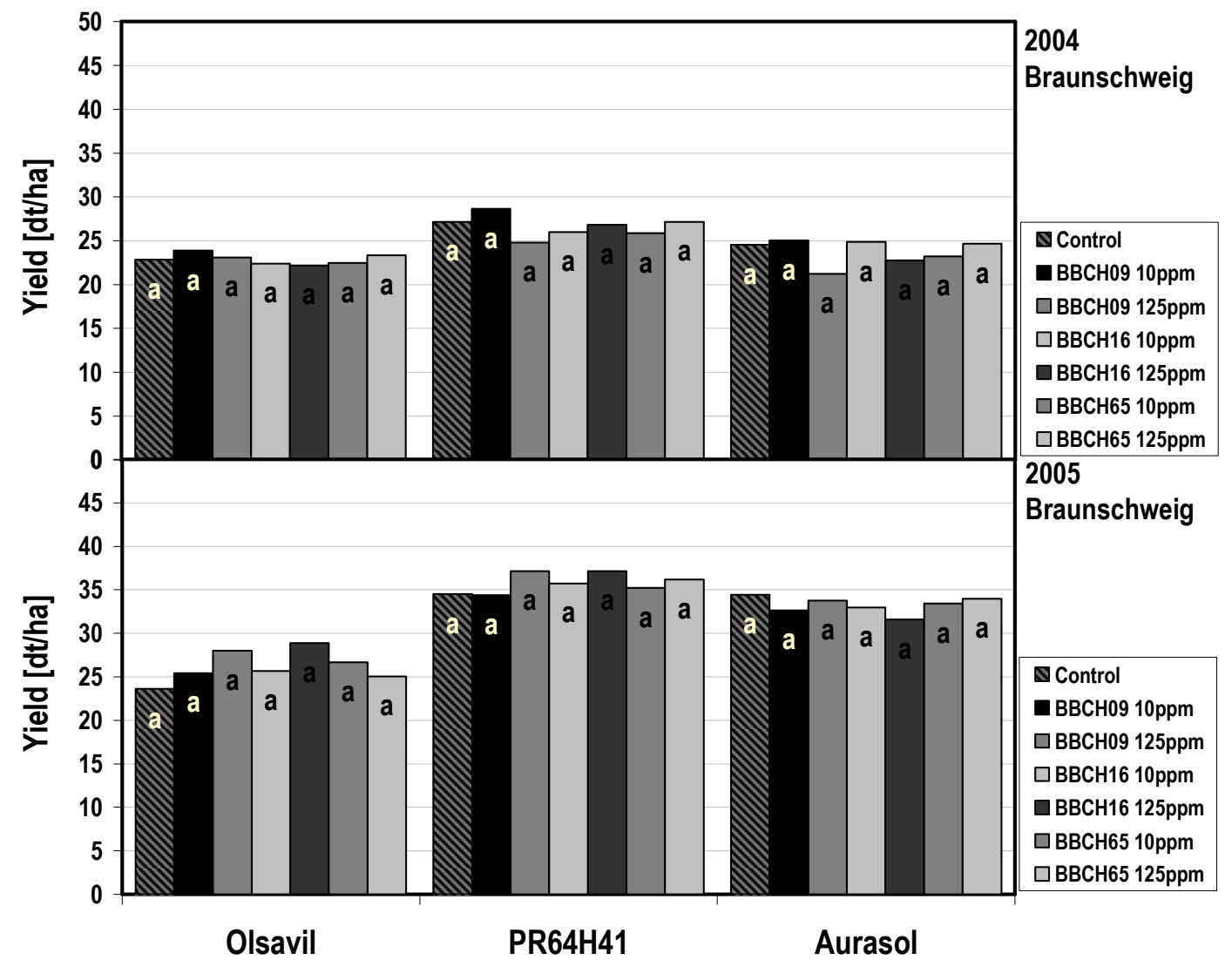

Figure 3.10: Influence of Bion $^{\circledR}$ leaf spray application on achene yield (dt/ha) at Braunschweig

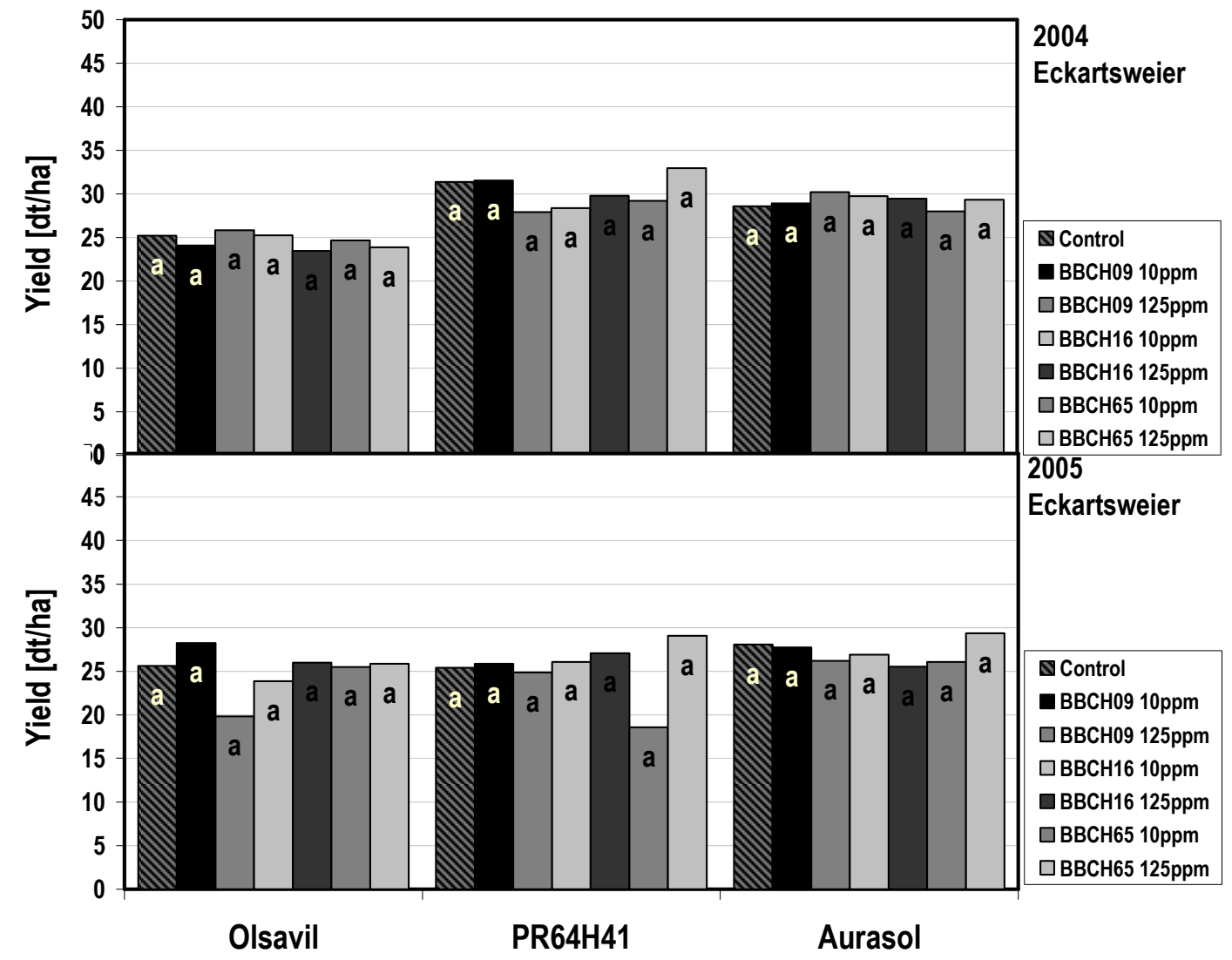

Figure 3.11: Influence of Bion ${ }^{\circledR}$ leaf spray application on achene yield (dt/ha) at Eckartsweier. 
In 2003, thousand seed weight (TSW) of the variety Olsavil was raised by Bion ${ }^{\circledR}$ applications, except of the applications at the growth stage $\mathrm{BBCH} 69$, where TSW was slightly decreased. A significant increase was only observed in PR64H41. Although all applications increased the TSW in PR64H41, only 125 ppm Bion ${ }^{\circledR}$ application at $\mathrm{BBCH} 09$ showed highly significant raise in comparison to the untreated control. Similarly, TSW was also increased in Aurasol by most of the Bion ${ }^{\circledR}$ applications. Exceptions occurred by applications at the growth stage $\mathrm{BBCH} 69.250$ ppm at this stage decreased TSW, whereas 125 ppm showed no influence. This positive effect of Bion ${ }^{\circledR}$ on TSW was not observed in the following experimental years. In 2004, a significant change was only obtained in Aurasol. 125 ppm Bion ${ }^{\circledR}$ applied at BBCH 65 significantly increased TSW from $40.8 \mathrm{~g}$ to $44.7 \mathrm{~g}$.

Plant height of all varieties was increased with the Bion ${ }^{\circledR}$ applications irrespective of the application time and concentration in 2003 at Braunschweig (Table A.15). The highest increase was observed in Olsavil with the $10 \mathrm{ppm} \mathrm{Bion}^{\circledR}$ at the earliest application date $\mathrm{BBCH} 09$, where the plant height was raised from $102.5 \mathrm{~cm}$ to 160.6 $\mathrm{cm}$. However, evaluated increase in plant height by Bion ${ }^{\circledR}$ leaf spraying could not been proven statistically. Additionally, this effect of Bion ${ }^{\circledR}$ application on plant height was not observed in the following experimental years (Figure A.4). All varieties showed only negligible changes in plant height. At Eckartsweier, plant height was evaluated only in 2003. No influence by Bion ${ }^{\circledR}$ was observed at the southern experimental site Eckartsweier. The plant height in the different experimental plots varied between 190 and $215 \mathrm{~cm}$ without any significance.

\section{Changes in quality components}

Oil content of all varieties after Bion ${ }^{\circledR}$ spray applications at both experimental sites in the three experimental years are listed in Table A.16-17. The analysis of the oil content in all varieties revealed an increase by the most of the 9 different Bion ${ }^{\circledR}$ variations at Braunschweig in 2003. Although, the most applications raised the oil content of $\mathrm{HO}$ sunflowers, no differences were observed between variations and varieties. A significant change was recorded only in Aurasol. In this variety, 125 ppm Bion $^{\circledR}$ application at $\mathrm{BBCH} 09$ resulted, with $54.3 \%$, in the highest oil content and was significantly higher than 250 ppm Bion ${ }^{\circledR}$ application at $\mathrm{BBCH} 51$, which showed $50 \%$ oil. 
Only 6 different Bion ${ }^{\circledR}$ variations were tested in the following experimental years at Braunschweig. Bion ${ }^{\circledR}$ applications showed only negligible influence in respect to the oil content in 2004. In fact, slight but insignificant decreases were observed by most Bion $^{\circledR}$ applications. Significant change in oil content was obtained only in Aurasol by 10 ppm Bion ${ }^{\circledR}$ applied at $\mathrm{BBCH}$ 09. It revealed, with $50.2 \%$, significantly higher oil content than 125 ppm Bion ${ }^{\circledR}$ applied at $\mathrm{BBCH} 16$, which showed only $47.2 \%$ oil in seed, and slightly higher than the untreated control, which presented $49.8 \%$ oil. Significant changes in oil content by the application of different Bion ${ }^{\circledR}$ variations were not observed in 2005.

At Eckartsweier, changes in oil content did not show any significant effect by the applications in 2003. Only in Aurasol, oil content was in general decreased insignificantly by the Bion $^{\circledR}$ applications regardless of the application time and concentration. In the following experimental years, no influence of Bion ${ }^{\circledR}$ application variations on oil content was observed.

The oil composition was in general not significantly affected by leaf spraying of the plant activator at both experimental sites during the main experiments (Table A.1819). The main component of the fatty acid composition oleic acid was not changed at any experimental site or year. Olsavil, the variety with the highest oleic acid content, showed a stable high oleic acid rates. In the first main experimental year at Braunschweig, the lowest value for the oleic acid in Olsavil was $89.79 \%$ induced by 125 ppm Bion ${ }^{\circledR}$ applied at BBCH69, whereas the highest was $91.88 \%$ by 10 ppm Bion $^{\circledR}$ at $\mathrm{BBCH} 65$. Similarly, variation in oleic acid content of Aurasol and PR64H41 was insignificant. However, there was some significant variation in linoleic and stearic acid content. Linoleic acid content of Olsavil was decreased with most of the Bion ${ }^{\circledR}$ applications. Significant decrease was observed by application of 10 and $250 \mathrm{ppm}$ Bion $^{\circledR}$ at $\mathrm{BBCH} 65$. In PR64H41, stearic acid content was decreased by 250 ppm Bion $^{\circledR}$ applied at $\mathrm{BBCH}$ 09. A significant but negligible variation in linoleic and stearic acid content was observed also in 2004 at both experimental sites. However, changes in stearic and linoleic acid contents were negligible and not consistent throughout the experiment and did not no influence the proportion of the oleic acid. 


\section{GREENHOUSE EXPERIMENTS ON THE BION ${ }^{\circledR}$ AS FUNGICIDAL APPLICATION}

In the first year of the main experiments in 2003, a greenhouse experiment was established in order to examine if the plant activator treatment can induce resistance in $\mathrm{HO}$ sunflowers against the fungal pathogen Sclerotinia sclerotiorum. Bion ${ }^{\circledR}$ was tested as seed treatment and leaf spray application at two growth stages $(\mathrm{BBCH} 12$ and $\mathrm{BBCH} 16)$ on two varieties, Aurasol and Olsavil. 5 inoculation dates were evaluated. Ratio of died plants in total number of plants was recorded for disease assessment.

\section{Inoculation date: first pair of leaves unfolded (BBCH 12)}

The first inoculation has been carried out when the first leaf pair appeared. A week after inoculation, the first evaluation of the fungal infection was carried out, followed by 10,13 and 14 days after inoculation. The results of the first inoculation date indicate that Bion ${ }^{\circledR}$ seed treatment could slightly slow down the Sclerotinia infection b in both tested varieties but could not avoid it (Figure 3.41-1). $90 \%$ of Aurasol and $100 \%$ of Olsavil plants were dead 14 days after inoculation.

\section{Inoculation date: 4 leaves (second pair) unfolded (BBCH 14)}

At the second inoculation date, a 125 ppm Bion ${ }^{\circledR}$ spray application in addition to the seed treatment was also tested in the greenhouse experiment. Bion ${ }^{\circledR}$ seed treatment showed again only a slight delay in Sclerotinia infection in both varieties while Bion ${ }^{\circledR}$ applied at first pair of leaves stage significantly decreased infection rate in Aurasol (Figure 3.41-2). 17 days after inoculation, only $30 \%$ of Bion ${ }^{\circledR}$ applied Aurasol plants were completely infected and dead in comparison to $100 \%$ infected plants in the untreated control. In Olsavil, Bion ${ }^{\circledR}$ spray application could only slow down the infection until 15 days after inoculation, however all plants were dead at the end of the experiment.

\section{Inoculation date: 6 leaves unfolded $(\mathrm{BBCH} 16)$}

Bion $^{\circledR}$ seed treatment and 125 ppm Bion ${ }^{\circledR}$ spray application at first leave pair stage $(\mathrm{BBCH} 12)$ was tested at the third inoculation date. Plants were inoculated when they reached $\mathrm{BBCH} 16$ stage. BION seed treatment could only slow down the infection until the 23 days after inoculation in Aurasol, but all plants were dead already 26 days after inoculation (Figure $3.41-3$ ). Only $10 \%$ of the Bion ${ }^{\circledR}$ sprayed plants were 
dead up to the $23^{\text {rd }}$ day after inoculation, however infection rate rapidly increased after this day and reached $90 \%$ at the end of the experiment. Olsavil showed a little different response to both seed and leaf treatment of Bion ${ }^{\circledR}$. Seed treatment showed higher infection rate at the $23^{\text {rd }}$ day after the inoculation. On the other hand, leaf spray application could decrease the infection rate until the end of the experiment.

\section{Inoculation date: Inflorescence emergence (BBCH 51)}

Additionally a later leaf application of $\mathrm{Bion}^{\circledR}$ was tested at the $4^{\text {th }}$ inoculation date. Bion ${ }^{\circledR}$ was also applied when 6 leaves of the plants were unfolded. Inoculation was carried out at inflorescence emergence stage. Control plants showed already at the first evaluation day with $40 \%$ a high infection rate in Aurasol (Figure 3.41-4). In contrast, all Bion ${ }^{\circledR}$ applications showed low to no infection 17 days after inoculation. Seed treatment delayed the infection until the $38^{\text {th }}$ day of the inoculation, but than increased the rate. Leaf spraying at $\mathrm{BBCH} 12$ and at $\mathrm{BBCH} 16$ also increased the infection rate at the $45^{\text {th }}$ day after inoculation. On the other hand, only seed treatment could decrease the infection in Olsavil. Both leaf applications caused a slight increase in infection rate.

\section{Inoculation date: Inflorescence clearly separated from foliage leaves (BBCH 57)}

Bion ${ }^{\circledR}$ seed treatment as well as both application times for leaf treatment were tested at the $5^{\text {th }}$ inoculation date. Inoculation was carried out when the inflorescence was clearly separated from foliage leaves. In both varieties, control plants showed the highest infection rate and fastest infection development (Figure 3.41-5). At the end of the experiment, only $20 \%$ of the seed treated plants of Aurasol were dead while all Olsavil plants survived. However, both varieties showed symptoms of the infection (data not shown). Inoculated leaf and lateral branch of all plants was completely dry and some of the plant's stems showed large lesions. Leaf applications showed in both studied varieties a noticeable decrease in degree of infection, yet it was less than those which achieved by the seed treatment. 

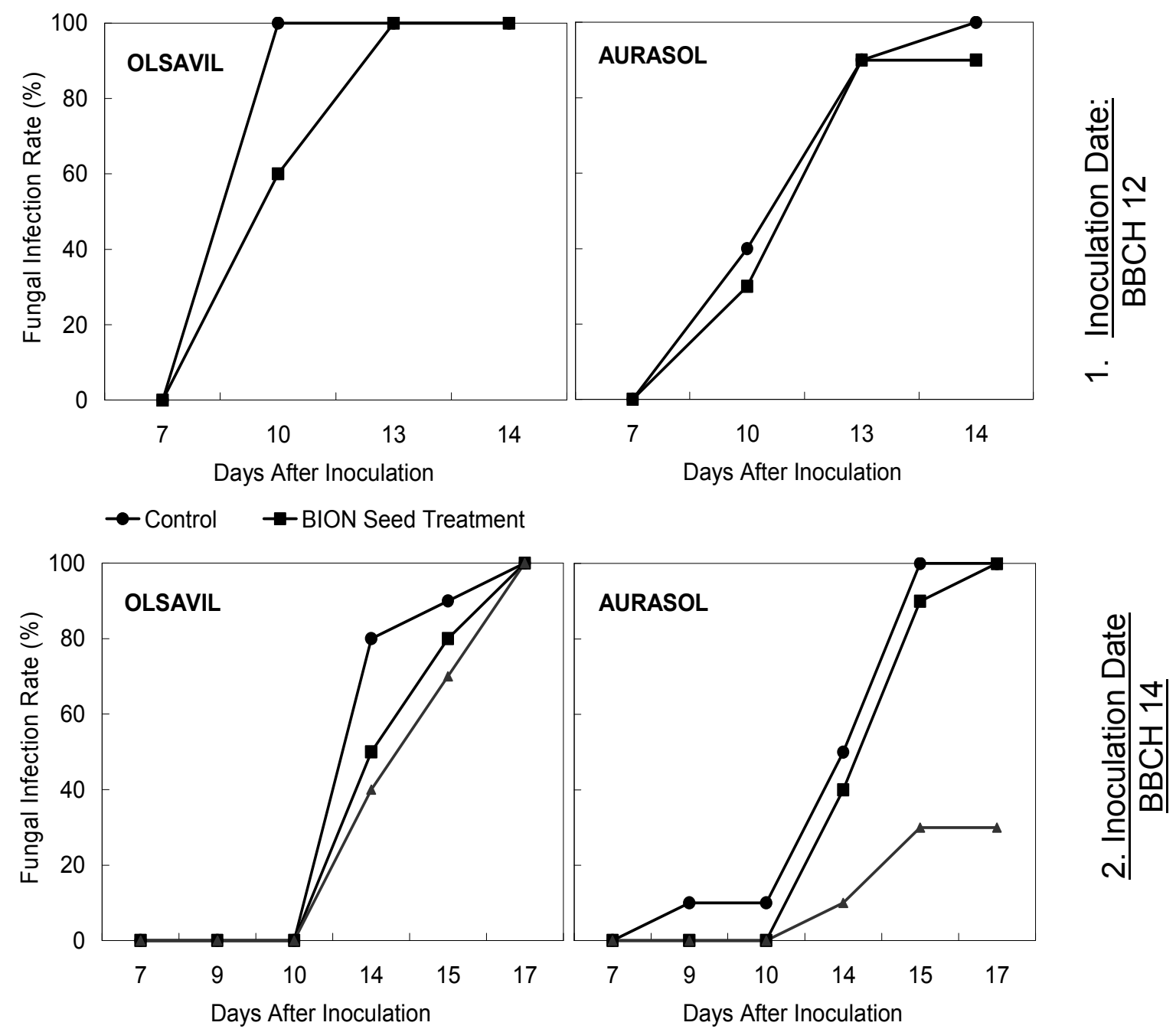

$\rightarrow$ Control $\rightarrow$ BION Seed Treatment $\rightarrow$ BION Spray / BBCH12
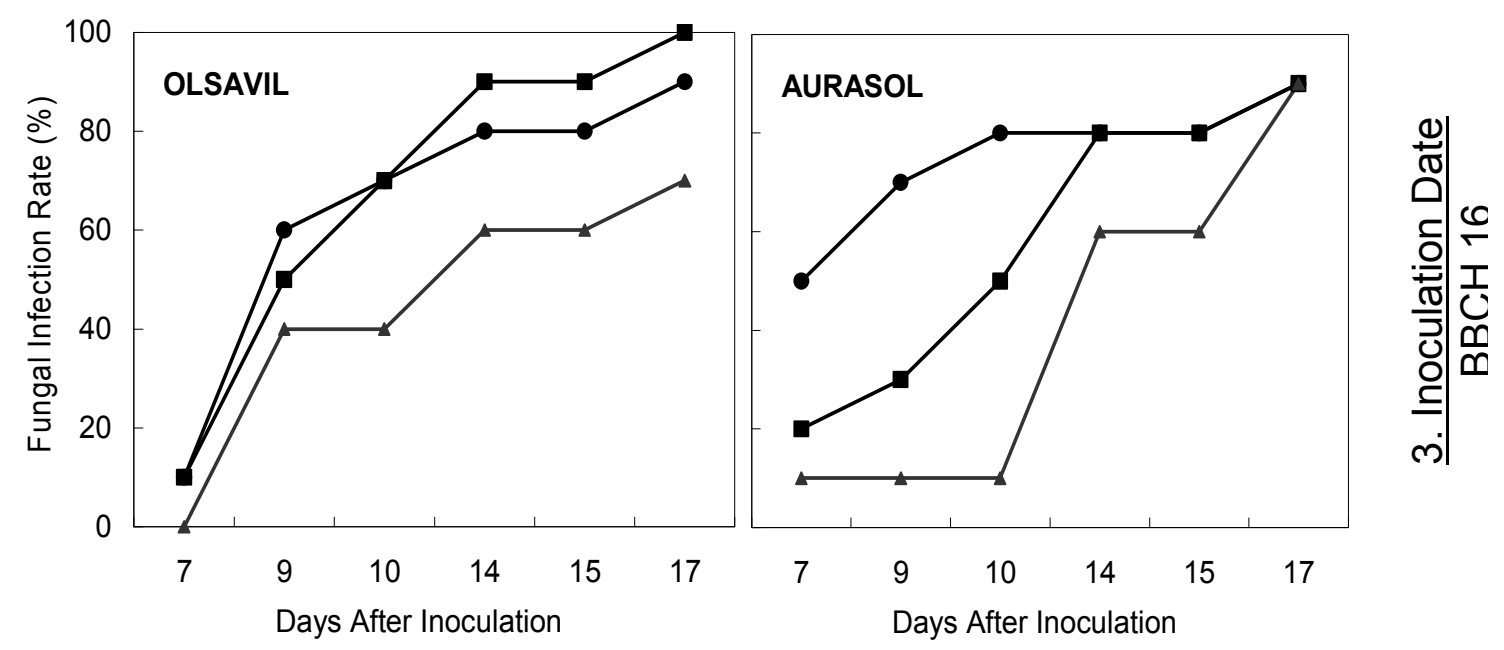

$\rightarrow$ Control $\rightarrow$ BION Seed Treatment

$\neg$ BION Spray / BBCH12 

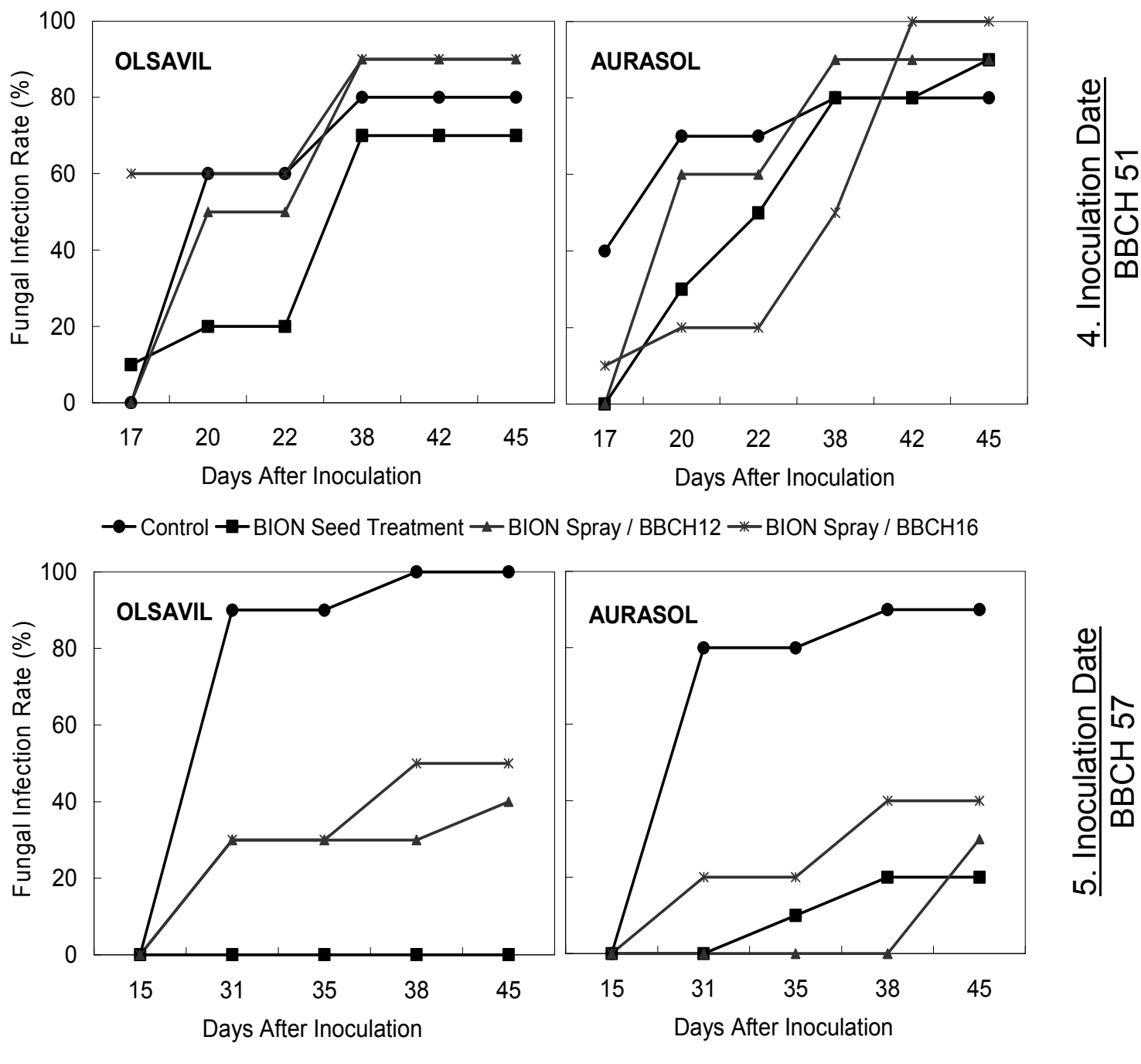

Figure 3.12: Infection rates by Sclerotinia sclerotioum after inoculation 1) at first leave pair stage, 2) at second leave pair stage, 3) at 6 leaves unfolded stage, 4) at inflorescence emergence stage, 5) when the inflorescence clearly separated from foliage leaves.

\subsubsection{Effect of ammonium based liquid fertilization}

\section{Changes in fungal infection rate}

Urea ammonium nitrate was tested as liquid fertilizer in three different $N$ concentrations $(48 \mathrm{~kg}, 60 \mathrm{~kg}$ and $72 \mathrm{~kg} \mathrm{~N} / \mathrm{ha}$ ) at emergence stage in the preliminary experiments in 2002, with two different application techniques, point injection and surface application. Fungal infection rate varied depending on the variety with ammonium based liquid fertilizer (Figure 3.13). Fungal infection reached overall $100 \%$ in variety Olsavil with liquid fertilization irrespective of the application method and $\mathrm{N}$ concentration. Variety PR64H61 showed $80 \%$ infection rate in untreated control plots. Except of the application of urea ammonium nitrate solution containing 
$48 \mathrm{~kg} \mathrm{~N} / \mathrm{ha}$, all liquid fertilizer applications showed an infection rate more than $80 \%$. In contrast to the other two varieties, significant increase in fungal infection rate was observed in variety Aurasol with liquid fertilizer. Surface application of urea ammonium nitrate containing the lowest $\mathrm{N}$ concentration (48 $\mathrm{kg} \mathrm{N} / \mathrm{ha}$ ), applied at emergence stage resulted in a significant increase of fungal disease rates in comparison to the control. Surface application of the liquid fertilizer using higher $\mathrm{N}$ concentrations (60 and $71 \mathrm{~kg} \mathrm{~N} / \mathrm{ha}$ ), as well as injection of fertilizer solution in all different concentrations caused slight increase in Sclerotinia white rot and grey mould, however on a lower significance level.

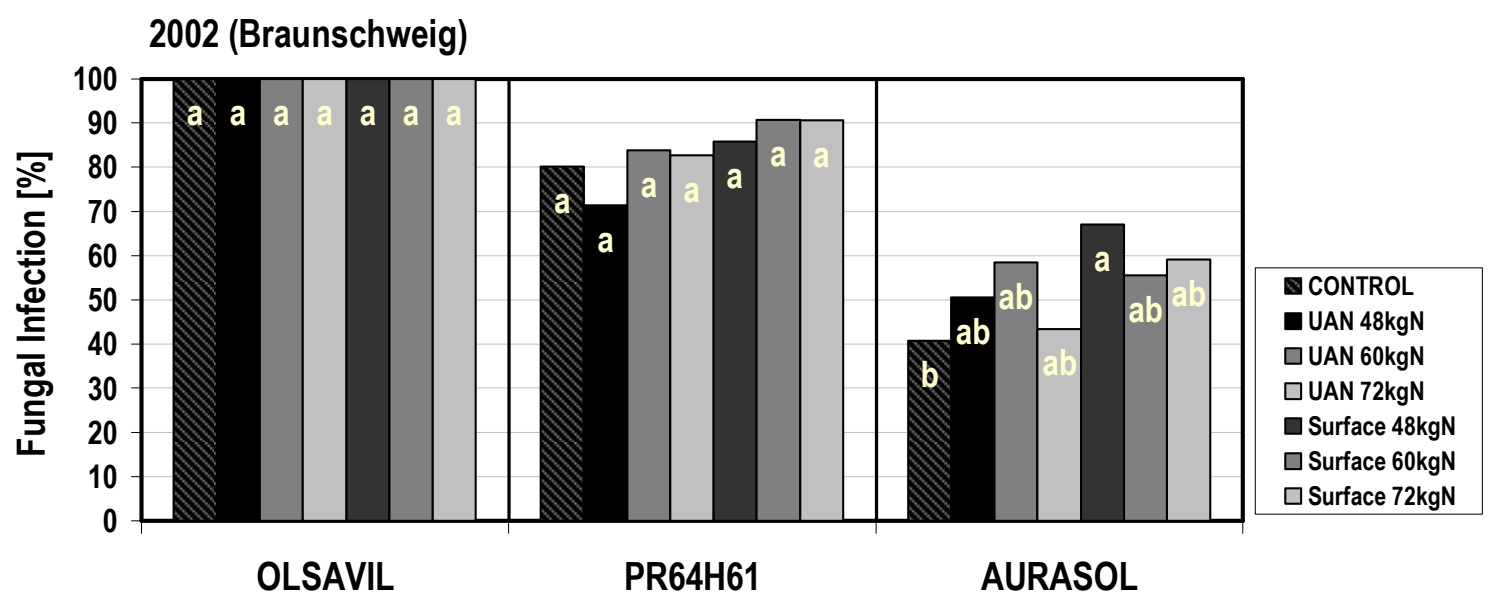

Figure 3.13: Influence of liquid fertilizer applications on fungal infection rate (\%) in all varieties in 2002 at Braunschweig. UAN: urea ammonium nitrate solution (injected).

In the main field experiments, unlike the preliminary field experiment, only fertilizer application by injection was used. Liquid fertilizer was tested only in 2003 and 2004. Due to the very low fungal infection rates in the first experimental year 2003, it was not possible to observe any influence by liquid fertilizers (Table A.21). Fungal infection rates in experimental year 2004 increased dramatically at both experiment sites (Figure 3.14-15). Infection rates varied from $72 \%$ to $94 \%$ at Braunschweig. In Olsavil and Aurasol, fungal infection rate showed in general a slight tendency to decrease by liquid fertilizer. However, decreases in infection rates were irregular and not significant. In contrast, all liquid fertilizer applications increased the fungal infection rates at Eckartsweier in 2004. Increase in infection rate by the UAN supply at the growth stage $\mathrm{BBCH} 16$ was observed in all three varieties. 


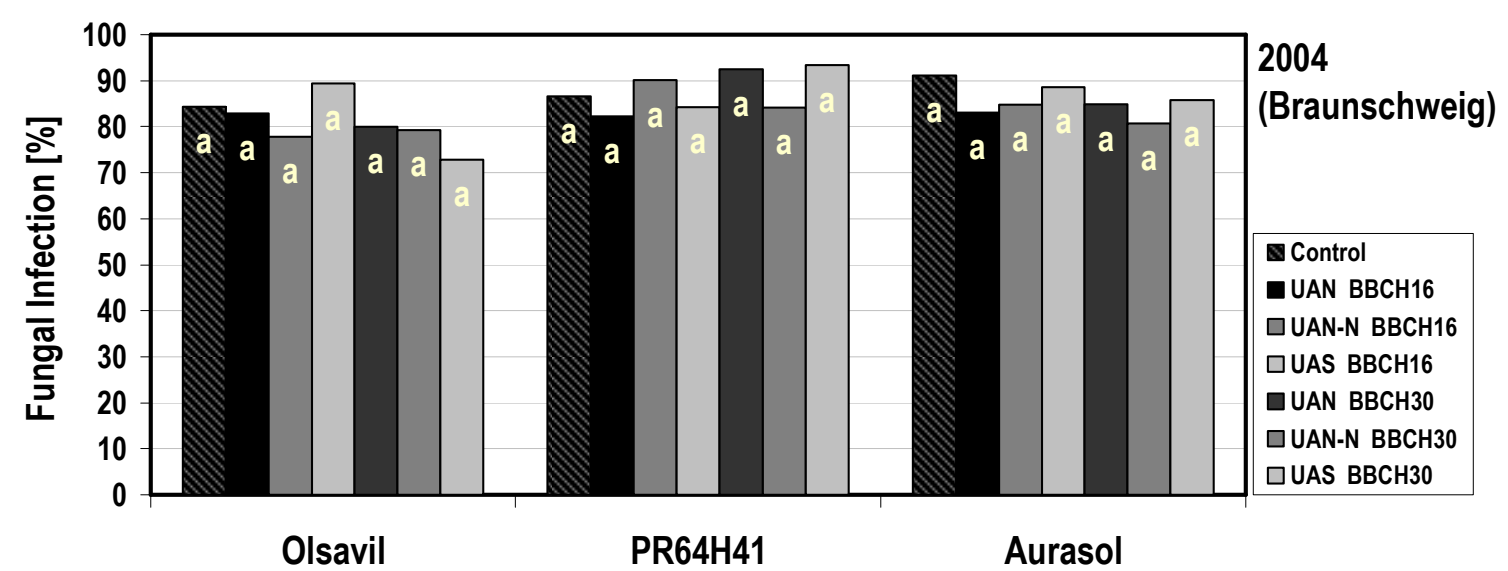

Figure 3.14: Influence of liquid ammonium fertilizer on fungal infection rate at Braunschweig in 2004. UAN: urea ammonium nitrate solution, UAN-N: urea ammonium nitrate solution with nitrification inhibitor, UAS urea ammonium sulphate solution $N$ concentration: $48 \mathrm{kgN} / \mathrm{ha}$.

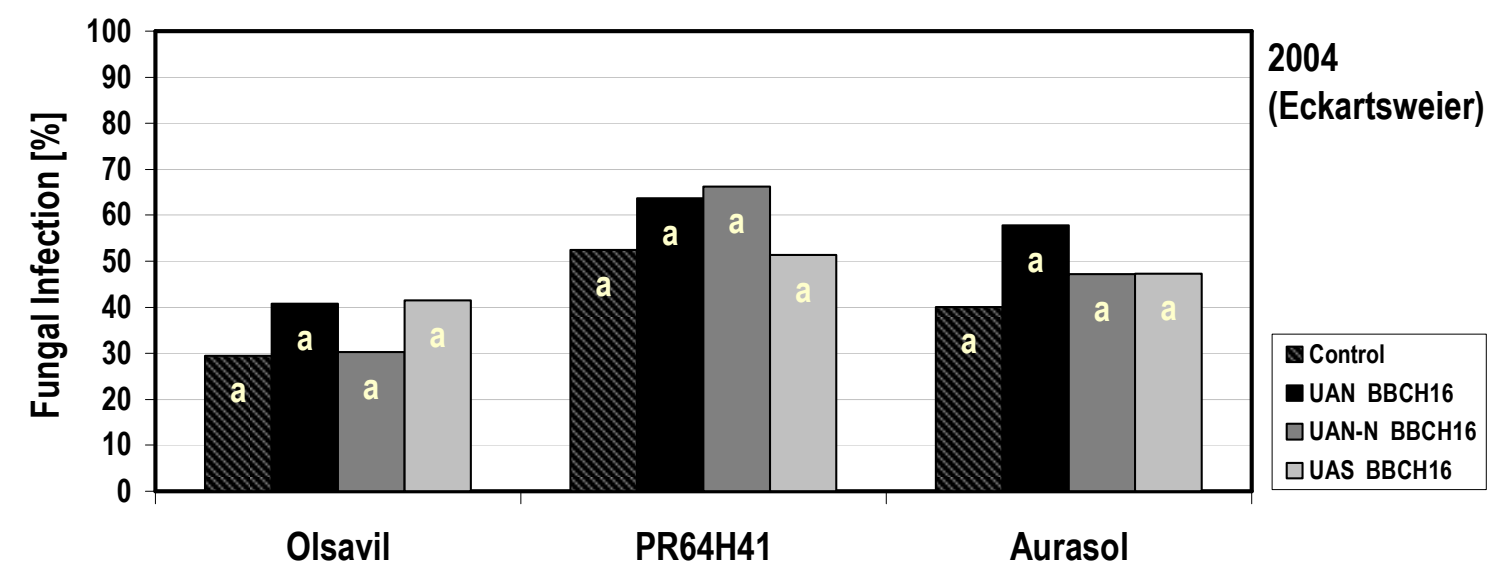

Figure 3.15: Influence of liquid ammonium fertilizer on fungal infection rate (\%) at Eckartsweier in 2004. UAN: urea ammonium nitrate solution, UAN-N: urea ammonium nitrate solution with nitrification inhibitor, UAS urea ammonium sulphate solution $\mathrm{N}$ concentration : $50 \mathrm{kgN} / \mathrm{ha}$.

\section{Changes in yield components}

Application of ammonium based fertilizer solution did not result in any significant change in yield parameters in 2002 (Table A.22-24). In response to the different variations of liquid ammonium fertilizer, the achene yield of Olsavil and PR64H41 was in general slightly higher than the conventionally fertilized control at Braunschweig in 2003, depending on the $\mathrm{N}$-concentration and application time, whereas Aurasol showed a less response to the liquid fertilization (Table 3.12). In Olsavil, the highest yield increase, from $28.7 \mathrm{dt} /$ ha to $37 \mathrm{dt} / \mathrm{ha}$, was observed by UAN-N with $48 \mathrm{~kg} \mathrm{~N}$ applied at $\mathrm{BBCH} 30$. The same ammonium solution, applied at the same time with higher $\mathrm{N}$ concentration (60 kg/ha) resulted, with $30.6 \mathrm{dt} / \mathrm{ha}$ in a much less yield increase in comparison to the lower $\mathrm{N}$ fertilization. Similarly in most 
liquid fertilizer applications, a lower $\mathrm{N}$-concentration revealed higher achene yield, except of UAN-N applied at $\mathrm{BBCH} 16$ and UAS applied at $\mathrm{BBCH} 30$. PR64H41 responded with higher yield increases to the most of the fertilizer variations. The highest yield increase was obtained by UAN applied at $\mathrm{BBCH} 30$, followed by the UAS application at $\mathrm{BBCH} 30$ irrespective of the $\mathrm{N}$ concentration. Different $\mathrm{N}$ concentrations revealed generally similar achene yield in PR64H41. The influence of liquid ammonium fertilization on the achene yield of Aurasol was in general negligible. Exceptionally, UAN-N supply with $48 \mathrm{~kg} \mathrm{~N}$ at $\mathrm{BBCH} 30$ caused yield decrease. However, changes in achene yield by liquid fertilizer could not be proven statistically.

In contrast, all variations of liquid ammonium fertilizer, independent of the $\mathrm{N}$ concentration and application time, caused decrease in achene yield in all three varieties at Eckartsweier in 2003. The highest yield decrease, from $33.7 \mathrm{dt} / \mathrm{ha}$ to 23.8 $\mathrm{dt} / \mathrm{ha}$, was observed in Olsavil by UAS with $48 \mathrm{~kg} \mathrm{~N}$ applied at $\mathrm{BBCH} 16$. Also at Eckartsweier, changes in achene yield were statistically insignificant.

Achene yield at Braunschweig was in general lower in 2004 than in previous experiment year. Figure 3.16 shows the influence of different ammonium fertilizations on the yield. The results indicate that the application of ammonium based fertilizers at different growth stages does not change achene yield significantly. However, a general tendency towards a yield increase by liquid fertilization, irrespective of the $\mathrm{N}$ concentration and application time could be observed in Olsavil. In contrast, PR64H41 and Aurasol responded negatively to all variations of liquid fertilization in respect to the achene yield.

At Eckartsweier, achene yield of sunflowers were slightly higher than at Braunschweig. Olsavil showed nearly no response to the liquid ammonium fertilization (Figure 3.17). Achene yield of PR64H41 was slightly decreased with all types of ammonium fertilization. The highest decrease was observed by UAN-N application, where the achene yield was reduced from $31.4 \mathrm{dt} /$ ha by the conventional fertilization to $27.4 \mathrm{dt} / \mathrm{ha}$. In contrast, liquid fertilization slightly increased the achene yield in Aurasol. Nevertheless, changes in yield by application of three different liquid 
fertilizers were only negligible in all varieties and generally not significant. There were no consistent results in achene yield regarding ammonium based liquid fertilization.

Table 3.12: Influence of liquid ammonium fertilizer on achene yield (dt/ha) at both experiment sites in 2003.

\begin{tabular}{|c|c|c|c|c|c|c|}
\hline & \multicolumn{3}{|c|}{ BRAUNSCHWEIG } & \multicolumn{3}{|c|}{ ECKARTSWEIER } \\
\hline & Olsavil & PR64H41 & Aurasol & Olsavil & PR64H41 & Aurasol \\
\hline Control & $28.7 a$ & $31.3 a$ & $33.7 a$ & $33.7 a$ & $35.4 a$ & $34.2 a$ \\
\hline${ }^{*} \mathrm{UAN}$ BBCH-16 48kgN & $30.6 a$ & $35.2 a$ & $32.5 a$ & $28.2 a$ & $23.4 a$ & $31.0 a$ \\
\hline UAN BBCH-16 60kgN & $26.6 a$ & $35.9 a$ & $35.3 a$ & $24.8 a$ & $27.6 a$ & $31.9 a$ \\
\hline †UAN-N BBCH-16 48kgN & $30.2 a$ & $32.3 a$ & $30.9 a$ & $27.5 a$ & $24.7 a$ & $31.4 a$ \\
\hline UAN-N BBCH16 60kgN & $26.0 a$ & $36.6 a$ & $31.8 a$ & $25.7 a$ & $27.4 a$ & $32.4 a$ \\
\hline${ }^{\dagger}$ UAS BBCH-16 48kgN & $31.2 \mathrm{a}$ & $30.7 a$ & $32.6 a$ & $23.8 a$ & $27.4 a$ & $30.4 a$ \\
\hline UAS BBCH-16 60kgN & $28.0 a$ & $33.4 a$ & $29.5 a$ & $28.5 a$ & $25.4 a$ & $32.1 \mathrm{a}$ \\
\hline UAN BBCH-30 48kgN & $29.4 a$ & $38.9 a$ & $30.6 a$ & - & - & - \\
\hline UAN BBCH-30 60kgN & $32.6 a$ & $38.0 a$ & $33.1 \mathrm{a}$ & - & - & - \\
\hline UAN-N BBCH-30 48kgN & $37.0 a$ & $34.8 a$ & $27.8 a$ & - & - & - \\
\hline UAN-N BBCH-30 60kgN & $30.6 a$ & $34.3 a$ & $31.2 \mathrm{a}$ & - & - & - \\
\hline UAS BBCH-30 48kgN & $24.1 \mathrm{a}$ & $37.6 a$ & $34.6 a$ & - & - & - \\
\hline UAS BBCH-30 60kgN & $31.3 a$ & $36.5 a$ & $35.3 a$ & - & - & - \\
\hline
\end{tabular}

Other yield parameters such as plant height, TSW and head diameter were only evaluated at Braunschweig. Although, the plant height of all varieties was in general slightly increased in 2003 and 2004, influence of the liquid fertilization on plant height was insignificant (Table A.25).

Thousand seed weight was slightly increased by the liquid fertilization in all varieties in 2003, however, significant increase was observed only in Olsavil (Table A.26). UAS with $60 \mathrm{~kg} \mathrm{~N}$ applied at BBCH 16 showed, with $52 \mathrm{~g}$, significantly higher TSW than the same ammonium solution with $48 \mathrm{~kg} \mathrm{~N}$ injected at $\mathrm{BBCH} 16$, which revealed only $37 \mathrm{~g}$ TSW. In comparison, conventionally fertilized control showed $40.2 \mathrm{~g}$ TSW. Both injection time of UAN-N with $48 \mathrm{~kg} \mathrm{~N}$ showed noticeable increase in TSW, however was statistically insignificant. Also, PR64H41 and Aurasol showed insignificant increase in TSW with most of the liquid fertilizer applications. Similarly, in 2004 TSW was slightly increased by all liquid ammonium fertilizer applications (Figure A.4). Overall, effect of ammonium injection on TSW was with one exception insignificant and not consistent. Head diameter revealed no change in response to 
the liquid ammonium fertilization in any variety in 2003 (Table A.26). Similar results were observed also in the following experimental year 2004 (data not shown).

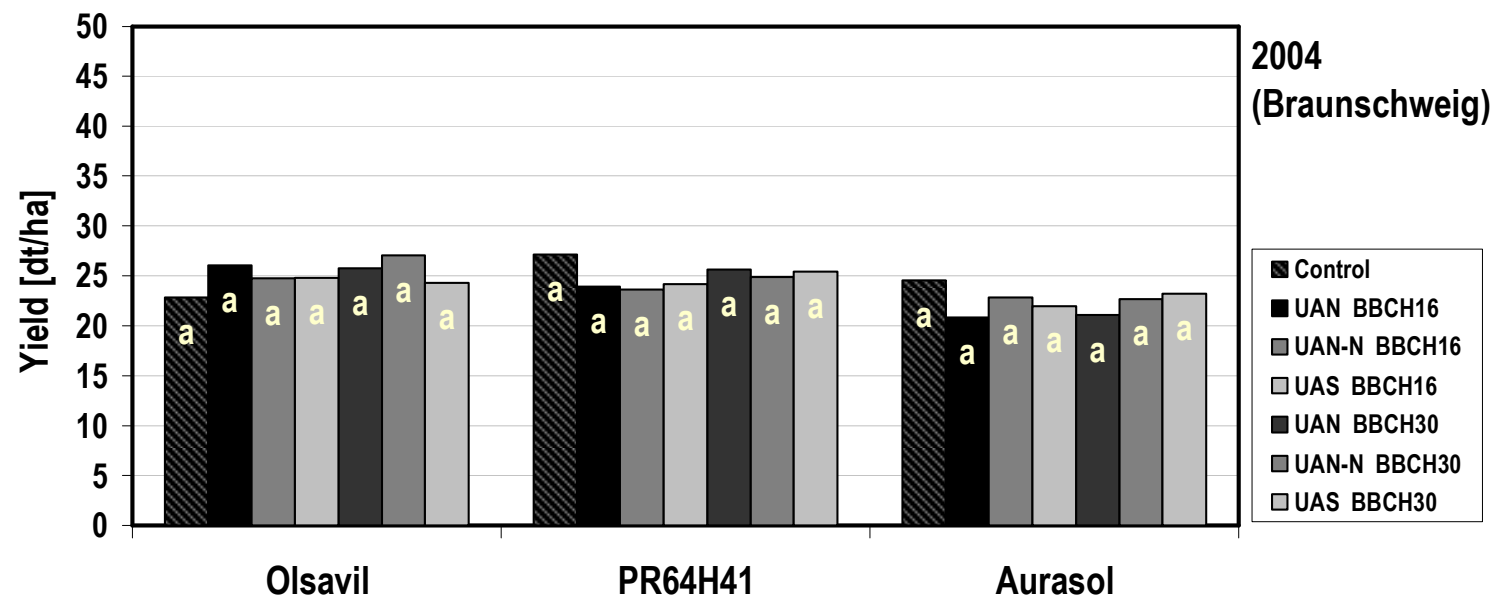

Figure 3.16: Influence of liquid ammonium fertilizer on achene yield (dt/ha) at Braunschweig in 2004. UAN: urea ammonium nitrate solution, UAN-N: urea ammonium nitrate solution with nitrification inhibitor, UAS urea ammonium sulphate solution, $\mathrm{N}$ concentration: $48 \mathrm{kgN} / \mathrm{ha}$

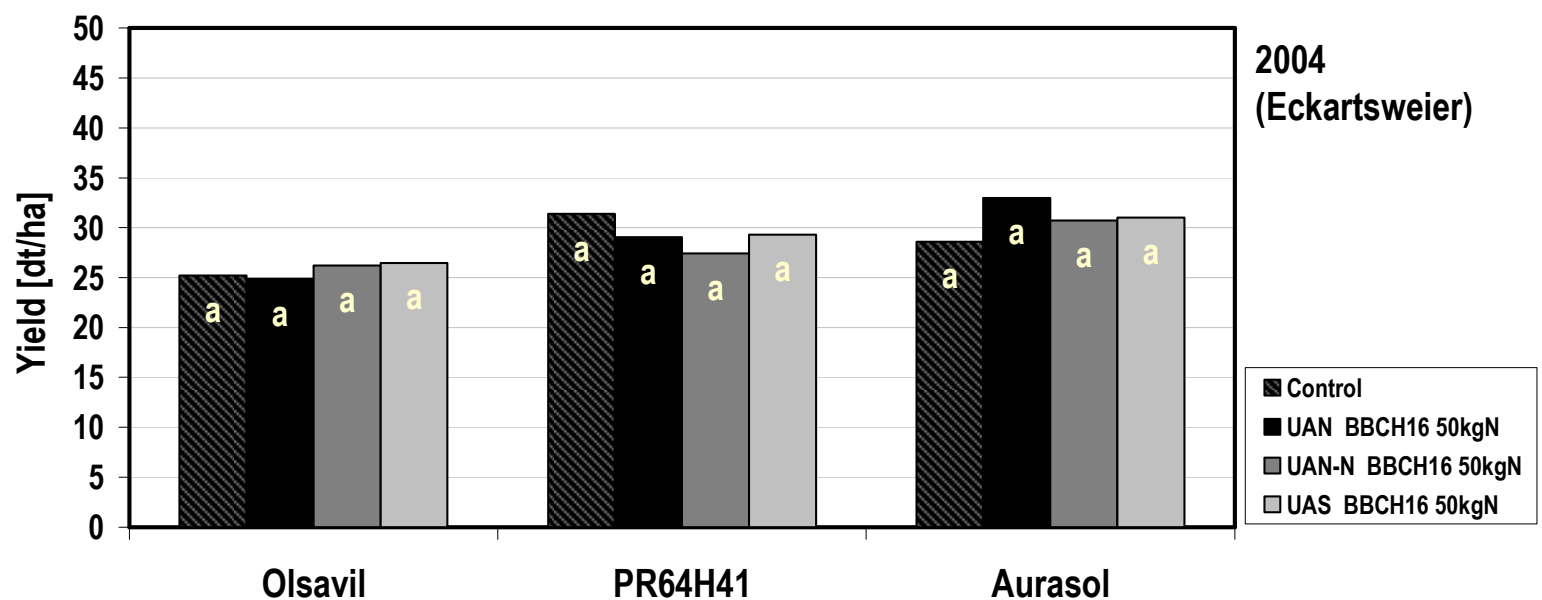

Figure 3.17: Influence of liquid ammonium fertilizer on achene yield (dt/ha) at Eckartsweier in 2004. UAN: urea ammonium nitrate solution, UAN-N: urea ammonium nitrate solution with nitrification inhibitor, UAS urea ammonium sulphate solution. $\mathrm{N}$ concentration: $50 \mathrm{kgN} / \mathrm{ha}$

\section{Changes in quality components}

Table 3.13 shows the changes in oil content of the three varieties by different liquid fertilizer applications at both experimental sites in 2003. The results indicate that the oil content of all varieties was in general raised by the ammonium based liquid fertilizer supply. A significant change in oil content, however, was observed only in variety Olsavil. UAS with $60 \mathrm{~kg} \mathrm{~N}$ applied at BBCH 16 and UAN-N with $48 \mathrm{~kg} \mathrm{~N}$ applied at $\mathrm{BBCH} 30$ increased the oil content of the $\mathrm{HO}$ sunflower variety 
significantly. In contrast, UAN-N with $60 \mathrm{~kg} \mathrm{~N}$ applied at BBCH 30 showed the lowest oil content and was significantly lower than most of the other liquid fertilizer applications, however, was not significantly lower than the control. Also the oil content of PR64H41 showed a tendency of the oil content to increase by most of the liquid ammonium injections. However, the increase in oil content in this variety was negligible and insignificant. Unlike the variety Olsavil, the highest raise was observed by UAN-N with $48 \mathrm{~kg} \mathrm{~N}$ applied at BBCH 16 followed by UAS with $48 \mathrm{~kg} \mathrm{~N}$ applied at $\mathrm{BBCH}$ 16. Different from the first two varieties, Aurasol showed nearly no response to the liquid fertilization method.

In 2004, oil content of all varieties was increased by the liquid ammonium fertilizer of the application time and $\mathrm{N}$ concentration at Braunschweig (Table 3.14). Highest increase in oil content was observed in variety Olsavil, where the control revealed $51.5 \%$ oil and all liquid fertilizer applications around $55 \%$. However, significant increase was obtained only in Aurasol. In contrast to the results at Braunschweig, oil content was slightly decreased by most of the liquid ammonium fertilizer applications regardless of the $\mathrm{N}$ concentration and application time at Eckartsweier in 2003-2004. However, the reduction in oil content by ammonium based liquid fertilizer applications was negligible and statistically not significant.

Table 3.13: Influence of liquid ammonium fertilizer on oil content (\%) at both experimental sites in $\mathbf{2 0 0 3}$

\begin{tabular}{|c|c|c|c|c|c|c|}
\hline & \multicolumn{3}{|c|}{ BRAUNSCHWEIG } & \multicolumn{3}{|c|}{ ECKARTSWEIER } \\
\hline & Olsavil & PR64H41 & Aurasol & Olsavil & PR64H41 & Aurasol \\
\hline Control & $46.8 \mathrm{bc}$ & $50.0 a$ & $51.2 a$ & $51.4 a$ & $50.6 a$ & $48.3 a$ \\
\hline${ }^{*} \mathrm{UAN}$ BBCH-16 48kgN & $50.7 a b c$ & $52.6 a$ & $53.7 a$ & $50.4 a$ & $46.4 a$ & $47.1 \mathrm{a}$ \\
\hline UAN BBCH-16 60kgN & $45.9 b c$ & $51.8 a$ & $53.7 a$ & $50.5 a$ & $46.8 a$ & $49.6 a$ \\
\hline${ }^{\dagger} \mathrm{UAN}-\mathrm{N}$ BBCH-16 48kgN & $51.6 a b$ & $54.6 a$ & $51.9 a$ & $49.4 a$ & $47.2 \mathrm{a}$ & $49.1 \mathrm{a}$ \\
\hline UAN-N BBCH16 60kgN & $52.3 a b$ & $52.9 a$ & $51.2 a$ & $52.3 a$ & $49.1 a$ & $45.0 a$ \\
\hline${ }^{\dagger}$ UAS BBCH-16 48kgN & $51.9 a b$ & $54.4 a$ & $53.8 a$ & $50.7 a$ & $48.2 a$ & $48.3 a$ \\
\hline UAS BBCH-16 60kgN & $54.0 a$ & $51.4 a$ & $51.9 a$ & $47.3 a$ & $46.5 a$ & $45.4 a$ \\
\hline UAN BBCH-30 48kgN & 49.6abc & $51.2 a$ & $49.7 a$ & - & - & - \\
\hline UAN BBCH-30 60kgN & 48.8abc & $53.4 a$ & $50.9 a$ & - & - & - \\
\hline UAN-N BBCH-30 48kgN & $54.5 a$ & $51.9 a$ & $50.3 a$ & - & - & - \\
\hline UAN-N BBCH-30 60kgN & $44.6 \mathrm{c}$ & $50.0 a$ & $50.5 a$ & - & - & - \\
\hline UAS BBCH-30 48kgN & $45.9 b c$ & $51.9 a$ & $50.6 a$ & - & - & - \\
\hline UAS BBCH-30 60kgN & 49.6abc & $51.3 a$ & $51.9 a$ & - & - & - \\
\hline
\end{tabular}


Table 3.14: Influence of liquid ammonium fertilizer on oil content (\%) at both experimental sites in 2004.

\begin{tabular}{|c|c|c|c|c|c|c|}
\hline & \multicolumn{3}{|c|}{ BRAUNSCHWEIG } & \multicolumn{3}{|c|}{ ECKARTSWEIER } \\
\hline & Olsavil & PR64H41 & Aurasol & Olsavil & PR64H41 & Aurasol \\
\hline Control & $51.5 a$ & $50.4 a$ & $49.8 b$ & $51.5 a$ & $49.8 a$ & $49.6 a$ \\
\hline *UAN BBCH16 48kgN & $54.9 a$ & $51.4 a$ & 51.9ab & $50.1 a$ & $48.4 a$ & $48.0 a$ \\
\hline${ }^{\dagger} \mathrm{UAN}-\mathrm{N}$ BBCH $1648 \mathrm{kgN}$ & $54.9 a$ & $51.6 a$ & $52.5 a$ & $49.9 a$ & $47.0 \mathrm{a}$ & $48.2 a$ \\
\hline${ }^{\dagger+}$ UAS BBCH16 48kgN & $55.0 a$ & $51.7 a$ & $51.4 \mathrm{ab}$ & $51.4 a$ & $49.1 a$ & $48.6 a$ \\
\hline UAN BBCH30 48kgN & $55.1 a$ & $51.9 a$ & $52.2 a$ & - & - & - \\
\hline UAN-N BBCH30 48kgN & $55.2 a$ & $52.3 a$ & $52.3 a$ & - & - & - \\
\hline UAS BBCH30 48kgN & $55.1 \mathrm{a}$ & $52.4 a$ & 51.8ab & - & - & - \\
\hline
\end{tabular}

*UAN: urea ammonium nitrate solution, 'UAN-N: urea ammonium nitrate solution with nitrification inhibitor, ${ }^{\dagger+}$ UAS urea ammonium sulphate solution, $\mathrm{N}$ concentration: $50 \mathrm{~kg} \mathrm{~N} / \mathrm{ha}$ and $80 \mathrm{~kg} \mathrm{~N} / \mathrm{ha}$ at Eckartsweier.

In response to the different liquid fertilizer applications, fatty acid composition was in general not changed at Braunschweig in 2003 (Table A.27). Statistically significant changes were observed in oleic acid content of Olsavil. $60 \mathrm{~kg} \mathrm{~N} / \mathrm{ha}$ UAS application at $\mathrm{BBCH} 16$ significantly increased oleic acid content in this variety. Liquid fertilizer applications showed no significant influence on the oleic content of PR64H41 and Aurasol (data for Aurasol not shown). Similarly, oleic acid content was also not effected in the following experimental year (Figure A.6-8). Changes in linoleic and stearic acid in both experimental years were negligible and mostly insignificant. UAN-N with $80 \mathrm{~kg} \mathrm{~N}$ and UAS with $50 \mathrm{~kg} \mathrm{~N}$ both applied at BBCH 16 caused a significant decrease in oleic acid in Olsavil at Eckartsweier in 2003 (Figure 3.18). Also other liquid fertilizer applications decreased oleic acid content but only slightly. Oleic acid of PR64H41 and Aurasol was also decreased by most of the liquid fertilizer applications, however this loss was statistically not significant. Linoleic and stearic acid content was in general not influenced by the applied fertilizer method. Only UAS application with $50 \mathrm{~kg} \mathrm{~N}$ at $\mathrm{BBCH} 16$ increased stearic acid content significantly in Olsavil.

In contrast to the previous experimental year, fatty acid composition of Olsavil was not influenced by the liquid ammonium fertilizer applications in 2004 at Eckartsweier (Figure 3.19). But in PR64H41, oleic acid content was significantly increased by UAN as well as UAS both with $50 \mathrm{~kg} \mathrm{~N}$ applied at $\mathrm{BBCH}$ 16. The same applications increased also the linoleic acid content of this variety. In Aurasol, a slight decrease in oleic acid and an increase in linoleic acid content was observed. However, changes 
in oil composition were statistically insignificant. The stearic acid content was not influenced significantly in any variety.

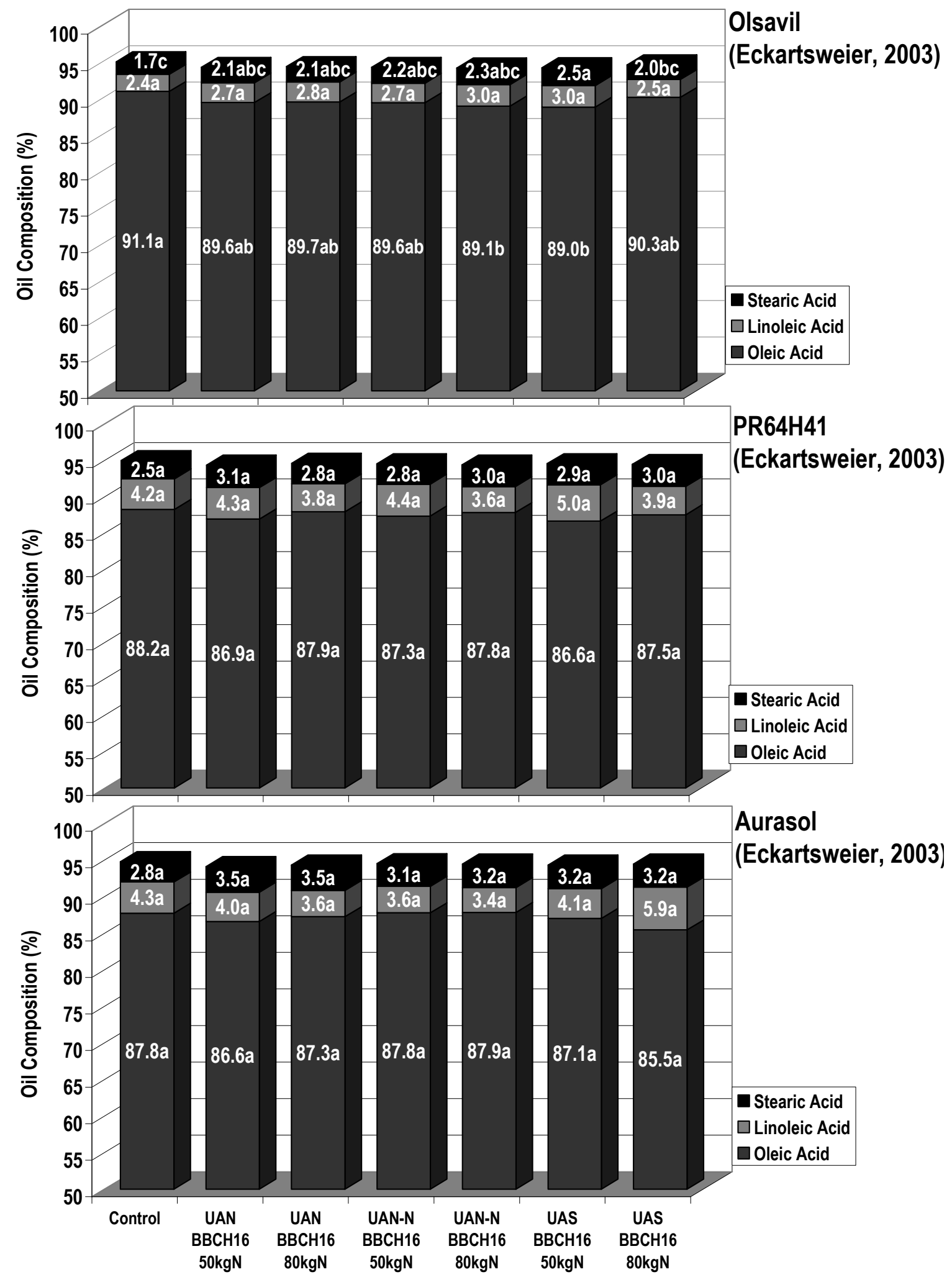

Figure 3.18: Influence of liquid ammonium fertilizer on oil composition (\%) at Eckartsweier in 2003. UAN: urea ammonium nitrate solution, UAN-N: urea ammonium nitrate solution with nitrification inhibitor, UAS urea ammonium sulphate solution. 

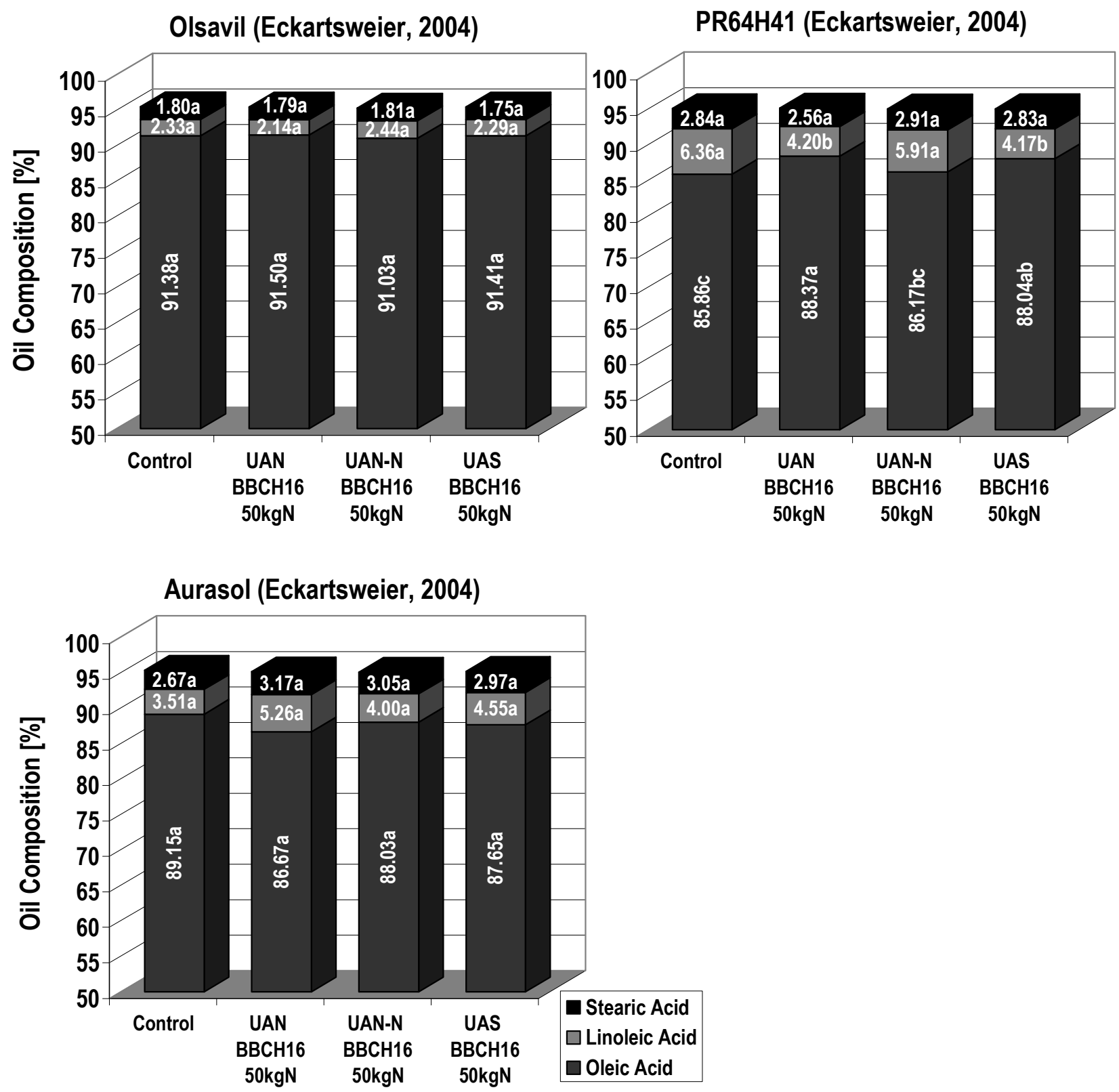

Figure 3.19: Influence of liquid ammonium fertilizer on oil composition (\%) at Eckartsweier in 2004. UAN: urea ammonium nitrate solution, UAN-N: urea ammonium nitrate solution with nitrification inhibitor, UAS urea ammonium sulphate solution. $\mathrm{N}$ concentration: $50 \mathrm{kgN} / \mathrm{ha}$

\subsubsection{Effect of ammonium based liquid fertilization method in combination with Bion ${ }^{\circledR}$ application}

\section{Changes in fungal infection rate}

A combination of ammonium based liquid fertilizer with plant activator aplication resulted in similar effects on yield and quality parameters as the liquid fertilizer applications alone in 2002. Figure 3.20 shows the effect of these combined approaches on fungal infection rate. Variety Olsavil was $100 \%$ infected by the fungal 
pathogens Sclerotinia and Botrytis independent of $\mathrm{N}$ application type and concentration, as well as Bion ${ }^{\circledR}$ concentration. Only a slight increase in fungal infection rate was recorded in PR64H61. In comparison to the $80.2 \%$ fungal infection with the control, the combined approach showed from $81.3 \%$ up to $97 \%$ fungal infection rate. With $40.7 \%$ infection, untreated control with conventional $60 \mathrm{~kg} \mathrm{~N} / \mathrm{ha}$ showed the lowest infection rate in Aurasol, whereas all applications with liquid fertilizer and the plant activator showed more than $60 \%$ infection. Changes in fungal infection were overall statistically not significant with any of the liquid fertilizer and Bion $^{\circledR}$ combination irrespective from application type and concentration in comparison to the control.

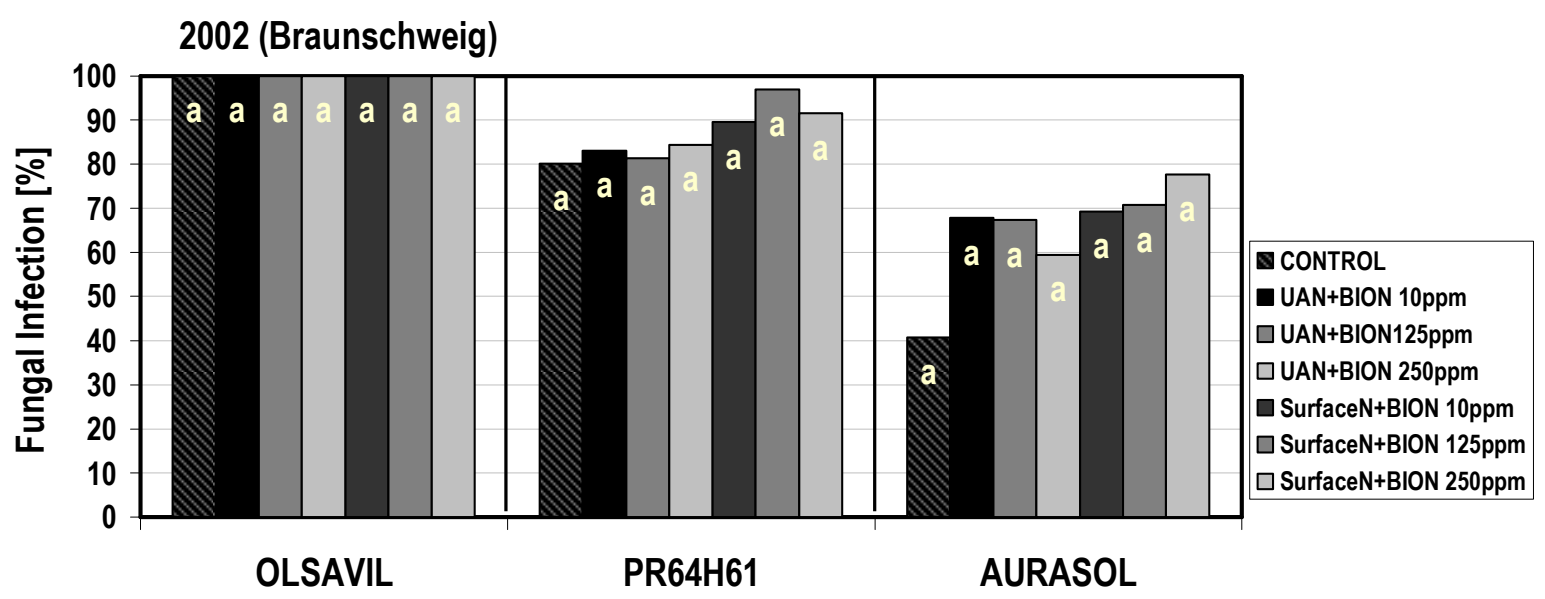

Figure 3.20: Influence of liquid fertilizer+ Bion ${ }^{\circledR}$ combinations on fungal infection rate (\%) in all varieties in 2002 at Braunschweig. (UAN: urea ammonium nitrate solution)

Since the fungal infection rate was too low in 2003, no significant change could be observed at both experiment sites (Table A.28). Application of plant activator was restricted to two concentrations, 250 and 500ppm, in 2004 at both experimental sites. Additionally, a later application time $(\mathrm{BBCH} 30)$ was included to the application scheme at Braunschweig. Figure 21 shows the influence of these combinations on fungal infection rate in 2004 at Braunschweig. The results indicate, although no significant influence was observed statistically, application of UAN combined with 500 ppm Bion ${ }^{\circledR}$ injected at $\mathrm{BBCH} 16$ decreased the infection rate clearly in both Olsavil and PR64H41. These applications were not tested at Eckartsweier. 


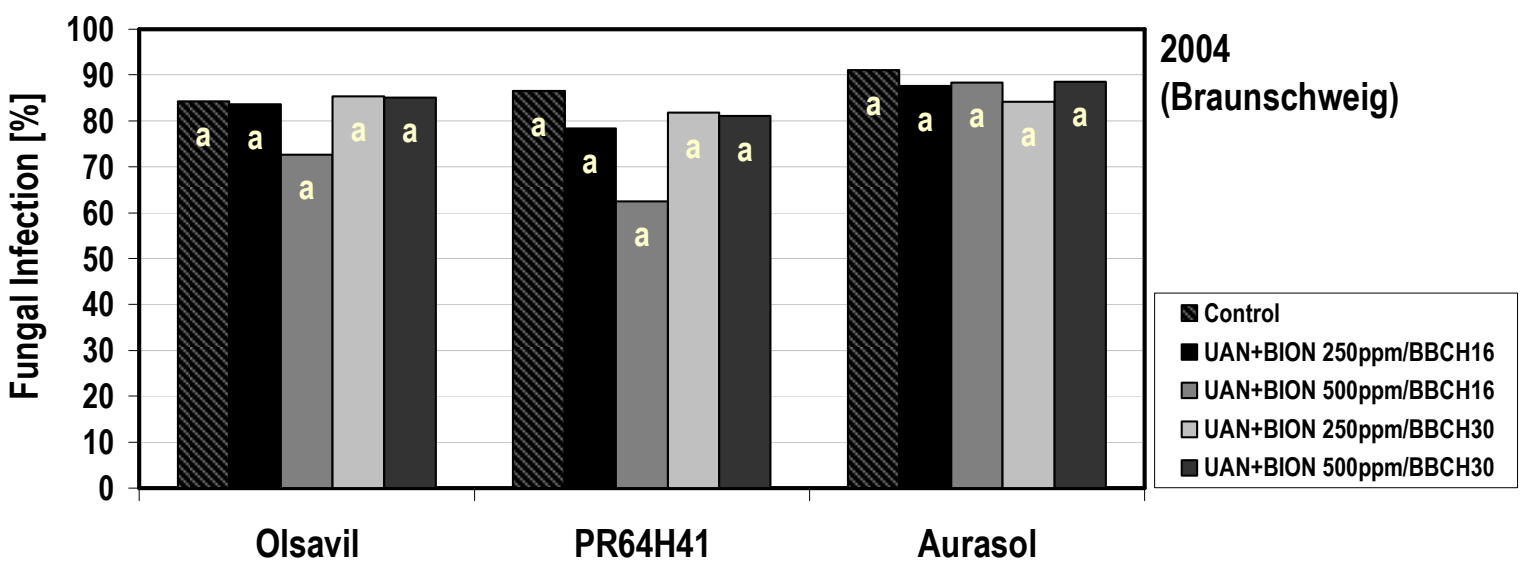

Figure 3.21: Influence of liquid fertilizer - Bion ${ }^{\circledR}$ combination on fungal infection rate $(\%)$ at Braunschweig in 2004. UAN: urea ammonium nitrate solution (48kg $/ / \mathrm{ha})$.

UAN mixed with 250 and $500 \mathrm{ppm}$ Bion ${ }^{\circledR}$ was applied only at the earlier growth stage (BBCH16) at Eckartsweier in 2004. From statistical point of view, there was no significant change in fungal infection (Figure 3.22). However there was, in contrast to the results at Braunschweig, a tendency to increase in infection by the application of the combination method in all varieties. The highest raise in fungal infection was observed in Olsavil. Infection rate was increased from $30 \%$ to $50 \%$ by UAN+250 ppm Bion ${ }^{\circledR}$ and to $43 \%$ by UAN+500 ppm Bion ${ }^{\circledR}$. Similar results were observed also in PR64H41 and Aurasol, however raise in infection was lower in comparison to Olsavil.

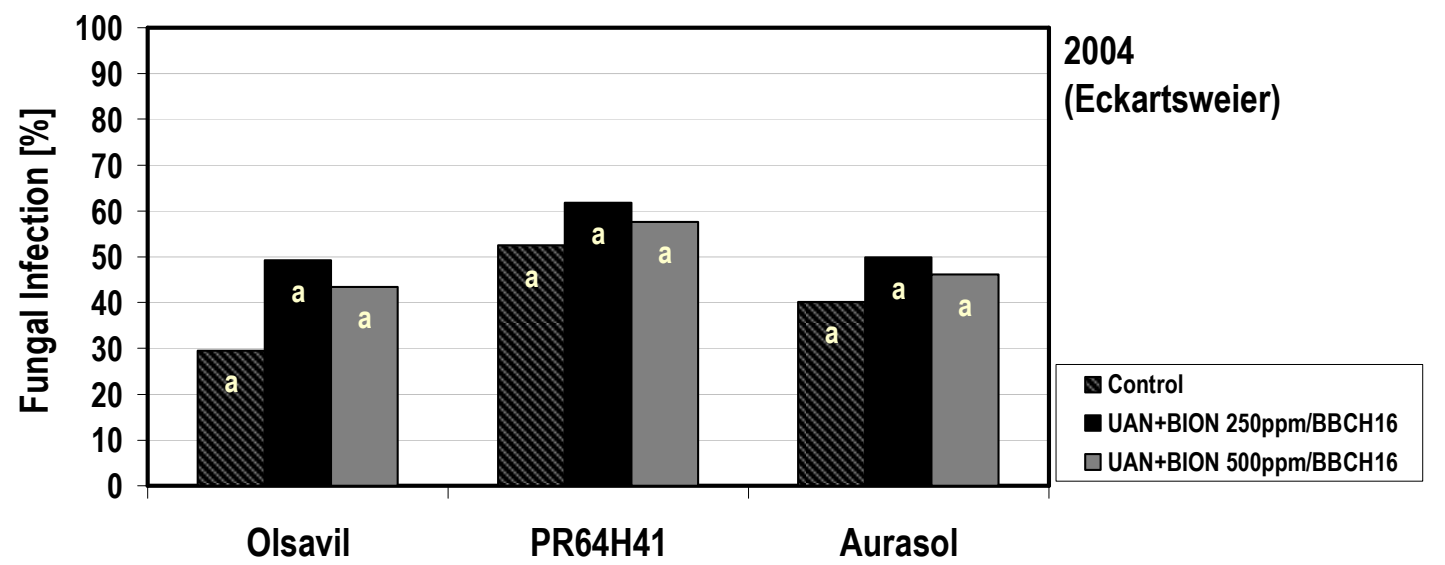

Figure 3.22: Influence of liquid fertilizer - Bion ${ }^{\circledR}$ combination on fungal infection rate (\%) at Eckartsweier in 2004. UAN: urea ammonium nitrate solution $(50 \mathrm{kgN} / \mathrm{ha})$ 


\section{Changes in yield components}

Yield parameters were not significantly influenced by the tested combinations in 2002 (Table A.29-31). Achene yield of Olsavil in response to the application of liquid fertilizer - Bion ${ }^{\circledR}$ combination was not changed significantly in 2003 at Braunschweig (Figure 3.23). All applications, except of UAN combined with 250 ppm Bion ${ }^{\circledR}$ applied at $\mathrm{BBCH} 16$, caused only a slight decrease in yield. Also in PR64H41 only a tendency of the yield to decrease was observed by most applications except of UAN with 1000 ppm Bion ${ }^{\circledR}$. Similarly, Aurasol responded with slight decrease to the combine applications, although the changes were insignificant. Highest increase in both PR64H41 and Aurasol was observed by the UAN combination with 250 ppm Bion $^{\circledR}$. In the following experimental year 2004 , only 250 and 500 ppm Bion ${ }^{\circledR}$ combinations were tested. Additionally, a second application time was included to the application scheme.

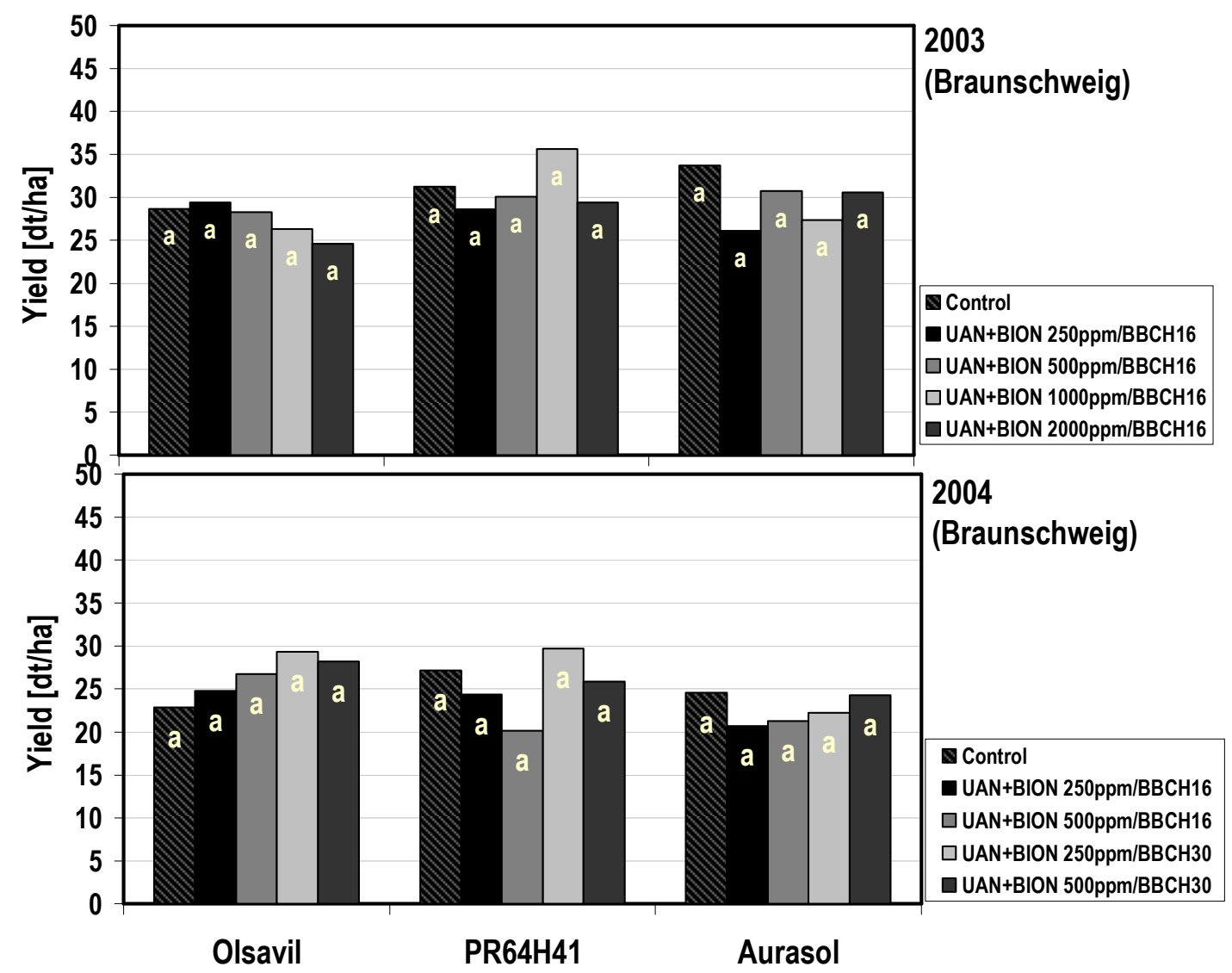

Figure 3.23: Influence of liquid fertilizer - Bion ${ }^{\circledR}$ application combination on achene yield (dt/ha) at Braunschweig in 2003 and 2004. UAN: urea ammonium nitrate solution $(48 \mathrm{kgN} / \mathrm{ha})$. 
At Eckartsweier, yield response to the combined application was negative in 2003 (Figure 3.24). Achene yield of Olsavil and PR64H41 was significantly decreased by the liquid fertilizer + Bion $^{\circledR}$ applications regardless of the Bion ${ }^{\circledR}$ concentration and application time. Highest reduction in achene yield was observed in PR64H41 where the yield was decreased from $36 \mathrm{dt} / \mathrm{ha}$ to about $25 \mathrm{dt} / \mathrm{ha}$ by the combined applications. Yield reductions occurred in Aurasol were however not significant. In 2004 , the second year of this application, only one application time (BBCH 16) was tested at Eckartsweier. Results indicate very low change in achene yield regarding the application liquid fertilizer + Bion $^{\circledR}$. Yield was only slightly increased in Olsavil and Aurasol by both Bion ${ }^{\circledR}$ concentrations, while it was slightly decreased in PR64H41. There were no significant changes in achene yields by any of the combined applications.

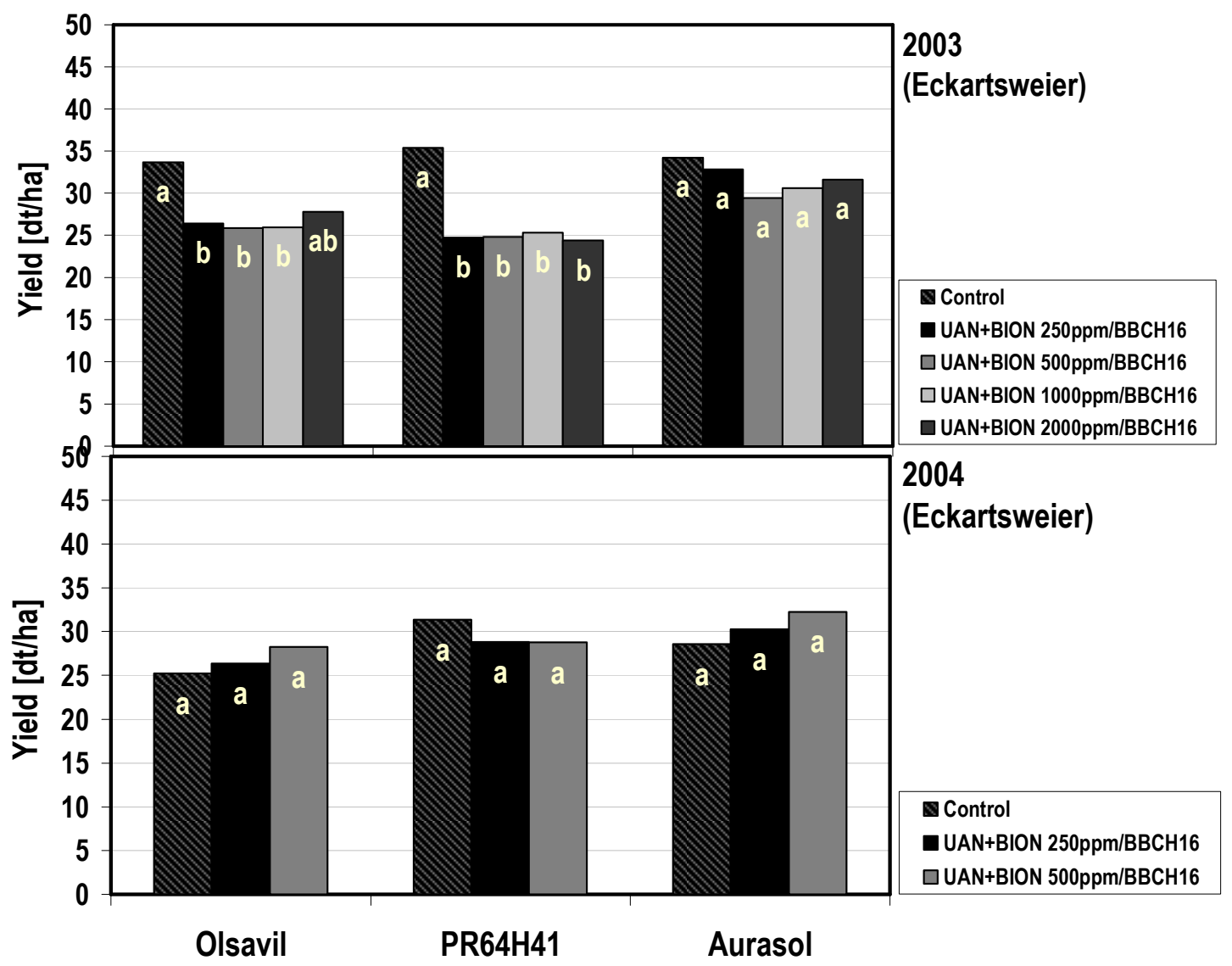

Figure 3.24: Influence of CULTAN - Bion ${ }^{\circledR}$ combination on achene yield (dt/ha) of all varieties at Eckartsweier in 2003. UAN: urea ammonium nitrate solution (50kgN/ha). 
Plant height of all varieties was increased by all liquid fertilizer + Bion $^{\circledR}$ applications regardless of the application time and Bion ${ }^{\circledR}$ concentration at Braunschweig in 2003 (Figure 3.25). However, changes in plant height were insignificant from statistical point of view. In the following year, similar results were observed regarding plant height. An additional application time revealed no remarkable change in comparison to the untreated control or to the other applications.

Plant height was recorded only in the first year 2003 for Eckartsweier. Figure 3.26 shows the changes in height with application of combined method. Opposite to the changes at Braunschweig, plant height was reduced in all varieties by all applications irrespective of the application time and Bion ${ }^{\circledR}$ concentration. Significant changes, however, were observed only in Aurasol. Plant height of Aurasol was significantly reduced by $25 \mathrm{~cm}$ by the application of UAN mixed with 250 and 1000 ppm Bion ${ }^{\circledR}$.

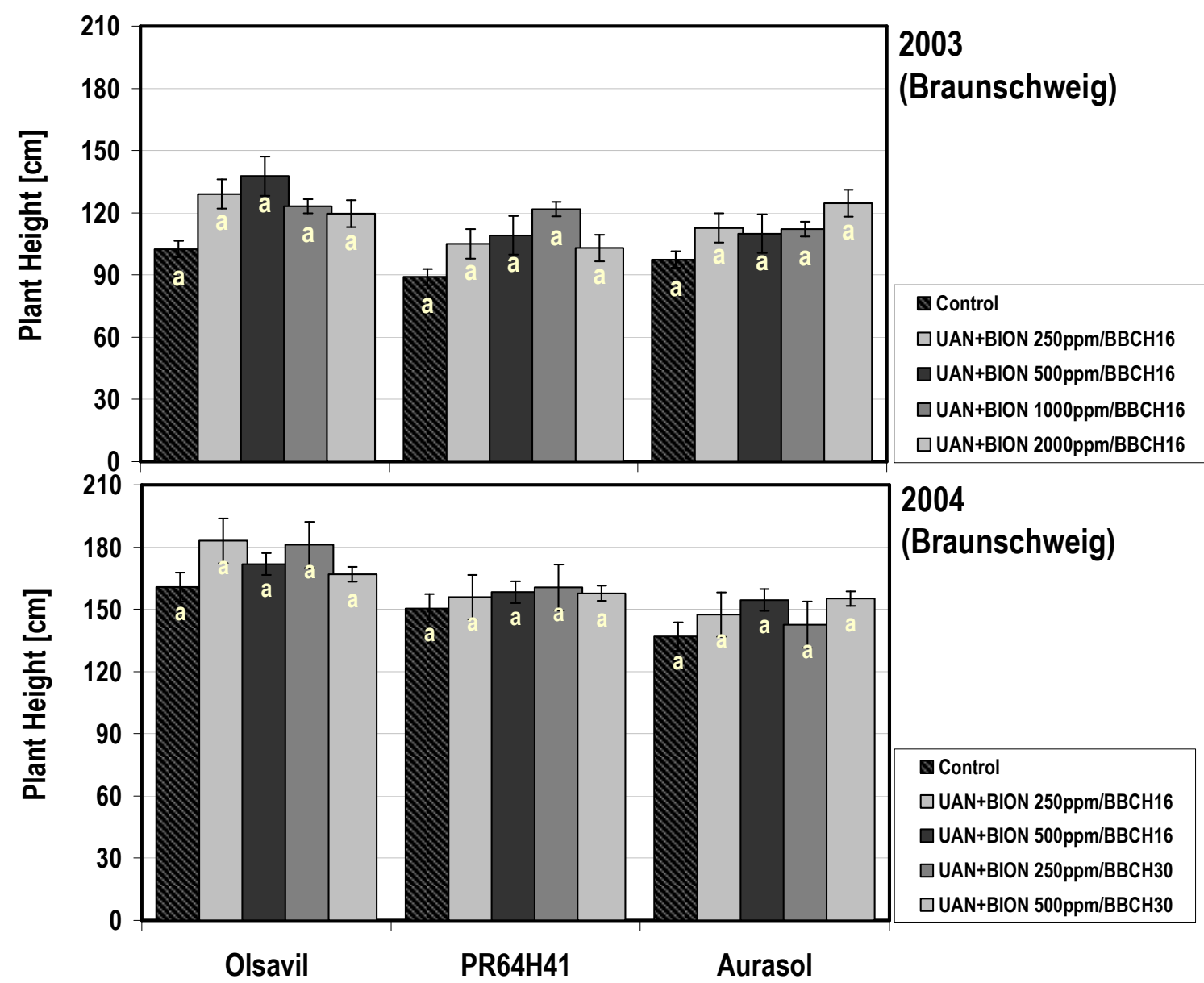

Figure 3.25: Influence of liquid fertilizer - Bion ${ }^{\circledR}$. combination on plant height $(\mathrm{cm})$ at Braunschweig in 2003 and 2004. UAN: urea ammonium nitrate solution (48kgN/ha). 


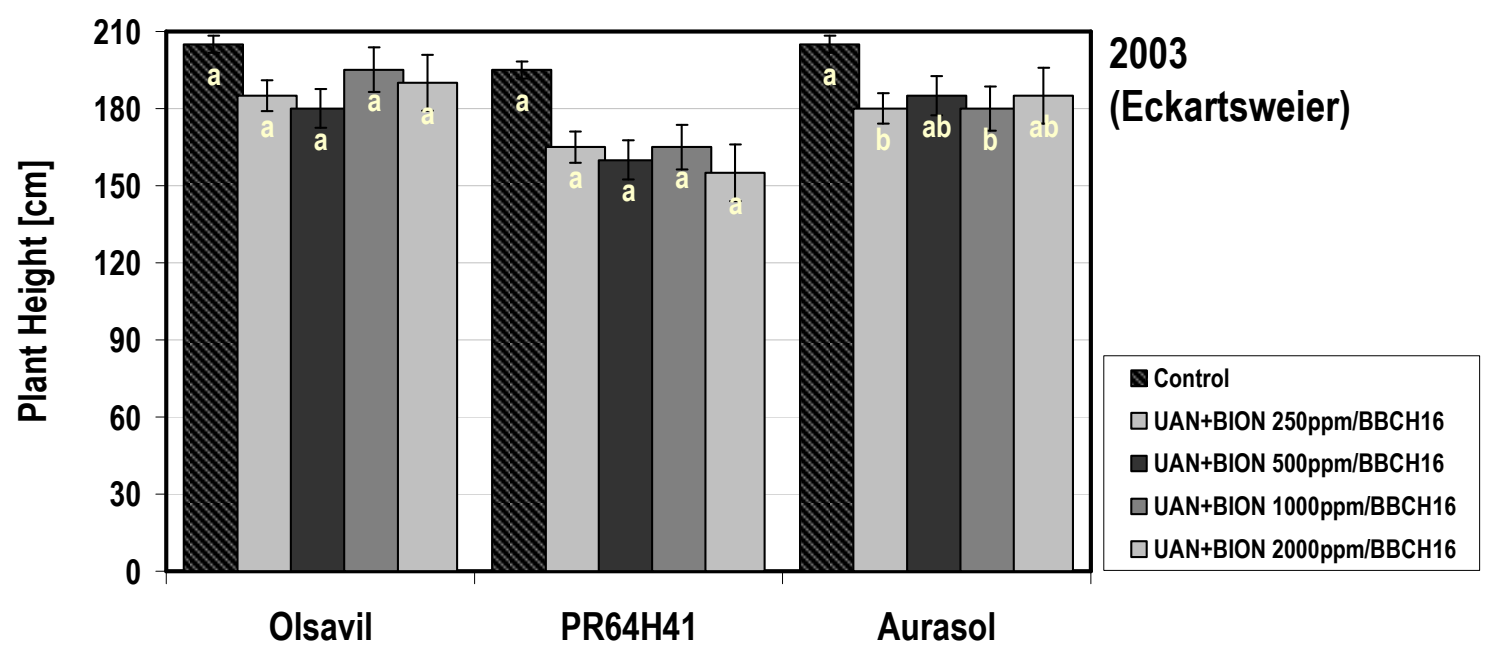

Figure 3.26: Influence of liquid fertilizer - Bion ${ }^{\circledR}$ combination on plant height $(\mathrm{cm})$ at Eckartsweier in 2003. UAN: urea ammonium nitrate solution $(50 \mathrm{kgN} / \mathrm{ha})$.

Combining urea ammonium nitrate solution with plant activator in different concentrations did not show any influence on the other yield components in any experiment site (data not presented), except of the thousand seed weight at Braunschweig in 2004 (Figure 3.27). Combined applications raised TSW of all varieties regardless of the application time and Bion ${ }^{\circledR}$ concentrations. Changes in TSW were statistically not significant in Olsavil. PR64H41 and Aurasol revealed significant increase in TSW in respond to the applications with Bion ${ }^{\circledR}$ added liquid fertilizer. UAN with 500 ppm. Bion ${ }^{\circledR}$ in PR64H41 and UAN with 250 as well as 500 ppm Bion ${ }^{\circledR}$ in Aurasol revealed significant increases.

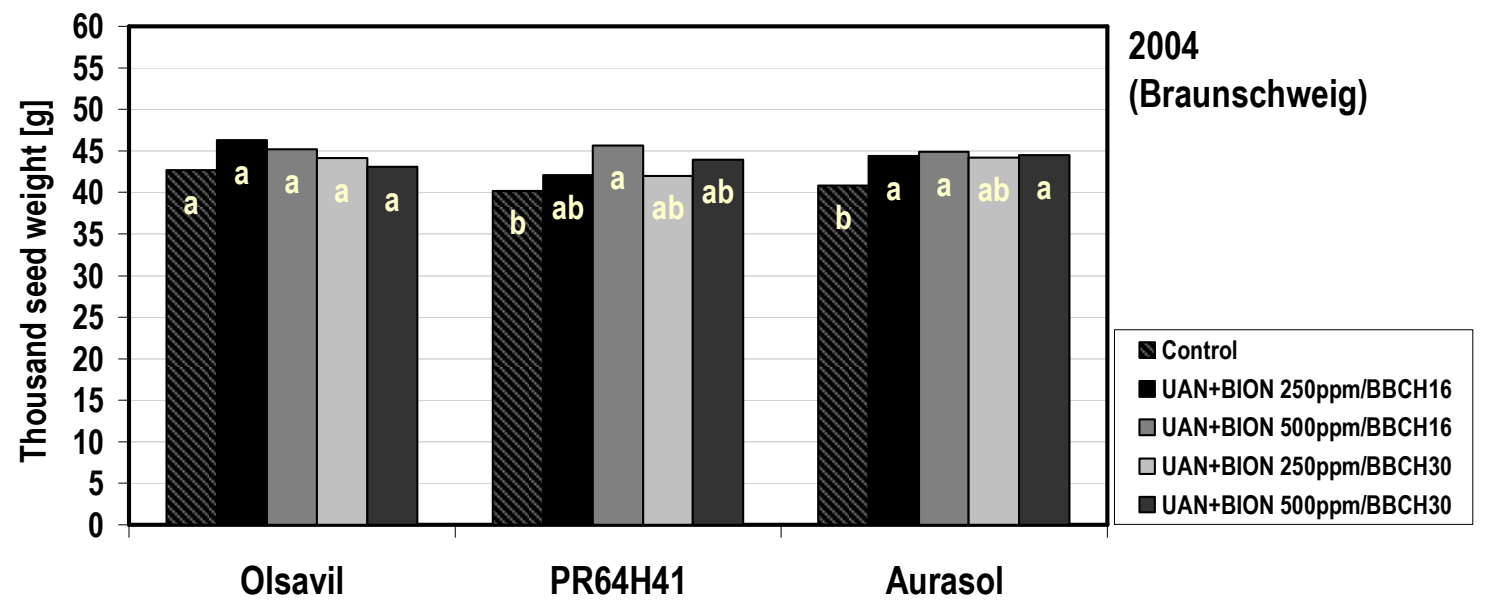

Figure 3.27: Influence of liquid fertilizer - Bion $^{\circledR}$ combination on thousand seed weight $(\mathrm{g})$ at Braunschweig in 2004. UAN: urea ammonium nitrate solution (48kgN/ha). 


\section{Changes in quality components}

Other yield and quality parameters were not influenced by the tested combinations in 2002 except of oleic acid content of the oil (Figure 3.28). Oleic acid percentage was negatively affected in variety PR64H61. Injection of $10 \mathrm{ppm}$ Bion ${ }^{\circledR}$ in combination with urea ammonium nitrate and surface application of $250 \mathrm{ppm}$ Bion ${ }^{\circledR}$ combined with urea ammonium nitrate significantly decreased the oleic acid content in comparison to the control.

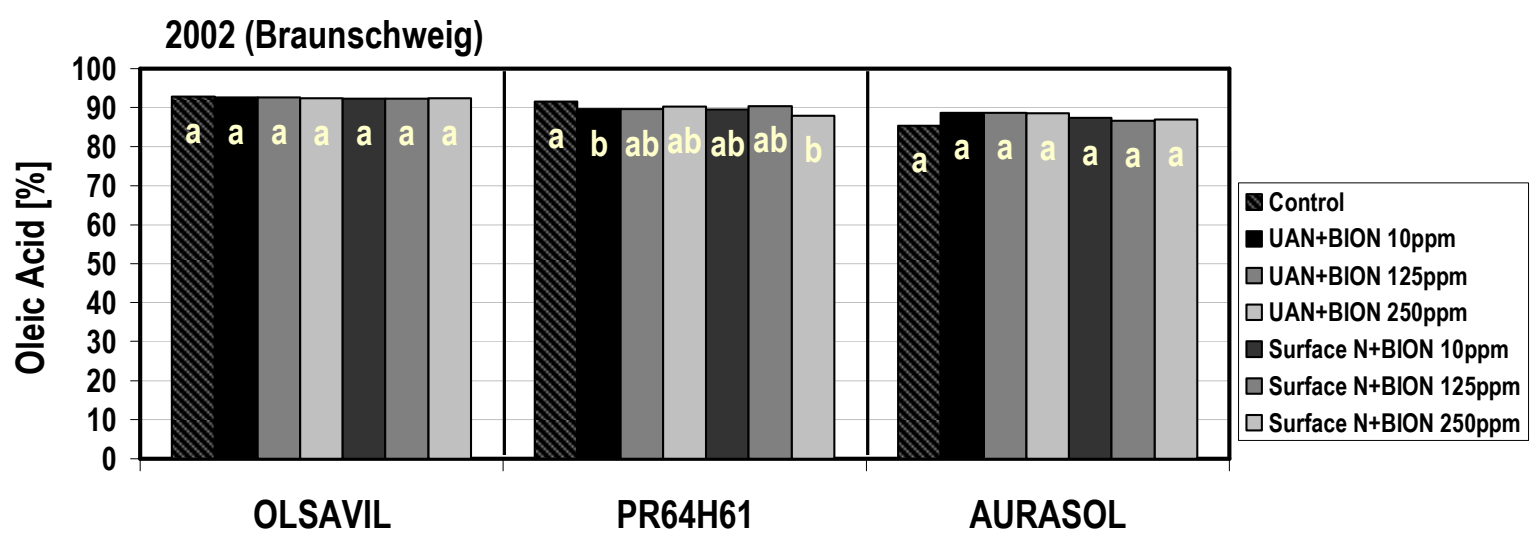

Figure 3.28: Influence of liquid fertilizer- Bion ${ }^{\circledR}$ combinations on oleic acid content (\%) of all varieties in 2002 at Braunschweig. (UAN: urea ammonium nitrate solution)

In the first year of the main field experiments, oil content showed a tendency to increase in Olsavil by the application of liquid fertilizer mixed with the plant activator at Braunschweig (Figure 3.29). All applications but UAN with 2000 ppm Bion ${ }^{\circledR}$ applied at $\mathrm{BBCH} 16$ raised the oil content slightly. It was only the application UAN with 1000 ppm Bion ${ }^{\circledR}$ that showed a noticeable change in oil content in PR64H41. Influence of this application on Aurasol was negligible and not consistent. However, none of the changes were statistically significant. On the contrary, combination of both methods significantly changed oil content in 2004. It was significantly raised in Olsavil and Aurasol by all the combined applications independent of the application time and Bion $^{\circledR}$ concentration. Changes in oil content of the variety PR64H41 were statistically not significant, however, it showed also tendency to increase by all applications.

At Eckartsweier, opposite of the results observed at Braunschweig, oil content of $\mathrm{HO}$ sunflower varieties was in general decreased (Figure 3.30). In 2003, the most applications influenced the oil content negatively in all varieties. However, no significant change could be observed. Also in 2004 , oil content of all varieties showed 
a negative response to all applications with UAN + Bion ${ }^{\circledR}$. Significant difference was however observed only in Olsavil. Oil content was reduced from $51.5 \%$ to $49.2 \%$ by application of UAN with 500 ppm Bion ${ }^{\circledR}$ at $\mathrm{BBCH} 16$.

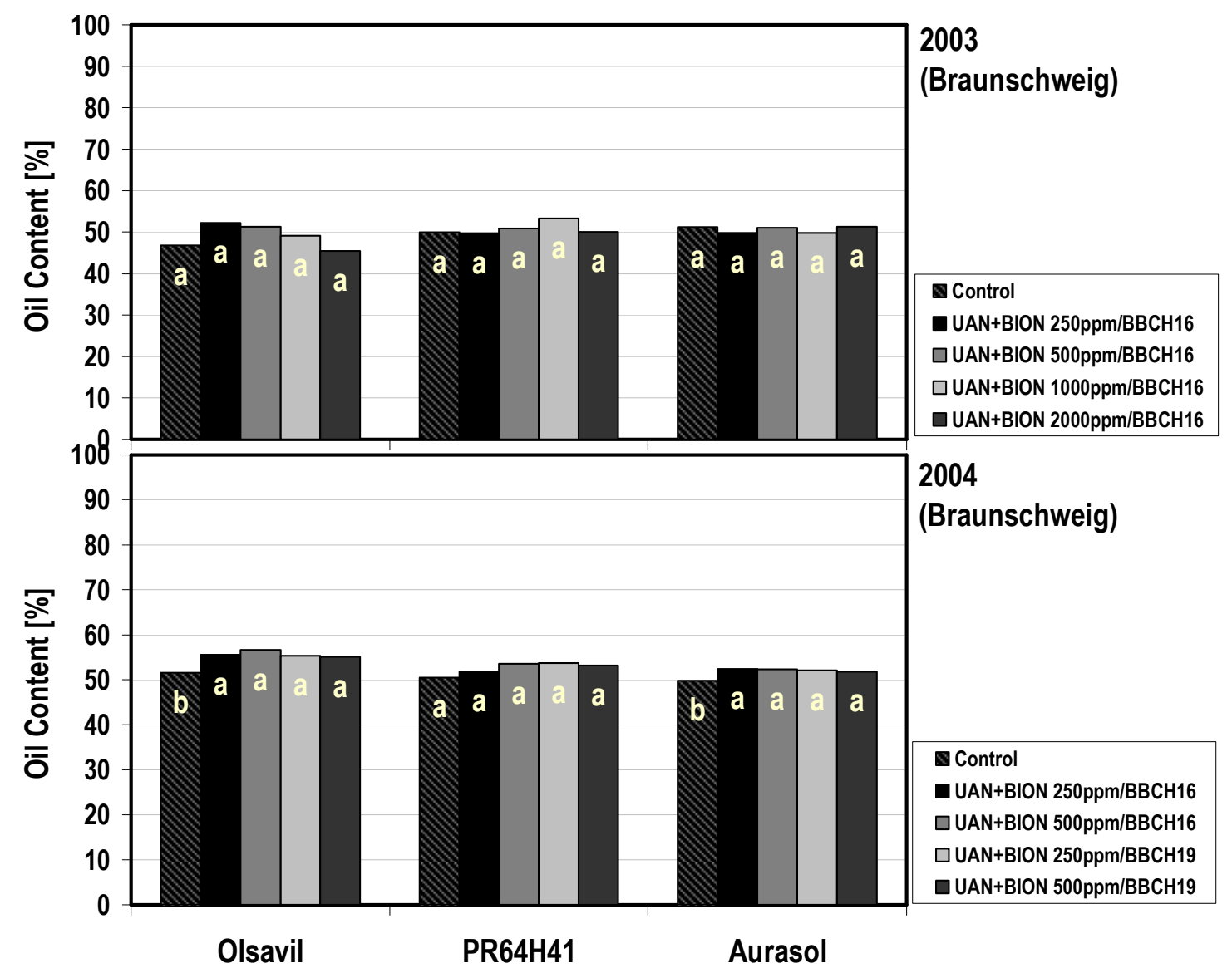

Figure 3.29: Influence of liquid fertilizer - Bion ${ }^{\circledR}$ combination on oil content (\%) at Braunschweig in 2003-2004. UAN: urea ammonium nitrate solution (48 kgN/ha).

Fatty acid composition was in general not significantly influenced by the combined application (Table A.28-29) in 2002. Oleic acid content, the main component of the HO sunflower oil, of all varieties showed no response to any application regardless of the application time and $\mathrm{Bion}^{\circledR}$ concentration at any experimental site in 2003-2004 but only in Aurasol at Eckartsweier in 2004. Oil content of Aurasol was significantly reduced from $892 \%$ to $87.8 \%$ by UAN with 250 ppm Bion ${ }^{\circledR}$ and to $87.5 \%$ by UAN with 500 ppm Bion ${ }^{\circledR}$. Significant differences were observed in linoleic and stearic acid content at both experimental sites in 2003, however those were inconsistent. A noticeable change was observed in linoleic acid at both experimental sites. Linoleic acid content of Aurasol was decreased at Braunschweig by all the applications, but it was only significant by UAN application with 500 ppm Bion ${ }^{\circledR}$ applied at $\mathrm{BBCH} 30$. In 
contrast, it was increased significantly by both applied Bion ${ }^{\circledR}$ concentrations in UAN at Eckartsweier.

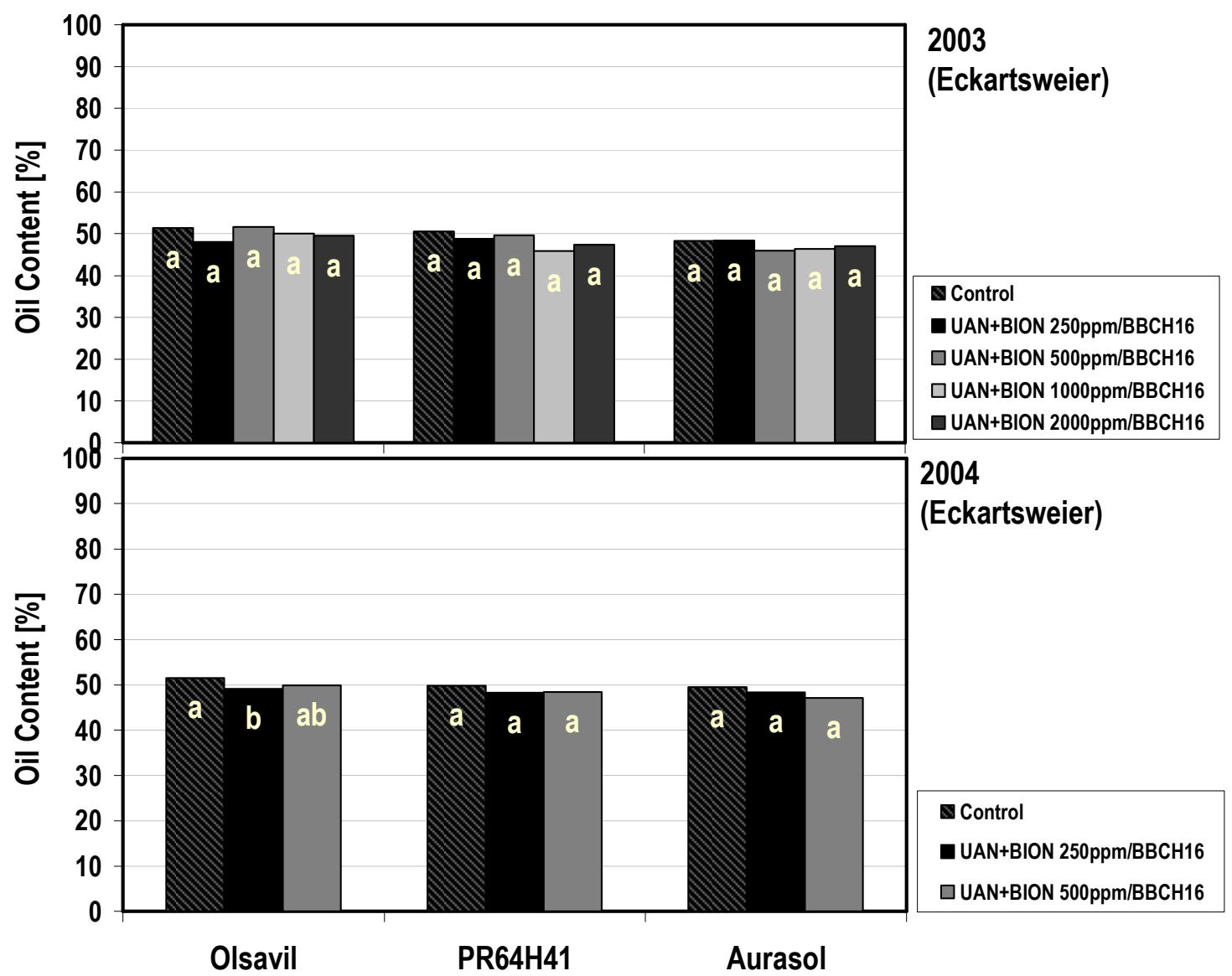

Figure 3.30: Influence of liquid fertilizer - Bion ${ }^{\circledR}$ combination on oil content (\%) at Eckartsweier in 2003-2004. UAN: urea ammonium nitrate solution (50 kgN/ha).

\subsubsection{Effect of Mikro-Vital}

\section{Changes in fungal infection rate}

In the first year of the main field experiments, Mikro-Vital was tested only at Braunschweig. No significant variation in infection rate was observed in 2003 (data not shown). In the following years 2004 and 2005, in addition to the Mikro-Vital application, its combination with 125 ppm Bion ${ }^{\circledR}$ applied at around $30 \mathrm{~cm}$ plant height (BBCH 16) was added to the application scheme and was tested at both experimental sites. Figure 3.31 shows the changes in fungal infection rate by these two applications at both experiment sites. Infection rates were very high in 2004 at Braunschweig regardless of the applications. Only a slight decrease was observed by both applications, however was insignificant. In the following experimental year, 
infection rates were much lower irrespective of the applications. Also in 2005, no significant change occurred.

In response to Mikro-Vital application, fungal infection rate was slightly increased in Olsavil in 2004 at Eckartsweier. In contrast, a noticeable decrease was observed in PR64H41 and Aurasol. This slight effect was however not observed in 2005. Fungal infection showed nearly no response regarding Mikro-Vital + Bion $^{\circledR}$ combination in both experimental years. Statistically, none of these applications showed any significant influence on fungal infection rate.

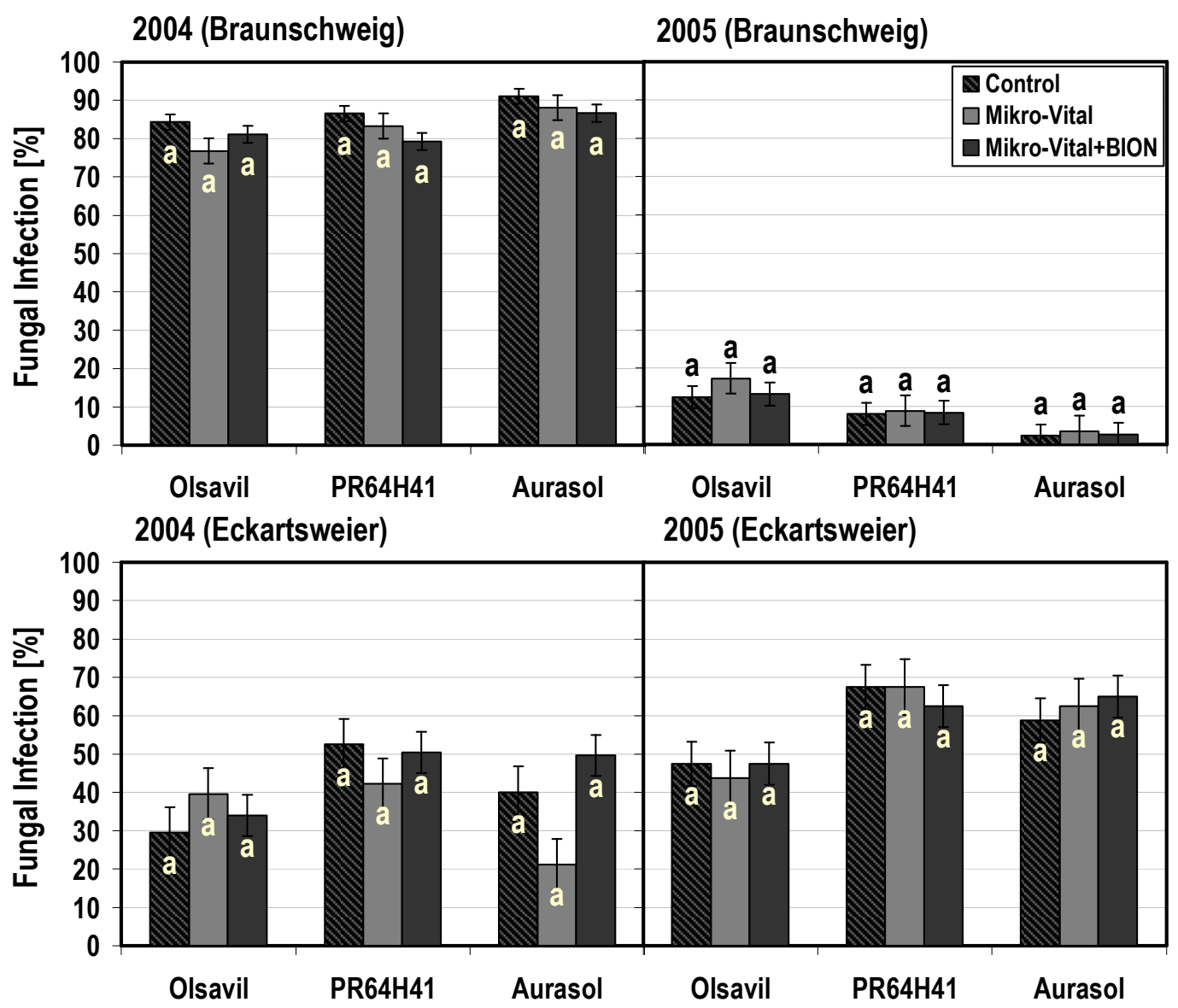

Figure 3.31: Influence of Mikro-Vital and its combination with Bion ${ }^{\circledR}$ on fungal infection rate $(\%)$ of all varieties at both experiment sites.

\section{Changes in yield components}

Mikro-Vital application did not influence achene yield significantly in 2002 (Table 3.15). In general, plant height was shorter with the bacterial fertilizer. A significant decrease in plant height, however, was only observed in variety Olsavil with the 
highest plant height in comparison to the other two varieties. The most important quality parameter, the oleic acid content, was significantly increased only by the application of Mikro-Vital in PR64H61. In contrast linoleic acid amount was significantly decreased.

Table 3.15: Influence of Mikro-Vital application on yield and quality parameters for all three varieties in 2002 at Braunschweig.

\begin{tabular}{lrrrrrr}
\hline \hline & \multicolumn{2}{c}{ OLSAVIL } & \multicolumn{2}{c}{ PR64H61 } & \multicolumn{2}{c}{ AURASOL } \\
& Control & Mikro-Vital & Control & Mikro-Vital & Control & Mikro-Vital \\
\hline Achene yield (dt/ha) & $30.5 \mathrm{a}$ & $27.1 \mathrm{a}$ & $31.1 \mathrm{a}$ & $29.2 \mathrm{a}$ & $31.3 \mathrm{a}$ & $30.2 \mathrm{a}$ \\
Plant height (cm) & $\mathbf{1 6 1 . 8 a}$ & $\mathbf{1 5 0 . 6 b}$ & $148.5 \mathrm{a}$ & $138.3 \mathrm{a}$ & $135.2 \mathrm{a}$ & $135.3 \mathrm{a}$ \\
Head diameter (cm) & $13.3 \mathrm{a}$ & $14.3 \mathrm{a}$ & $14.7 \mathrm{a}$ & $15.1 \mathrm{a}$ & $12.8 \mathrm{a}$ & $12.5 \mathrm{a}$ \\
TSW $^{*}(\mathrm{~g})$ & $45.1 \mathrm{a}$ & $51.4 \mathrm{a}$ & $57.7 \mathrm{a}$ & $66.1 \mathrm{a}$ & $59.8 \mathrm{a}$ & $54.4 \mathrm{a}$ \\
Oil content (\%) $_{\text {Oleic acid (\%) }}$ & $55.7 \mathrm{a}$ & $54.8 \mathrm{a}$ & $54.4 \mathrm{a}$ & $52.8 \mathrm{a}$ & $51.6 \mathrm{a}$ & $52.6 \mathrm{a}$ \\
Linoleic acid (\%) & $92.4 \mathrm{a}$ & $92.5 \mathrm{a}$ & $\mathbf{8 9 . 1 b}$ & $\mathbf{9 1 . 1 a}$ & $87.9 \mathrm{a}$ & $88.1 \mathrm{a}$ \\
Stearic acid (\%) & $2.5 \mathrm{a}$ & $2.5 \mathrm{a}$ & $\mathbf{5 . 2 a}$ & $\mathbf{3 . 2 b}$ & $4.8 \mathrm{a}$ & $4.8 \mathrm{a}$ \\
\hline \hline
\end{tabular}

*TSW: Thousand seed weight.

Yield data achieved by the bacterial fertilizer applications in 2004 and 2005 are presented in the Figure 3.32. The yields were not significantly changed by Mikro-Vital treatment in 2003 (data not shown). Also in 2004, there were no statistically significant differences by the two different treatments using the bacterial fertilizer. Only a slight increase in achene yield could be observed by pure Mikro-Vital alone in Olsavil. This effect could be reproduced in 2005. Additionally, combined application of Mikro-Vital and Bion ${ }^{\circledR}$ also slightly increased the achene yield of Olsavil. The other two varieties showed nearly no response to the treatments.

At Eckartsweier, both treatments showed an increase in achene yield in Olsavil and Aurasol in 2004. However this yield increase was higher and only significant in Aurasol in contrast to Olsavil. Yield was insignificantly decreased by Mikro-Vital treatment in PR64H41. Similar results were observed also in the following experimental year. Both Mikro-Vital treatments showed a slight increase in Olsavil and Aurasol while they caused a slight decrease in PR64H41. 

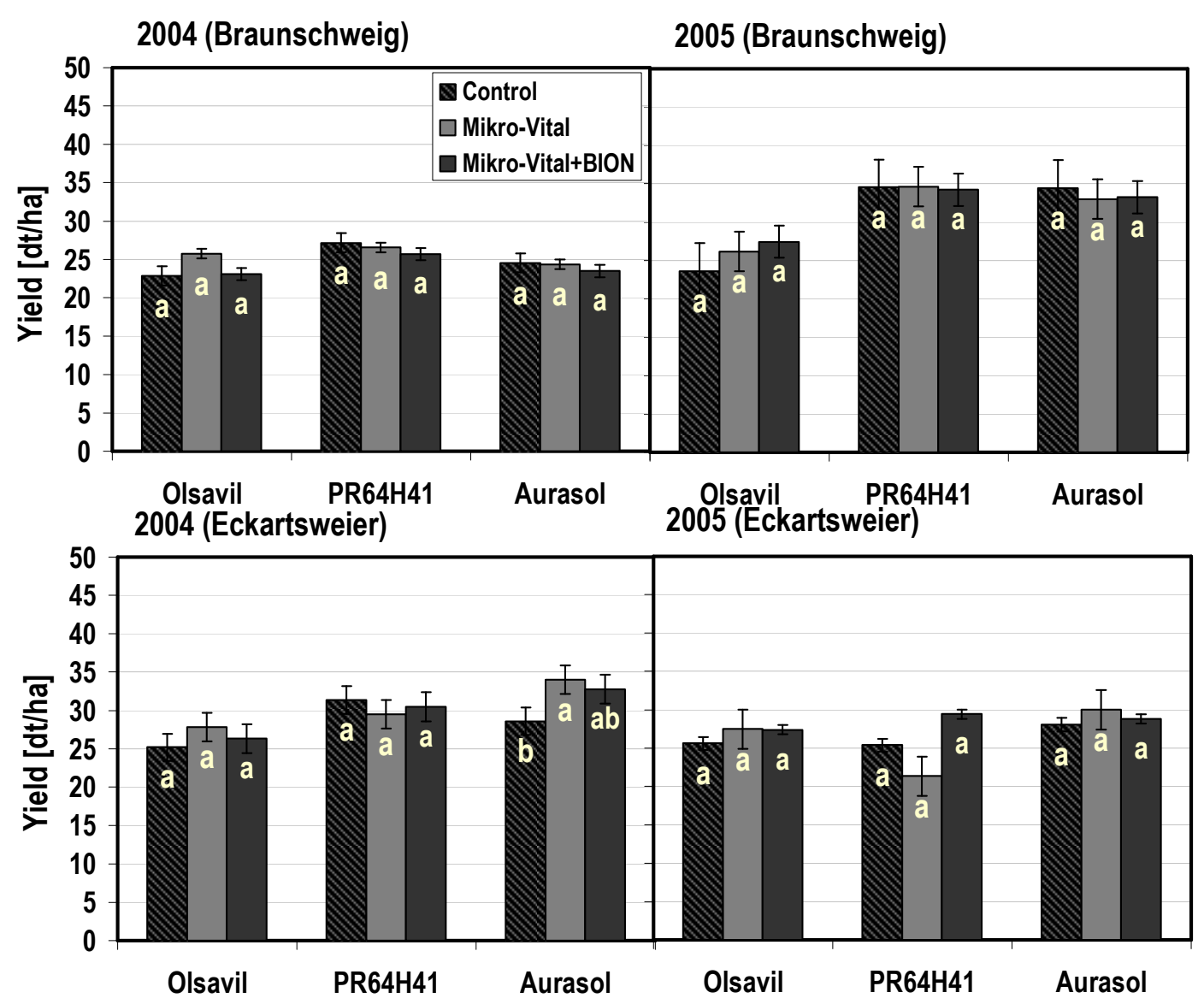

Figure 3.32: Influence of Mikro-Vital and its combination with Bion ${ }^{\circledR}$ on achene yield (dt/ha) at both experiment sites in 2004-2005.

Other yield parameters such as plant height, head diameter, and thousand seed weight were evaluated for Mikro-Vital treatments only at Braunschweig. Results of yield parameters are presented in detail in Table 3.16. Statistical analysis of the results indicates that, there were no significant differences among bacterial mixture treatments on any yield component, except of a decrease in head diameter of Olsavil in 2005. However, it was not a reproduced in the following experimental year or by any other variety. Also TSW was slightly decreased by Mikro-Vital treatment in Olsavil in the same experimental year, was however insignificant. 
Table 3.16: Influence of Mikro-Vital and its combination with Bion ${ }^{\circledR}$ on yield components at both experimental sites.

\begin{tabular}{|c|c|c|c|c|c|c|}
\hline & \multicolumn{3}{|c|}{2004} & \multicolumn{3}{|c|}{2005} \\
\hline & $\begin{array}{l}\text { Plant } \\
\text { height } \\
\text { (cm) }\end{array}$ & $\begin{array}{l}\text { Head } \\
\text { diameter } \\
(\mathrm{cm})\end{array}$ & $\begin{array}{l}\text { TSW } \\
\text { (g) }\end{array}$ & $\begin{array}{l}\text { Plant } \\
\text { height } \\
\text { (cm) }\end{array}$ & $\begin{array}{l}\text { Head } \\
\text { diameter } \\
(\mathrm{cm})\end{array}$ & $\begin{array}{l}\text { TSW } \\
\text { (g) }\end{array}$ \\
\hline \multicolumn{7}{|l|}{ OLSAVIL } \\
\hline Control & $160.83 a$ & $13.25 a$ & $42.68 a$ & $194.23 a$ & $13.90 \mathrm{a}$ & $44.03 a$ \\
\hline Mikro-Vital & $170.25 a$ & $12.98 a$ & $42.92 a$ & $195.18 a$ & $12.75 b$ & $41.58 a$ \\
\hline Mikro-Vital+ ${ }^{*}$ Bion $^{\circledR}$ & $166.75 a$ & $12.85 a$ & $42.19 a$ & $196.45 a$ & $13.30 \mathrm{ab}$ & $44.14 a$ \\
\hline \multicolumn{7}{|l|}{ PR64H41 } \\
\hline Control & $150.40 a$ & $13.25 a$ & $40.19 a$ & $176.23 a$ & $13.08 a$ & $49.17 a$ \\
\hline Mikro-Vital & $157.20 a$ & $13.30 a$ & $42.36 a$ & $178.88 a$ & $12.95 a$ & $50.05 a$ \\
\hline Mikro-Vital+ Bion $^{\circledR}$ & $144.80 \mathrm{a}$ & $13.30 a$ & $38.56 a$ & $178.63 a$ & $13.38 a$ & $48.88 a$ \\
\hline \multicolumn{7}{|l|}{ AURASOL } \\
\hline Control & $136.93 a$ & $12.28 \mathrm{a}$ & $40.83 a$ & $178.25 a$ & $12.50 \mathrm{a}$ & $46.21 \mathrm{a}$ \\
\hline Mikro-Vital & $139.40 a$ & $12.30 \mathrm{a}$ & $42.86 a$ & $180.43 a$ & $12.45 a$ & $47.56 a$ \\
\hline Mikro-Vital+ Bion $^{\circledR}$ & $146.90 a$ & $12.50 \mathrm{a}$ & $41.82 a$ & $185.20 \mathrm{a}$ & $12.58 a$ & $46.35 a$ \\
\hline
\end{tabular}

${ }^{*}$ Bion $^{\circledR}$ : $125 p p m$ applied at BBCH16 growth stage

\section{Changes in quality components}

Oil content of all three varieties was slightly increased by Mikro-Vital treatment in 2003 (Figure 3.33). In the following experimental years, oil content was not significantly changed by either Mikro-Vital or its combination with the plant activator at both experimental sites (Figure A.9). Evaluation of the important fatty acids such as oleic acid, linoleic acid, and stearic acid at both experiment sites showed also no significant variation in both experimental years except of oleic acid content in Aurasol. At Eckartsweier, oil content in Aurasol was significantly reduced by application of Mikro-Vital in combination with the plant activator in 2004 (Table A.3435).

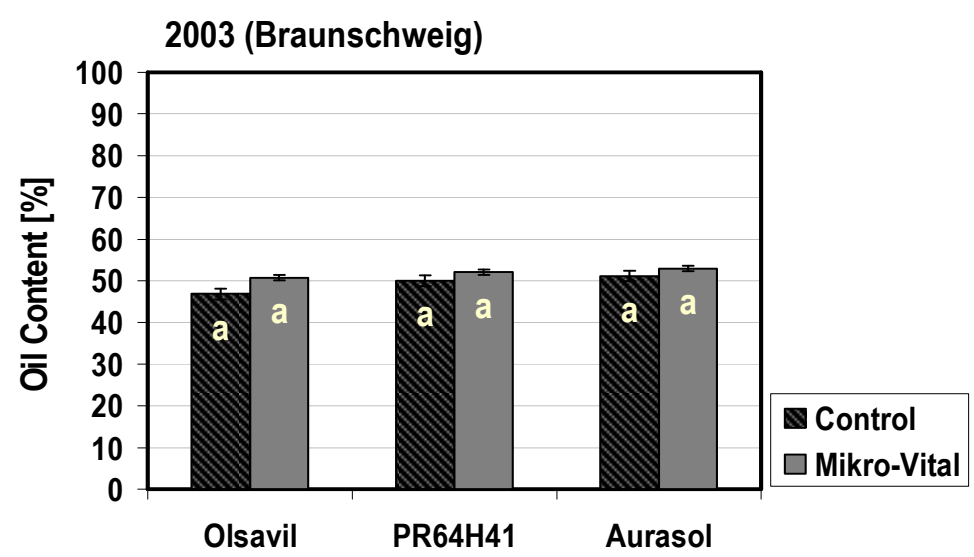

Figure 3.33: Influence of Mikro-Vital on oil content (\%) of all varieties at Braunschweig in 2003. 


\subsection{SUGAR CONTENT AND SUGAR COMPOSITION OF THE PLANT PARTS}

\subsubsection{Total sugar content}

Total sugar content consisted of the sum of all analyzed water soluble carbohydrates. Aurasol, total sugar content of all analyzed plant parts was the highest at the first harvest date, 118 days after sowing, and was reduced consistently with time until ripeness in 2002 (Figure 4.34). Nearly all sugar content was degraded in all plant parts in the fully ripe plants. Sugar content of the inner disc was the highest 118 and 145 days after sowing in comparison to the stem segments and the other head parts. Due to different maturity times, there were both not ripe (green) and ripe plants at the harvest. Therefore, those were analyzed separately. The sugar budget of the green and ripe plants differed at the last sampling date 159 days after sowing. Green plants had the highest sugar content in the inner disc. At this date, the ripe plants contained nearly no sugar in all plant parts but only some in seeds.

In 2003, all selected varieties were analyzed for sugars starting from the earlier vegetation stages. All three varieties showed similar sugar content in different plant parts at the first two sampling dates, 66 and 79 days after sowing (Figure 3.47). Sugar content of the plant head increased at 86 days after sowing whereas it decreased in the stem segments. At 109 days after sowing, the highest total sugar content was in the plant heads in all varieties. At this date, Olsavil showed the highest sugar content in the plant head as well as in the stem segments. No sugars were left in any stem segment of PR64H41 and only low amount of sugars. At the last sample date, 122 days after sowing, Aurasol contained no sugars in any plant parts but some in seeds. Olsavil and PR64H41 had only a small percentage of sugars in the stem segments and higher sugar content in the head parts. The highest sugar content at this date was revealed in Olsavil. It showed relatively higher amount of sugars in the outer and inner discs.

\subsubsection{Fructose}

In the analyses in 2002, the highest fructose was observed in the discs during the total measurement except at the harvest in Aurasol (Figure 3.46). Fructose content was the highest at the first sample date measured in all plant parts. Also in comparison to the other sugar types, fructose was in general higher. Outer and inner discs as well as the second stem segment showed high fructose content in 
comparison to the other plant parts. Also in the other stem segments, relatively high fructose content was measured at the first date. Seeds contained fructose only at this first sample date. Fructose was reduced dramatically at the second sample date in the stem segments. Inner and outer discs showed still higher amount of fructose content. In the green plants at 159 days after sowing, no fructose was left in the first two segments of the stem and only a small amount in the upper segments. But plant head excluding the seeds showed still a noticeable amount of fructose. No fructose was measured in the seeds at the dates later than 118 days after sowing. Fructose was in general the highest sugar type in all plant parts at the measured dates.

In 2003, fructose was higher in stem segments than in the plant head for all varieties at 66 days after sowing (Figure 3.35). However, fructose was not the highest sugar type in any plant part at this date. Fructose content was reduced at 79 days after sowing in the stem segments while it was increased in the plant head. Only in Olsavil, fructose was reduced in the plant head as well. At 86 days after sowing, fructose content rose in all plant parts throughout all three varieties. In comparison to the other sugar types and to the other plant parts, the highest fructose was measured in the first three stem segments from the bottom. At 109 days after sowing, fructose content again dropped down in all plant parts. However, it was still the highest sugar type in most of the plant parts except the seeds. Only in Olsavil, Fructose was nearly the same amount in the plant head parts as Glucose. At 122 days after sowing, there was still a higher amount of fructose in the inner and outer discs of Olsavil, while there was only a small amount of it in the other plant parts. Also PR64H41 revealed some fructose in the discs but none in the other plant parts. Only very small amount of fructose was measured in the seeds in Aurasol at this last date.

\subsubsection{Glucose}

Higher glucose content was measured in the discs in comparison to the other plant parts at all sample dates in 2002 (Figure 3.46). A great part of the glucose content in the discs and in the receptacle was reduced with the time except in the outer disc. The glucose was increased from 145 to 159 days after sowing in the green plants in outer discs. In the seeds, only less than $1 \%$ glucose was found at 118 days after sowing. After this date, the seeds contained no glucose anymore. Also in the stem segments, only small amount of glucose was detected from the beginning of the 
measurement date, and it slowly degraded until the harvest. No glucose was measured in any ripe plant parts.

Glucose content of the plant parts slightly differed between the selected varieties (Figure 3.47). Olsavil showed in general higher glucose content in all parts throughout the experiment in 2003. Higher glucose content in all selected varieties was measured in the stem segments at 66 days after sowing. Particularly the last segment from the bottom contained the highest glucose at this date and also at 79 and 86 days after sowing. At 109 days after sowing, there was only a small amount of glucose was left in the stems of Olsavil and Aurasol. No glucose was left in the stem in PR64H41 after this date. In contrast, high amount of glucose was measured in the plant head parts. The highest glucose was observed in the discs followed by the receptacle for all varieties. The seeds contained only a small amount of glucose in Olsavil and Aurasol but none in PR64H41. At the last sample date, no glucose was left in stems and in seeds in any variety. Only some glucose was detected in the discs of Olsavil and PR64H41.

\subsubsection{Sucrose}

The Sucrose content showed a different behavior and overall was lower in all plant parts in comparison to the other two sugar types in 2002 (Figure 3.46). Different from the other sugar types, the highest sucrose was measured in the upper stem segments at 118 days. It was then slowly degraded in the stem at the measurement date of 145 days after sowing while it increased in the seeds. Starting from this measurement date, sucrose was the only existing sugar type in the seeds. Green plants 159 days after sowing showed an equal amount of sucrose in the upper stem segments and the disc parts. In ripe and dried plants still a low amount of sucrose was detected in the $4^{\text {th }}$ stem segment and but higher amount in the seeds.

Similar to the previous year the sugar analyses in 2003 showed that the sucrose was the lowest sugar type in plants in all varieties during the all sample dates (Figure 3.47). At 66 days after sowing, the sucrose content was higher in the stem segments than in the plant head. Sucrose was decreased in all plant parts at the second sample date. The least sucrose amount at this date was measured in Aurasol. It was increased at the 86 days after sowing in all plant parts. At this date, sucrose content 
was still higher in the stem, particularly in the first 3 segments. Only in Aurasol, sucrose content was higher in the plant head than the stem. At 109 days after sowing, sucrose content increased in the head parts but therefore decreased in the stem segments. Olsavil contained the highest sucrose in the seeds while PR64H41 and Aurasol showed the highest sucrose in the inner discs. At the last sample date, the highest sucrose content was measured in the seeds for all varieties. At this date, sucrose was the main and highest sugar type in the seeds.

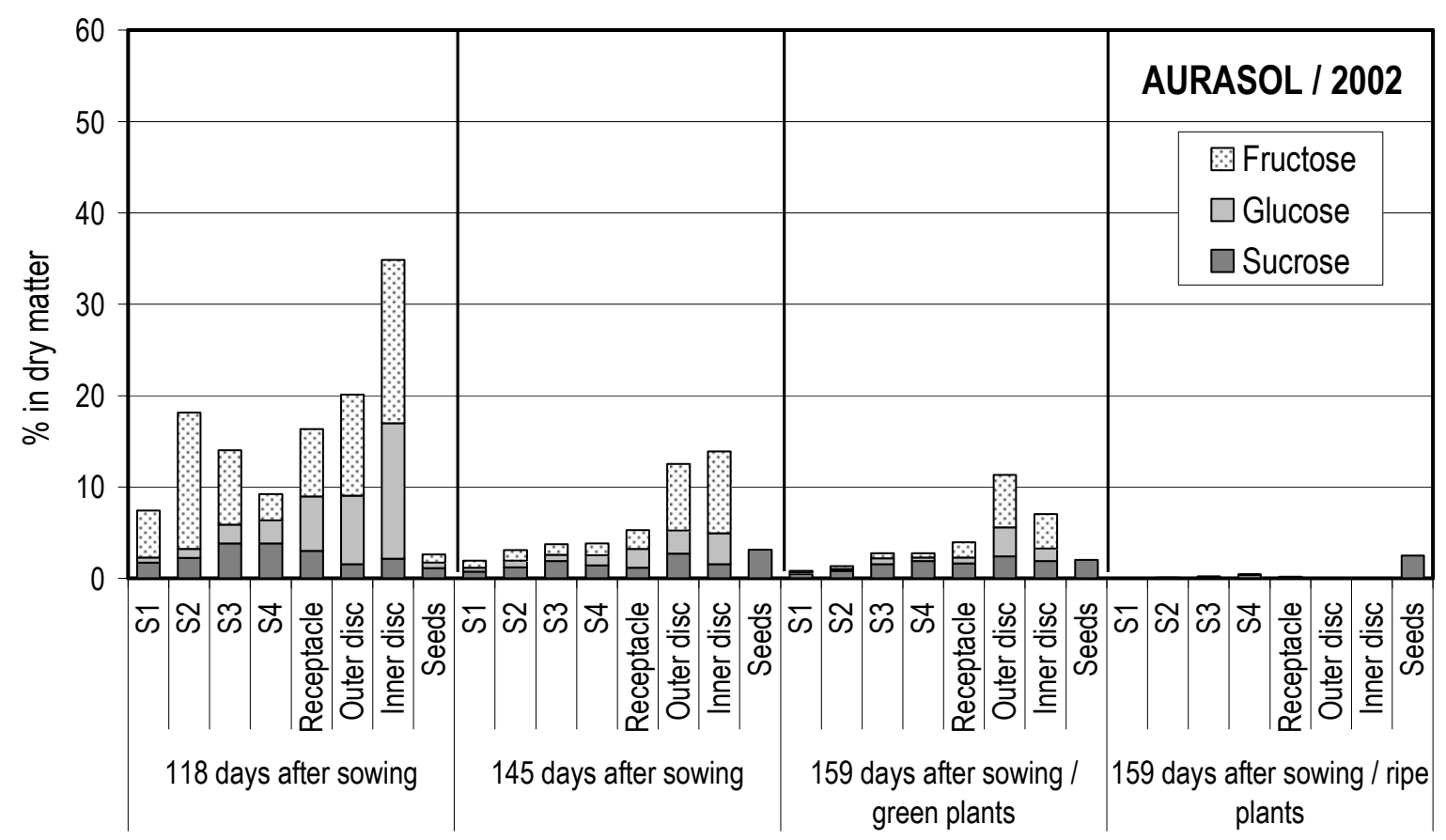

Figure 3.34: Sugar content of the stem segments and head parts sampled at 3 different growth stages in Aurasol in 2002. S: Stem segments starting from the bottom. 

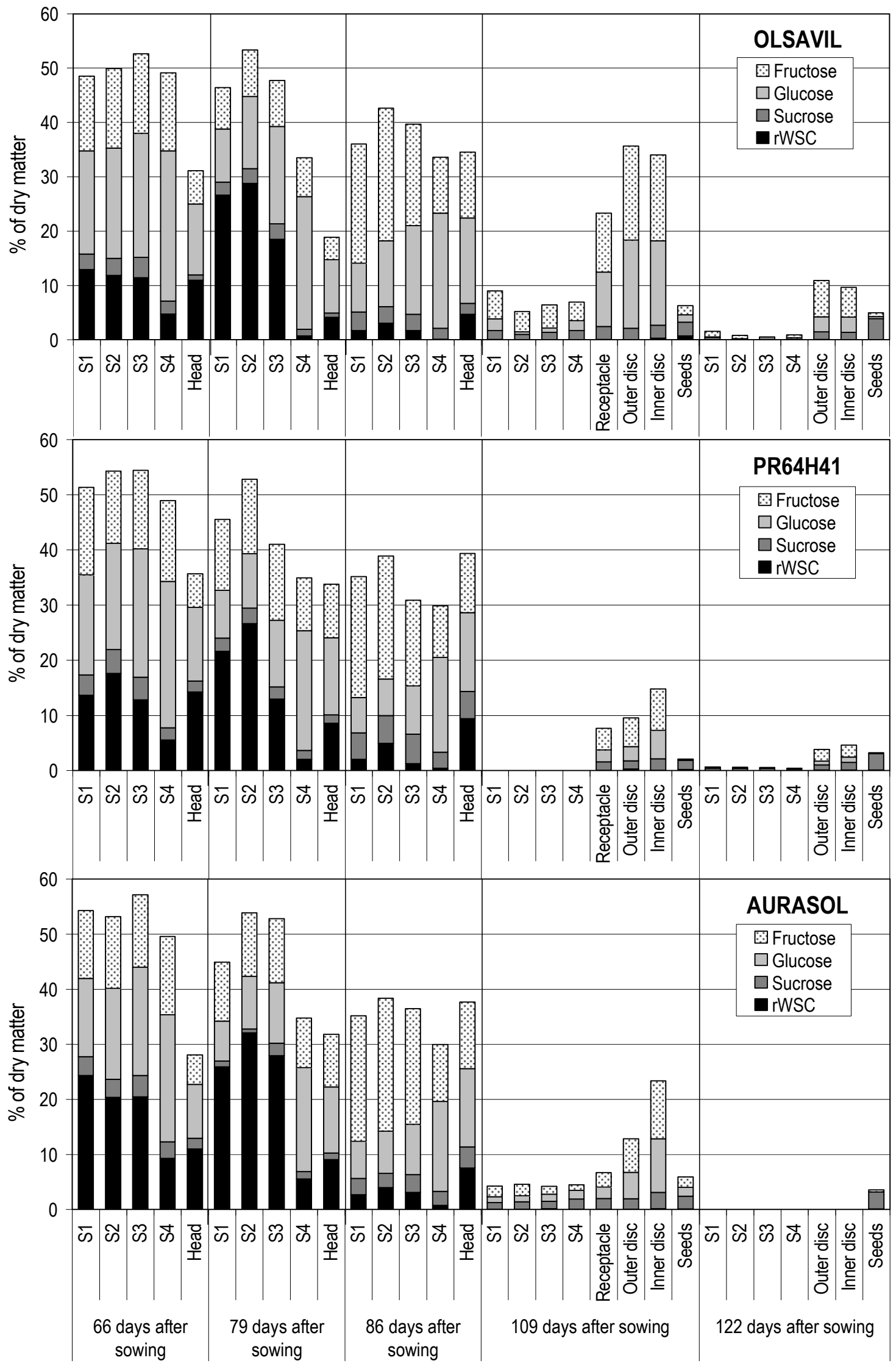

Figure 3.35: Sugar content of the stem segments and head parts sampled at 5 different growth stages in 2003. S: Stem segments starting from the bottom 


\subsubsection{Other water soluble carbohydrates}

Different from the sugar analyses 2002, additionally, fraction of remaining water soluble carbohydrates (rWSC) was also analyzed in 2003. Analysis results showed that rWCS existed in the plants mainly in the earlier sample dates (Figure 3.47). At 66 days after sowing, high amount of rWCS was measured in the first 3 segments of the stems and also in the plant head. rWCS content was lower in the last stem segment in all varieties at this date. It was even more decreased at 79 days after sowing in the $4^{\text {th }}$ segment and also in the plant head whereas it highly increased in the first 3 stem segments. At 86 days after sowing, most of the rWCS in the stem were dramatically decreased. In the meanwhile, it was increased in the plant head in Olsavil and PR64H41. At the last two sample dates, no rWCS at all was left in the stem and even the plant head parts and the seeds contained only a very small amount (less than 1\%). 


\section{4}

\section{DISCUSSION}

\subsection{Achene and oil yield of HO sunflowers}

$\mathrm{HO}$ sunflowers are reported to have comparable achene yield potential to the conventional sunflower yields (Lühs and Friedt, 1999). In fact, Monotti et al. (2003) reported that some high oleic varieties produce similar or even higher achene yield than the regular varieties, and different variety trials confirm that $\mathrm{HO}$ sunflowers have a quite similar achene yield potential to the regular type (Table 4.1). However, the promising yield potential of $\mathrm{HO}$ sunflowers is not achievable in practice. Actual achene yield values of this study show a great difference in comparison to the variety trials. With $29 \mathrm{dt} / \mathrm{ha}$, our field trial results stand far below the yield potential of the high oleic sunflowers which is around $40 \mathrm{dt} / \mathrm{ha}$ (UFOP, 2005, 2006). However, it is a general phenomenon that the predicted yields are higher in sunflowers compared to the actual yields because the countries in northwestern Europe like Germany are marginal for production and therefore there is high yield insecurity caused by environmental factors (Harrison, 1996; Lühs et al., 1999).

Oil content of $\mathrm{HO}$ sunflowers is quite the same as that of regular types as it was reported by the variety trials of the TLL (2007). Nevertheless, UFOP (2005-2006) and DLR (2007) reported a slightly lower oil content of HO sunflowers. Interestingly, our study results reached higher oil contents than the reported oil content levels for both regular and $\mathrm{HO}$ sunflowers. Although it was reported that some $\mathrm{HO}$ cultivars tend to have lower oil yield than the conventional sunflower cultivars (Monotti, 2004), evaluation trials also show that some $\mathrm{HO}$ varieties can produce higher oil yield 
(Monotti, 2003). As regards the fatty acid composition, HO sunflower hybrids show very stable fatty acid composition (Monotti et al., 2003), whereas the regular sunflower hybrids present a larger variation in oleic acid (Izquierdo et al., 2002)

Table 4.1: Achene yield (dt/ha) and oil content (\%) of regular and high oleic sunflowers reported by different research units.

\begin{tabular}{|c|c|c|c|c|}
\hline & FAL & UFOP(1) $^{(1)}$ & $\operatorname{TLL}^{(2)}$ & $D_{L}{ }^{(3)}$ \\
\hline \multicolumn{5}{|l|}{ Achene yield (dt/ha) } \\
\hline Regular sunflowers & - & 41.0 & 36.0 & 39.5 \\
\hline HO sunflowers & 29.0 & 38.4 & 38.4 & 38.5 \\
\hline \multicolumn{5}{|l|}{ Oil content $(\%)$} \\
\hline Regular sunflowers & - & 48.0 & 46.5 & 48.5 \\
\hline HO sunflowers & 50.5 & 46.8 & 46.8 & 46.9 \\
\hline
\end{tabular}

\subsubsection{Influence of environment and location}

Achene yield

The two different locations selected for this study represent two different climatic conditions for sunflower production in Germany. Unlike our expectations, location as influencing factor on the achene yield was not significant. Although the research fields near Braunschweig represent a marginal site for sunflower production, achene yield seems to be satisfactory and not strongly influenced by the unfavorable location in comparison to the warmer area with a slightly better soil quality at Eckartsweier. In contrast, Reinbrecht and Claupein (2004) observed greater differences between the achene yields at different locations. Furthermore, it was argued by Vetter (1996) that the location and soil differences have more influence on the $\mathrm{HO}$ sunflower yield than its genetic potential. Since our findings are not in agreement with those reported in both regular and $\mathrm{HO}$ sunflowers, it is essential to discuss changes in the achene yield at different locations corresponding different environmental factors in different years. The meteorological data shows that 2003 was the hottest and driest year whereas the following study years were moderate and in comparison colder with higher rainfall. These significant differences in the weather conditions during the sunflower growing period were mainly responsible for the modifications in grain yield. HO sunflower achene yields were higher in 2003 where nearly no fungal diseases 
were observed at both locations. This positive effect of dry weather and higher temperatures on the yield was confirmed by Reinbrecht and Claupein (2004). Due to the missing fungal diseases in this year, the slightly higher achene yield at Eckartsweier might be associated with the location advantage.

In the more unfavorable year 2004 with higher precipitation and colder temperatures great yield loss was experienced at both locations and at the same time the influence of location became more obvious. Only in this year, the less favorable location Braunschweig was disadvantaged mainly due to the weather conditions and showed significantly less achene yield than at Eckartsweier. This dramatic yield loss is not only a result of the worse weather condition for sunflower cultivation, but to a high extent also of more intensive fungal disease attack, which will also be discussed more precisely in the corresponding subchapter. Dramatically higher fungal disease rates were observed at Braunschweig in comparison to the second experimental site Eckartsweier as well as to the other study years, mainly caused by the heavy rainfall at the end of the of vegetation period at the ripening. On the other hand, totally the opposite results were achieved in 2005 with significant higher achene yield and lower fungal disease rates at Braunschweig than at Eckartsweier. A clear conclusion derived from the yield results obtained at different locations is that the $\mathrm{HO}$ sunflower yield stability is very much dependent on the fungal disease level associated with the wet and cold weather conditions at the second half of the vegetation period. Irrespective of being marginal or favorable for sunflower production, cultivation areas in Germany are generally under production risk due to high precipitation and cooler temperatures at the end of summer and the beginning of autumn. Therefore, locations more southwards of Germany with better soil quality might have only a small advantage for security in $\mathrm{HO}$ sunflower production. Furthermore, cultivation areas at northern Germany show inadequate temperature sum during the critical growing period as a limiting factor whereas it is inadequate precipitation in southern areas.

\section{Oil content and oil composition}

Higher oil content in sunflowers are the result of a high green matter production during the flowering, not too high summer temperatures and a good water supply 
during the flowering and seed filling stage (Hugger, 1989). These criteria are principally given at the northern production areas. However, a positive significant effect of location on the level of oil content was revealed in this study with the southern site showing a higher oil content than the northern site. This result is not necessarily a contradiction but rather a positive reflection of the sunflower's oil productivity to the better water availability at the flowering stage at the southern location Eckartsweier in the study years 2003 and 2005. It was also found by Pinthus (1963) that the high temperatures together with the high evaporation during the flowering cause decreases in oil yield components. Despite of the higher temperatures, the precipitation was also higher at Eckartsweier which probably led to the higher oil contents.

It is reported that not only oil content but also the oil composition is highly dependent on environmental differences, irrespective of the genotype (Ayerdi-Gotor et al., 2007). Another study describes that, oleic, linoleic, and stearic acid contents were significantly affected by the growth year but the oil content was stable throughout all experimental years (Robinson, 1978). In this study, the main effect of the year 2005 with moderate rainfall was an obvious decrease in oleic acid content and a concurrent increase in linoleic acid. Although the fatty acid composition of the $\mathrm{HO}$ cultivars shows a greater stability in comparison to the regular ones (Salera and Baldini, 1998; Flagella, 2002), it is also known to differ between cultivars and by varying environmental conditions (Connor and Sadras, 1992). Especially the temperature (Rondanini et al., 2003; Tremolieres et al., 1982; Robertson et al., 1978) and the water regimes (Flagella et al., 2006; Flagella et al., 2000; Baldini et al., 2000) may have a major influence on the fatty acid characteristics during seed filling. Some authors explain the decrease in oleic acid with higher water availability in both high oleic (Flagella, 2002; Baldini et al., 2000) and regular genotypes (Talha and Osman, 1974). On the other hand, Unger (1982) and Tonev (2006) found an increase in oleic/linoleic acid ratio with higher water availability during the seed filling period. Additionally, it is found that higher temperatures during seed filling cause an increase in oleic acid content (Flagella, 2002; Jones, 1984; Unger, 1982). Since the individual growth stages during the field trials were not recorded in this study, it is not possible 
to interpret the year influence on the oil composition by differences in the observed parameters.

\subsubsection{Influence of genotype}

Achene yield and disease tolerance

The results of this study demonstrate a strong variation in the achene yield as well as the fatty acid composition between different cultivars. As representative of the late maturing varieties Olsavil showed the lowest achene yield. Additionally, the yield of Olsavil seems to vary quite dramatically with changing weather conditions, since the yield dropped down drastically in colder years with higher rainfall in comparison to the more optimal sunflower production year 2003. These results conflict with Hebeisen (2006) and Sämann (2002) who argued that a longer vegetation period is generally associated with higher yields. The reason for the yield decrease might be colder temperatures and high humidity around harvest time (Meyer, 2005). It is also known that late maturity is a disadvantage in central Europe due to low temperature sum and higher rainfall in autumn and especially due to the fungal disease attack at the end of the vegetation period (Lühs, 1999). Therefore, the late maturing varieties are under higher yield risk due to the late fungal disease susceptibility. However our results agreed with this hypothesis, since the latest maturing variety Olsavil showed also the least disease severity in the most favorable study years for fungal infections proving its better tolerance against the critical fungal diseases. Additionally, the fact that Olsavil showed lower yield in the southward location Eckartsweier proves its bad adaptability to more favorable locations with higher average summer temperatures. Concerning the quality parameter, Olsavil was the only variety that showed instable oil content. The higher temperatures and lower rainfall caused a decrease in oil content. Although it has the highest oleic acid within the tested varieties, even the oleic acid of this late variety was negatively influenced by the warm and dry weather in 2003 . However it was only a $1 \%$ absolute difference in oleic acid content.

The moderate maturing variety PR64H41 showed the highest yield stability throughout the study years and at both locations, and so the least variation during the different environmental conditions. Even though, yield losses occurred in the critical production year 2004 where the disease severity appeared to be the highest in 
comparison to the other years. Unfortunately, this moderate variety also shows the highest fungal disease susceptibility. Even the mid early variety Aurasol showed similar results with high disease susceptibility in unfavorable years and a high yield loss as the conclusion. In contrast to several authors (Crowley, 1998; Askew, 1993, 1992), the earlier maturity does not necessarily secure less susceptibility to the Botrytis and Sclerotinia diseases. They both showed very good oil content stability but poor stability in oleic acid content. The environmental conditions in 2005 caused in both varieties a high loss in oleic acid content. Irrespective of the variety selection, environmental conditions cause variations in the yield and quality parameters as well as the disease levels. Although, an appropriate choice of variety could be an effective mean to produce sunflower oil with high and stable oleic acid content (Monotti, 2003), additional agricultural approaches are necessary in order to secure the yield and quality, regardless of the production location.

\subsubsection{Fungal diseases and their influence}

In the field experiments of 2002, more precise fungal disease evaluations of Sclerotinia sclerotiorum and Botrytis cinerea were carried out at different developmental stages in order to observe the development of the disease severity (Figure A.1). Results of this evaluation showed the appearance of the severe fungal infections much later in the vegetation period prevalently at the harvest. Apparently, most of the infections were caused by the air-borne pathogens which attacked sunflowers probably during the flowering stage and infected prevalently the plant heads followed by the stems at the ripening stage. In fact, the susceptibility of sunflowers to both head rot and grey mould increases already at the flowering (Church et al., 1992, Prats et al., 2003), only their damage in the field is visualized when the plants are at the physiological maturity stage. The late infections causes even more risk for $\mathrm{HO}$ sunflower cultivars since they stay approximately two weeks longer on the field. In spite, plants were harvested much later in 2002 , due to a delay in sowing time which also triggered the increase in infection rate.

The highest variation in this study was found in year, and in location $\mathrm{x}$ year interaction. Severity of both diseases was rather dependent on the environmental conditions than the study location and the selected varieties. In the comparable 
studies of head rot disease, Rönicke et al. (2005) found highly significant genotype $x$ environment interactions. In contrast, in the studies of Hahn (2002) and Rönicke et al. (2004) the variances of genotype $x$ environment were below the genotypic variance. The higher variance in experimental year in the study may be because of more pronounced differences of the environments for the experiments and also the less difference between the selected cultivars in respect to the disease tolerance. 2003 has been an extreme year from climatic point of view, with only $244 \mathrm{~mm}$ precipitation and relatively high temperatures during the vegetation period that lasted from end of April till mid September. Only some root Sclerotinia was observed in this year with no influence on the achene yield, which was mainly caused by the soil borne pathogens, since the environmental conditions were probably not favorable for air-borne pathogen infections. The unusual cool and wet conditions throughout the 2004 season were ideal for Sclerotinia head rot and Botrytis grey mould infections and development, especially at Braunschweig. The higher rainfall after flowering at Eckartsweier in 2005 probably increased the disease severity at this location. High negative correlation between the disease rate and the achene yield proves the negative influence of fungal infections on the sunflower yield. In fact, the main influencing factor found to be the fungal infection rate. To some extend, the high difference between the actual and potential yield may be associated with the severity of the fungal diseases in locations where diseases are the major constraint in sunflower production. Such decrease in yield loss due to Sclerotinia diseases is reported in sunflower (Sadras et al., 2000; Pereira et al., 1999), in peanut (Marinelli et al., 1998), in soybean (Wrather et al., 2001). Grey mould causes also significant yield loss in sunflower (Church, 1992) and e.g. in linseed (Mercer et al., 1994). Concerning the quality parameters, the fungal diseases showed no influence on the oil content and the fatty acid composition. Our results confirm the result of Hahn (2002) who found no correlations between oil content and Sclerotinia head rot reactions, and are also mostly consistent with those of Gulya et al. (1986) who found only small reduction in oil content but no change in fatty acid composition.

\subsubsection{Fungicide application}

Significant negative correlation between the fungal infection rate and achene yield shows the importance of disease management in high yielding $\mathrm{HO}$ sunflower 
production. A significant reduction in fungal diseases will significantly reduce losses in yield and quality (Rashid, 2005). Although, there is no permitted fungicide in Germany against leaf and stem diseases of sunflowers, we tested a systemic fungicide Folicur ${ }^{\circledR}$ as a conventional plant protection approach in order to examine its potential against HO sunflower's fungal pathogens.

The selected fungicide tebuconazole appears not effective against the fungal diseases of sunflowers. Our findings are in agreement with Halley (2005) who also tested Folicur, among other fungicides, against Sclerotinia head rot in sunflower and found no differences neither in the severity of the head rot nor in the yields by any fungicide treatments. Heier et al. (2005) even found an increase in disease severity with the fungicide treatment rather than a decrease. In contrast, Rashid (2005) reported that several other fungicides are effective against head rot disease in sunflowers, when applied twice, however only at high levels of infection. He also demonstrated high yield increases as a conclusion of the disease reduction. The results of this study concluded the fact that the treatment of Folicur causes yield suppression when applied at warm and dry weather conditions but only at southern location. Fungicide application at flowering together with the warm temperatures might have caused a stress in sunflower plants and led to a yield decrease. However there is no report available proving this hypothesis.

\subsection{Alternative agricultural approaches}

\subsubsection{The plant activator BTH $\left(\right.$ Bion $\left.^{\circledR}\right)$}

Efficacy on fungal diseases

BTH is the most studied resistance inducer and several available data concern the effects of this compound on foliar pathogens (Vallad and Goodman, 2004). It is reported to be by far the best studied chemical elicitors available, and activates a systemic induced resistance across a broad range of plant-pathogen interactions (Lawton et al., 1996; Maleck et al., 2000; Uknes et al., 1992; Ward et al., 1991). A resistance induction of BTH was reported against fungal diseases (Baysal, 2001; Ruess et al., 1995; Kessmann et al., 1996; Fritz, 1996; Görlach et al., 1996), against bacterial diseases (Zeller and Zeller, 1998; Louws et al., 2001), and against viral diseases (Anfoka, 2000). BTH in form of Bion ${ }^{\circledR}$ is usually applied as foliar spray but it 
can also induce resistance when applied as seed treatment e.g in sunflowers (Sauerborn et al., 2002), bean (Siegrist et al., 1997), oilseed rape (Jensen et al., 1998), cashew (Lopez and Lucas, 2002) and melon (Buzi et al., 2004). Our results of the greenhouse experiments show that the use of BTH as a seed treatment can induce an increased level of resistance to Sclerotinia in HO sunflowers, when the infection occurs after inflorescence emergence. However, BTH shows nearly no influence on the earlier infections. Similarly, Iriti and Faoro (2003) argued that BTH has proved to be a very efficient resistance inducer in bean cultivars against rust with a single application when a long induction phase elapsed before challenge inoculation. They also found that the resistance activated by BTH is long-lasting, as bean plants were fully protected for at least 1 month. It is as well reported that plants need only 2-7 days of interval after application of the inducing agent for the development of resistance (Baysal, 2001; Schweizer et al., 1989; Jenns et al., 1979) and are protected against diseases for up to 3-6 weeks (Prats et al., 2002; Kessmann et al., 1994). The fact that the BTH did not provide protection against sclerotinia infections earlier during plant development (from first leave pairs until 6 leaves stage) can be explained by the young plants being more sensitive against the severe pathogen attacks.

Our field experiments were carried out under conditions of natural infection pressure with conventional agricultural practices to obtain a more objective view on efficacy of BTH treatment if used in practice. Study results revealed that BTH seed treatment does not provide any significant reduction in Sclerotinia or Botrytis diseases when applied under field conditions, since most probably the environmental factors interfere with the efficacy. Zeller and Laux (2002), and Fried (1999) also reported that BION does not provide a consistent protection levels on the field trials, shows strong fluctuations in efficacy and therefore is not recommended in practice. Another explanation to the not existence of the seed treatment's efficacy is that, since airborne fungal infections occur much later in the vegetation period, induced resistance by seed treatment does last long enough to provide a protection in the last critical period for fungal infections being the developmental stage just before maturity. 
Foliar application of BTH under controlled conditions in the greenhouse experiments induced resistance against Sclerotinia and provided good levels of disease control (>60\% less disease rate at the last observation date), when plants were inoculated at the pre-flowering stage, although foliar spraying was done at the leaf development stage. It proves the long lasting activated resistance. However, in the field trials expression of induced resistance by BTH foliar spraying was inconsistent. It provided, depending on the experimental year, location and the variety, from none to $90 \%$ disease reduction. Derived from the study results, the BTH was more effective in years subjected to moderate disease pressure and least effective in years with very high disease pressure, which showed similarities to findings of Allen (2007) who found the same results with the BTH seed treatment influence on cotton seedlings.

Increasing the concentration of BTH does not necessarily increase the resistance level; quite the contrary, the lowest dose of BTH foliar application at the earliest application stage provided the best control against the fungal diseases, when the disease levels were the highest. In case of moderate and low fungal infection levels, the dosage and the application time showed no influence on the protection level. Similarly, Rühl (2003) reported that foliar application of Bion ${ }^{\circledR}$ induces good levels of resistance against Sclerotinia and especially against Botrytis, irrespective of the application time and concentration, however strongly dependent on the variety. Dann et al. (1998) argued that the greatest reductions by BTH foliar treatment are observed in the more susceptible cultivars. Our findings agreed with this hypothesis, as we found that BTH treatments were particularly effective in more susceptible varieties PR64H41 and Aurasol.

In contrast to several reports, BTH found to be not consistently effective on the field experiments against both fungal diseases. Its efficacy differed quite dramatically in different trial years and slightly at different experimental locations. Apart from these, its efficacy was affected when it was applied under field conditions instead of controlled greenhouse conditions. Indeed, there are several examples of induced resistance providing lower levels of disease control (Miles et al., 2004) or also many reports of induced resistance not providing disease control (Graham and Leite, 2004; Huth and Balke, 2002; Si-Ammour et al., 2003). Because induced resistance is a 
plant response to attempted infection, it stands to reason that the expression of this response will be affected by a range of factors, including genotype and the environment (Walters et al., 2005). Generally, on monocots the induced resistance by BTH appears to be much longer lasting than that on dicots (Oostendorp et al., 2001). Environmental stress can influence plant resistance to pathogens (Ayres, 1984) and therefore such interactions have to be taken into account when induced resistance is used in a field situation (Walter s et al., 2005). Concluding from the study results as well as from several reports, the efficacy of BTH treatment in the field conditions is not reliable, and therefore cannot be used as a complete control against fungal pathogens in $\mathrm{HO}$ sunflower. There is still a lack of understanding what factors may be interfering with its efficacy under field conditions.

\section{Influence on the yield and quality components}

Regardless from any change in disease levels, BTH foliar application showed a tendency to increase (up to 55\%) the achene yield in northern experimental location (Braunschweig) and vice versa to decrease (up to 54\%) in southern location (Eckartsweier), particularly expressed in a warm and dry year. A reduction in dry matter production after BTH treatment was confirmed by Sauerborn et al. (2001) which agrees with our results from Eckartsweier. Heil et al. (2000) explained the growth depression as a consequence of the associated allocation costs which then occur as a result of de novo production of compounds leading to pathogen resistance and those proteins that are involved in growth related processes. Faessel et al. (2008) found a dose-dependant growth inhibition after BTH treatment, under pathogen-free conditions in the first stage of soybean development. However, this inhibition was temporary and recovered rapidly in optimal growth conditions, as also reported by Zhu et al. (2003). The growth inhibition after chemical induction by BTH has been confirmed also in cauliflower (Godard et al., 1999), tomato (Louws et al., 2001) however was not observed in bean (Iriti and Faoro, 2003). Although the results revealed from Eckartsweier agreed quite well with some reports, the results from Braunschweig conflicted with both our and those authors' findings. As a matter of fact, BTH induced plants produced more achene yield coupled with a higher head diameter and thousand seed weight as well as a higher plant height. Although, such an increase was observed by most of the BTH applications and in all varieties, in 
particular, the foliar applications at emergence and at flowering, as well as $\mathrm{PR} 64 \mathrm{H} 41$ the variety with the more stable yield showed the highest increase in yield. These different results can be explained by the nutritional status of the plant and the environmental conditions. In fact, in wheat, fitness cost of BTH-treated plants was greater in poor nitrogen conditions (Heil et al., 2000). In a recent work of Dietrich et al. (2005), the effect of different environmental conditions on seed production of Arabidopsis treated with BTH was investigated. Authors observed in deed a growth depression during the first week after resistance induction. However, the induced plants partly or overcompensated and exhibited improved plant growth depending on the cultivation conditions such as nitrogen supply or length of the growing period. Our study results seem to be the only report which agrees on the beneficial effect of inducing resistance in case of pathogen lack.

Not only were the yield components influenced by the BTH application but also oil content. In this extreme year (almost pathogen-free conditions), a dose-independent increase in oil content (up to 16\%) by BTH foliar application was observed particularly in variety Olsavil followed by PR64H41 and Aurasol at Braunschweig. As in case of achene yield, the oil content was also decreased at Eckartsweier, however in comparison to the northern location, the change in oil content was relatively low (up $8 \%$ reduction). It should be noted that there is no study on the investigation of the BTH influence on the quality components. Negative association between the oil and protein content has been reported for sunflower (Connor and Sadras, 1992). An increase in oil content could be explained by the production of SAR related proteins competing with that of the synthesized for grain composition resulting reduction in protein content and increase in oil content. Indeed, Dietrich et al. (2005) reported that induced plants cultivated under high $\mathrm{N}$ conditions reached higher protein contents. Due to cultivation system differences, the plants received lower $\mathrm{N}$ fertilization at Braunschweig, which probably influenced the protein/oil ratio and thus led to an increase in oil content. 


\subsubsection{Ammonium based liquid fertilization}

\section{Influence on fungal diseases}

Nitrogen supply can influence disease development. Application of nitrogen above the recommended rate has often been shown to significantly increase disease incidence (Solomon et al., 2003; Snoeijers et al. 2000; Agrios, 1997). Snoeijers et al. argued that in the case of nitrogen availability in high concentrations, pathogens can easily acquire nitrogen and will cause more severe diseases on these plants than on host plants with limited nitrogen supply. Sochting and Verreet (2004) reported that a reduced $\mathrm{N}$ fertilization reduced the appearence of Sclerotinia sclerotiorum in oilseed rape. The form of nitrogen available to plants and pathogens also affects the severity of fungal diseases (Huber and Watson, 1974). Ammonium increases the level of diseases caused by Sclerotinia on tomato, Botrytis on broad bean, as well as Fusarium and Rhizoctonia on citrus, wheat, cotton, and sugar beet.

In agreement with these reports, ammonium based liquid fertilizer caused either no change or an increase in fungal disease rate depending on the variety and the environmental conditions. Aurasol, the variety with the least disease susceptibility was severely affected by ammonium fertilization.

In contrast to many reported studies, increasing $\mathrm{N}$ concentration does not necessarily cause an increase in disease level. In particular, Felgentreu (2003) reported no negative effect on infection level by ammonium based liquid fertilization. Furthermore, the method of application appears to have an impact on the severity of infections. The surface application of urea ammonium nitrate showed the most severe effect on disease severity. According to the conventional fertilization methods, $60-80 \mathrm{~kg} \mathrm{~N} / \mathrm{ha}$ is recommended for sunflowers depending of the soil properties. Interestingly, the reduced $\mathrm{N}$ fertilization variant (48 $\mathrm{kg} \mathrm{N} / \mathrm{ha}$ ) of the surface application technique caused the highest infection level, probably due to the fact that sub-optimal nitrogen availability might weaken the plants and lead to more diseases.

In the grey mould pathogen Botrytis cinerea, the formation of primary lesions on tomatoes was more frequent with low nitrogen levels (Hoffland et al., 1999). Thus, either insufficient or superabundant $\mathrm{N}$ fertilization can lead to an increase in fungal diseases (Solomon et al., 2003). Insufficient N weakens the plant and leads to higher 
susceptibility. Vice versa, high nitrogen availability provides excess nutrient that is also available for pathogens, promotes the growth of ill-defended plant tissue, or diverts metabolic resources into the assimilation of the nutrient.

\section{Influence on yield and quality}

Techniques of ammonium based liquid $\mathrm{N}$-application as deep placement in the soil termed CULTAN - has been intensively investigated (Sommer, 2003). This method is well studied in cereals but rather sparse in winter oilseed rape and canola production, and not at all in sunflowers. Information on the influence of liquid $\mathrm{N}$ soil placement method on seed yield and yield quality are contradictory. Boelcke (2003) reported no change in achene yield in oilseed rape but increases and decreases in cereals depending on the application conditions. Kuecke (2003) found an increase in achene yield of winter wheat and rye, however, it was not investigated which yield parameters might have caused the yield increase. Our findings agree with those authors, since an increase in yield was observed as a result of an elevated thousand seed weight (TSW). Although achene yield showed also decreases depending on the experimental year and location, increase in TSW was almost predominant and mainly reproducible. Achene yield decrease in varieties PR64H41 and Aurasol in 2004 at Braunschweig probably occurred due to severe fungal disease losses in this particular year.

Rathke et al. (2006) argued that deep placing of $\mathrm{N}$ liquid fertilizer at the main root depth can enhance plant growth and increase yield, particularly under drought conditions when the water potential of the surface soil decreases but ample water is available in the subsoil. Our findings from warm and dry year are in conflict with his argument since yield level fluctuated with liquid $\mathrm{N}$ fertilization method at Braunschweig, whereas yield was reduced by all $\mathrm{N}$ applications at Eckartsweier. Significantly different yields at different locations were also reported and explained as a result of soil differences by Boelcke (2003). The results of this study proves the hypothesis that liquid $\mathrm{N}$ fertilizer injection method leads to higher yields on sites characterized by light soils, since yields were consistently higher at Braunschweig than at Eckartsweier with loamy soils. An elevated $\mathrm{N}$ fertilizer level showed no yield increase, unlike it is reported in regular fertilization studies (Zubillaga et al., 2002), 
which is apparently a positive effect of liquid fertilization soil placement in respect of reducing fertilizer demand.

The influence of the fertilization method on the quality parameters is contradictory. The variation of the $\mathrm{N}$-form had no effect on the oil content of winter oilseed rape (Franck and Becker, 1982; Bailey, 1990). Felgentreu (2003) reported a decrease in oil content of oilseed rape and an increase in protein content by CULTAN method. In this study, oil content was decreased by most of the liquid fertilizer applications, however, this was apparent only at the southwards located site Eckartsweier. In contrast, oil content was predominantly increased at Braunschweig. In contrast to Behrens (2002) who found no significant change by changing the $\mathrm{N}$-form on the fatty acid composition in the seed, oleic acid content significantly increased and decreased depending on the year, location and application time.

\subsubsection{Combination of Bion ${ }^{\circledR}$ and Ammonium Fertilization}

\section{Influence on fungal diseases}

A combined application of both Bion ${ }^{\circledR}$ and liquid fertilization leading to a slow uptake of both nutrients and the resistance inducing agent through the plant roots did not result the expected synergy effect on disease severity. In contrast, a decreased resistance was observed, despite lower $\mathrm{N}$ supply. It is documented that increasing nitrogen supply causes decreasing resistance against fungi (Kiraly, 1976). Our results were supported by Wieseet et al. (2003), who also found decreasing resistance even at the lowest $\mathrm{N}$ supply when Bion ${ }^{\circledR}$ was applied 12 days after sowing. An increase in disease severity could be explained by the fact that in interactions between the plant and the pathogen, the fungus relies on the nutrients derived from the host plant and living tissue (Mendgen et al., 2000; Hampp et al., 1999). Therefore differences in plant nutrition approach my directly affect the nutrients delivered to the pathogen and thus the resistance of the plant (Graham, 1983; Marschner, 1995). Additionally, since it has not been investigated before, we have also no information about the affect of liquid fertilizer on the Bion ${ }^{\circledR}$ solution and it's uptake by the plant. Regarding to the root uptake of BTH by the plants, Tosi et al (1999) reported an increased resistance in sunflower plants against Plasmopara, when BTH was applied as a soil drench. 


\section{Influence on the yield and quality}

The most remarkable affect of the combination method was nearly constant decrease in achene yield which was prevailing at southwards location. The yield depression can be explained by higher concentration of BTH which was discussed comprehensively under influence of Bion ${ }^{\circledR}$. This effect was interpreted as a consequence of the associated allocation costs which occur as a result of production of compounds leading to pathogen resistance and those proteins that are involved in growth related processes. However, increasing the Bion ${ }^{\circledR}$ concentration in the fertilizer solution up to 2,000ppm resulted no significant difference in its influence. Furthermore, yield reducing effect of this method was lower at the northwards location, although the thousand seed weight was significantly increased. In contrast, applying chemical fertilizers with BTH produced an increase in yield of cucumber (Bayoumi and Hafez, 2006).

Another remarkable effect of the combination method was on the seed quality, where location dependent significant changes were observed. The combined application caused a decrease in oil content at Eckartsweier whereas it was increased at Braunschweig. These results are quite similar to the single Bion ${ }^{\circledR}$ application results of this study which was discussed previously. Since Bion ${ }^{\circledR}$ uptake through the roots took place slowly over the vegetation due to high concentration spot effect of the liquid fertilization placement, its influence on oil content might have been enhanced. Apart from this, soil differences between the locations might have played also an important role causing contradictory results. Interactions between the soil properties and induced resistance by BTH (Wiese et al, 2003) and liquid fertilizer placement (Boelcke, 2003) have been well documented.

\subsubsection{Mikro-Vital}

\section{Influence on fungal diseases}

The bacterial mixture Mikro-Vital containing 3 different bacterial strains has not been investigated as a disease control approach in Europe except its production country Hungary. However, many strains of soil plant growth-promoting rhizobacteria (PGPR) including also Pseudomonas spp., Azotobacter spp.and Azospirillum spp are well 
documented to show an antagonistic mechanism that have biological control effect in the rhizosphere (Cook, 1993; Emmert and Handelsmann, 1999; Paulitz and Belanger, 2001; Whips, 2001). Disease-suppressive microorganisms commonly share certain important properties such as effective and competitive colonization in the soil, stimulation of host defence by induced systemic resistance (ISR) and systemic acquired resistance (SAR), or direct antagonistic effects on the pathogens. The use of PGPR strains to induce resistance in plants against diseases has been widely studied (Biles and Martyn, 1989; Liu et al., 1995; Wei et al., 1996). Haas and Keel (2003) especially focused on the antagonistic mechanisms of certain Pseudomonas spp. strains and reported that, when added to the soil in sufficient numbers, those bacterial strains cause a significant reduction of root disease caused by different pathogenic organisms. Furthermore, bio-control strains of pseudomonas have received particular attention because they are easy to grow in vitro. Pseudomonas spp. takes up $50 \%$ of Mikro-Vital bacterial mixture. The producer company BIO-NAT (1998) reported significant decreases in soil-borne Sclerotinia diseases in sunflowers, however, with much higher concentrations such as 10, 20, and $30 \mathrm{l} / \mathrm{ha}$. The most actually, the company produces the concentrated formulation with 1, 2 and $3 \mathrm{I} /$ ha recommended dosages, which was also used in this study. It was also observed in the product trials by the company that significant reductions occurred in Fusarium spp. pathogens in soil after both $1 \mathrm{I} /$ ha and $3 \mathrm{I} /$ ha Mikro-Vital treatments. The results of this study, however, showed no significant influence in Sclerotinia and Botrytis diseases by Mikro-Vital applications. Although, some slight reductions in disease rates in a year or location were observed, those effects were not reproducible. It must be noted that the most of the infections occurred in this study were air-borne head and/or stem infections. Therefore it is not possible to interpret whether or not the application showed positive effect as a disease control mechanism. However, we carried out an additional experiment on Mikro-Vital on HO sunflowers in 2006 with 1, 2 and $3 \mathrm{l} /$ ha concentrations (data not shown and not published). Indeed, the highest dosage showed a good reduction in both head (26\%) and stem (53\%) disease rate, although, even these positive results were not applicable for all selected varieties. Nevertheless, these unofficial results agree with the argument that bacterial strains may cause a reduction in fungal diseases when 
applied in higher concentrations. But the recommended low dosage does not show a reliable control mechanism.

\section{Influence on the yield and quality}

The strains of PGPR are found to increase plant growth and productivity and can be classified as yield enhancers (Kannaiyan, 2003; Fages, 1994; Hartmann and Zimmer, 1994; Okon and Labandera-Gonzalez, 1994). Evaluation on field inoculation experiments with Azospirillum singly or in combination with dinitrogen fixers leads to the conclusion that these bacteria strains are capable of promoting the yield of important agricultural crops in different soils and climatic regions (Tilak and Singh, 2002). Fages and Arsac (1991) reported positive plant growth-promoting effect on sunflowers by inoculation of Azospirillum and other PGPR strains. The results of this study was not entirely in agreement with those reports, since the treatment of MikroVital containing three different PGPR strains showed no significant change in yield in dry weather conditions. Nevertheless, the bacterial mixture was capable of increasing the yield under higher water availability. The investigations of Bensalim et al. (1998) showed also normalization of the plant performance besides yield improvement which agrees with our findings, since achene yield was not changed by Mikro-Vital treatment even under low water availability. Although, PGPR strains are reported to improve plant performance in stressful environments (Jaleel et al., 2007), water deficit might have affected bacterial activity in the soil. Forchetti et al (2007) reported that the growth of bacterial strains was negatively influenced by water stress.

Result of this study also showed that Mikro-Vital treatment slightly increased oil content, especially in warm and dry year. This effect was however was not consistent over the experimental years. Effect of PGPR on the quality performance of the crops is relatively less investigated. An increase in oil content might be a result of a direct growth promotion which can be explained by the production of plant growth regulators by PGPR (Lifshitz et al. 1987; Frankenberger and Arshad 1995) Asghar et al. (2002 and 2004) reported consistent increase in oil content of rapeseed by rhizobacteria. They found a high correlation between auxin production by PGPR and several yield components. 


\subsection{Sugar content of sunflower plant parts}

\subsubsection{Role of sugars in fungal infections}

The infection process of Botrytis cinerea and Sclerotinia sclerotiorum comprises the attachment of conidium (Botrytis) or ascospores (Sclerotinia), germination, penetration of host surface, degradation of the cell walls, killing of the host tissue, tissue maceration and sporulation (van Kan, 2006; Prins, et al, 2000; Cerboncini, 2003). Sugars in form of glucose, fructose, and sucrose, as sole carbon sources support high fungal growth and sporulation (Calvo et al., 2002; Luchese and Harrigan, 1993). In gray mold fungus Botrytis cinerea, spore germination and plant infection are stimulated in the presence of nutrients particularly sugars (Doehlemann et al., 2005). Of the sugars, fructose has been pointed out as the best inducer of germination in $B$. cinerea, being more effective than glucose and other hexoses or disaccharides (Blakeman, 1975), although glucose is usually the most efficient hexose not only as a nutrient, but also as a signaling compound. For a better understanding on the mechanisms of fungus infection in sunflower plants, it is important to stress on the role of the specific sugars as nutrient source in all stages of Botrytis and Sclerotinia pathogenesis, and to observe the distribution and the ratio of specific sugars in entire plant.

\subsubsection{Dynamics of sugars in the plant}

Because of the fact that both Botrytis gray mold and Sclerotinia head rot infections occur mainly in sunflower plant heads, it is important to investigate the amount, distribution and the dynamics of their $\mathrm{C}$ - and energy- source being sugars in the plant and plant head during the period between flowering and harvest when sunflower plants are most susceptible to fungal pathogens. For a better understanding of its dynamics, sugars in form of fructose, glucose, and sucrose of stem segments and plant heads were analyzed during the late vegetation period starting from the flowering stage using HPLC. After seed filling, the plant heads were analyzed separately as receptacle, outer and inner discs, and seeds. A sugar analysis of sunflower plant parts as such has not been investigated before. There are, however, a couple of similar reports, which in part analyzed sugar content of sunflower plant parts. Shiroya (1977) investigated the translocation of the sugars in ${ }^{14} \mathrm{C}$-glucose fed and illuminated plants ( $\geq 5$ weeks old) in successive sections of the stems by 
examining the radioactivity. He found a higher glucose percentage in the upper stem parts than sucrose and fructose, whereas the sucrose content was higher than that of glucose and fructose in the lower stem parts. His study also showed that sucrose is the main substance of translocation. Moreover, he argued that glucose is translocated to the upper parts of the stems while mainly sucrose was translocated to the lower parts. A more recent study on the phloem transport sugars by using ${ }^{13} \mathrm{C}$ and ${ }^{14} \mathrm{C}$-pulse labeled plants was carried out by Alkio et al. (2002). They reported that glucose, fructose and sucrose are the most abundant sugars in leaf blade, petiole and stem of sunflower during seed filling, while sucrose is the main transport sugar in the sunflower phloem. The most recent findings were reported by Pereira et al. (2008) who investigated stems and receptacles at seed filling and post-physiological maturity phase for non-structural carbohydrates (NSC) including sugars, and their dynamics. Pereira et al. concluded that stem NSC content decreases from early grain filling to maturity while receptacle NSC content first rises and then decreases during grain filling. They also found cultivar differences in stem and receptacle NSC content in parts from anthesis till maturity.

Since the reports reviewed above are not entirely comparable with the current study, they will be discussed only in part when suitable. The current study results show that the fructose and glucose content is higher than sucrose content in all stem segments from full flowering till maturity, which conflicts in part with Shiroya's findings. Fructose and glucose are the main sugars until physiological maturity, as it was also discussed by Alkio et al. (2002), whereas there was also a high amount of fructan observable until seed filling. In contrast, sucrose was the least sugar during the complete late vegetation period in all plant parts except seeds, and seems to be the main sugar only in seeds. Similar to the results of Pereira et al. (2008), total sugar content of the plant head decreased during the flowering stage and increased again during early seed filling. Interestingly, the content of fructose and glucose, the most attractive sugars from the point of view of fungus germination and nutrition, increases at seed filling stage in most plant parts. Particularly, the receptacle as well as the plant discs contains at this stage a high amount of those sugars, which are the main nutrient sources for both studied fungal pathogens, which varied in studied cultivars as it was also reported by Pereira et al. (2008). The late maturing variety Olsavil showed still a 
quite high fructose and glucose content in plant heads as well as in stems at seed filling and maturation stage, which theoretically makes this variety more susceptible to the pathogens at the late stage of the vegetation period. Considering the typical hanging position of the sunflower head just before or at maturity, the receptacle easily keeps the precipitation water on its top and therefore stays moist. Thus, sunflower heads, enriched with sugars as $C$ and energy source for fungal pathogens in combination with the conserved humidity provide very good growing conditions for fungal development at the end of the vegetation period, when the autumn rainfall is additionally favorable for diseases. For sunflower breeding, it therefore can be recommended to select for earlier varieties and cultivars with strait or curved but not dropping stems. 


\section{5}

\section{CONCLUSION}

The results presented in this study demonstrate that high oleic sunflowers as an alternative oleic acid source is only conditionally suitable for its production in central Europe, more specifically in Germany. HO sunflower's yield and quality is strongly related to the environmental conditions. Irrespective of being marginal (northwards) or favorable (southwards) for sunflower production, cultivation areas in Germany are generally under production risk due to high precipitation and cooler temperatures at the end of vegetation period. An appropriate choice of variety with correct maturing time provides only insufficient yield stability. The main influencing factor on the yield appears to be the fungal disease severity. Appropriate disease management is essential in high yielding $\mathrm{HO}$ sunflower production. The selected fungicide tebuconazole (Folicur) is found to be not effective against the fungal diseases of sunflowers. The efficacy of BTH $\left(\right.$ Bion $^{\circledR}$ ) treatment under controlled conditions is moderate, however, not reliable in the field conditions, and therefore cannot be used as a complete control against fungal pathogens in $\mathrm{HO}$ sunflowers. There is still a lack of understanding what factors may be interfering with its efficacy under field conditions. The ammonium based liquid fertilizer (CULTAN method) might increase the disease severity but does not influence yield significantly, and therefore could be recommended as an alternative fertilizer method considering its environmental and economical advantages. The bacterial mixture does also not provide any control against fungal diseases. Due to its nutrient providing advantage, it can be used as a plant nutrition method. Since neither location and/or variety choice nor the studied approaches provide a reliable disease control method, further researches should stress on breeding for disease resistance. For sunflower breeding, it can be 
recommended to select for earlier varieties and cultivars with strait or curved but not dropping stems, in order to avoid late fungal infections. 


\section{6}

\section{SUMMARY}

\section{"Agronomic approaches in yield and quality stability of high oleic (HO) sunflowers (Helianthus annuus L.)"}

Sunflower (Helianthus annuus L.) is, together with soybean, rapeseed and peanut, one of the most important annual crops in the world grown for edible oil. Regular sunflower oil is characterized by its high content of the essential linoleic acid (C18:2). The high oleic $(\mathrm{HO})$ sunflower oil is in appearance very similar to regular sunflower oil. However, the fatty acid profile differs quite dramatically from the regular type. The $\mathrm{HO}$ sunflower oil contains over $80 \%$ oleic acid (C18:1), whereas the regular sunflower oils oleic acid content stays around $20 \%$.

The high oleic sunflower has a high potential for industrial use such as oleo chemistry, bio lubricants or bio diesel. Oil from recent high oleic sunflower varieties contains up to $90 \%$ oleic acid and more. Although the $\mathrm{HO}$ sunflower has a yield potential comparable to the conventional sunflowers, there are certain constraints that hinder its production in Germany. Cold and wet weather conditions affect sunflower's potential during the period of seedling establishment as well as the harvest. Fungal diseases especially Sclerotinia sclerotiorum (white rot) and Botrytis cinerea (grey mould) are prevalent. Therefore it is essential to explore and test alternative agricultural approaches that ensure stable kernel and oil yield, desired oil composition, and promote healthy plant development in the predominantly wet autumn, since HO sunflowers mature late under central European climatic conditions.

Three different $\mathrm{HO}$ sunflower varieties representing different ripening classes were examined for yield, quality and fungal disease rate at two different locations, Braunschweig and Eckartsweier, representing two different climatic regions in central Europe. Following approaches were tested in this study: Since there is no registered fungicide for sunflowers in Germany, a broad spectrum fungicide Folicur, which is predominantly used on rape seeds, was examined for its potential in controlling fungal diseases in sunflowers. As an alternative disease control method, the resistance inducing agent Benzo $(1,2,3)$ thiadiazole-7-carbothioic $(B T H)$ as the commercial available product BION (Syngenta) was tested under field conditions. Additionally, greenhouse experiments were conducted at Braunschweig in 2003 in order to observe the effect of BTH application on Sclerotinia infection at different 
growth stages under controlled conditions. Ammonium based liquid fertilizer injection, commonly called as CULTAN in Germany, was examined as an alternative plant nutrition method and for its potential to reduce fungal attacks. The bacterial mixture "Mikro-Vital" has been developed to supply the plants with nutrients and to suppress soil-borne fungal pathogens by soil application.

Since fungal pathogens use sugar as the carbohydrate and energy source, sugar content of different plant parts was analyzed at different growth stages to find out possible correlation between the time fungal infection and the sugar content in these plant parts.

The three $\mathrm{HO}$ sunflower varieties showed good kernel and oil yield performance under both climatic conditions. However, the varieties showed low tolerance against fungal diseases and were severely infected in cold and wet years.

Results indicate that the commercial fungicide does not reduce fungal infection rate and even showed in some cases yield suppression. Quality parameters were not affected by fungicide application.

The resistance inducing product $\mathrm{BION}$ could suppress fungal disease severity only in the first experimental year, but not in the following experimental years in 2003-2005. It slightly increased the oil content in the first year, whereas no significant change in oil content and composition was observed in a mean of all experimental years. Under greenhouse conditions, it could slow down the Sclerotinia infection but did not hinder it.

Ammonium based liquid fertilization in general did not reduce fungal infection rate. Slight increases and decreases were observed in grain yield depending on the variety, location and year. It caused increase in oil content at Braunschweig and a decrease at Eckartsweier. Oil composition was not changed by the alternative fertilization method.

Mikro-Vital application also could not proof as a method for control of fungal diseases. It resulted a slight increase in yield but only depended on the variety and this increase was not constant through the years. Only in warm and dry year, oil content was increased but in general neither oil content nor the composition was changed.

Sugar analysis showed that there is still a high amount of sugar in the plant head at the end of the vegetation period which acts as attraction center for fungal pathogens. 


\section{7}

\section{ZUSAMMENFASSUNG}

\section{"Pflanzenbauliche Ansätze zur Ertrags- und Qualitätssicherung bei hochölsäurehaltigen (HO) Sonnenblumen (Helianthus annuus L.)"}

Die Sonnenblume (Helianthus annuus L.) ist zusammen mit Sojabohne, Raps und Erdnuss eine der bedeutendsten einjährigen Kulturpflanzen, die weltweit zur Erzeugung von Speiseöl angebaut werden.

Konventionelles Sonnenblumenöl ist durch seinen hohen Anteil an der essentiellen Linolsäure (C18:2) gekennzeichnet. Das Öl der hochölsäurehaltigen (HO)Sonnenblume ähnelt visuell dem der konventionellen Sonnenblume zwar sehr, allerdings unterscheidet sich die Fettsäurezusammensetzung beider Öle hingegen sehr deutlich. Das Öl der HO-Sonnenblume beinhaltet mehr als $80 \%$ Ölsäure (C18:1), während der Anteil dieser Fettsäure in Sorten der konventionellen Sonnenblume lediglich etwa $20 \%$ beträgt.

Die hochölsäurehaltige Sonnenblume besitzt ein großes Potential für eine industrielle Verwendung z. B. in der Oleochemie, für biologische Schmierstoffe oder als Biodiesel. Das Öl der derzeitigen Sorten von HO-Sonnenblumen enthält sogar bis zu $90 \%$ und mehr Ölsäure. Obwohl das Ertragspotential der HO-Sonnenblume ähnlich dem konventioneller Sonnenblumen ist, gibt es einige Einschränkungen, die der Ausdehnung ihres Anbaus in Deutschland entgegenstehen. Kühle und feuchte Wetterbedingungen beeinträchtigen das Ertragspotential der Sonnenblume vorwiegend während der frühen Keimlingsentwicklung und der späten Abreife vor der Ernte. Typisch ist das Auftreten pilzlicher Krankheiten, besonders Sclerotinia sclerotiorum (Stängel- und Korbfäule) und Botrytis cinerea (Grauschimmel), vorwiegend zum Ende der Vegetationsperiode. Daher ist es bedeutsam alternative pflanzenbauliche Ansätze zu erarbeiten und prüfen, die eine Korn- und Ölertragsstabilität sowie die gewünschte Ölkomposition garantieren und die Gesunderhaltung der Pflanzenbestände im vorwiegend feuchten Herbst sicherstellen, da HO-Sonnenblumen unter mitteleuropäischen Klimabedingungen spät abreifen.

Drei HO-Sonnenblumensorten, die unterschiedliche Reifegruppen repräsentieren, wurden an zwei Standorten, Braunschweig und Eckartsweier, die zwei 
unterschiedliche Klimaregionen Mitteleuropas widerspiegeln, auf ihren Ertrag, ihre Qualität und den Befall mit pilzlichen Schaderregern untersucht. Folgende Ansätze wurden im Rahmen dieser Studie untersucht: Da zurzeit kein Fungizid für den Einsatz an Sonnenblumen in Deutschland zugelassen ist, wurde das Breitbandfungizid Folicur, welches vorwiegend im Rapsanbau eingesetzt wird, auf seine Wirksamkeit zur Kontrolle pilzlicher Krankheiten bei Sonnenblumen untersucht. Als ein alternatives Verfahren zur Unterdrückung pilzlicher Krankheiten wurde das resistenzinduzierende Mittel Benzo $(1,2,3)$ thiadiazole-7-carbothioic $(B T H)$ in Form des kommerziell verfügbaren Produkts BION (Syngenta) unter Feldbedingungen getestet. Zusätzliche Gewächshausversuche in Braunschweig im Jahr 2003 dienten dazu, die Wirkung einer BION-Anwendung auf künstlich mit Sclerotinia infizierte Pflanzen unterschiedlichen Entwicklungsstadiums unter kontrollierten Bedingungen zu beobachten. Ammonium-basierte Flüssiginjektionsdüngung, üblicherweise in Deutschland als CULTAN abgekürzt, wurde als alternative Form der Pflanzenernährung auf ihr Potential zur Unterdrückung pilzlicher Angriffe untersucht. Außerdem sollte die Bodenapplikation der Bakterienmischung "Mikro-Vital“, deren Hauptzweck die Verfügbarmachung von Nährstoffen für Kulturpflanzen ist, zeigen, ob sie zusätzlich bodenbürtige pilzliche Schaderreger unterdrücken kann.

Da pilzliche Schaderreger Zucker als Kohlenstoff- und Energiequelle nutzen, wurde der Zuckergehalt unterschiedlicher Pflanzenteile zu unterschiedlichen Entwicklungsstadien analysiert, um herauszufinden, ob eine Korrelation zwischen dem Zeitpunkt der Pilzinfektion und dem Zuckeranteil in diesen Pflanzenteilen existiert.

Die drei HO-Sonnenblumensorten zeigten in beiden geprüften klimatischen Regionen gute Korn- und Ölerträge. Allerdings offenbarten sie auch eine geringe Toleranz gegenüber Pilzkrankheiten und waren in kühlen und feuchten Jahren stark infiziert.

Die Ergebnisse zeigen weiterhin, dass das geprüfte kommerzielle Fungizid die Pilzinfektionsrate nicht verringert, teilweise sogar eine Verschlechterung verursachte. Die bedeutendsten Qualitätsparameter wurden durch eine Fungizidbehandlung hingegen nicht beeinträchtigt.

Der Resistenzinduktor BION konnte nur im ersten Versuchsjahr den Pilzbefall vermindern, nicht jedoch in den Folgejahren 2003-2005. Seine Anwendung steigerte im ersten Jahr leicht den Ölgehalt, allerdings traten im Mittel der Versuchsjahre keine signifikanten Veränderungen des Ölgehalts und der Ölzusammensetzung auf. Unter Gewächshausbedingungen konnte das Mittel eine Sclerotinia-Infektion verzögern, jedoch nicht verhindern.

Ammonium-basierte Flüssigdüngung reduzierte generell nicht die Infektionsrate. Geringe Zu- und Abnahmen des Kornertrags in Abhängigkeit von Sorte, Standort und Jahr konnten beobachtet werden. Sie verursachte des Weiteren eine Zunahme des Ölgehalts in Braunschweig, jedoch eine Abnahme in Eckartsweier. Die Ölzusammensetzung wurde generell nicht beeinflusst.

Die Ausbringung von Mikro-Vital konnte als Verfahren der Kontrolle von Pilzinfektionen nicht überzeugen. Das Mittel resultierte in einem geringfügigen 
Ertragszuwachs, der jedoch lediglich sortenabhängig und nicht stabil über alle Versuchsjahre auftrat. Nur in warmen und trockenen Jahren wurde der Ölgehalt angehoben, jedoch blieben sonst üblicherweise Ölgehalt und -zusammensetzung unverändert.

Die Zuckeruntersuchung zeigte beträchtliche Zuckermengen im Korb am Ende der Vegetationsperiode, die als Attraktionszentrum für pilzliche Schaderreger fungieren können. 


\section{8}

\section{REFERENCES}

Ahmad, S. (2001) Environmental Effects on Seed Characteristics of Sunflower (Helianthus annuus L.), J. Agronomy \& Crop Science, 187:213-216

Alkio, M., Diepenbrock, W. and Grimm, E. (2002) Evidence for sectorial photoassimilate supply in the capitulum of sunflower (Helianthus annuus L.). New Phytologist 156:445-456.

Allen, S.J. (2007) Field evaluation of a seed treatment that induces resistance to Thielaviopsis basicola in cotton. Invited paper (Plant pathology and disease management), Symposium - "Seedling Diseases". September 11, 2007

Anfoka, G.H. (2000) Benzo-(1,2,3)-thiadiazole-7-carbothioic acid-S-methyl ester induces systemic resistance in tomato (Lycopersicon esculentum. Mill cv. Vollendung) to cucumber mosaic virus. Crop Protect. 19:401-405.

Askew, M. F. (1992) A review of novel oil seed and fibre crops and their potential for UK.

Askew, M. F. (1993) Novel oil, fibre and protein crops in UK, A Future Perspective; Brighton Crop Protection Conference 1993 6A-2 pp 658.

Ayerdi-Gotor, A., Berger, M.; Labalette, F.; Centis, S., Daydé, J., Calmon, A. (2007) Variability of minor components in sunflower (Helianthus annuus L.) oil from a multi-local study. Current Advances in the Biochemistry and Cell Biology of Plant Lipids, Proceedings of the 17th International Symposium on Plant Lipids held on the campus of Michigan State University, East Lansing, Michigan, in July 2006, Edit: Christoph Benning \& John Ohlrogge, ISBN Number: 978-1-4276-1965-5, 248-252

Ayres, P. G. 1984. The interaction between environmental stress injury and abiotic disease physiology. Annu. Rev. Phytopathol. 22:53-75. 
Bailey, L.D. (1990) The effects of 2-chloro-6(trichlormethyl)-pyridine ("NServe") and $\mathrm{N}$ fertilizers on productivity and quality of Canadian oilseed rape. Can. J. Plant Sci. 70:979-986.

Baldini, M., Giovanardi, R., Vannozzi, G. (2000) Effect of different water availability on fatty acid composition of the oil in standard and high oleic sunflower hybrids. In: Proceedings of XV International Sunflower Conference, Toulouse, 1:79-84.

Bardin, S.D. and Huang, H.C. (2001) Research on biology and control of Sclerotinia diseases in Canada. Review, Can.J.Plant Pathol. 23: 88-98

Bayer Crop Science (2004) Folicur- Autumn disease control and growth regulation for oilseed rape, Bayer Crop Science Ltd. Hauxton, Cambridge.

Bayoumi, Y. A. and Hafez, Y. M. (2006) Effect of organic fertilizers combined with benzo $(1,2,3)$ thiadiazole-7-carbothioic acid S-methyl ester (BTH) on the cucumber powdery mildew and the yield production. Acta Biologica Szegediensis. Volume 50(3-4):131-136.

Baysal, Ö. (2001) The induced resistance against fire blight by the plant activator $\mathrm{BTH}(\mathrm{BION} \otimes)$ or extract of Hedera helix leaves and studies on the mode of action. Thesis Submitted for the degree of Doctor of Agricultural Sciences of the Faculty of Agricultural Sciences Georg-August-Universität Göttingen

Baysal, Ö., (2001) The induced resistance against fire blight by the plant activator BTH $(B I O N \otimes)$ or extract of Hedera helix leaves and studies on mode of action. PhD Thesis. Institute of Plant Pathology and Plant Protection of the GeorgAugust-Universität Götingen

Baysal, O., Soylu, E.M., Soylu, S. (2003) Induction of defence-related enzymes and resistance by the plant activator acibenzolar-S-methyl in tomato seedlings against bacterial canker caused by Clavibacter michiganensis ssp. michiganensi. Plant Pathol 52:747-753.

Behrens, T. (2002) Stickstoffeffizienz von Winterraps (Brassica napus L.) in Abhaengigkeit von der Sorte sowie einer in Menge. In: Zeit und Form variierten Stickstoffdüngung, Cuvillier Verlag, Gottingen.

Benhamou, N. and Belanger, R.R. (1998) Benzothiadiazole-mediated induced resistance to Fusarium oxysporum f. sp. Radicis-lycopersici in tomato. Plant.Physiol. 118, 1203-1212.

Bensalim, S., Nowak, J., Asiedu, S.K. (1998) A plant growth promoting rhizobacterium and temperature effects on performance of 18 clones of potato. Am J Potato Res 75:145-152

Biles, C. L., and Martyn, R. D. (1989) Local and systemic resistance induced in watermelons by formae speciales of Fusarium oxysporum. Phytopathology 79:856-860. 
Bio-Mikro Kft (2005) General description and handout of the MIKRO-VITAL bacteria-fertilizer. Bio-Nat Ltd. 8125 Sárkeresztúr, Kossuth, Ungarn.

Blakeman, J.P. (1975.) Germination of Botrytis cinerea conidia in vitro in relation to nutrient conditions on leaf surfaces. Trans. Br. Mycol. Soc. 65, 239-247.

Blanke, M. and Bacher, W. (1999) Ammonium (CULTAN) fertilizer reduces nitrate leaching and increases epicuticular wax, chlorophyll, photosynthetic efficiency and disease resistance in cabbage.

Boelcke, B. (2003) Effekte der N-Injektionsdüngung auf Ertrag und Qualität von Getreide und Raps in Mecklenburg-Vorpommern. Landbauforschung Völkenrode, Sonderheft 245:45-53

Buschmann, H. and Sauerborn, J. (2002) Induced resistance in sunflower against Orobanche cumuna. IOBC/wprs Bulletin 25:145.

Buzi, A., Chilosi, G., De Sillo, D., Magro, P. (2004) Induction of resistance in melon to Didymella bryoniae and Sclerotinia sclerotiorum by seed treatments with acibenzolar-S-methyl and methyl jasmonate but not with salicylic acid. J Phytopathol 152:34-42.

Calvo, A. M., Wilson, R. A., Bok, J. W., and Keller, N. P. (2002) Relationship between secondary metabolism and fungal development. Microbiol. Mol. Biol. Rev. 66:447-459

CETIOM (1989) La Culture du Tournesol. Paris 1984-1990.

Chahal, A.S., Ahuja, K.L., Raheja, R.K. and Badwal, S.S. (1988) Head rot of sunflower- its effect on the grain yield and oil components. Proc. $12^{\text {th }}$ Int. Sunflower Conf., Novi Sad. 2:143.

Church, V. J. (1992) Epidemiology in relation to control of grey mould (Botrytis cinerea) on sunflower. BCPC Conference - Pests \& Diseases, pp. 739-744.

Church, V. J., Fitt, B. D. L., McCartney, A. (1992) Epidemiology of grey mould (caused by Botrytis cinerea) on sunflower in the UK. Proceedings of the 13th International Sunflower Conference, Pisa, Italy 1:726-731.

Clarke, R.G., Porter, I.J. and Woodroofe, M. (1992) Effect of sowing date on the incidence of Sclerotinia stem rot (Sclerotinia minor) and yield of sunflowers. Proceedings of the Australian Sunflower Association 9th Workshop, Yeppon, Australia: S. 69-71.

Connor, D.J., Sadras, V.O. (1992) Physiology of yield expression in sunflower. Field Crops Res. 30, 333-389.

Cook, R.J. (1993) Making greater use of introduced microorganisms for biological control of plant pathogens. Annu. Rev. Phytopathol. 31:53-80 
Crowley, J.G. (1998) The potential of new crop introductions. Teagasc, 19 Sandymount Avenue, Dublin 4, ISBN $190113850 \mathrm{X}$

Dann, E., Diers, B., Byrum, J. and Hammerschmidt, R. (1998) Effect of treating soybean with 2, 6-dichloroisonicotinic acid (INA) and benzothiadiazole (BTH) on seed yields and the level of disease caused by Sclerotonia sclerotiorum in field and greenhouse studies. European Journal of Plant Pathology, 104:271-278.

Degener, J., Melchinger A. E., Gumber R. K. and Hahn, V. (1998) Breeding for Sclerotinia resistance in sunflower: a modified screening test and assessment of genetic variation in current germplasm. Plant Breeding 117:367—372.

Degener, J., Melchinger, A. E. and Hahn, V. (1999) Optimal allocation of resources in evaluating current sunflower inbred lines for resistance to Sclerotinia. Plant Breeding 118:157-160.

Diepenbrock, W., and G. Pasda (1995) Sunflower (Helianthus annuus L.). - In Diepenbrock, W. and H. C. Becker (eds): Physiological potentials for yield improvement of annual oil and protein crops. Blackwell Wissenschafts Verlag, Berlin Wien, 91-148.

Dieraurer, H. (2000) Sonnenblumen, Merkblatt. Forschungsinstitut für biologischen Landbau (FIBL), Frick, Schweiz.

Dietrich, R., Ploss, K., Heil, M. (2005) Growth responses and fitness costs after induction of pathogen resistance depend on environmental conditions. Plant Cell Environ 28:211-222.

Doehlemann, G., Molitor, F., and Hahn, M. (2005) Molecular and functional characterization of a fructose specific transporter from the gray mold fungus Botrytis cinerea. Fungal Genet Biol 42: 601-610.

Dompert, W. and Beringer, H. (1976) Einfluss von Reifedauer, Temperatur und Sauerstoffversorgung auf die Bildung von ungesättigten Fettsäuren und Tocopherolen in Sonnenblumenfrüchten. z.Pflanzenerhähr.Bodenkd. 176:157167.

Duncan, R.W., Fernando, D.W.G., Rashid, K.Y. (2003) Susceptibility period of Sclerotinia head rot (Sclerotinia sclerotiorum) infection in sunflower. Sunflower Research - Workshop, National Sunflower Association, Bismarck, ND, USA

Emmert, E.A.B. and Handelsman, J. (1999).Biocontrol of plant disease: a (Gram-) positive perspective. FEMS Microbiol.Lett. 171:1-9

Faessel, L., Nassr, N., Lebeau, T., Walter, B. (2008) Effects of the Plant Defence Inducer Acibenzolar-S-Methyl on Hypocotyl Rot of Soybean Caused by Rhizoctonia solani AG-4, Journal of Phytopathology. 156: 236-242

Fages, J. (1994) Azospirillum inoculants and field experiments. In Azospirillum/plant associations. Edited by Y. Okon. CRC Press, Boca Raton, Fla. pp. 87-110 
Fages,, J., and Arsac, J.F. (1991) Sunflower inoculation with Azospirillum and other plant growth promoting rhizobacteria. Plant Soil, 137:87-90.

Fan, Z.W., Buschmann, H. and Sauerborn, J. (2003) The efficacy of resistance inducing agents fort he control of sunflower broomrape (Orobanche cumuna)

Felgentreu, C. (2003) Erste Ergebnisse beim Einsatz des Injektionsverfahrens bei Winterraps in Brandenburg. In: Kuecke, M. (Ed.), Anbauverfahren mit NInjektion (CULTAN): Ergebnisse, Perspektiven, Erfahrungen, vol. 245. Landbauforsch, Völkenrode, Sonderheft 245: 57-62.

Ferryman, S.A.M., Fitt, B.D.L. and Harold, J. F. S. (2002) Factors affecting the development of Botrytis cinerea (grey mould) on linseed (Linum usitatissimum) buds, flowers and capsules. Annals of Applied Biology 140.1: 1-12

Flagella, Z., Di Caterina, R., Monteleone, M., Giuzio, L., Pompa, M., Tarantino, E., Rotunno, T. (2006) Potentials for sunflower cultivation for fuel production in southern Italy. HELIA, 29:81-88

Flagella, Z., Rotunno, T., Di Caterina, R., de Simone, G., De Caro, A., (2000) Effect of supplementary irrigation on seed yield and oil quality of sunflower (Helianthus annuus L.) grown in a sub-arid environment. In: Proceedings of XV International Sunflower Conference, Toulouse, 1:139-144.

Flagella, Z., Rotunno, T., Tarantino, E., Di Caterina, R. and Caro De ,A. (2002) Changes in seed yield and oil fatty acid composition of high oleic sunflower (Helianthus annuus L.) hybrids in relation to the sowing date and the water regime. European Journal of Agronomy 17:221-230

Forchetti, G., Masciarelli, O., Alemano, S., Alvarez, D. and Abdala, G. (2007) Endophytic bacteria in sunflower (Helianthus annuus L.): isolation, characterization, and production of jasmonates and abscisic acid in culture medium. Applied Microbiology and Biotechnology 76: 1145-1152

Franck, E., Becker, F.A. (1982) Ergebnisse mehrja"hriger Feldversuche zur Optimierung der N-Düngung zu Winterraps. Landwirtsch. Forsch. 35:109-118.

Frankenberger, W.T. Jr. and Arshad, M. (1995) Phytohormones in soil: microbial production and function. Marcel Dekker, New York

Fried, A. (1999) Feuerbrand-Bekämpfungsversuche 1998. Obstbau 2:71-74

Fritz, I.G. (1996) Physiologische Wirkungen von Resistenzinduktoren, primäre und sekundäre Reaktionen im Wirt-Pathogen-System Gurke/ echter Gurkenmehltau. Dissertation, TH, Darmstadt.

Gianessi, L. P., Cressida, S. S., Sujatha, S., Carpenter, J. E., (2002) Fungal Resistant Sunflower, Plant Biotechnology: Current and Potential Impact For Improving Pest Management In U.S. Agriculture an Analysis of 40 Case Studies June 2002, National Center for Food and Agricultural Policy 
Godard, J-F., Ziadi, S., Monot, C., Le Corre, D., Silue,' D. (1999) Benzothiadiazole (BTH) induces resistance in cauliflower (Brassica oleracea var. botrytis) to downy mildew of crucifers caused by Peronospora parasitica. Crop Protect 18:397-405.

Görlach, J., Volrath, S., Knauf-Beiter, G., Hengy, G., Beckhove, U., Kogel, K.H., Oostendorp, M., Staub, E., Ward, E., Kessmann, H. and Ryals, J. (1996). Benzothiadiazole, a novel class of inducers of systemic acquired resistance, activates gene expression and disease resistance in wheat. Plant Cell 8, 629643.

Graf, T., Wurl, G. and Biertümpfel, A. (1999) Chancen und Möglichkeiten der Bereitstellung maßgeschneiderter Pflanzenöle. Symposium BUGA'99 (Magdeburg): Gülzower Fachgespräche - Lacke und Farben aus nachwachsenden Rohstoffen. Fachagentur Nachwachsende Rohstoffe e.V. (FNR); D-18276 Gülzow. S. 18 - 32.

Graham R. D. (1983) Effects of nutrient stress on susceptibility of plants to disease with particular reference to the trace elements. Adv. Bot. Res. 10, 221-276.

Graham, J. H., and Leite, R. P. (2004). Lack of control of citrus canker by induced systemic resistance compounds. Plant Dis. 88:745-750.

Gulya, T. J., Rashid, K. Y. and Masirevic, S. M. (1997) Sunflower Diseases. In: Schneiter, A. A. (Ed): Sunflower Technology and Production. Agronomy, 35:263-379.

Gulya, T. J., Vick, B. A. and Nelson, B. D. (1989) Sclerotinia head rot of sunflower in North Dakota,: 1986: Incidence, effect on yield and oil components, and sources of resistance. Plant Disease 73:504 - 507.

Haas, D. and Keel, C. (2003) Regulation of antibiotic production in root-colonizing pseudomonas spp. and relevance for biological control of plant disease. Annu. Rev. Phytopathol. 41:117-53

Hahn, V. (2002) Genetic variation for resistance to Sclerotinia head rot in sunflower inbred lines. Field Crops Res. 77:153-159.

Halley, S. (2005) Fungicide Efficacy for Sclerotinia Head Rot Control on Sunflower. North Dakota State University, Langdon Research Extension Center, Plant Pathology Research. http://www.ag.ndsu.edu/langdon/plantpathology.html

Hampp R., J.Wiese, S.Mikolajewski, and U.Nehls (1999) Biochemical and molecular aspects of $\mathrm{C} / \mathrm{N}$ interaction in ectomycorrhizal plants An update. Plant Soil 215:1-10.

Harris, H.C., McWilliam, J.R., Mason, W.K. (1978) Influence of temperature on oil content and composition of sunflower seed. Australian Journal of Agricultural Research 29:1203-1212.

Harrison, P. A. and Butterfield, R. E. (1996) Effects of climate change on Europewide winter wheat and sunflower productivity, Clim Res, 7:225-241 
Hartmann, A., and Zimmer, W. (1994) Physiology of Azospirillum. In Azospirillum/plant associations. Edited by Y. Okon. CRC Press, Boca Raton, Fla. pp. 15-39.

Hebeisen, T., Hunziker, H., Pellet, Z.D., and Grosjean, Y. (2006) Züchtungsfortschritt und Sortenprüfung bei Winterraps und Sonnenblumen. Agroscope FAL-Reckenholz, Agroscope Changins-Wädenswil, Nyon, Fachtagung „Ölpflanzen im Fokus“. 1-5

Heier, T., Jain, S.K., Kogel, K-H., and Pons-Kühneman J. (2005) Influence of Nfertilization and fungicide strategies on Fusarium head blight severity and mycotoxin content in winter wheat. J Phytopathol 2005, 153(9), 551 -557

Heil, M., Hilpert, A., Kaiser, W., Linsenmair, K.E. (2000) Reduced growth and seed sed following chemical induction of pathogen defence: does systemic acquired resistance (SAR) incur allocation costs? J Ecol 88:645-654.

Hoffmann, G.M., Schmutterer, H. (1999) Parasitäre Krankheiten und Schädlinge an landwirtschaftlichen Nutzpflanzen -Sonnenblume-. Verlag an Eugen Ulmer, Stuttgart, 2. Aufl., 626-632.

Huang, Y., Deverall, B.J., Tang, W.H., Wang, W. and Wu, F.W. (2000) Foliar application of acibenzolar-S-methyl and protection of postharvest rock melons and Hami melons from disease European Journal of Plant Pathology 106: 651656, 2000.

Hugger, H. (1989) Sonnenblumen.: Züchtung, Anbau, Verarbeitung. - 95 S., Ulmer, Stuttgart.

Huguet, N.I. and Heiland, P. (2000) Analysis of a severe attack of Sclerotinia head rot of sunflower in Argentina (Sclerotinia sclerotiorum (Lib.) de Bary). In: Proc. 15th Int. Sunflower Conference, 12-15 June, Toulouse, France. Int. Sunflower Association, Paris, France. 2:190 - 195.

Huth, W. and Balke, K. (2002). Bion-without effect on the development of BYDV infected plants of winter barley. J. Plant Dis. Prot. 109:286-290.

Iriti, M., Faoro, F. (2003) Benzothiadiazole (BTH) induces cell-death independent resistance in Phaseolus vulgaris against Uromyces appendiculatus. J Phytopathol 151: 171-180

Izquierdo, N., Aguirrezàbal, L., Andrade, F., and Pereyra, V. (2002) Night temperature affects fatty acid composition in sunflower oil depending on the hybrid and phenological stage. Field Crops Reserarch, 77(2): 115-126.

Jaleel, C.A., Manivannan, P., Sankar, B., Kishorekumar, A., Gopi, R., Somasundaram, R. and Panneerselvam,R. (2007) Pseudomonas fluorescens enhances biomass yield and ajmalicine production in Catharanthus roseus under water deficit stress. Colloids and Surfaces B: Biointerfaces 60:7-11 
Jenns, A.E., Caruso, F.L. and Kuć, J. (1979) Non-specific resistance to pathogens induced systemically by local infection of cucumber with tobacco necrosis virus, Colletotrichum lagenarium or Pseudomonas lachrymans. Phytopathol. Mediter. 18:129-134.

Jensen, B.J., Latunde-Dada, A.O., Hudson, D., Lucas, J.A. (1998) Protection of Brassica seedlings against downy mildew and damping-off by seed treatment with CGA 245704, an activator of systemic acquired resistance. Pest Sci 52:6369.

Jentsch, U., Günther, K. and Barthelmes, G. (2007) Ergebnisse der Landessortenversuche zu Sommerölfrüchten, Zusammenstellung der Ergebnisse der Landessortenversuche 2004 bis 2006 in den neuen Bundesländern zu Sommerraps, Sonnenblumen und Öllein. Thüringer Landesanstalt für Landwirtschaft (TLL), Landesamt für Verbraucherschutz, Landwirtschaft und Flurneuordnung, Brandenburg.

Jones, O.R., (1984). Yield, water-use efficiency, and oil concentration and quality of dryland sunflower grown in the southern high plains. Agron. J. 76, 229-235.

Käb, H. (2001) Marktanalyse: Industrielle Einsatzmöglichkeiten von High Oleic Pflanzenölen. In Gülzower Fachgespräche: Band 19 Herausgeber: FNR

Kandel, H. (2006) Cropping Issues in Northwest Minnesota, Volume 3 Issue 10, 25 July 2006, Northwest Research \& Outreach Center.

Kannaiyan, S. (2003) Inoculant production in developing countries - problems, potentials and success. In: Hardarson G, Broughton WJ (Eds.), Maximising the use of biological nitrogen fixation in agriculture. Kluwer Academic Publishers. The Netherlands. pp. 187- 198.

Kedera, J. (1997) Plant Diseases - Oil Seed Plants. Review of Kenyan Agricultural Research 30: 34-36.

Kennedy, I.R. and Tchan, Y.T. (1992) Biological nitrogen fixation in nonleguminous field crops: Recent advances. Plant and Soil 141: 93- 118.

Kessmann, H., Oostendorp, M., Ruess, W., Staub, T., Kunz, W. and Ryals, J. (1996) Systemic activated resistance - a new technology for plant disease control. Pesticide Outlook. June, 1996, 256-257.

Kessmann, H., Staub, T., Ligon, J., Oostendorp, M. and Ryals, J. (1994) Activation of systemic acquired disease resistance in plants. Europ. J. Plant Pathol. 100:359-369.

Kiraly, Z. (1976) Plant disease resistance as influenced by biochemical effects of nutrients in fertilizers. Proc. 12th Colloqu. Int. Potash Inst. Bern: Fertilizer Use and Plant Health, p. 33-46.

Kogel, K.H. and Langen, G. (2005) Induced resistance and gene expression in cereals, Cellular Microbiology, 7 (11):1555-1564 
Kücke, M. (2003) Ertrag und Kornqualität von Winterweizen und Winterroggen nach $\mathrm{N}$-Injektionsdüngung - Feldversuchsergebnisse 2001. In: Anbauverfahren mit N-Injektion (CULTAN), Ergebnissen, Persperktiven, Erfahrungen. Hrsg: Martin Kücke. Landbauforschung Völkenrode FAL, Sonderheft 245, 69-80.

Kücke, M. and Greef, J. M. (2006) Experimental Results and Practical Experiences with the Fluid Fertilizers Point Injection Fertilization in Europe and Potentials to Optimize Fertilization and to Minimize Environmental Pollution, $18^{\text {th }}$ World Congress of Soil Science, July 9-15, 2006, Pennsylvania, USA, 170- 22.

Lawton, K., Friedrich, L., Hunt, M. K., Weymann, T., Delaney, H. and Kessmann, T. S. and Ryals, J. (1996). Benzothiadiazole induces disease resistance in Arabidopsis by activation of the systemic acquired resistance signal transduction pathway. Plant J. 10:71-82.

Lazar, A.L., Georgescu, T., Hatman, M., Cretu, A., Marquard, R. and Schlösser, E. (1986) Einfluss von Stengel- und Korbbefall von Sonnenblumen durch Sclerotinia sclerotiorum (Lib.) de Bary auf die Qualität von Sonnenblumenkernen. Giessener Abhandl. z. Agrar- und Wirtschaftsforschung des europäischen Ostens, Bd. 140, 85-91.

Leite, M. V. B. C. R., de Olivera, F. M. \& Castigloni, V. B. R. (2000) Occurrence of Sclerotinia sclerotiorum rot in sunflower fields sowed after harvesting of summer crops, in the state of Parana, Brazil. In: Proc. 15th Int. Sunflower Conference, 12-15 June, Toulouse, France. Int. Sunflower Association, Paris, France. 2:7-14.

LFL, (2006) Sonnenblumen zur Kornnutzung (Helianthus annuus L.), LfL Information, Bayerische Landesanstalt für Landwirtschaft, Institut für Pflanzenbau und Pflanzenzüchtung, Freising-Weihenstephan, 7. Auflage.

Lifshitz, R., Kloepper, J.W., Kozlowksi, M., Simson, C., Carlson, J., Tipping, B. and Zaleska, I. (1987) Growth promotion of canola (rapeseed) seedling by a strain of Pseudomonas putida under gnotobiotic condition. Can J Microbiol 33:390-395

Liu, L., Kloepper, J.W., Tuzun, S. (1995) Induction of systemic resistance in cucumber against fusarium wilt by plant growth-promoting rhizobacteria. Phytopathology 85: 695- 98

Lopez, A.M.Q., Lucas, J.A. (2002) Effects of plant defence activators on anthracnose disease of cashew. Eur J Plant Pathol 108:409-420.

Louws, F.J., Wilson, M., Campbell, H.L., Cuppels, D.A., Jones, J.B., Shoemaker, P.B., Sahin, F. and Miller, S.A. (2001) Field control of bacterial spot and bacterial speck of tomato using a plant activator. Plant Disease, 85, 481-488.

Luchese, R. H., and Harrigan, W. F. (1993). Biosynthesis of aflatoxin-the role of nutritional factors. J. Appl. Bacteriol. 74: 5-14.

Lühs, W. and Friedt, W. (1999) Anbauempfehlungen für hochölsäurehaltige Sonnenblumen (HO-Sonnenblumen) in Deutschland. Herausgeber: Dr. B. 
Schlüter, Bundesforschungsanstalt für Landwirtschaft, Institut für Pflanzenbau und Grünlandwirtschaft. 4. erweiterte Auflage.

Malamy, J., Carr, J.F., Klessing, D.F., Raskin, I. (1990) Salicylic acid: a likely endogenous signal in the resistance response of tobacco to viral infection. Science 250:1002-1004.

Maleck, K., Levine, A., Eulgem, T., Morgan, A., Schmid, J., LawHeil, K.A., Dangl, J.L., and Dietrich, R.A.. (2000). The transcriptome of Arabidopsis thaliana during systemic acquired resistance. Nat. Genet. 26:403-410.

Marinelli, A., March, G.J., Rago, A. and Giuggia, J.. (1998) Assessment of crop loss in peanut caused by Sclerotinia sclerotiorum, S. minor, and Sclerotium rolfsii in Argentina. Int. J. Pest Manage. 44:251-254.

Marschner, H. (1995) Mineral Nutrition of Higher Plants. Academic Press, San Diego, CA.

Masirevic, S. and Gulya, T. J. (1992) Sclerotinia and Phomopsis-two devastating sunflower pathogens. Field Crop Research, 30:271-300.

Mendgen K., C.Struck, R. T.Voegele, and M.Hahn (2000) Biotrophy and rust haustoria. Physiol. Mol. Plant Pathol. 56:141-145.

Mercer, P. C., Hardwick, N .V., Fitt, B. D. L., Sweet, J. B. (1994). Diseases of linseed in the United Kingdom. Plant Varieties and Seeds 7:135-150.

Meyer, R., Baltensperger, D.D., Schlegelm, A.J., Krall, J.M., Lee, C. and Shroyer, J.P., (2005) High plains sunflower production handbook. Kansas State University Agricultural Experiment Station and Cooperative Extention Service, MF2384.1-4

Mielke, H. (2002) Pflanzenschutz bei Nachwachsenden Rohstoffen, Zuckerrübe, Ölund Faserpflanzen, Mitteilungen aus der Biologischen Bundesanstalt für landund Forstwirtschaft, Berlin-Dahlem, Heft 391, 50-59.

Miles, A. K., Willingham, S. L. and Cooke, A. W. (2004) Field evaluation of strobilurins and a plant activator for the control of citrus black spot. Aust. Plant Pathol. 33:371-378.

Monotti, M. (2003) Growing non-food sunflower in dryland conditions. Ital. J. Agron., 8, 1, 3-8

Monotti, M., Laureti, D., Conti, D., Pieri, S., Ridoni, G., Del Pino, A. M. (2003) Nuove varietà alto oleico di girasole. L'Informatore Agrario, LIX, 11, 43-47

Monotti, M., Pino, A. M. del, Laureti, D., Pieri, S., Conti, D., Ridoni, G. M. (2004) Productivity and quality characters of high oleic acid cultivars of sunflower. Informatore Agrario, 60: 57-61 
Müller-Sämann, K. M., Reinhardt, G., Vetter, R. and Gärtner S. (2003) Nachwachsende Rohstoffe in Baden-Württemberg: Identifizierung vorteilhafter Produktlinien zur stofflichen Nutzung unter besonderer Berücksichtigung umweltgerechter Anbauverfahren. Abschlussbericht, Förderzeichen: BWA 20002. 4-11.

Nelson, B., and Lamey, A. (2000). Sclerotinia Diseases of Sunflower. NDSU Extension Circular PP-840

Okon, Y., and Labandera-Gonzalez, C.A. (1994) Agronomic applications of Azospirillum: an evaluation of 20 years worldwide field inoculation. Soil Biol. Biochem. 26: 1591-1601.

Oostendorp, M., Kessmann, H., Friedrich, L., Geissmann, A., Görlach, J., Hengy, G., Nordmeyer, D., Reist, R., Ruess, W., and Staub, T. (1996): Influence of plant activator $\mathrm{BION} \otimes$ and of triazolefungicides on plant defence mechanisms. Gesunde Pflanze, 48, 260-264.

Oostendorp, M., Kunz, W., Dietrich, B., and Staub, T. (2001). Induced disease resistance in plants by chemicals. Eur. J. Plant Pathol. 107:19-28.

Paulitz, T.C. and Belanger, R.R. (2001) Biological control in greenhouse systems. Annu. Rev. Phytopathol. 39:103-33

Pereira, L.M., Sadras, V. O. and Trapani, N. (1999) Genetic improvement of sunflower in Argentina between 1930 and 1995. I. Yield and its components. Field Crops Research 62:157-166

Pereira, M. L., Berney, A., Hall, A.J. and Trápani, N. (2008) Contribution of preanthesis photoassimilates to grain yield: Its relationship with yield in Argentine sunflower cultivars released between 1930 and 1995. Field Crops Research. 105: $88-96$

Pinthus, M. J. (1963) Some environmental effects on the oil yield components of sunflower seeds. Plant Foods for Human Nutrition 9:328-336

Porter, I. J. and Clarke, R. G. (1992): Sclerotinia stem rot of sunflowers: the disease in perspective. Proceedings of the Australian Sunflower Association 9th Workshop, Yeppon, Australia: S. 64-68.

Prats, E., Bazzalo, M.E., Leon, A., Jorrin, J.V. (2003). Accumulation of soluble phenolic compounds in sunflower capitula correlates with resistance to Sclerotinia sclerotiorum. Euphytica. 132:321-329.

Prats, E., Rubiales, D., and Jorrin, J. (2002): Acibenzolar-S-methyl-induced resistance to sunflower rust (Puccinia helianthi) is associated with an enhancement of coumarins on foliar surface. Physiological and Molacular Plant Pathology, 60, 155-162.

Prins, T. W., Tudzynski, P., von Tiedemann, A., Tudzynski, B., ten Have, A., Hansen, M., Tenberge, K., and van Kan, J. A. L. (2000). Infection strategies 
of Botrytis cinerea and related necrotrophic pathogens. In J. W. Kronstad (ed.), Fungal pathology. Kluwer, Dordrecht, The Netherlands, 33-64

Rashid, K.Y. (2004): Can Sclerotinia head rot be managed by fungicide applications? Sunflower Research - Workshop, National Sunflower Association, Bismarck, ND, USA

Rashid, K.Y. (2005) Control of Sclerotinia Head Rot in Sunflower. Sunflower Research - Workshop, National Sunflower Association, Bismarck, ND, USA

Rashid, K.Y. (2005): Control of Sclerotinia head rot in sunflower. Sunflower Research - Workshop, National Sunflower Association, Bismarck, ND, USA

Rawson, H.M., Dunstone, R.L., Long, M.J., and Begg, J.E. (1984): Canopy development, light interception and seed production in sunflower as influenced by temperature and radiation. Aust.J.Plant Physiol. 11, 255-265.

Reinbrecht, C. and Claupein, W. (2004) Möglichkeiten des Anbaus alternativer Ölpflanzenarten-Bedeutung der Verwendung genetischer Ressourcen. In Onfarm-Erhaltung genetischer Ressourcen von Getreide und Ölpflanzen, Beispiele, Methoden, Ergebnisse. Tagung vom 04. bis 05. November 2004, ISBN: 3-00-016314-x, 77-89

Robertson, J.A., Chapman, G.W. Jr, Wilson, J.R., (1978) Relation of day after flowering to chemical composition and physiological maturity of sunflower seed. JAOCS 55, 266-269.

Robinson, R.G.. (1978). Sunflower science and technology. En: J. Carter (Ed.). Production and culture. Am. Soc. Agron. 19: 89-143.

Rondanini, D., Savin, R., and Hall, A.J., (2003) Dynamics of fruit growth and oil quality of sunflower (Helianthus annuus L.) exposed to brief intervals of high temperature during grain filling. Field Crops Research 83: 79-90.

Rönicke, S., Hahn, V., and Friedt, W. (2005): Resistance to Sclerotinia sclerotiorum of "high oleic" sunflower inbred lines. Plant Breeding 124, 376-381. Blackwell Verlag, Berlin

Ruess, W., Kunz, W., Staub, T., Poppinger, N. and Ahly-Goy, P. (1995): Plant activator CGA 245704, a new technology for disease management XIII. International Plant Protection Congress, The Hague. The Netherlands, 2/7/July, 1995.

Ruess, W., Kunz,W., Staub, T., Poppinger, N., and Ahly-Goy, P., (1995). Plant activator CGA 245704, a new technology for disease management XIII. International Plant Protection Congress, The Hague. The Netherlands, 2/7/July, 1995.

Rühl, G. F. (2003): Pflanzenbauliche Untersuchungen zur Ertragssicherung von HOSonnenblumen. Deutsch-Türkische Agrarforschung, 7. Symposium, Verband Deutsch-Türkischer Agrar- und Naturwissenschaftler. Ankara, Türkei 
Sadras, V.O., Trápani, N., Pereyra, V.R., López Pereira, M., Quiroz, F. and Mortarini, M. (2000). Intraspecific competition and fungal diseases as sources of variation in sunflower yield. Field Crops Res. 67:51-58

Salera, E., Baldini, M. (1998) Performance of high and low oleic acid hybrids of sunflower under different environmental conditions. Note II. Helia 21 (28), 5568.

Sauerborn, J., Buschmann, H., Ghiasi, K.G., and. Kogel, K.H. (1999): Benzothiadiazole activated resistance in sunflower (Helianthus annuus) to the root-parasitic weed Orobanche cumuna. The American Phytopathological Society, 92:59-64.

Sauerborn, J., Buschmann, H., Ghiasvand Ghiasi, K, Kogel, K-H. (2002) Benzothiadiazole activates resistance in sunflower (Helianthus annuus) to the root-parasitic weed Orobanche cumana. Phytopathology 92: 59-64

Schlüter, B (2001) Ausdehnung des Anbaus von High-Oleic-Sonnenblumen in Deutschland. Abschlussbericht, Fördernummer: 97NR056-F

Schlüter, B. and Rühl, G. (1999) Ertragssicherung bei High-Oleic-Sonnenblumen durch pflanzenbauliche Maßnahmen. Abschlussbericht

Schöber-Butin, B., Garbe, V., Bartels, G. (1999): Farbatlas Krankheiten und Schädlinge an landwirtschaftlichen Kulturpflanzen. Verlag Eugen Ulmer, Stuttgart, 203-218.

Schumacher, F.J. (2001): Praxiserfahrungen mit der Düngung nach dem CULTANVerfahren am Niederrhein. Ergebnissen, Persperktiven, Erfahrungen. Hrsg: Martin Kücke. Landbauforschung Völkenrode FAL, Sonderheft 245, 61-68.

Schuster, W.H. (1993): Die Züchtung der Sonnenblume (Helianthus annuus L.). Fortschritte der Pflanzenzüchtung; Heft 14, Paul Parey Verlag, Berlin-Hamburg.

Schweizer, P., Hunziker, W. and Mosinger, E., (1989) cDNA cloning in vitro transcription and partial sequence analysis of mRNA from winter wheat (Triticum aestivum L.) with induced resistance to Erysiphe graminis f. sp. tritici. Plant Mol. Biol. 12, 643-654.

Shiroya, M. (1977) Translocation of organic substances in sunflower I. Downward translocation of ${ }^{14} \mathrm{C}$-sucrose. Plant and Cell Physiology 18: 633-639

Si-Ammour, A., Mauch-Mani, B., and Mauch, F. (2003). Quantification of induced resistance against Phytophthora species expressing GFP as a vital marker: Beta-aminobutyric acid but not BTH protects potato and Arabidopsis from infection. Mol. Plant Pathol. 4:237-248.

Siegrist, J., Glenewinkel, D., Kolle, C., Schmidkte, M., (1997) Chemically induced resistance in green bean against bacterial and fungal pathogens. J Plant Dis Protect 104:599-610. 
Slatter, J. S. (1992): Sunflower planting strategies to minimise disease losses. Proceedings of the Australian Sunflower Association 9th Workshop, Yeppon, Queensland: S. 86-93.

Solomon P.S., Tan K.C., and Oliver R.P. (2003) The nutrient supply of pathogenic fungi; a fertile field for study. Mol Plant Pathol 4: 203-210

Sommer, K. (1992): Controlled uptake long term ammonia nutrition for plants "CULTAN" cropping system. In: Nitrogen cycling and leaching in cool and wet regions of Europe. COST 814, Workshop. Ed: E. Francois, K. Pithan and N. Batriaux-Thill, Commission of the European Communities, Belgium. 58-63.

Sommer, K. (2001): Grunlagen des “CULTAN"-Verfahrens. In: Anbauverfahren mit N-Injektion (CULTAN). Ergebnissen, Persperktiven, Erfahrungen. Hrsg: Martin Kücke. Landbauforschung Völkenrode FAL, Sonderheft 245, 1-22.

Sommer, K. and Mertz, M. (1974): Wachstum, Ertrag und Mineralstoffaufnahme von Pflanzen- beeinflusst durch Ammonium oder Nitrat. Landwirtsch.Forsch. 27, 1974, 8-30.

Sommer, K. and von Fischer, F. (1993): Ergebnisse aus 6-jährigen Fruchtfolgeversuchen: Z-Rüben, W-Weizen und W-Gerste bei einer N-Düngung nach dem CULTAN-Verfahren. VDLUFA-Schriftenreihe 37, Kongreßband. 75-78.

Soylu, E. M., Baysal, Ö. and Soylu, S. (2003): Induction of disease resistance and antioxidant enzymes by acibenzolar-S-methyl against bacterial canker (Clavibacter Michiganensis ssp. Michiganensis) in tomato. Journal of Plant Pathology, 85, 175-181.

Sticher, L., Mauch-Mani, B., Metraux, J.P. (1997): Systematic acquired resistance. Annual Review of Phytopathology 35, 235-270.

Sumner, M.E. (1990) Crop responses to Azospirillum inoculation. Adv. Soil Sci. 12: 53-123.

Syngenta. (2001): Media highlights: The Plant Activator, Syngenta Crop Protection, Inc., Greensboro, N.C. http://www.syngentacropprotection-us.com/

Termorshuizen, A. J. (2002): Cultural control. In: Waller, J. M.; Lenné, J. M. \& Waller, S. J. (Eds.): Plant Pathologist's Pocketbook. 3rd Edition, CAB International Publishing, Wallingford Oxon, UK. S. 318-327.

Tonev, K. T. (2006) Agronomy characteristics of high yielding sunflower crop, (Resume of Research for Habilitation) Res. Commun. of U.S.B. branch Dobrich Web-based version, AGRARIAN SCIENCES. 8:162-173

Tosi, L., Luigetti, R., and Zazzeroni, A. (1999) Benzothiadiazole induces resistance to Plasmopara helianthi in sunflower plants. J. Phytopathol. 147:365-370. 
Tourvieille de Labrouhe, D., Mestries, E. and Vear ,F. (1996): Multilocal Sclerotinia sclerotiorum Resistance Test. In: A. Pouzet (ed.), ISA Symposium I: Diseases Tolerance in Sunflower, 71-76. Beijing, China.

Trémoliéres, A., Dubacq, J.P., Drapier, D., (1982.) Unsaturated fatty acids in maturing seeds of sunflower and rape: regulation by temperature and light intensity. Phytochemistry 21, 1-45.

UFOP (2003): Anbauratgeber Sonnenblumen, UFOP Praxisinformation, Aktualisierte Auflage Union zur Förderung von Öl- und Proteinpflanzen E.V. Berlin.

UFOP (2006): Sortenversuche 2005 mit Winterraps, Futtererbsen und Sonnenblumen, Union zur Förderung von Öl- und Proteinpflanzen e. V. UFOP Schriften Heft 30.

UFOP (2007): Sortenversuche 2006 mit Winterraps und Sonnenblumen, Union zur Förderung von Öl- und Proteinpflanzen e. V. UFOP Schriften Heft 31.

Uknes, S., Mauch-Mani, B., Moyer, M., Potter, S., Williams, S., Dincher, S., Chandler, D., Slusarenko, A., Ward, E., and Ryals, J. (1992). Acquired resistance in Arabidopsis. Plant Cell 4:645-656.

Unger, P.W., (1982) Time and frequency of irrigation effects on sunflower production and water use. Soil Sci. Soc. Am. J. 46, 1072-1076.

Vallad, G.E., Goodman, R.M. (2004) Systemic acquired resistance and induced systemic resistance in conventional agriculture. Crop Sci 44:1920-1934.

van Kan,. J.A.L (2006) Licensed to kill: the lifestyle of a necrotrophic plant pathogen. Trends Plant Sci. 11, 247-253.

Vetter, R. (1996) Anbaueignung neuer Ölpflanzen als alternative Kulturen in der Rheinebene, ITADA Projekt Nr. 9, Abschlußbericht, IfUL Müllheim

Ward, E.R., Uknes, S.J., Williams, S.C., Dincher, S.S., Wiederhold, D.L., Alexander, D.C., Ahl-Goy, P., Metraux, J.-P. and Ryals, J.A. (1991). Coordinate gene activity in response to agents that induce systemic acquired resistance. Plant Cell 3:1085-1094.

Wei, G., Kloepper, J.W., Tuzun, S. (1996) Induced systemic resistance to cucumber diseases and increased plant growth by plant growth-promoting rhizobacteria under field conditions. Phytopathology 86: 221- 24

Weimar, S. (2001): Untersuchungen zur N-Düngung nach dem CULTAN-Verfahren bei Getreide, Zuckerrüben und Kartoffeln in Rheinland-Pfalz. Ergebnissen, Persperktiven, Erfahrungen. Hrsg: Martin Kücke. Landbauforschung Völkenrode FAL, Sonderheft 245, 23-44.

Weimar, S., Anderl, A. and Goetz, M. (2007) Versuchsbericht Sonnenblumen 2006, Versuchswesen Pflanzenbau Rheinland-Pfalz, Ministerium für Wirtschaft, Verkehr, Landwirtschaft und Weinbau, Dienstleistungszentren Ländlicher Raum 
(DLR) Landwirtschaftliche Untersuchungs- und Forschungsanstalt (LUFA) Speyer, Versuchsserien: Landessortenversuche Sonnenblumen, EUSortenprüfung Sonnenblumen, Sortenprüfung Sonnenblumen (high-oleic) Bericht 15/2006.

Whipps, J.M. (2001) Microbial interactions and biocontrol in the rhizosphere. J. Exp. Bot. 52:487-511

Wiese J., Bagy M. M. K., Schubert S. (2003) Soil properties, but not plant nutrients $(\mathrm{N}, \mathrm{P}, \mathrm{K})$ interact with chemically induced resistance against powdery mildew in barley. Journal of Plant Nutrition and Soil Science. 166, 379-384

Wrather, J.A., Anderson, T.R., Arsyad, D.M., Tan, Y., Ploper, L.D., Porta- Puglia, A., Ram, H.H. and Yorinori, J.T. (2001), Soybean disease loss estimates for the top ten soybean-producing counries in 1998, Canadian Journal of Plant Pathology, 23:115-121

Zeller, V. and Zeller, W. (1998) Studies on control of fire blight with plant activator BION. Acta Horticult. 489, 639-645.

Zeller, V.W. and Laux, P. (2002): Perspectives of fire blight control using biological and other alternative preparations, GESUNDE PFLANZEN, 54. Jahrg., Heft 3+4, 86-91.

Zeller, W. and Zeller, V. (1999) Control of fire blight with the plant activator BION®. Proc.of the $8^{\text {th }}$ Int.Workshop on Fire Blight, 639-645.

Zhu, J.Z., Qiu, X., Moore, P.H., Borth, W., Hu, J., Ferreira, S., Albert, H.H. (2003) Systemic acquired resistance induced by BTH in papaya. Physiol Mol Plant Pathol 63:237-248.

Zimmer, D.E. and Hoes, J.A. (1978) Diseases. In: Carter, J.F.: Sunflower science and Technology, Agr.Soc.Am.Agron, Madison/Wisc., 225-262. 


\section{APPENDIX}

Table A.1: Pearson's correlation coefficients between all evaluated parameters across all varieties in Braunschweig.

\begin{tabular}{|c|c|c|c|c|c|c|c|c|}
\hline & \multicolumn{8}{|c|}{ Evaluated parameters $(\mathrm{N}=10)$} \\
\hline & $\begin{array}{c}\text { Fungal } \\
\text { infection } \\
\text { rate }\end{array}$ & $\begin{array}{l}\text { Plant } \\
\text { height }\end{array}$ & $\begin{array}{l}\text { Head } \\
\text { diameter }\end{array}$ & $\begin{array}{l}\text { Grain } \\
\text { yield }\end{array}$ & TSW & $\begin{array}{c}\text { Oil } \\
\text { content }\end{array}$ & $\begin{array}{l}\text { Oleic } \\
\text { acid }\end{array}$ & $\begin{array}{c}\text { Linoleic } \\
\text { acid }\end{array}$ \\
\hline \multicolumn{9}{|c|}{ Olsavil } \\
\hline Plant height & 0.09 & 1.00 & & & & & & \\
\hline Head diameter & -0.24 & 0.21 & 1.00 & & & & & \\
\hline Grain yield & -0.26 & -0.30 & 0.25 & 1.00 & & & & \\
\hline TSW & 0.03 & 0.59 & 0.22 & 0.10 & 1.00 & & & \\
\hline Oil content & $0.79^{* *}$ & 0.27 & -0.01 & -0.57 & 0.19 & 1.00 & & \\
\hline Oleic acid & $0.90^{* * *}$ & 0.26 & -0.22 & -0.25 & 0.25 & $0.88^{* * *}$ & 1.00 & \\
\hline Linoleic acid & $-0.64^{*}$ & 0.54 & 0.57 & -0.11 & 0.33 & -0.35 & -0.59 & 1.00 \\
\hline \multicolumn{9}{|c|}{ PR64H41 } \\
\hline Plant height & 0.10 & 1.00 & & & & & & \\
\hline Head diameter & 0.48 & 0.44 & 1.00 & & & & & \\
\hline Grain yield & $-0.70^{*}$ & 0.07 & 0.19 & 1.00 & & & & \\
\hline TSW & -0.49 & 0.55 & 0.41 & $0.85^{* *}$ & 1.00 & & & \\
\hline Oil content & -0.02 & -0.16 & 0.43 & 0.55 & 0.44 & 1.00 & & \\
\hline Oleic acid & 0.55 & $-0.67^{*}$ & -0.25 & -0.59 & $-0.78^{* *}$ & -0.05 & 1.00 & \\
\hline Linoleic acid & -0.35 & $0.68^{*}$ & 0.50 & $0.64^{*}$ & $0.86^{* *}$ & 0.34 & $-0.94^{* * *}$ & 1.00 \\
\hline \multicolumn{8}{|c|}{ Aurasol } & 0.33 \\
\hline Plant height & -0.20 & 1.00 & & & & & & \\
\hline Head diameter & -0.32 & -0.29 & 1.00 & & & & & \\
\hline Grain yield & $-0.84^{* *}$ & 0.20 & $0.66^{*}$ & 1.00 & & & & \\
\hline TSW & $-0.65^{*}$ & 0.24 & $0.79^{* *}$ & $0.91^{* * *}$ & 1.00 & & & \\
\hline Oil content & -0.05 & $-0.70^{*}$ & 0.36 & 0.11 & 0.14 & 1.00 & & \\
\hline Oleic acid & 0.50 & $-0.94^{* * *}$ & 0.21 & -0.39 & -0.37 & 0.60 & 1.00 & \\
\hline Linoleic acid & -0.44 & $0.94^{* * *}$ & -0.20 & 0.36 & 0.40 & -0.50 & $-0.98^{* * *}$ & 1.00 \\
\hline Stearic acid & $-0.76^{*}$ & 0.50 & 0.13 & $0.70^{*}$ & 0.46 & -0.49 & $-0.66^{*}$ & 0.53 \\
\hline
\end{tabular}
${ }^{*},{ }^{* *},{ }^{* * *}$ Significant at the $0.05,0.01$ and 0.001 probability levels respectively. 
Table A.2: Pearson's correlation coefficients between all evaluated parameters across all varieties in Eckartsweier.

\begin{tabular}{|c|c|c|c|c|c|}
\hline & \multicolumn{5}{|c|}{ Evaluated parameters $(\mathrm{N}=10)$} \\
\hline & $\begin{array}{c}\text { Fungal } \\
\text { infection rate }\end{array}$ & $\begin{array}{l}\text { Grain } \\
\text { yield }\end{array}$ & $\begin{array}{c}\text { Oil } \\
\text { content }\end{array}$ & $\begin{array}{l}\text { Oleic } \\
\text { acid }\end{array}$ & $\begin{array}{c}\text { Linoleic } \\
\text { acid }\end{array}$ \\
\hline \multicolumn{6}{|c|}{ Olsavil } \\
\hline Grain yield & $-0.64^{*}$ & 1.00 & & & \\
\hline Oil content & 0.49 & -0.28 & 1.00 & & \\
\hline Oleic acid & -0.27 & -0.18 & -0.12 & 1.00 & \\
\hline Linoleic acid & 0.58 & -0.04 & 0.34 & $-0.88^{* * *}$ & 1.00 \\
\hline Stearic acid & 0.21 & -0.10 & -0.08 & $-0.71^{*}$ & 0.50 \\
\hline \multicolumn{6}{|c|}{ PR64H41 } \\
\hline Grain yield & $-0.64^{*}$ & 1.00 & & & \\
\hline Oil content & 0.21 & -0.35 & 1.00 & & \\
\hline Oleic acid & $-0.67^{*}$ & 0.60 & -0.39 & 1.00 & \\
\hline Linoleic acid & $0.69^{*}$ & $-0.65^{*}$ & 0.41 & $-1.00^{* * *}$ & 1.00 \\
\hline Stearic acid & 0.54 & -0.21 & 0.05 & -0.60 & 0.56 \\
\hline \multicolumn{6}{|c|}{ Aurasol } \\
\hline Grain yield & -0.57 & 1.00 & & & \\
\hline Oil content & -0.55 & 0.45 & 1.00 & & \\
\hline Oleic acid & -0.18 & -0.05 & -0.18 & 1.00 & \\
\hline Linoleic acid & 0.30 & -0.14 & 0.09 & $-0.98^{* * *}$ & 1.00 \\
\hline Stearic acid & 0.27 & 0.19 & 0.04 & $-0.76^{*}$ & $0.67^{*}$ \\
\hline
\end{tabular}

Table A.3: Oil content and composition in dependent of the experimental year

\begin{tabular}{lllll}
\hline & $\begin{array}{c}\text { Oil } \\
\text { content }\end{array}$ & $\begin{array}{c}\text { Oleic } \\
\text { acid }\end{array}$ & $\begin{array}{c}\text { Linoleic } \\
\text { acid }\end{array}$ & $\begin{array}{c}\text { Stearic } \\
\text { acid }\end{array}$ \\
\hline Braunschweig & & & & \\
\hline 2003 & $49.3 \mathrm{a}$ & $88.9 \mathrm{a}$ & $3.2 \mathrm{~b}$ & $2.6 \mathrm{a}$ \\
2004 & $50.6 \mathrm{a}$ & $89.2 \mathrm{a}$ & $3.9 \mathrm{~b}$ & $2.0 \mathrm{~b}$ \\
2005 & $49.7 \mathrm{a}$ & $86.9 \mathrm{~b}$ & $6.0 \mathrm{a}$ & $2.5 \mathrm{a}$ \\
Eckartsweier & & & & \\
\hline 2003 & $51.3 \mathrm{ab}$ & $89.0 \mathrm{a}$ & $3.6 \mathrm{~b}$ & $2.3 \mathrm{~b}$ \\
2004 & $50.3 \mathrm{~b}$ & $88.8 \mathrm{a}$ & $4.1 \mathrm{~b}$ & $2.4 \mathrm{ab}$ \\
2005 & $51.8 \mathrm{a}$ & $87.3 \mathrm{~b}$ & $5.6 \mathrm{a}$ & $2.6 \mathrm{a}$ \\
\hline
\end{tabular}

Table A.4: Influence of fungicide application on yield and quality parameters in all three varieties in preliminary field experiments at Braunschweig.

\begin{tabular}{lrrrrrr}
\hline & \multicolumn{2}{c}{ OLSAVIL } & \multicolumn{2}{c}{ PR64H61 } & \multicolumn{2}{c}{ AURASOL } \\
& Control & Fungicide & Control & Fungicide & Control & Fungicide \\
\hline Fungal infection (\%) & $100.0 \mathrm{a}$ & $100.0 \mathrm{a}$ & $80.2 \mathrm{a}$ & $86.0 \mathrm{a}$ & $40.7 \mathrm{a}$ & $49.4 \mathrm{a}$ \\
Grain yield (dt/ha) & $33.9 \mathrm{a}$ & $28.2 \mathrm{a}$ & $26.4 \mathrm{a}$ & $28.2 \mathrm{a}$ & $28.1 \mathrm{a}$ & $34.2 \mathrm{a}$ \\
Plant height (cm) & $166.8 \mathrm{a}$ & $171.4 \mathrm{a}$ & $145.7 \mathrm{a}$ & $146.3 \mathrm{a}$ & $140.8 \mathrm{a}$ & $151.4 \mathrm{a}$ \\
Head diameter (cm) & $17.5 \mathrm{a}$ & $16.8 \mathrm{a}$ & $17.3 \mathrm{a}$ & $18.3 \mathrm{a}$ & $15.5 \mathrm{a}$ & $15.2 \mathrm{a}$ \\
TSW $^{*}(\mathrm{~g})$ & $63.3 \mathrm{a}$ & $63.7 \mathrm{a}$ & $66.6 \mathrm{a}$ & $73.5 \mathrm{a}$ & $63.1 \mathrm{a}$ & $65.4 \mathrm{a}$ \\
Oil content (\%) & $53.9 \mathrm{a}$ & $52.9 \mathrm{a}$ & $52.4 \mathrm{a}$ & $50.4 \mathrm{a}$ & $50.9 \mathrm{a}$ & $49.9 \mathrm{a}$ \\
Oleic acid (\%) & $92.8 \mathrm{a}$ & $92.7 \mathrm{a}$ & $91.6 \mathrm{a}$ & $90.7 \mathrm{a}$ & $85.4 \mathrm{a}$ & $86.7 \mathrm{a}$ \\
Linoleic acid (\%) & $2.1 \mathrm{a}$ & $2.3 \mathrm{a}$ & $2.9 \mathrm{a}$ & $3.7 \mathrm{a}$ & $7.5 \mathrm{a}$ & $6.1 \mathrm{a}$ \\
Stearic acid (\%) & $1.2 \mathrm{a}$ & $1.2 \mathrm{a}$ & $1.5 \mathrm{a}$ & $1.7 \mathrm{a}$ & $2.8 \mathrm{a}$ & $2.9 \mathrm{a}$ \\
\hline
\end{tabular}

${ }^{*}$ TSW: Thousand seed weight. 


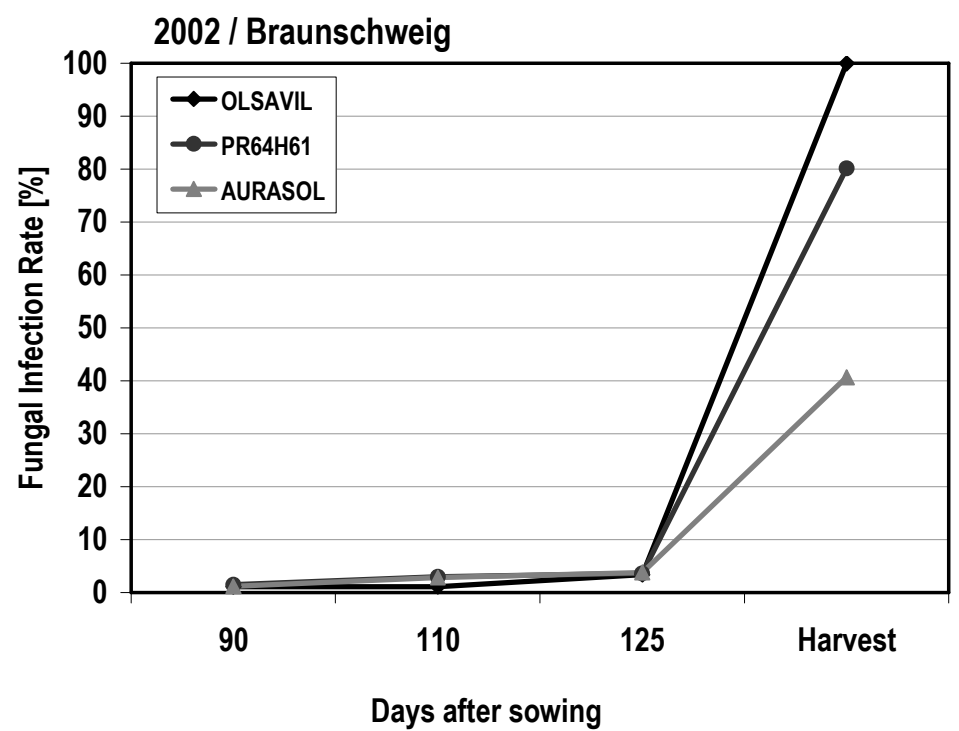

Figure A.1: Fungal infection rates (\%) at four different sunflower growth stages of three varieties in 2002 at Braunschweig (Harvest: 155 \pm 5 days after sowing,

Table A.5: Influence of $\mathrm{BION}^{\circledR}$ seed treatment on oil content and composition (\%) for all three varieties at Braunschweig in 2003.

\section{Oil content Oleic acid Linoleic acid Stearic acid}

\begin{tabular}{|c|c|c|c|c|}
\hline \multirow{2}{*}{\multicolumn{5}{|c|}{ Olsavil }} \\
\hline & & & & \\
\hline Control & $46.8 \mathrm{a}$ & $89.8 a$ & $2.7 a$ & $1.9 a$ \\
\hline $\mathrm{BION}^{\circledR}$-Seed $25 \mathrm{ppm}$ & $48.4 a$ & $90.3 a$ & $2.4 a$ & $1.8 \mathrm{a}$ \\
\hline BION $^{\circledR}$-Seed $250 \mathrm{ppm}$ & $48.8 a$ & $90.5 a$ & $2.3 a$ & $1.8 a$ \\
\hline \multicolumn{5}{|l|}{ PR64H61 } \\
\hline Control & $49.9 a$ & $88.3 a$ & $3.6 a$ & $2.7 a$ \\
\hline $\mathrm{BION}^{\circledR}$-Seed $25 \mathrm{ppm}$ & $52.6 a$ & $87.9 a$ & $4.4 a$ & $2.4 a$ \\
\hline BION $^{\circledR}$-Seed $250 \mathrm{ppm}$ & $51.8 \mathrm{a}$ & $88.2 a$ & $4.1 a$ & $2.4 a$ \\
\hline \multicolumn{5}{|l|}{ Aurasol } \\
\hline Control & $51.1 \mathrm{a}$ & $88.6 a$ & $3.2 a$ & $3.0 a$ \\
\hline BION $^{\circledR}$-Seed $25 p p m$ & $51.6 a$ & $88.3 a$ & $3.5 a$ & $2.8 \mathrm{a}$ \\
\hline $\mathrm{BION}^{\circledR}$-Seed $250 \mathrm{ppm}$ & $51.3 a$ & $88.0 \mathrm{a}$ & $3.7 a$ & $2.9 a$ \\
\hline
\end{tabular}

Table A.6: Influence of $\mathrm{BION}^{\circledR}$ seed treatment on oil content and composition (\%) for all three varieties at Braunschweig in 2004.

\begin{tabular}{|c|c|c|c|c|}
\hline & $\begin{array}{c}\begin{array}{c}\text { Oil content } \\
(\%)\end{array} \\
\end{array}$ & $\begin{array}{c}\begin{array}{c}\text { Oleic acid } \\
(\%)\end{array} \\
\end{array}$ & $\begin{array}{c}\begin{array}{c}\text { Linoleic acid } \\
(\%)\end{array} \\
\end{array}$ & $\begin{array}{c}\text { Stearic acid } \\
(\%)\end{array}$ \\
\hline \multicolumn{5}{|l|}{ Olsavil } \\
\hline Control & $51.5 a$ & $91.6 a$ & $2.5 a$ & $1.4 a$ \\
\hline BION $^{\circledR}$-Seed 25ppm & $52.5 a$ & $92.0 a$ & $2.2 a$ & $1.4 a$ \\
\hline BION $^{\circledR}$-Seed $250 p p m$ & $51.7 a$ & $91.5 a$ & $2.5 a$ & $1.4 a$ \\
\hline \multicolumn{5}{|l|}{ PR64H61 } \\
\hline Control & $50.4 a$ & $88.0 a$ & $4.7 a$ & $2.1 a$ \\
\hline $\mathrm{BION}^{\circledR}$-Seed 25ppm & $49.5 a$ & $88.7 a$ & $3.8 a$ & $2.2 a$ \\
\hline $\mathrm{BION}^{\circledR}$-Seed $250 \mathrm{ppm}$ & $50.1 \mathrm{a}$ & $88.2 a$ & $4.6 a$ & $2.0 a$ \\
\hline \multicolumn{5}{|l|}{ Aurasol } \\
\hline Control & $49.7 a$ & $87.9 a$ & $4.3 a$ & $2.5 a$ \\
\hline $\mathrm{BION}^{\circledR}$-Seed 25ppm & $49.3 a$ & $88.2 a$ & $4.1 a$ & $2.5 a$ \\
\hline $\mathrm{BION}^{\circledR}$-Seed 250ppm & $48.8 \mathrm{a}$ & $88.3 a$ & $3.9 a$ & $2.5 a$ \\
\hline
\end{tabular}


Table A.7: Influence of $\mathrm{BION}^{\circledR}$ seed treatment on oil content and composition (\%) conditions for all three varieties at Eckartsweier in 2004.

\begin{tabular}{|c|c|c|c|c|}
\hline & $\begin{array}{c}\text { Oil content } \\
(\%)\end{array}$ & $\begin{array}{c}\text { Oleic acid } \\
(\%)\end{array}$ & $\begin{array}{c}\text { Linoleic acid } \\
(\%)\end{array}$ & $\begin{array}{c}\text { Stearic acid } \\
(\%)\end{array}$ \\
\hline \multicolumn{5}{|l|}{ Olsavil } \\
\hline Control & $51.5 a$ & $91.3 a$ & $2.3 a$ & $1.8 a$ \\
\hline $\mathrm{BION}^{\circledR}$-Seed 25ppm & $50.6 a$ & $91.2 \mathrm{a}$ & $2.3 a$ & $1.7 a$ \\
\hline BION $^{\circledR}$-Seed 250ppm & $51.3 a$ & $91.0 \mathrm{a}$ & $2.4 a$ & $1.7 a$ \\
\hline \multicolumn{5}{|l|}{ PR64H61 } \\
\hline Control & $49.8 a$ & $85.8 a$ & $6.3 a$ & $2.8 a$ \\
\hline $\mathrm{BION}^{\circledR}$-Seed 25ppm & $49.1 a$ & $86.8 a$ & $5.4 a$ & $2.7 a$ \\
\hline $\mathrm{BION}^{\circledR}$-Seed 250ppm & $50.1 a$ & $87.4 a$ & $4.9 a$ & $2.6 a$ \\
\hline \multicolumn{5}{|l|}{ Aurasol } \\
\hline Control & $49.5 a$ & $89.1 a$ & $3.5 a$ & $2.6 \mathrm{~b}$ \\
\hline $\mathrm{BION}^{\circledR}$-Seed 25ppm & $48.9 a$ & $87.6 a$ & $4.2 a$ & $3.2 a$ \\
\hline $\mathrm{BION}^{\circledR}$-Seed 250ppm & $48.8 \mathrm{a}$ & $87.6 a$ & $4.2 a$ & $3.1 \mathrm{ab}$ \\
\hline
\end{tabular}

Table A.8: Influence of $\mathrm{BION}^{\circledR}$ seed treatment on oil content and composition (\%) for all three varieties at Eckartsweier in 2005.

\begin{tabular}{|c|c|c|c|c|}
\hline & $\begin{array}{c}\text { Oil content } \\
(\%)\end{array}$ & $\begin{array}{c}\text { Oleic acid } \\
(\%)\end{array}$ & $\begin{array}{c}\text { Linoleic acid } \\
(\%)\end{array}$ & $\begin{array}{c}\text { Stearic acid } \\
(\%)\end{array}$ \\
\hline \multicolumn{5}{|l|}{ Olsavil } \\
\hline Control & $52.7 a$ & $90.8 a$ & $3.1 a$ & $1.7 a$ \\
\hline $\mathrm{BION}^{\circledR}$-Seed 25ppm & $52.5 a$ & $90.7 a$ & $3.2 a$ & $1.6 a$ \\
\hline BION $^{\circledR}-$ Seed 250ppm & $53.1 \mathrm{a}$ & $90.8 a$ & $3.2 a$ & $1.7 a$ \\
\hline \multicolumn{5}{|l|}{ PR64H61 } \\
\hline Control & $52.9 a$ & $84.2 a$ & $8.1 a$ & $2.8 a$ \\
\hline $\mathrm{BION}^{\circledR}$-Seed 25ppm & $52.2 a$ & $85.2 a$ & $7.2 a$ & $2.8 a$ \\
\hline BION $^{\circledR}$-Seed 250ppm & $52.0 a$ & $86.9 a$ & $5.5 a$ & $2.7 a$ \\
\hline \multicolumn{5}{|l|}{ Aurasol } \\
\hline Control & $49.7 a$ & $86.6 a$ & $5.5 a$ & $3.2 a$ \\
\hline $\mathrm{BION}^{\circledR}$-Seed 25ppm & $49.9 a$ & $87.2 a$ & $4.9 a$ & $3.1 \mathrm{a}$ \\
\hline $\mathrm{BION}^{\circledR}$-Seed 250ppm & $50.6 a$ & $86.1 \mathrm{a}$ & $6.0 a$ & $3.0 a$ \\
\hline
\end{tabular}

Table A.9: Influence of $\mathrm{BION}^{\circledR}$ leaf spray application on fungal infection rate (\%) for all three varieties at both experiment sites in 2003.

\begin{tabular}{|c|c|c|c|c|c|c|}
\hline & \multicolumn{3}{|c|}{ Braunschweig } & \multicolumn{3}{|c|}{ Eckartsweier } \\
\hline & Olsavil & PR64H41 & Aurasol & Olsavil & PR64H41 & Aurasol \\
\hline Control & $3.3 a$ & $0.9 a$ & $0.4 a$ & $2.5 a$ & $1.0 \mathrm{~b}$ & $1.0 \mathrm{a}$ \\
\hline $\mathrm{BION}^{\circledR}$ Spray 10ppm/BBCH09 & $0.0 \mathrm{a}$ & $3.0 a$ & $1.3 a$ & $3.0 a$ & $0.5 b$ & $0.9 a$ \\
\hline $\mathrm{BION}^{\circledR}$ Spray $125 \mathrm{ppm} / \mathrm{BBCH} 09$ & $4.0 \mathrm{a}$ & $3.5 a$ & $0.8 a$ & $0.4 a$ & $1.5 b$ & $2.5 a$ \\
\hline $\mathrm{BION}^{\circledR}$ Spray 250ppm/BBCH09 & $9.1 \mathrm{a}$ & $6.0 \mathrm{a}$ & $0.4 a$ & $2.0 \mathrm{a}$ & $6.5 a b$ & 3.0a \\
\hline $\mathrm{BION}^{\circledR}$ Spray 10ppm/BBCH16 & $0.0 \mathrm{a}$ & $0.4 a$ & $0.4 a$ & $4.5 a$ & $15.2 a$ & $1.0 \mathrm{a}$ \\
\hline $\mathrm{BION}^{\circledR}$ Spray $125 p p m / \mathrm{BBCH} 16$ & $0.5 a$ & $1.0 \mathrm{a}$ & $0.0 a$ & $2.5 a$ & $4.5 b$ & $0.5 a$ \\
\hline $\mathrm{BION}^{\circledR}$ Spray $250 \mathrm{ppm} / \mathrm{BBCH} 16$ & $1.7 \mathrm{a}$ & 3.0a & $0.0 a$ & $6.5 a$ & $1.0 \mathrm{~b}$ & $0.5 a$ \\
\hline BION ${ }^{\circledR}$ Spray 10ppm/BBCH51 & $0.5 a$ & $2.5 a$ & $0.9 a$ & $4.0 \mathrm{a}$ & $5.6 a b$ & $2.5 a$ \\
\hline $\mathrm{BION}^{\circledR}$ Spray $125 \mathrm{ppm} / \mathrm{BBCH} 51$ & $5.4 a$ & $0.5 a$ & $0.0 a$ & $4.5 a$ & $2.5 b$ & $0.0 a$ \\
\hline BION ${ }^{\circledR}$ Spray 250ppm/BBCH51 & $3.2 a$ & $2.7 a$ & $0.9 a$ & $0.5 a$ & $3.0 \mathrm{~b}$ & $1.0 \mathrm{a}$ \\
\hline $\mathrm{BION}^{\circledR}$ Spray 10ppm/BBCH65 & $5.7 a$ & $0.5 a$ & $0.0 a$ & $7.0 a$ & $2.9 \mathrm{~b}$ & $0.9 a$ \\
\hline $\mathrm{BION}^{\circledR}$ Spray $125 \mathrm{ppm} / \mathrm{BBCH} 65$ & $0.5 a$ & $2.2 a$ & $1.0 a$ & $3.5 a$ & $2.5 b$ & $0.4 a$ \\
\hline $\mathrm{BION}^{\circledR}$ Spray 250ppm/BBCH65 & $0.5 a$ & $9.1 \mathrm{a}$ & $0.4 a$ & $3.5 a$ & $5.1 \mathrm{ab}$ & $2.5 a$ \\
\hline $\mathrm{BION}^{\circledR}$ Spray 10ppm/BBCH69 & $1.7 a$ & $3.9 a$ & $2.8 a$ & $4.0 \mathrm{a}$ & $3.1 \mathrm{~b}$ & $0.0 \mathrm{a}$ \\
\hline $\mathrm{BION}^{\circledR}$ Spray $125 \mathrm{ppm} / \mathrm{BBCH} 69$ & $2.9 a$ & $0.4 a$ & $0.4 a$ & $3.5 a$ & $3.0 \mathrm{~b}$ & $1.0 \mathrm{a}$ \\
\hline $\mathrm{BION}^{\circledR}$ Spray 250ppm/BBCH69 & $1.9 a$ & $10.2 a$ & $0.4 a$ & $1.5 a$ & $2.5 b$ & $2.5 a$ \\
\hline
\end{tabular}




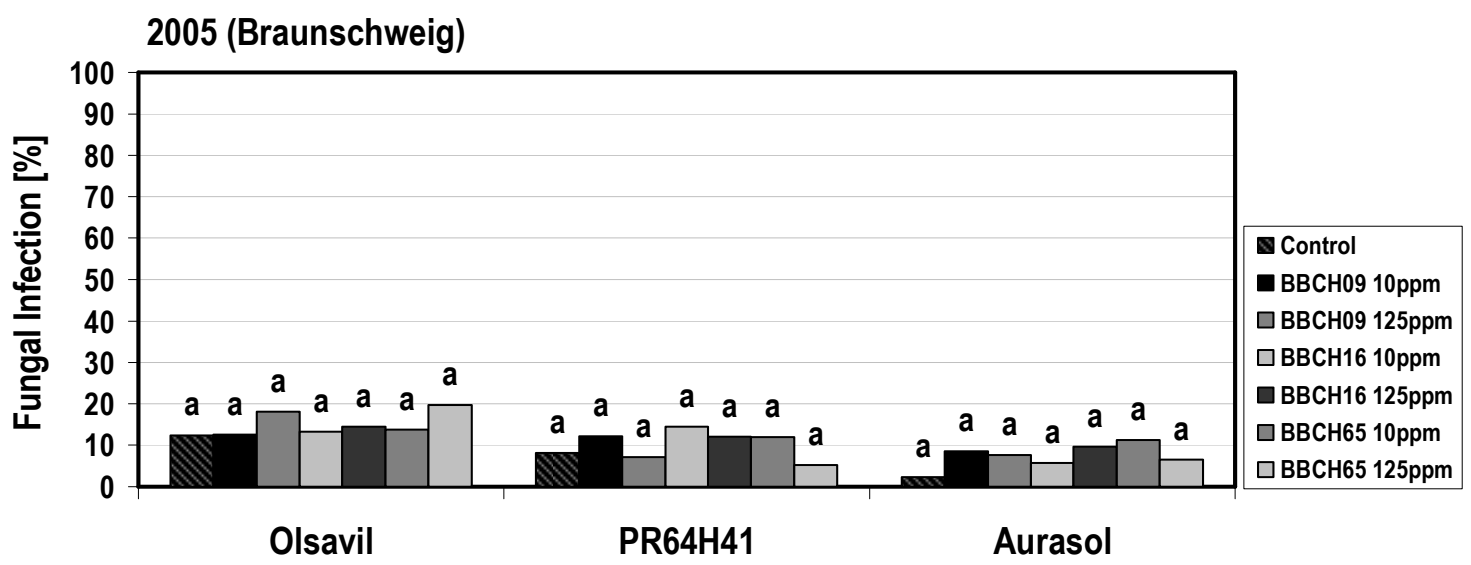

Figure A.2: Influence of $\mathrm{BION}^{\circledR}$ leaf spray application on fungal infection rate (\%) at Braunschweig in 2005.

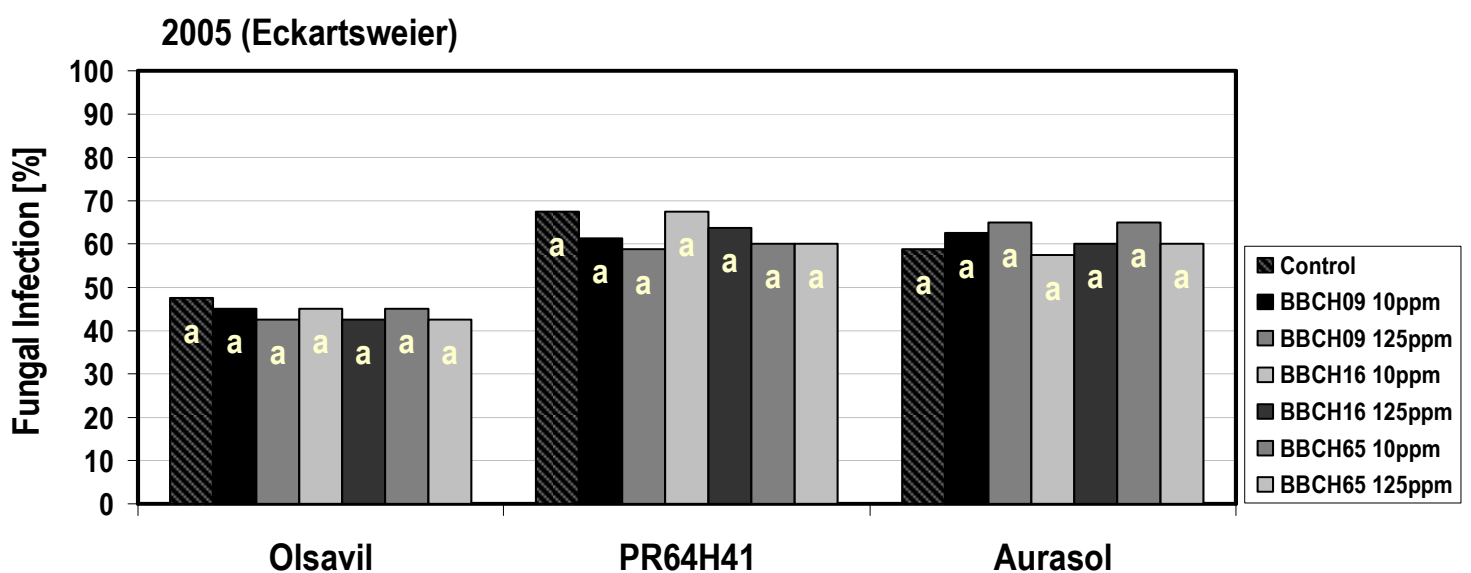

Figure A.3: Influence of $\mathrm{BION}^{\circledR}$ leaf spray application on fungal infection rate (\%) at both experiment sites at Eckartsweier in 2005.

Table A.10: Influence of $\mathrm{BION}^{\circledR}$ leaf spray application on yield and quality parameters of all three varieties in Olsavil in 2002 at Braunschweig.

\begin{tabular}{|c|c|c|c|c|c|c|c|c|}
\hline & $\begin{array}{c}\text { Grain } \\
\text { yield } \\
\text { (dt/ha) }\end{array}$ & $\begin{array}{l}\text { Plant } \\
\text { height } \\
\text { (cm) }\end{array}$ & $\begin{array}{l}\text { Head } \\
\text { diam. } \\
(\mathrm{cm})\end{array}$ & $\begin{array}{c}\text { TSW }^{*} \\
(\mathrm{~g})\end{array}$ & Oil (\%) & $\begin{array}{c}18: 1 \\
(\%)\end{array}$ & $\begin{array}{c}18: 2 \\
(\%)\end{array}$ & $\begin{array}{c}18: 0 \\
(\%)\end{array}$ \\
\hline Control & $30.5 a$ & $161.8 a$ & $13.3 a$ & $45.1 \mathrm{a}$ & $55.7 a$ & $92.4 a$ & $2.5 a$ & $1.2 \mathrm{a}$ \\
\hline $\mathrm{BBCH}-51^{\dagger} 10 p p m$ & $31.9 a$ & $161.7 a$ & $14.5 a$ & $52.9 a$ & $55.3 a$ & $92.7 a$ & $2.5 a$ & $1.2 \mathrm{a}$ \\
\hline BBCH-51 125ppm & $32.2 a$ & $154.7 a$ & $14.6 a$ & $51.7 a$ & $55.5 a$ & $91.9 a$ & $2.4 a$ & $1.2 \mathrm{a}$ \\
\hline BBCH-51 250ppm & $35.2 a$ & $159.0 a$ & $14.5 a$ & $50.6 a$ & $55.4 a$ & $92.6 a$ & $2.6 a$ & $1.2 \mathrm{a}$ \\
\hline ВBCH-65 10ppm & $32.4 a$ & $165.9 a$ & $14.5 a$ & $55.5 a$ & $54.6 a$ & $92.5 a$ & $2.4 a$ & $1.2 \mathrm{a}$ \\
\hline BBCH-65 125ppm & $32.9 a$ & $157.8 \mathrm{a}$ & $14.6 a$ & $53.6 a$ & $54.2 a$ & $92.6 a$ & $2.2 \mathrm{a}$ & $1.3 a$ \\
\hline BBCH-65 250ppm & $33.5 a$ & $161.4 \mathrm{a}$ & $13.9 a$ & $55.1 \mathrm{a}$ & $54.1 \mathrm{a}$ & $92.5 a$ & $2.4 a$ & $1.3 a$ \\
\hline Mean & 32.6 & 160.3 & 14.3 & 52.1 & 54.9 & 92.5 & 2.4 & 1.2 \\
\hline $\mathrm{LSD}_{0.05}$ & 6.1 & 30.0 & 2.7 & 15.8 & 2.6 & 1.7 & 0.7 & 0.4 \\
\hline
\end{tabular}

${ }^{*} \mathrm{TSW}$ : Thousand seed weight, ${ }^{\dagger} \mathrm{BION}^{\circledR}$ application times 
Table A.11: Influence of $\mathrm{BION}^{\circledR}$ application on yield and quality parameters in PR64H61 in preliminary field experiments in 2002 at Braunschweig.

\begin{tabular}{lcccccccc}
\hline & $\begin{array}{c}\text { Grain } \\
\text { yield } \\
\text { (dt/ha) }\end{array}$ & $\begin{array}{c}\text { Plant } \\
\text { height } \\
\text { (cm) }\end{array}$ & $\begin{array}{c}\text { Head } \\
\text { diam. } \\
\text { (cm) }\end{array}$ & $\begin{array}{c}\text { TSW* } \\
\text { (g) }\end{array}$ & Oil (\%) & $\begin{array}{c}\mathbf{1 8 : 1} \\
\text { (\%) }\end{array}$ & $\begin{array}{c}\mathbf{1 8 : 2} \\
\mathbf{( \% )}\end{array}$ & $\begin{array}{c}\mathbf{1 8 : 0} \\
\text { (\%) }\end{array}$ \\
\hline Control & $31.1 \mathrm{a}$ & $148.5 \mathrm{a}$ & $14.7 \mathrm{a}$ & $57.7 \mathrm{a}$ & $54.4 \mathrm{a}$ & $89.1 \mathrm{a}$ & $5.2 \mathrm{a}$ & $1.5 \mathrm{a}$ \\
$\mathrm{BBCH}-51^{\dagger}$ 10ppm & $27.6 \mathrm{a}$ & $132.6 \mathrm{a}$ & $17.7 \mathrm{a}$ & $65.9 \mathrm{a}$ & $50.3 \mathrm{a}$ & $90.1 \mathrm{a}$ & $3.8 \mathrm{a}$ & $1.8 \mathrm{a}$ \\
$\mathrm{BBCH}-51$ 125ppm & $27.7 \mathrm{a}$ & $138.7 \mathrm{a}$ & $18.0 \mathrm{a}$ & $74.4 \mathrm{a}$ & $50.1 \mathrm{a}$ & $89.8 \mathrm{a}$ & $4.2 \mathrm{a}$ & $1.8 \mathrm{a}$ \\
$\mathrm{BBCH}-51$ 250ppm & $25.5 \mathrm{a}$ & $133.1 \mathrm{a}$ & $18.0 \mathrm{a}$ & $71.7 \mathrm{a}$ & $50.1 \mathrm{a}$ & $90.7 \mathrm{a}$ & $3.4 \mathrm{a}$ & $1.7 \mathrm{a}$ \\
$\mathrm{BBCH}-65$ 10ppm & $28.8 \mathrm{a}$ & $137.9 \mathrm{a}$ & $17.6 \mathrm{a}$ & $65.7 \mathrm{a}$ & $52.4 \mathrm{a}$ & $90.4 \mathrm{a}$ & $3.8 \mathrm{a}$ & $1.6 \mathrm{a}$ \\
$\mathrm{BBCH}-65$ 125ppm & $29.1 \mathrm{a}$ & $142.9 \mathrm{a}$ & $16.2 \mathrm{a}$ & $64.4 \mathrm{a}$ & $52.4 \mathrm{a}$ & $89.5 \mathrm{a}$ & $4.7 \mathrm{a}$ & $1.7 \mathrm{a}$ \\
$\mathrm{BBCH}-65250 \mathrm{ppm}$ & $32.0 \mathrm{a}$ & $139.9 \mathrm{a}$ & $14.6 \mathrm{a}$ & $59.1 \mathrm{a}$ & $54.2 \mathrm{a}$ & $90.5 \mathrm{a}$ & $3.6 \mathrm{a}$ & $1.7 \mathrm{a}$ \\
\hline $\mathrm{Mean}$ & 28.8 & 139.1 & 16.70 & 65.55 & 51.99 & 90.01 & 4.13 & 1.69 \\
$\mathrm{LSD}_{0.05}$ & 17.5 & 16.8 & 10.55 & 24.32 & 8.89 & 3.54 & 3.30 & 0.52 \\
\hline
\end{tabular}

Table A.12: Influence of $\mathrm{BION}^{\circledR}$ application on yield and quality parameters in Aurasol in preliminary field experiments in 2002 at Braunschweig.

\begin{tabular}{|c|c|c|c|c|c|c|c|c|}
\hline & $\begin{array}{c}\text { Grain } \\
\text { yield } \\
\text { (dt/ha) }\end{array}$ & $\begin{array}{c}\text { Plant } \\
\text { height } \\
(\mathrm{cm}) \\
\end{array}$ & $\begin{array}{l}\text { Head } \\
\text { diam. } \\
(\mathrm{cm}) \\
\end{array}$ & $\begin{array}{c}\text { TSW* }^{*} \\
\text { (g) }\end{array}$ & Oil (\%) & $\begin{array}{l}18: 1 \\
(\%)\end{array}$ & $\begin{array}{c}18: 2 \\
(\%)\end{array}$ & $\begin{array}{c}18: 0 \\
(\%)\end{array}$ \\
\hline Control & $31.3 a$ & $135.2 a$ & $12.8 a$ & $59.8 a$ & $51.6 a$ & $87.9 a$ & $4.8 a$ & $2.9 a$ \\
\hline $\mathrm{BBCH}-51^{\dagger} 10 p p m$ & $31.6 a$ & $137.4 a$ & $14.3 a$ & $57.9 a$ & $51.6 a$ & $87.4 a$ & $5.3 a$ & $3.0 \mathrm{a}$ \\
\hline BBCH-51 125ppm & $32.9 a$ & $136.8 \mathrm{a}$ & $12.9 a$ & $57.2 a$ & $51.9 a$ & $87.9 a$ & $4.7 a$ & $3.0 \mathrm{a}$ \\
\hline BBCH-51 250ppm & $32.2 a$ & $132.5 a$ & $13.5 a$ & $61.1 \mathrm{a}$ & $51.5 a$ & $88.4 a$ & $4.4 a$ & $3.0 a$ \\
\hline BBCH-65 10ppm & $33.4 a$ & $143.7 a$ & $13.0 \mathrm{a}$ & $56.3 a$ & $51.5 a$ & $87.6 a$ & $4.9 a$ & $3.0 \mathrm{a}$ \\
\hline $\mathrm{BBCH}-65$ 125ppm & $31.1 \mathrm{a}$ & $136.2 a$ & $14.0 \mathrm{a}$ & $60.2 a$ & $50.8 a$ & $88.2 a$ & $4.5 a$ & $2.9 a$ \\
\hline $\mathrm{BBCH}-65$ 250ppm & $32.2 a$ & $132.8 \mathrm{a}$ & $13.3 a$ & $57.9 a$ & $50.8 a$ & $87.2 \mathrm{a}$ & $5.1 \mathrm{a}$ & $3.1 \mathrm{a}$ \\
\hline Mean & 32.1 & 136.4 & 13.4 & 58.6 & 51.4 & 87.8 & 4.8 & 3.0 \\
\hline $\mathrm{LSD}_{0.05}$ & 8.6 & 21.4 & 3.8 & 18.9 & 3.8 & 3.9 & 3.7 & 0.3 \\
\hline
\end{tabular}

Table A.13: Influence of $\mathrm{BION}^{\circledR}$ leaf spray application on head diameter and TSW for all three varieties at Braunschweig in 2003.

\begin{tabular}{|c|c|c|c|c|c|c|}
\hline & \multicolumn{3}{|c|}{ Head diameter $(\mathbf{c m})$} & \multicolumn{3}{|c|}{ Thousand seed weight (g) } \\
\hline & Olsavil & PR64H41 & Aurasol & Olsavil & PR64H41 & Aurasol \\
\hline Control & $13.4 a$ & $11.8 \mathrm{a}$ & $13.0 \mathrm{a}$ & $40.2 a$ & $39.3 b$ & $44.6 a$ \\
\hline $\mathrm{BION}^{\circledR}$ Spray 10ppm/BBCH09 & $15.8 \mathrm{a}$ & $14.7 a$ & $14.6 a$ & $48.9 a$ & $49.3 a b$ & $51.4 a$ \\
\hline $\mathrm{BION}^{\circledR}$ Spray $125 \mathrm{ppm} / \mathrm{BBCH} 09$ & $15.3 a$ & $14.8 a$ & $13.2 \mathrm{a}$ & $48.6 a$ & $54.3 a$ & $49.0 a$ \\
\hline $\mathrm{BION}^{\circledR}$ Spray 250ppm/BBCH09 & $15.9 a$ & $14.3 a$ & $12.9 a$ & $49.8 a$ & $49.1 \mathrm{ab}$ & $51.5 a$ \\
\hline $\mathrm{BION}^{\circledR}$ Spray 10ppm/BBCH16 & $15.1 \mathrm{a}$ & $14.3 a$ & $12.8 \mathrm{a}$ & $41.2 a$ & $50.5 a b$ & $47.0 a$ \\
\hline $\mathrm{BION}^{\circledR}$ Spray 125ppm/BBCH16 & $14.2 \mathrm{a}$ & $13.5 a$ & $12.8 a$ & $42.6 a$ & $48.1 \mathrm{ab}$ & $46.4 a$ \\
\hline $\mathrm{BION}^{\circledR}$ Spray 250ppm/BBCH16 & $14.2 \mathrm{a}$ & $12.9 a$ & $13.4 a$ & $43.2 \mathrm{a}$ & $47.3 a b$ & $51.9 a$ \\
\hline $\mathrm{BION}^{\circledR}$ Spray 10ppm/BBCH51 & $14.2 a$ & $13.7 a$ & $12.7 a$ & $42.0 \mathrm{a}$ & 43.9ab & $47.8 \mathrm{a}$ \\
\hline $\mathrm{BION}^{\circledR}$ Spray $125 p p m / \mathrm{BBCH} 51$ & $15.3 a$ & $14.0 \mathrm{a}$ & $13.0 \mathrm{a}$ & $43.0 a$ & $47.2 \mathrm{ab}$ & $47.7 a$ \\
\hline $\mathrm{BION}^{\circledR}$ Spray 250ppm/BBCH51 & $14.8 \mathrm{a}$ & $13.1 \mathrm{a}$ & $13.5 a$ & $42.4 a$ & $42.4 a b$ & $45.0 \mathrm{a}$ \\
\hline $\mathrm{BION}^{\circledR}$ Spray 10ppm/BBCH65 & $15.9 a$ & $14.5 a$ & $12.7 a$ & $51.8 a$ & $50.3 a b$ & $49.5 a$ \\
\hline $\mathrm{BION}^{\circledR}$ Spray $125 p p m / \mathrm{BBCH} 65$ & $15.4 a$ & $14.1 \mathrm{a}$ & $13.0 \mathrm{a}$ & $45.2 a$ & $49.8 a b$ & $50.4 a$ \\
\hline $\mathrm{BION}^{\circledR}$ Spray 250ppm/BBCH65 & $15.2 a$ & $14.2 \mathrm{a}$ & $14.2 \mathrm{a}$ & $44.4 a$ & $49.2 a b$ & $49.1 \mathrm{a}$ \\
\hline $\mathrm{BION}^{\circledR}$ Spray $10 \mathrm{ppm} / \mathrm{BBCH} 69$ & $13.3 a$ & $12.6 a$ & $13.1 \mathrm{a}$ & $38.2 a$ & $42.6 a b$ & $45.6 a$ \\
\hline $\mathrm{BION}^{\circledR}$ Spray $125 \mathrm{ppm} / \mathrm{BBCH} 69$ & $13.7 a$ & $13.7 a$ & $12.9 a$ & $36.0 \mathrm{a}$ & $46.6 a b$ & $44.7 a$ \\
\hline $\mathrm{BION}^{\circledR}$ Spray 250ppm/BBCH69 & $13.7 a$ & $13.1 \mathrm{a}$ & $11.9 a$ & $42.4 a$ & $42.1 \mathrm{ab}$ & $42.1 \mathrm{a}$ \\
\hline
\end{tabular}


Table A.14: Influence of $\mathrm{BION}^{\circledR}$ leaf spray application on head diameter and TSW for all three varieties at Braunschweig in 2004-2005.

\begin{tabular}{|c|c|c|c|c|c|c|}
\hline & \multicolumn{3}{|c|}{ Head diameter $(\mathrm{cm})$} & \multicolumn{3}{|c|}{ Thousand seed weight (g) } \\
\hline & Olsavil & PR64H41 & Aurasol & Olsavil & PR64H41 & Aurasol \\
\hline \multicolumn{7}{|c|}{2004} \\
\hline Control & $13.3 a$ & $13.3 a$ & $12.3 a$ & $42.7 a$ & $40.2 a$ & $40.8 b$ \\
\hline $\mathrm{BION}^{\circledR}$ Spray 10ppm/BBCH09 & $13.1 \mathrm{a}$ & $13.2 a$ & $12.1 \mathrm{a}$ & $43.8 a$ & $42.2 a$ & $40.6 b$ \\
\hline $\mathrm{BION}^{\circledR}$ Spray 125ppm/BBCH09 & $12.9 a$ & $13.2 a$ & $11.7 a$ & $44.0 a$ & $42.7 a$ & $42.5 a b$ \\
\hline $\mathrm{BION}^{\circledR}$ Spray 10ppm/BBCH16 & $12.4 a$ & $13.2 a$ & $12.4 a$ & $41.6 a$ & $39.8 a$ & $42.3 a b$ \\
\hline $\mathrm{BION}^{\circledR}$ Spray $125 p p m / \mathrm{BBCH} 16$ & $12.8 a$ & $12.7 a$ & $12.6 a$ & $42.7 a$ & $38.9 a$ & $39.9 b$ \\
\hline $\mathrm{BION}^{\circledR}$ Spray 10ppm/BBCH65 & $12.6 a$ & $12.5 a$ & $11.7 a$ & $43.2 \mathrm{a}$ & $39.3 a$ & $40.8 b$ \\
\hline $\mathrm{BION}^{\circledR}$ Spray $125 p p m / \mathrm{BBCH} 65$ & $12.9 a$ & $12.6 a$ & $12.3 a$ & $43.1 \mathrm{a}$ & $40.0 a$ & $44.7 a$ \\
\hline \multicolumn{7}{|c|}{2005} \\
\hline Control & $13.9 a$ & $13.1 \mathrm{a}$ & $12.5 a$ & $44.0 \mathrm{a}$ & $49.2 a$ & $46.2 a$ \\
\hline $\mathrm{BION}^{\circledR}$ Spray 10ppm/BBCH09 & $13.3 a$ & $13.3 a$ & $12.4 a$ & $43.7 a$ & $51.8 a$ & $46.3 a$ \\
\hline $\mathrm{BION}^{\circledR}$ Spray $125 \mathrm{ppm} / \mathrm{BBCH} 09$ & $13.5 a$ & $13.1 \mathrm{a}$ & $12.9 a$ & $43.1 \mathrm{a}$ & $52.6 a$ & $48.3 a$ \\
\hline $\mathrm{BION}^{\circledR}$ Spray 10ppm/BBCH16 & $13.1 \mathrm{a}$ & $13.3 a$ & $12.1 \mathrm{a}$ & $42.6 a$ & $52.5 a$ & $46.6 a$ \\
\hline $\mathrm{BION}^{\circledR}$ Spray $125 \mathrm{ppm} / \mathrm{BBCH} 16$ & $13.4 \mathrm{a}$ & $13.3 a$ & $12.4 \mathrm{a}$ & $45.2 \mathrm{a}$ & $50.2 a$ & $47.1 \mathrm{a}$ \\
\hline $\mathrm{BION}^{\circledR}$ Spray 10ppm/BBCH65 & $13.4 a$ & $13.4 a$ & $12.8 a$ & $42.8 a$ & $49.0 a$ & $47.3 a$ \\
\hline $\mathrm{BION}^{\circledR}$ Spray $125 \mathrm{ppm} / \mathrm{BBCH} 65$ & $13.8 \mathrm{a}$ & $13.4 a$ & $12.5 a$ & $43.9 a$ & $52.8 a$ & $46.7 a$ \\
\hline
\end{tabular}

Table A.15: Influence of $\mathrm{BION}^{\circledR}$ leaf spray application on plant height $(\mathbf{c m})$ for all three varieties at both experiment sites in 2003.

\begin{tabular}{|c|c|c|c|c|c|c|}
\hline & \multicolumn{3}{|c|}{ Braunschweig } & \multicolumn{3}{|c|}{ Eckartsweier } \\
\hline & Olsavil & PR64H41 & Aurasol & Olsavil & PR64H41 & Aurasol \\
\hline Control & $102.5 a$ & $89.0 a$ & $97.4 a$ & $205.0 a$ & $195.0 a$ & $205.0 a$ \\
\hline $\mathrm{BION}^{\circledR}$ Spray 10ppm/BBCH09 & $160.6 a$ & $18.7 a$ & $130.7 a$ & $215.0 a$ & $195.0 a$ & $205.0 a$ \\
\hline $\mathrm{BION}^{\circledR}$ Spray $125 \mathrm{ppm} / \mathrm{BBCH} 09$ & $134.6 a$ & $138.7 a$ & $136.2 a$ & $210.0 a$ & $180.0 a$ & $210.0 a$ \\
\hline $\mathrm{BION}^{\circledR}$ Spray 250ppm/BBCH09 & $144.2 a$ & $125.5 a$ & $152.8 \mathrm{a}$ & $162.5 a$ & $195.0 \mathrm{a}$ & $195.0 \mathrm{a}$ \\
\hline $\mathrm{BION}^{\circledR}$ Spray 10ppm/BBCH16 & $139.1 a$ & $137.8 a$ & $147.7 a$ & $210.0 a$ & $185.0 a$ & $195.0 a$ \\
\hline $\mathrm{BION}^{\circledR}$ Spray $125 p p m / \mathrm{BBCH} 16$ & $149.5 a$ & $123.5 a$ & $130.2 a$ & $205.0 a$ & $200.0 a$ & $200.0 a$ \\
\hline $\mathrm{BION}^{\circledR}$ Spray 250 ppm/BBCH 16 & $142.2 a$ & $127.6 a$ & $143.5 a$ & $190.0 a$ & $.0 a$ & $195.0 \mathrm{a}$ \\
\hline $\mathrm{BION}^{\circledR}$ Spray 10ppm/BBCH51 & $131.7 a$ & $120.3 a$ & $133.5 a$ & $205.0 a$ & $190.0 a$ & $195.0 a$ \\
\hline $\mathrm{BION}^{\circledR}$ Spray $125 p p m / \mathrm{BBCH} 51$ & $145.6 a$ & $132.4 a$ & $135.6 a$ & $200.0 a$ & $185.0 \mathrm{a}$ & 195.0a \\
\hline $\mathrm{BION}^{\circledR}$ Spray 250 ppm/BBCH51 & $147.4 a$ & & $5 a$ & $190.0 a$ & $185.0 \mathrm{a}$ & $195.0 \mathrm{a}$ \\
\hline $\mathrm{BION}^{\circledR}$ Spray $10 \mathrm{ppm} / \mathrm{BBCH} 65$ & $119.2 a$ & $132.9 a$ & $148.9 a$ & $205.0 a$ & $190.0 a$ & $220.0 a$ \\
\hline $\mathrm{BION}^{\circledR}$ Spray $125 \mathrm{ppm} / \mathrm{BBCH} 65$ & $152.1 \mathrm{a}$ & $140.8 a$ & $132.9 a$ & $215.0 a$ & $190.0 \mathrm{a}$ & $200.0 a$ \\
\hline $\mathrm{BION}^{\circledR}$ Spray 250ppm/BBCH65 & $149.5 a$ & $5 a$ & $\mathrm{Da}$ & $0 a$ & $0 a$ & $.0 \mathrm{a}$ \\
\hline $\mathrm{BION}^{\circledR}$ Spray $10 \mathrm{ppm} / \mathrm{BBCH} 69$ & $142.2 a$ & & & $.0 a$ & $.0 a$ & $195.0 a$ \\
\hline $\mathrm{BION}^{\circledR}$ Spray $125 p p m / \mathrm{BBCH} 69$ & $145.3 a$ & & & $.0 a$ & $0 a$ & $185.0 a$ \\
\hline $\mathrm{BION}^{\circledR}$ Spray $250 \mathrm{ppm} / \mathrm{BBCH} 69$ & $145.9 a$ & $135.5 a$ & $123.2 \mathrm{a}$ & $215.0 a$ & $190.0 \mathrm{a}$ & $200.0 a$ \\
\hline
\end{tabular}




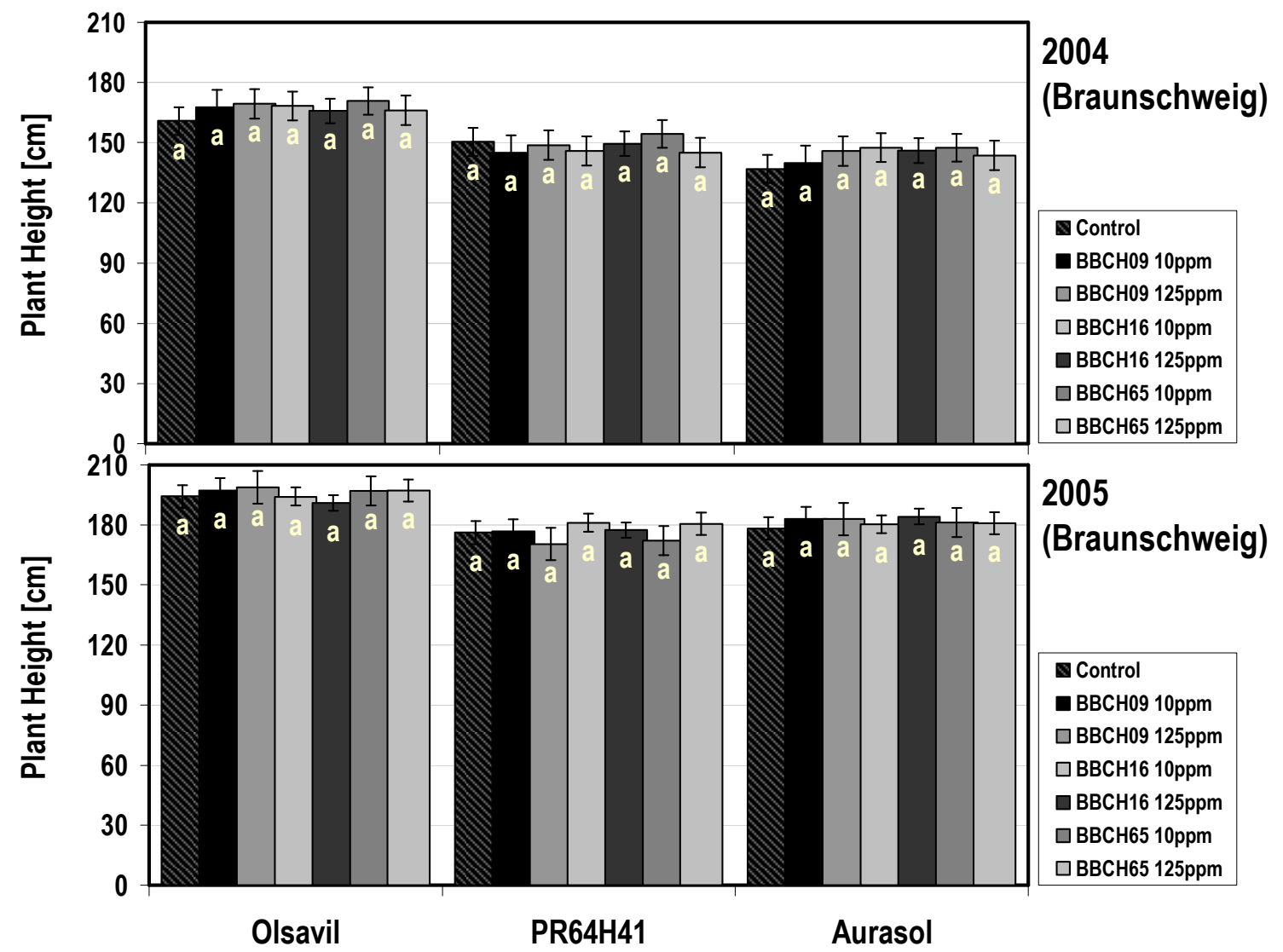

Figure A.4: Influence of $\mathrm{BION}^{\circledR}$ leaf spray application on plant height $(\mathrm{cm})$ at Braunschweig.

Table A.16: Influence of $\mathrm{BION}^{\circledR}$ leaf spray application on oil content (\%) for all three varieties at both experiment sites in 2003.

\begin{tabular}{|c|c|c|c|c|c|c|}
\hline & \multicolumn{3}{|c|}{ BRAUNSCHWEIG } & \multicolumn{3}{|c|}{ ECKARTSWEIER } \\
\hline & Olsavil & PR64H41 & Aurasol & Olsavil & PR64H41 & Aurasol \\
\hline Control & $46.8 a$ & $50.0 a$ & $51.2 a b c d$ & $51.3 a$ & $50.5 a$ & $48.2 a$ \\
\hline $\mathrm{BION}^{\circledR}$ Spray 10ppm/BBCH09 & $50.7 a$ & $54.6 a$ & 53.8abc & $51.4 a$ & $52.5 a$ & $44.2 a$ \\
\hline $\mathrm{BION}^{\circledR}$ Spray $125 p p m / \mathrm{BBCH} 09$ & $53.2 a$ & $54.6 a$ & $54.3 a$ & $51.2 a$ & $50.0 a$ & $48.4 a$ \\
\hline $\mathrm{BION}^{\circledR}$ Spray 250ppm/BBCH09 & $54.4 a$ & $55.0 a$ & 53.7abc & $51.8 a$ & $51.9 a$ & $46.7 a$ \\
\hline $\mathrm{BION}^{\circledR}$ Spray $10 \mathrm{ppm} / \mathrm{BBCH} 16$ & $51.3 a$ & $53.7 a$ & 51.9abcd & $49.6 a$ & $52.4 a$ & $46.4 a$ \\
\hline $\mathrm{BION}^{\circledR}$ Spray $125 p p m / \mathrm{BBCH} 16$ & $49.2 a$ & $52.7 a$ & $53.6 a b c$ & $47.9 a$ & $52.2 a$ & $46.8 a$ \\
\hline $\mathrm{BION}^{\circledR}$ Spray 250ppm/BBCH16 & $49.3 a$ & $52.5 a$ & $52.8 \mathrm{abcd}$ & $48.8 a$ & $49.1 \mathrm{a}$ & $46.0 \mathrm{a}$ \\
\hline $\mathrm{BION}^{\circledR}$ Spray 10ppm/BBCH51 & $48.9 a$ & $51.0 a$ & $50.8 \mathrm{dc}$ & $49.3 a$ & $50.4 a$ & $48.2 a$ \\
\hline $\mathrm{BION}^{\circledR}$ Spray $125 p p m / \mathrm{BBCH} 51$ & $48.4 a$ & $52.0 a$ & $51.7 \mathrm{abcd}$ & $49.6 a$ & $51.0 a$ & $47.5 \mathrm{a}$ \\
\hline $\mathrm{BION}^{\circledR}$ Spray 250ppm/BBCH51 & $48.3 a$ & $51.8 \mathrm{a}$ & $50.0 d$ & $49.6 a$ & $48.4 a$ & $47.4 a$ \\
\hline $\mathrm{BION}^{\circledR}$ Spray $10 \mathrm{ppm} / \mathrm{BBCH} 65$ & $52.7 a$ & $53.1 \mathrm{a}$ & $54.1 \mathrm{ab}$ & $51.1 \mathrm{a}$ & $51.0 a$ & $47.8 \mathrm{a}$ \\
\hline $\mathrm{BION}^{\circledR}$ Spray $125 p p m / \mathrm{BBCH} 65$ & $51.6 a$ & $54.1 \mathrm{a}$ & $52.1 \mathrm{abcd}$ & $51.6 a$ & $51.8 a$ & $50.1 \mathrm{a}$ \\
\hline $\mathrm{BION}^{\circledR}$ Spray 250 pm/BBCH65 & $52.3 a$ & $53.6 a$ & $53.4 a b c$ & $47.4 a$ & $53.0 \mathrm{a}$ & $47.6 a$ \\
\hline $\mathrm{BION}^{\circledR}$ Spray 10ppm/BBCH69 & $51.3 a$ & $52.7 a$ & 53.0abcd & $48.8 a$ & $50.9 a$ & $46.9 a$ \\
\hline $\mathrm{BION}^{\circledR}$ Spray $125 p p m / \mathrm{BBCH} 69$ & $46.6 a$ & $52.4 a$ & $51.1 \mathrm{bcd}$ & $52.2 a$ & $50.2 a$ & $47.8 \mathrm{a}$ \\
\hline $\mathrm{BION}^{\circledR}$ Spray 250ppm/BBCH69 & $49.9 a$ & $52.6 a$ & 53.0abcd & $52.0 \mathrm{a}$ & $46.6 a$ & $47.9 a$ \\
\hline
\end{tabular}


Table A.17: Influence of $\mathrm{BION}^{\circledR}$ leaf spray application on oil content (\%) for all three varieties at both experiment sites in 2005 .

\begin{tabular}{|c|c|c|c|c|c|c|}
\hline & \multicolumn{3}{|c|}{ BRAUNSCHWEIG } & \multicolumn{3}{|c|}{ ECKARTSWEIER } \\
\hline & Olsavil & PR64H41 & Aurasol & Olsavil & PR64H41 & Aurasol \\
\hline \multicolumn{7}{|l|}{2004} \\
\hline Control & $51.5 a$ & $50.4 a$ & $49.8 a b$ & $51.5 a$ & $49.8 a$ & $49.6 a$ \\
\hline $\mathrm{BION}^{\circledR}$ Spray 10ppm/BBCH09 & $51.7 a$ & $50.6 a$ & $50.2 a$ & $51.4 a$ & $50.3 a$ & $49.7 a$ \\
\hline $\mathrm{BION}^{\circledR}$ Spray $125 p p m / \mathrm{BBCH} 09$ & $50.6 a$ & $47.7 a$ & $47.4 a b$ & $51.4 a$ & $50.4 a$ & $48.9 a$ \\
\hline $\mathrm{BION}^{\circledR}$ Spray 10ppm/BBCH16 & $51.8 a$ & $48.0 a$ & $49.4 a b$ & $50.1 a$ & $49.6 a$ & $50.3 a$ \\
\hline $\mathrm{BION}^{\circledR}$ Spray $125 p p m / \mathrm{BBCH} 16$ & $50.7 a$ & $48.3 a$ & $47.2 \mathrm{~b}$ & $52.4 a$ & $50.8 a$ & $49.2 a$ \\
\hline $\mathrm{BION}^{\circledR}$ Spray 10 ppm/BBCH65 & $51.4 a$ & $47.6 a$ & $49.9 a b$ & $51.3 a$ & $50.9 a$ & $48.9 a$ \\
\hline $\begin{array}{l}\text { BION }^{\circledR} \text { Spray } 125 p p m / B B C H 65 \\
2005\end{array}$ & $52.0 a$ & $48.3 a$ & $49.7 a b$ & $49.9 a$ & $50.4 a$ & $49.2 a$ \\
\hline Control & $49.1 a$ & $50.8 a$ & $49.3 a$ & $52.7 a$ & $52.9 a$ & $49.7 a$ \\
\hline $\mathrm{BION}^{\circledR}$ Spray 10ppm/BBCH09 & $48.8 a$ & $51.0 a$ & $50.2 a$ & $52.7 a$ & $52.6 a$ & $49.3 a$ \\
\hline $\mathrm{BION}^{\circledR}$ Spray $125 p p m / \mathrm{BBCH} 09$ & $50.4 a$ & $52.2 a$ & $51.0 a$ & $52.8 a$ & $53.1 \mathrm{a}$ & $50.1 a$ \\
\hline $\mathrm{BION}^{\circledR}$ Spray 10ppm/BBCH16 & $49.2 a$ & $51.8 a$ & $50.2 a$ & $53.6 a$ & $52.6 a$ & $49.9 a$ \\
\hline $\mathrm{BION}^{\circledR}$ Spray $125 p p m / \mathrm{BBCH} 16$ & $48.8 a$ & $51.2 a$ & $50.6 a$ & $53.3 a$ & $53.4 a$ & $50.5 a$ \\
\hline $\mathrm{BION}^{\circledR}$ Spray $10 p p m / \mathrm{BBCH} 65$ & $49.9 a$ & $51.8 a$ & $50.7 a$ & $52.8 a$ & $52.9 a$ & $51.1 \mathrm{a}$ \\
\hline $\mathrm{BION}^{\circledR}$ Spray $125 p p m / \mathrm{BBCH} 65$ & $49.4 a$ & $51.1 \mathrm{a}$ & $49.3 a$ & $53.0 \mathrm{a}$ & $52.7 \mathrm{a}$ & $50.4 a$ \\
\hline
\end{tabular}

Table A.18: Influence of $\mathrm{BION}^{\circledR}$ leaf spray application on oil composition (\%) of Olsavil and PR64H41 at Braunschweig in 2003.

\begin{tabular}{|c|c|c|c|c|c|c|}
\hline & \multicolumn{3}{|c|}{ OLSAVIL } & \multicolumn{3}{|c|}{ PR64H41 } \\
\hline & $\begin{array}{l}\text { Oleic } \\
\text { acid } \\
(\%)\end{array}$ & $\begin{array}{c}\text { Linoleic } \\
\text { acid } \\
(\%)\end{array}$ & $\begin{array}{c}\text { Stearic } \\
\text { acid } \\
(\%)\end{array}$ & $\begin{array}{l}\text { Oleic } \\
\text { acid } \\
(\%)\end{array}$ & $\begin{array}{c}\text { Linoleic } \\
\text { acid } \\
(\%)\end{array}$ & $\begin{array}{c}\text { Stearic } \\
\text { acid } \\
(\%)\end{array}$ \\
\hline Control & $89.8 a$ & $2.7 a$ & $1.9 a$ & $88.3 a$ & $3.6 a$ & $2.7 a$ \\
\hline $\mathrm{BION}^{\circledR}$ Spray $10 \mathrm{ppm} / \mathrm{BBCH} 09$ & $91.2 a$ & $2.1 \mathrm{ab}$ & $1.6 a$ & $88.9 a$ & $3.9 a$ & $2.3 a b$ \\
\hline $\mathrm{BION}^{\circledR}$ Spray $125 \mathrm{ppm} / \mathrm{BBCH} 09$ & $91.3 a$ & $2.1 \mathrm{ab}$ & $1.6 a$ & $88.9 a$ & $3.8 a$ & $2.3 a b$ \\
\hline $\mathrm{BION}^{\circledR}$ Spray 250ppm/BBCH09 & $91.7 a$ & $2.1 \mathrm{ab}$ & $1.4 a$ & $89.6 a$ & $3.4 a$ & $2.2 \mathrm{~b}$ \\
\hline $\mathrm{BION}^{\circledR}$ Spray 10ppm/BBCH16 & $90.9 a$ & $2.2 a b$ & $1.7 a$ & $89.6 a$ & $3.3 a$ & $2.2 a b$ \\
\hline $\mathrm{BION}^{\circledR}$ Spray $125 \mathrm{ppm} / \mathrm{BBCH} 16$ & $90.6 a$ & $2.3 a b$ & $1.8 \mathrm{a}$ & $89.3 a$ & $3.1 \mathrm{a}$ & $2.4 a b$ \\
\hline $\mathrm{BION}^{\circledR}$ Spray 250 ppm/BBCH 16 & $90.4 a$ & $2.4 a b$ & $1.8 \mathrm{a}$ & $88.6 a$ & $3.7 a$ & $2.4 a b$ \\
\hline $\mathrm{BION}^{\circledR}$ Spray $10 p p m / \mathrm{BBCH} 51$ & $90.1 a$ & $2.6 a b$ & $1.8 \mathrm{a}$ & $88.3 a$ & $3.6 a$ & $2.6 a b$ \\
\hline $\mathrm{BION}^{\circledR}$ Spray $125 p p m / \mathrm{BBCH} 51$ & $90.4 a$ & $2.4 a b$ & $1.8 \mathrm{a}$ & $88.8 \mathrm{a}$ & $3.5 a$ & $2.5 a b$ \\
\hline $\mathrm{BION}^{\circledR}$ Spray 250ppm/BBCH51 & $90.0 a$ & $2.5 a b$ & $1.9 a$ & $88.8 \mathrm{a}$ & $3.6 a$ & $2.4 a b$ \\
\hline $\mathrm{BION}^{\circledR}$ Spray 10ppm/BBCH65 & $91.8 a$ & $1.9 \mathrm{~b}$ & $1.5 a$ & $88.6 a$ & $3.8 a$ & $2.4 a b$ \\
\hline $\mathrm{BION}^{\circledR}$ Spray $125 \mathrm{ppm} / \mathrm{BBCH} 65$ & $90.9 a$ & $2.1 \mathrm{ab}$ & $1.6 a$ & $89.4 a$ & $3.4 a$ & $2.3 a b$ \\
\hline $\mathrm{BION}^{\circledR}$ Spray 250ppm/BBCH65 & $91.5 a$ & $1.9 \mathrm{~b}$ & $1.6 a$ & $88.8 a$ & $4.0 \mathrm{a}$ & $2.3 a b$ \\
\hline $\mathrm{BION}^{\circledR}$ Spray 10ppm/BBCH69 & $90.9 a$ & $2.3 a b$ & $1.7 a$ & $89.0 a$ & $3.1 \mathrm{a}$ & $2.5 a b$ \\
\hline $\mathrm{BION}^{\circledR}$ Spray $125 \mathrm{ppm} / \mathrm{BBCH} 69$ & $89.7 a$ & $2.5 \mathrm{ab}$ & $2.0 \mathrm{a}$ & $88.9 a$ & $3.4 a$ & $2.4 a b$ \\
\hline $\mathrm{BION}^{\circledR}$ Spray 250ppm/BBCH69 & $90.6 a$ & $2.3 a b$ & $1.8 \mathrm{a}$ & $88.9 a$ & $3.5 a$ & $2.3 a b$ \\
\hline
\end{tabular}


Table A.19: Influence of $\mathrm{BION}^{\circledR}$ leaf spray application on oil composition (\%) of all varieties at both experiment sites in 2004.

\begin{tabular}{|c|c|c|c|c|c|c|}
\hline & \multicolumn{3}{|c|}{ BRAUNSCHWEIG } & \multicolumn{3}{|c|}{ ECKARTSWEIER } \\
\hline & $\begin{array}{c}\text { Oleic } \\
\text { acid } \\
(\%) \\
\end{array}$ & $\begin{array}{c}\text { Linoleic } \\
\text { acid } \\
(\%) \\
\end{array}$ & $\begin{array}{c}\text { Stearic } \\
\text { acid } \\
(\%)\end{array}$ & $\begin{array}{c}\text { Oleic } \\
\text { acid } \\
(\%) \\
\end{array}$ & $\begin{array}{c}\text { Linoleic } \\
\text { acid } \\
(\%) \\
\end{array}$ & $\begin{array}{c}\text { Stearic } \\
\text { acid } \\
(\%) \\
\end{array}$ \\
\hline \multicolumn{7}{|l|}{ OLSAVIL } \\
\hline Control & $91.7 a$ & $2.5 a$ & $1.4 a$ & $91.4 a$ & $2.3 a$ & $1.8 \mathrm{a}$ \\
\hline BION ${ }^{\circledR}$ Spray 10ppm/BBCH09 & $91.9 a$ & $2.3 a$ & $1.4 a$ & $91.4 a$ & $2.4 a$ & $1.7 a b$ \\
\hline $\mathrm{BION}^{\circledR}$ Spray $125 \mathrm{ppm} / \mathrm{BBCH} 09$ & $91.6 a$ & $2.3 a$ & $1.6 a$ & $91.4 a$ & $2.2 a$ & $1.7 a b$ \\
\hline $\mathrm{BION}^{\circledR}$ Spray 10 ppm/BBCH16 & $91.7 a$ & $2.3 a$ & $1.5 a$ & $91.0 \mathrm{a}$ & $2.6 a$ & $1.8 a b$ \\
\hline $\mathrm{BION}^{\circledR}$ Spray $125 \mathrm{ppm} / \mathrm{BBCH} 16$ & $91.6 a$ & $2.4 a$ & $1.5 a$ & $91.6 a$ & $2.3 a$ & $1.6 b$ \\
\hline $\mathrm{BION}^{\circledR}$ Spray $10 \mathrm{ppm} / \mathrm{BBCH} 65$ & $91.7 a$ & $2.3 a$ & $1.5 a$ & $91.4 \mathrm{a}$ & $2.3 a$ & 1.7ab \\
\hline $\mathrm{BION}^{\circledR}$ Spray 125ppm/BBCH65 & $91.8 a$ & $2.4 a$ & $1.5 a$ & $91.5 a$ & $2.3 a$ & $1.6 a b$ \\
\hline \multicolumn{7}{|l|}{ PR64H41 } \\
\hline Control & $88.1 a$ & $4.7 a$ & $2.1 \mathrm{ab}$ & $85.9 a$ & $6.4 a$ & $2.8 a$ \\
\hline $\mathrm{BION}^{\circledR}$ Spray 10ppm/BBCH09 & $88.0 a$ & $5.0 \mathrm{a}$ & $2.0 \mathrm{~b}$ & $86.2 a$ & $6.2 a$ & $2.6 a$ \\
\hline $\mathrm{BION}^{\circledR}$ Spray $125 \mathrm{ppm} / \mathrm{BBCH} 09$ & $87.9 a$ & $4.5 a$ & $2.3 a b$ & $87.5 a$ & $5.0 \mathrm{a}$ & $2.6 a$ \\
\hline $\mathrm{BION}^{\circledR}$ Spray 10ppm/BBCH16 & $87.9 a$ & $4.5 a$ & $2.3 a b$ & $87.0 \mathrm{a}$ & $5.5 a$ & $2.5 a$ \\
\hline $\mathrm{BION}^{\circledR}$ Spray $125 \mathrm{ppm} / \mathrm{BBCH} 16$ & $88.5 a$ & $4.0 \mathrm{a}$ & $2.3 a b$ & $86.9 a$ & $5.5 a$ & $2.7 a$ \\
\hline $\mathrm{BION}^{\circledR}$ Spray $10 \mathrm{ppm} / \mathrm{BBCH} 65$ & $87.7 a$ & $4.6 a$ & $2.4 a$ & $86.9 a$ & $5.6 a$ & $2.7 a$ \\
\hline $\mathrm{BION}^{\circledR}$ Spray $125 \mathrm{ppm} / \mathrm{BBCH} 65$ & $88.0 a$ & $4.4 a$ & $2.3 a b$ & $88.1 \mathrm{a}$ & $4.4 a$ & $2.6 a$ \\
\hline \multicolumn{7}{|l|}{ AURASOL } \\
\hline Control & $87.9 a$ & $4.4 a$ & $2.6 a$ & $89.1 \mathrm{a}$ & $3.5 a$ & $2.7 a$ \\
\hline $\mathrm{BION}^{\circledR}$ Spray 10ppm/BBCH09 & $87.4 a$ & $5.0 a$ & $2.5 a$ & $88.7 a$ & $3.9 a$ & $2.7 a$ \\
\hline $\mathrm{BION}^{\circledR}$ Spray $125 \mathrm{ppm} / \mathrm{BBCH} 09$ & $87.7 a$ & $4.2 \mathrm{a}$ & $2.8 \mathrm{a}$ & $87.6 a$ & $4.7 a$ & $3.0 \mathrm{a}$ \\
\hline $\mathrm{BION}^{\circledR}$ Spray 10ppm/BBCH16 & $88.7 a$ & $3.7 a$ & $2.6 a$ & $88.2 a$ & $4.2 \mathrm{a}$ & $2.8 \mathrm{a}$ \\
\hline $\mathrm{BION}^{\circledR}$ Spray $125 \mathrm{ppm} / \mathrm{BBCH} 16$ & $87.9 a$ & $4.0 \mathrm{a}$ & $2.9 a$ & $87.7 \mathrm{a}$ & $4.6 a$ & $2.9 a$ \\
\hline $\mathrm{BION}^{\circledR}$ Spray $10 \mathrm{ppm} / \mathrm{BBCH} 65$ & $88.3 a$ & $4.1 \mathrm{a}$ & $2.5 a$ & $87.6 a$ & $4.8 a$ & $2.7 a$ \\
\hline $\mathrm{BION}^{\circledR}$ Spray $125 p p m / \mathrm{BBCH} 65$ & $88.2 a$ & $4.2 a$ & $2.6 a$ & $88.9 a$ & $3.6 a$ & $2.7 a$ \\
\hline
\end{tabular}


Table A.20: Influence of $\mathrm{BION}^{\circledR}$ leaf spray application on oil composition (\%) of all varieties at both experiment sites in 2005.

\begin{tabular}{|c|c|c|c|c|c|c|}
\hline & \multicolumn{3}{|c|}{ BRAUNSCHWEIG } & \multicolumn{3}{|c|}{ ECKARTSWEIER } \\
\hline & $\begin{array}{c}\text { Oleic } \\
\text { acid (\%) }\end{array}$ & $\begin{array}{l}\text { Linoleic } \\
\text { acid (\%) }\end{array}$ & $\begin{array}{c}\text { Stearic } \\
\text { acid (\%) }\end{array}$ & $\begin{array}{c}\text { Oleic } \\
\text { acid (\%) }\end{array}$ & $\begin{array}{l}\text { Linoleic } \\
\text { acid (\%) }\end{array}$ & $\begin{array}{c}\text { Stearic } \\
\text { acid (\%) }\end{array}$ \\
\hline \multicolumn{7}{|l|}{ OLSAVIL } \\
\hline Control & $90.4 a$ & $3.6 a$ & $1.5 a$ & $90.4 a$ & $3.6 a$ & $1.5 a$ \\
\hline $\mathrm{BION}^{\circledR}$ Spray $10 \mathrm{ppm} / \mathrm{BBCH} 09$ & $90.6 a$ & $3.8 a$ & $1.4 a$ & $90.6 a$ & $3.8 a$ & $1.4 a$ \\
\hline $\mathrm{BION}^{\circledR}$ Spray $125 \mathrm{ppm} / \mathrm{BBCH} 09$ & $90.3 a$ & $3.9 a$ & $1.5 a$ & $90.3 a$ & $3.9 a$ & $1.5 a$ \\
\hline $\mathrm{BION}^{\circledR}$ Spray $10 \mathrm{ppm} / \mathrm{BBCH} 16$ & $90.2 a$ & $3.9 a$ & $1.5 a$ & $90.2 a$ & $3.9 a$ & $1.5 a$ \\
\hline $\mathrm{BION}^{\circledR}$ Spray $125 p p m / \mathrm{BBCH} 16$ & $90.9 a$ & $3.5 a$ & $1.4 a$ & $90.9 a$ & $3.5 a$ & $1.4 a$ \\
\hline $\mathrm{BION}^{\circledR}$ Spray $10 \mathrm{ppm} / \mathrm{BBCH} 65$ & $90.7 a$ & $3.5 a$ & $1.5 a$ & $90.7 a$ & $3.5 a$ & $1.5 a$ \\
\hline $\mathrm{BION}^{\circledR}$ Spray $125 p p m / \mathrm{BBCH} 65$ & $90.3 a$ & $3.9 a$ & $1.5 a$ & $90.3 a$ & $3.9 a$ & $1.5 a$ \\
\hline \multicolumn{7}{|l|}{ PR64H41 } \\
\hline Control & $85.2 a$ & $7.1 \mathrm{a}$ & $2.8 a$ & $85.2 a$ & $7.1 \mathrm{a}$ & $2.8 a$ \\
\hline BION ${ }^{\circledR}$ Spray 10ppm/BBCH09 & $84.9 a$ & $7.5 a$ & $2.8 a$ & $84.9 a$ & $7.5 a$ & $2.8 a$ \\
\hline $\mathrm{BION}^{\circledR}$ Spray $125 \mathrm{ppm} / \mathrm{BBCH} 09$ & $85.3 a$ & $7.3 a$ & $2.8 a$ & $85.3 a$ & $7.3 a$ & $2.8 a$ \\
\hline $\mathrm{BION}^{\circledR}$ Spray $10 \mathrm{ppm} / \mathrm{BBCH} 16$ & $84.6 a$ & $7.7 a$ & $2.8 a$ & $84.6 a$ & $7.7 a$ & $2.8 a$ \\
\hline $\mathrm{BION}^{\circledR}$ Spray $125 \mathrm{ppm} / \mathrm{BBCH} 16$ & $85.1 \mathrm{a}$ & $7.4 a$ & $2.8 a$ & $85.1 \mathrm{a}$ & $7.4 a$ & $2.8 a$ \\
\hline $\mathrm{BION}^{\circledR}$ Spray 10 ppm/BBCH65 & $85.2 a$ & $7.5 a$ & $2.6 a$ & $85.2 a$ & $7.5 a$ & $2.6 a$ \\
\hline $\mathrm{BION}^{\circledR}$ Spray $125 p p m / \mathrm{BBCH} 65$ & $85.7 a$ & $6.9 a$ & $2.8 a$ & $85.7 a$ & $6.9 a$ & $2.8 a$ \\
\hline \multicolumn{7}{|l|}{ AURASOL } \\
\hline Control & $84.8 a$ & $7.3 a$ & $3.1 \mathrm{a}$ & $84.8 a$ & $7.3 a$ & $3.1 \mathrm{a}$ \\
\hline $\mathrm{BION}^{\circledR}$ Spray $10 p p m / \mathrm{BBCH} 09$ & $85.6 a$ & $6.8 a$ & $3.0 \mathrm{a}$ & $85.6 a$ & $6.8 a$ & $3.0 a$ \\
\hline $\mathrm{BION}^{\circledR}$ Spray $125 \mathrm{ppm} / \mathrm{BBCH} 09$ & $86.2 a$ & $6.4 a$ & $2.9 a$ & $86.2 a$ & $6.4 a$ & $2.9 a$ \\
\hline $\mathrm{BION}^{\circledR}$ Spray 10 ppm/BBCH16 & $85.4 a$ & $6.8 a$ & $3.1 \mathrm{a}$ & $85.4 a$ & $6.8 a$ & $3.1 \mathrm{a}$ \\
\hline $\mathrm{BION}^{\circledR}$ Spray $125 \mathrm{ppm} / \mathrm{BBCH} 16$ & $86.3 a$ & $6.1 \mathrm{a}$ & $3.0 \mathrm{a}$ & $86.3 a$ & $6.1 \mathrm{a}$ & $3.0 \mathrm{a}$ \\
\hline $\mathrm{BION}^{\circledR}$ Spray 10 ppm/BBCH65 & $85.1 \mathrm{a}$ & $7.1 \mathrm{a}$ & $3.1 a$ & $85.1 \mathrm{a}$ & $7.1 \mathrm{a}$ & $3.1 \mathrm{a}$ \\
\hline $\mathrm{BION}^{\circledR}$ Spray $125 \mathrm{ppm} / \mathrm{BBCH} 65$ & $85.8 a$ & $6.5 a$ & $3.1 \mathrm{a}$ & $85.8 a$ & $6.5 a$ & $3.1 \mathrm{a}$ \\
\hline
\end{tabular}

Table A.21: Influence of liquid ammonium fertilizer on fungal infection rate (\%) compared to control conditions for all three varieties at both experiment sites in 2003.

\begin{tabular}{|c|c|c|c|c|c|c|}
\hline & \multicolumn{3}{|c|}{ BRAUNSCHWEIG } & \multicolumn{3}{|c|}{ ECKARTSWEIER } \\
\hline & Olsavil & PR64H41 & Aurasol & Olsavil & PR64H41 & Aurasol \\
\hline Control & $3.3 a$ & $0.9 a$ & $0.4 a$ & $2.5 a$ & $1.0 a$ & $1.0 \mathrm{a}$ \\
\hline${ }^{*} \mathrm{UAN}$ BBCH16 48kgN & $1.5 a$ & $0.0 a$ & $0.4 a$ & $1.0 a$ & $15.0 a$ & $1.4 a$ \\
\hline UAN BBCH16 60kgN & $0.0 \mathrm{a}$ & $3.9 a$ & $1.8 a$ & $4.0 a$ & $1.9 a$ & $5.5 a$ \\
\hline 'UAN-N BBCH16 48kgN & $0.5 a$ & $0.5 a$ & $0.0 a$ & $5.6 a$ & $10.3 a$ & $2.0 a$ \\
\hline UAN-N BBCH16 60kgN & $0.0 \mathrm{a}$ & $0.4 a$ & $0.8 a$ & $7.0 a$ & $5.0 a$ & $0.5 a$ \\
\hline${ }^{+\dagger} \mathrm{UAS}$ BBCH16 48kgN & $1.4 a$ & $1.0 a$ & $0.0 \mathrm{a}$ & $6.6 a$ & $7.0 \mathrm{a}$ & $4.0 a$ \\
\hline UAS BBCH16 60kgN & $3.2 a$ & $3.8 a$ & $0.0 a$ & $4.0 \mathrm{a}$ & $6.1 \mathrm{a}$ & $0.5 a$ \\
\hline UAN BBCH30 48kgN & $2.1 \mathrm{a}$ & $1.9 a$ & $2.7 a$ & - & - & - \\
\hline UAN BBCH30 60kgN & $0.0 \mathrm{a}$ & 4.3a & $0.8 a$ & - & - & - \\
\hline UAN-N BBCH30 48kgN & $0.0 a$ & $7.9 a$ & $2.0 a$ & - & - & - \\
\hline UAN-N BBCH30 60kgN & $2.0 a$ & $0.4 a$ & $0.0 a$ & - & - & - \\
\hline UAS BBCH30 48kgN & $1.5 a$ & $3.4 a$ & $0.4 a$ & - & - & - \\
\hline UAS BBCH30 60kgN & $6.1 \mathrm{a}$ & $0.0 a$ & $10.5 a$ & - & - & - \\
\hline
\end{tabular}

*UAN:urea ammonium nitrate solution, ${ }^{\dagger} \mathrm{UAN}-\mathrm{N}$ : urea ammonium nitrate solution with nitrification inhibitor, ${ }^{+\dagger}$ UAS:urea ammonium sulphate solution, $\mathrm{N}$ concentration at Eckartsweier: $50 / 80 \mathrm{kgN} / \mathrm{ha}$. 
Table A.22: Influence of liquid ammonium fertilizer application on yield and quality parameters for Olsavil in preliminary field experiments in 2002 at Braunschweig.

\begin{tabular}{|c|c|c|c|c|c|c|c|c|c|}
\hline & $\begin{array}{c}\text { Fungal } \\
\text { infec. } \\
(\%)\end{array}$ & $\begin{array}{l}\text { Grain } \\
\text { yield } \\
\text { (dt/ha) }\end{array}$ & $\begin{array}{l}\text { Plant } \\
\text { height } \\
(\mathrm{cm})\end{array}$ & $\begin{array}{l}\text { Head } \\
\text { diam. } \\
(\mathrm{cm})\end{array}$ & $\begin{array}{c}\text { TSW }^{*} \\
\text { (g) }\end{array}$ & Oil (\%) & $\begin{array}{c}18: 1 \\
(\%)\end{array}$ & $\begin{array}{l}18: 2 \\
(\%)\end{array}$ & $\begin{array}{c}18: 0 \\
(\%)\end{array}$ \\
\hline$\overline{\text { Cont }}$ & $100.0 \mathrm{a}$ & $33.9 a$ & $166.8 b$ & $17.5 a$ & $63.3 \mathrm{ab}$ & $53.9 a$ & $92.8 a$ & $2.1 \mathrm{a}$ & $1.2 a b$ \\
\hline $\mathrm{UAN}^{\dagger}$ & $100.0 a$ & $33.2 \mathrm{a}$ & $170.0 \mathrm{ab}$ & 16.3ab & 59.9ab & $53.2 a$ & $92.2 a$ & $2.6 a$ & $1.3 a b$ \\
\hline UAN $60 N$ & $100.0 a$ & $35.1 \mathrm{a}$ & $180.8 \mathrm{ab}$ & $17.1 \mathrm{a}$ & $64.3 a b$ & $53.3 a$ & $92.8 a$ & $2.3 a$ & $1.2 \mathrm{~b}$ \\
\hline UAN 72N & $100.0 a$ & $30.1 a$ & 179.6ab & $15.5 a b$ & $62.3 a b$ & $53.1 \mathrm{a}$ & $92.3 a$ & $2.6 a$ & $1.3 a b$ \\
\hline $48 \mathrm{~N}$ & $100.0 a$ & $34.0 a$ & $183.6 a$ & 15.2ab & $61.7 \mathrm{ab}$ & $53.8 a$ & $92.3 a$ & $2.4 a$ & $1.2 a b$ \\
\hline Surf & & & & & $58.2 b$ & $54.0 a$ & $92.5 \mathrm{a}$ & $2.5 a$ & $1.2 a b$ \\
\hline Surface $72 \mathrm{~N}$ & & & & & $3 a$ & $51.7 a$ & $92.2 a$ & $2.5 a$ & $1.4 a$ \\
\hline Mean & & & & & 4 & & 92.5 & 2.4 & 1.3 \\
\hline $\mathrm{LSD}_{0.05}$ & 0.0 & 15.3 & 14.9 & 2.7 & 9.1 & 2.5 & 0.8 & 0.9 & 0.2 \\
\hline
\end{tabular}

${ }^{*}$ TSW: Thousand seed weight, ${ }^{\dagger}$ UAN: urea ammonium nitrate solution,

Table A.23: Influence of liquid ammonium fertilizer application on yield and quality parameters for PR64H61 in preliminary field experiments in 2002 at Braunschweig.

\begin{tabular}{|c|c|c|c|c|c|c|c|c|c|}
\hline & $\begin{array}{c}\text { Fungal } \\
\text { infec. } \\
(\%) \\
\end{array}$ & $\begin{array}{l}\text { Grain } \\
\text { yield } \\
\text { (dt/ha) }\end{array}$ & $\begin{array}{c}\text { Plant } \\
\text { height } \\
(\mathrm{cm}) \\
\end{array}$ & $\begin{array}{l}\text { Head } \\
\text { diam. } \\
(\mathrm{cm})\end{array}$ & $\begin{array}{c}\text { TSW }^{*} \\
(\mathrm{~g})\end{array}$ & Oil (\%) & $\begin{array}{c}18: 1 \\
(\%)\end{array}$ & $\begin{array}{c}18: 2 \\
(\%) \\
\end{array}$ & $\begin{array}{c}18: 0 \\
(\%) \\
\end{array}$ \\
\hline Control & $80.2 a$ & $26.4 a$ & $145.7 a$ & $17.3 a$ & $66.6 a$ & $52.4 a$ & $91.6 a$ & $2.9 a$ & $1.5 a$ \\
\hline $\mathrm{UAN}^{\dagger} 48 \mathrm{~N}$ & $71.3 a$ & $26.8 a$ & $149.0 a$ & $19.1 \mathrm{a}$ & $72.3 a$ & $50.4 a$ & $90.6 a$ & $3.7 a$ & $1.6 a$ \\
\hline UAN 60N & $83.8 a$ & $30.4 a$ & $148.3 a$ & $19.5 a$ & $70.8 a$ & $50.4 a$ & $90.4 a$ & $3.8 a$ & $1.6 a$ \\
\hline UAN 72N & $82.8 a$ & $31.3 a$ & $146.3 a$ & $18.8 a$ & $66.5 a$ & $50.8 a$ & $90.4 a$ & $3.9 a$ & $1.6 a$ \\
\hline Surface $48 \mathrm{~N}$ & $85.7 a$ & $21.9 a$ & $146.0 \mathrm{a}$ & $18.4 a$ & $76.3 a$ & $49.6 a$ & $90.4 a$ & $3.8 a$ & $1.8 a$ \\
\hline Surface $60 \mathrm{~N}$ & $90.7 a$ & $32.5 a$ & $150.8 a$ & $17.7 a$ & $71.2 a$ & $51.0 a$ & $89.0 a$ & $5.0 a$ & $1.7 a$ \\
\hline Surface $72 \mathrm{~N}$ & $90.6 a$ & $33.4 a$ & $153.9 a$ & $18.4 a$ & $79.1 a$ & $48.3 a$ & $90.4 a$ & $3.7 a$ & $1.8 \mathrm{a}$ \\
\hline Mean & 83.6 & 28.9 & 148.5 & 18.5 & 71.8 & 50.4 & 90.4 & 3.8 & 1.6 \\
\hline $\mathrm{LSD}_{0.05}$ & 32.0 & 12.5 & 17.5 & 4.1 & 16.4 & 5.3 & 2.8 & 2.5 & 0.3 \\
\hline
\end{tabular}

Table A.24: Influence of liquid ammonium fertilizer application on yield and quality parameters for Aurasol in preliminary field experiments in 2002 at Braunschweig.

\begin{tabular}{lccccccccc}
\hline & $\begin{array}{c}\text { Fungal } \\
\text { infec. } \\
\text { (\%) }\end{array}$ & $\begin{array}{c}\text { Grain } \\
\text { yield } \\
\text { (dt/ha) }\end{array}$ & $\begin{array}{c}\text { Plant } \\
\text { height } \\
\text { (cm) }\end{array}$ & $\begin{array}{c}\text { Head } \\
\text { diam. } \\
\text { (cm) }\end{array}$ & $\begin{array}{c}\text { TSW* } \\
\text { (g) }\end{array}$ & Oil (\%) & $\begin{array}{c}\mathbf{1 8 : 1} \\
\text { (\%) }\end{array}$ & $\begin{array}{c}\mathbf{1 8 : 2} \\
\mathbf{( \% )}\end{array}$ & $\begin{array}{c}\mathbf{1 8 : 0} \\
\text { (\%) }\end{array}$ \\
\hline Control & $\mathbf{4 0 . 7 b}$ & $\mathbf{2 8 . 1 a}$ & $\mathbf{1 4 0 . 8 a}$ & $\mathbf{1 5 . 5 a}$ & $\mathbf{6 3 . 1 a}$ & $\mathbf{5 0 . 9 a}$ & $\mathbf{8 5 . 4 a}$ & $\mathbf{7 . 5 a}$ & $\mathbf{2 . 8 a b}$ \\
UAN $^{\dagger}$ 48N & $50.5 \mathrm{ab}$ & $31.0 \mathrm{a}$ & $151.2 \mathrm{a}$ & $13.9 \mathrm{a}$ & $59.2 \mathrm{a}$ & $51.4 \mathrm{a}$ & $88.2 \mathrm{a}$ & $5.1 \mathrm{a}$ & $2.6 \mathrm{~b}$ \\
UAN 60N & $58.5 \mathrm{ab}$ & $33.2 \mathrm{a}$ & $145.4 \mathrm{a}$ & $16.6 \mathrm{a}$ & $69.1 \mathrm{a}$ & $48.4 \mathrm{a}$ & $88.1 \mathrm{a}$ & $4.7 \mathrm{a}$ & $2.9 \mathrm{ab}$ \\
UAN 72N & $43.4 \mathrm{ab}$ & $37.6 \mathrm{a}$ & $147.1 \mathrm{a}$ & $14.8 \mathrm{a}$ & $61.0 \mathrm{a}$ & $50.7 \mathrm{a}$ & $87.7 \mathrm{a}$ & $5.1 \mathrm{a}$ & $2.8 \mathrm{ab}$ \\
Surface 48N & $67.1 \mathrm{a}$ & $34.0 \mathrm{a}$ & $151.3 \mathrm{a}$ & $15.5 \mathrm{a}$ & $66.5 \mathrm{a}$ & $49.6 \mathrm{a}$ & $88.4 \mathrm{a}$ & $4.6 \mathrm{a}$ & $2.8 \mathrm{ab}$ \\
Surface 60N & $55.5 \mathrm{ab}$ & $37.3 \mathrm{a}$ & $162.9 \mathrm{a}$ & $14.5 \mathrm{a}$ & $62.1 \mathrm{a}$ & $48.7 \mathrm{a}$ & $86.8 \mathrm{a}$ & $5.8 \mathrm{a}$ & $3.1 \mathrm{a}$ \\
Surface 72N & $59.2 \mathrm{ab}$ & $33.2 \mathrm{a}$ & $152.4 \mathrm{a}$ & $16.1 \mathrm{a}$ & $69.0 \mathrm{a}$ & $\mathbf{4 7 . 9 a}$ & $86.7 \mathrm{a}$ & $5.9 \mathrm{a}$ & $2.9 \mathrm{ab}$ \\
\hline Mean & 53.6 & 33.5 & 150.2 & 15.3 & 64.3 & 49.7 & 87.3 & 5.5 & 2.8 \\
LSD $_{0.05}$ & 24.8 & 9.8 & 24.1 & 3.1 & 13.7 & 5.1 & 3.4 & 3.5 & 0.4 \\
\hline
\end{tabular}


Table A.25: Influence of liquid ammonium fertilizer on plant height (cm) for all three varieties at Braunschweig in 2003-2004.

\begin{tabular}{|c|c|c|c|c|c|c|}
\hline & \multicolumn{3}{|c|}{2003} & \multicolumn{3}{|c|}{2004} \\
\hline & Olsavil & PR64H41 & Aurasol & Olsavil & PR64H41 & Aurasol \\
\hline Control & $102.5 a$ & $89.0 a$ & $97.4 a$ & $160.8 a$ & $150.4 a$ & $136.9 a$ \\
\hline *UAN BBCH16 48kgN & $114.5 a$ & $102.3 a$ & $110.8 a$ & $169.7 a$ & $145.2 a$ & $139.1 \mathrm{a}$ \\
\hline UAN BBCH16 60kgN & $113.5 a$ & $98.8 a$ & $104.4 a$ & - & - & - \\
\hline${ }^{\dagger} \mathrm{UAN}-\mathrm{N}$ BBCH16 48kgN & $114.3 a$ & $90.1 \mathrm{a}$ & $90.8 \mathrm{a}$ & $173.5 a$ & $152.6 a$ & $139.4 a$ \\
\hline UAN-N BBCH16 60kgN & $123.1 \mathrm{a}$ & $103.0 \mathrm{a}$ & $107.7 a$ & - & - & - \\
\hline${ }^{+}$UAS BBCH $1648 \mathrm{kgN}$ & $116.6 a$ & $99.3 a$ & $104.1 \mathrm{a}$ & 169.1a & $155.3 a$ & $147.9 a$ \\
\hline UAS BBCH16 60kgN & $127.5 a$ & $95.7 a$ & $97.1 \mathrm{a}$ & - & - & - \\
\hline UAN BBCH30 48kgN & $109.9 a$ & $111.1 \mathrm{a}$ & $110.2 a$ & $169.5 a$ & $144.6 a$ & $138.2 a$ \\
\hline UAN BBCH30 60kgN & $112.4 a$ & $100.6 a$ & $103.6 a$ & - & - & - \\
\hline UAN-N BBCH3O $48 \mathrm{kgN}$ & $120.7 a$ & $91.3 a$ & $91.1 \mathrm{a}$ & $170.3 a$ & $147.1 \mathrm{a}$ & $138.7 a$ \\
\hline UAN-N BBCH30 60kgN & $121.2 \mathrm{a}$ & $104.8 a$ & 107.3a & - & - & - \\
\hline UAS BBCH30 48kgN & $118.5 a$ & 103.3a & $118.2 a$ & $166.6 a$ & $153.7 a$ & $149.6 a$ \\
\hline UAS BBCH30 60kgN & $121.0 \mathrm{a}$ & $101.9 a$ & $107.7 a$ & - & - & - \\
\hline
\end{tabular}

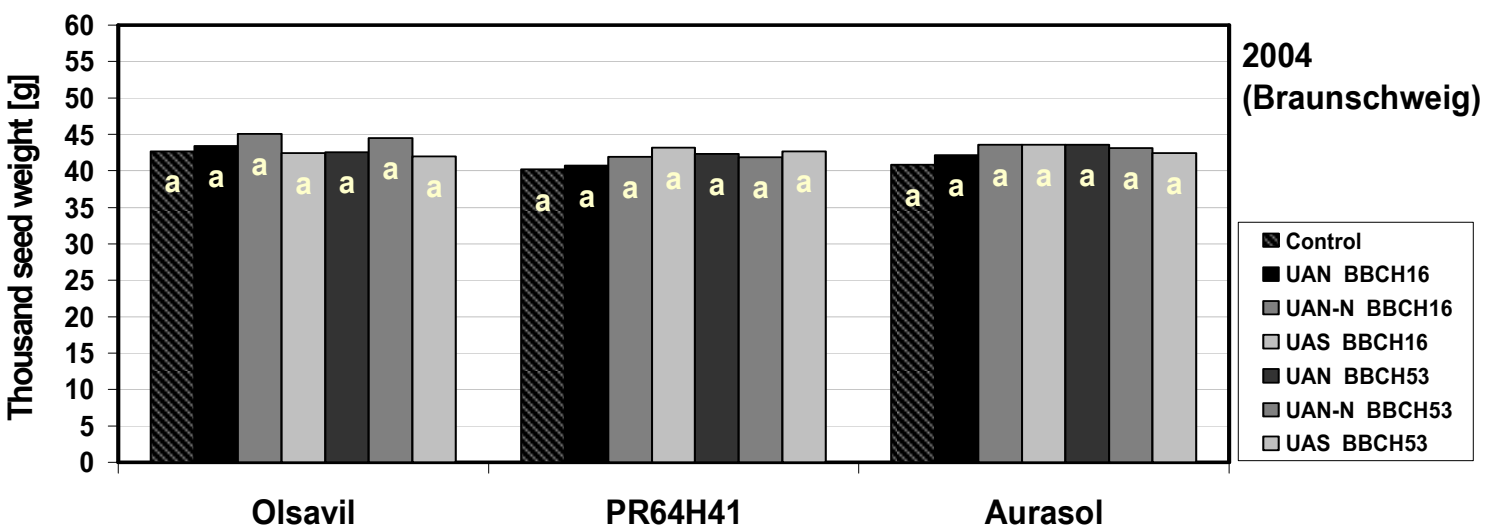

Figure A.5: Influence of liquid ammonium fertilizer on thousand seed weight $(\mathrm{g})$ at Braunschweig in 2004.

Table A.26: Influence of liquid ammonium fertilizer on yield for all three varieties at Braunschweig in 2003.

\begin{tabular}{llllllll}
\hline & \multicolumn{3}{c}{ Thousand seed weight (g) } & & \multicolumn{3}{c}{ Head diameter (cm) } \\
\cline { 2 - 3 } \cline { 7 - 8 } & Olsavil & PR64H41 & Aurasol & & Olsavil & PR64H41 & Aurasol \\
\hline Control & $40.2 \mathrm{ab}$ & $39.3 \mathrm{a}$ & $44.6 \mathrm{a}$ & & $13.4 \mathrm{a}$ & $11.8 \mathrm{a}$ & $13.0 \mathrm{a}$ \\
${ }^{*}$ UAN BBCH16 48kgN & $43.8 \mathrm{ab}$ & $43.4 \mathrm{a}$ & $50.6 \mathrm{a}$ & & $13.4 \mathrm{a}$ & $12.0 \mathrm{a}$ & $12.3 \mathrm{a}$ \\
UAN BBCH16 60kgN & $38.4 \mathrm{ab}$ & $44.2 \mathrm{a}$ & $47.5 \mathrm{a}$ & & $13.4 \mathrm{a}$ & $12.7 \mathrm{a}$ & $12.9 \mathrm{a}$ \\
tUAN-N BBCH16 48kgN & $46.0 \mathrm{ab}$ & $44.1 \mathrm{a}$ & $47.5 \mathrm{a}$ & & $14.0 \mathrm{a}$ & $13.4 \mathrm{a}$ & $12.1 \mathrm{a}$ \\
UAN-N BBCH16 60kgN & $40.6 \mathrm{ab}$ & $40.2 \mathrm{a}$ & $41.7 \mathrm{a}$ & & $13.1 \mathrm{a}$ & $11.8 \mathrm{a}$ & $12.2 \mathrm{a}$ \\
t+UAS BBCH16 48kgN & $42.3 \mathrm{ab}$ & $42.7 \mathrm{a}$ & $50.5 \mathrm{a}$ & & $13.8 \mathrm{a}$ & $12.5 \mathrm{a}$ & $12.6 \mathrm{a}$ \\
UAS BBCH16 60kgN & $52.0 \mathrm{a}$ & $41.3 \mathrm{a}$ & $43.6 \mathrm{a}$ & & $14.6 \mathrm{a}$ & $12.2 \mathrm{a}$ & $11.5 \mathrm{a}$ \\
\hline UAN BBCH30 48kgN & $39.9 \mathrm{ab}$ & $46.2 \mathrm{a}$ & $40.2 \mathrm{a}$ & & $12.8 \mathrm{a}$ & $13.1 \mathrm{a}$ & $11.3 \mathrm{a}$ \\
UAN BBCH30 60kgN & $40.3 \mathrm{ab}$ & $46.7 \mathrm{a}$ & $47.1 \mathrm{a}$ & & $13.0 \mathrm{a}$ & $13.7 \mathrm{a}$ & $12.4 \mathrm{a}$ \\
UAN-N BBCH30 48kgN & $49.9 \mathrm{ab}$ & $39.2 \mathrm{a}$ & $42.0 \mathrm{a}$ & & $14.1 \mathrm{a}$ & $12.2 \mathrm{a}$ & $11.1 \mathrm{a}$ \\
UAN-N BBCH30 60kgN & $38.3 \mathrm{ab}$ & $38.8 \mathrm{a}$ & $45.3 \mathrm{a}$ & & $14.0 \mathrm{a}$ & $12.3 \mathrm{a}$ & $12.4 \mathrm{a}$ \\
UAS BBCH30 48kgN & $37.0 \mathrm{~b}$ & $46.2 \mathrm{a}$ & $45.0 \mathrm{a}$ & & $12.7 \mathrm{a}$ & $12.6 \mathrm{a}$ & $11.6 \mathrm{a}$ \\
UAS BBCH30 60kgN & $42.8 \mathrm{ab}$ & $46.7 \mathrm{a}$ & $51.2 \mathrm{a}$ & & $14.4 \mathrm{a}$ & $13.0 \mathrm{a}$ & $12.7 \mathrm{a}$ \\
\hline
\end{tabular}


Table A.27: Influence of liquid ammonium fertilizer on oil composition (\%) for Olsavil and PR64H41 at Braunschweig in 2003.

\begin{tabular}{|c|c|c|c|c|c|c|}
\hline & \multicolumn{3}{|c|}{ OLSAVIL } & \multicolumn{3}{|c|}{ PR64H41 } \\
\hline & $\begin{array}{c}\text { Oleic } \\
\text { acid (\%) }\end{array}$ & $\begin{array}{l}\text { Linoleic } \\
\text { acid (\%) }\end{array}$ & $\begin{array}{c}\text { Stearic } \\
\text { acid (\%) }\end{array}$ & $\begin{array}{c}\text { Oleic } \\
\text { acid (\%) }\end{array}$ & $\begin{array}{l}\text { Linoleic } \\
\text { acid (\%) }\end{array}$ & $\begin{array}{c}\text { Stearic } \\
\text { acid (\%) }\end{array}$ \\
\hline Control & $89.8 a b c$ & $2.7 a$ & $1.9 a b$ & $88.3 a$ & $3.6 a$ & $2.7 a$ \\
\hline *UAN BBCH16 48kgN & $90.8 a b c$ & $2.4 a$ & $1.6 a b$ & $89.1 a$ & $3.2 \mathrm{a}$ & $2.4 a$ \\
\hline UAN BBCH16 60kgN & 89.6abc & $2.8 \mathrm{a}$ & $2.0 \mathrm{a}$ & $88.4 a$ & $3.9 a$ & $2.5 a$ \\
\hline${ }^{\dagger} \mathrm{UAN}-\mathrm{N}$ BBCH $1648 \mathrm{kgN}$ & $90.9 a b c$ & $2.5 a$ & $1.6 a b$ & $89.1 \mathrm{a}$ & 3.3a & $2.2 a$ \\
\hline UAN-N BBCH16 60kgN & $90.9 a b c$ & $2.1 \mathrm{a}$ & $1.5 a b$ & $89.1 \mathrm{a}$ & $3.6 a$ & $2.3 a$ \\
\hline${ }^{+}$UAS BBCH16 48kgN & $91.2 \mathrm{abc}$ & $2.2 a$ & $1.5 \mathrm{ab}$ & $89.3 a$ & $3.5 a$ & $2.2 a$ \\
\hline UAS BBCH16 60kgN & $92.0 a$ & $2.0 a$ & $1.3 \mathrm{~b}$ & $87.8 a$ & $4.0 \mathrm{a}$ & $2.6 a$ \\
\hline UAN BBCH30 48kgN & $90.1 \mathrm{abc}$ & $2.3 a$ & $1.8 a b$ & $88.7 a$ & $3.6 a$ & $2.5 a$ \\
\hline UAN BBCH30 60kgN & $90.6 a b c$ & $2.3 a$ & $1.8 a b$ & $88.1 a$ & $4.4 a$ & $2.4 a$ \\
\hline UAN-N BBCH30 48kgN & $92.0 \mathrm{ab}$ & $2.1 \mathrm{a}$ & $1.3 b$ & $88.1 \mathrm{a}$ & $3.7 a$ & $2.5 a$ \\
\hline UAN-N BBCH30 60kgN & $89.5 b c$ & $2.7 a$ & $2.1 \mathrm{a}$ & $87.7 a$ & $3.8 a$ & $2.8 a$ \\
\hline UAS BBCH30 48kgN & $89.2 c$ & $3.0 a$ & $2.1 \mathrm{a}$ & $87.4 a$ & $4.6 a$ & $2.6 a$ \\
\hline UAS BBCH30 60kgN & $90.8 \mathrm{abc}$ & $2.4 a$ & $1.6 a b$ & $88.1 \mathrm{a}$ & $3.7 a$ & $2.5 a$ \\
\hline
\end{tabular}

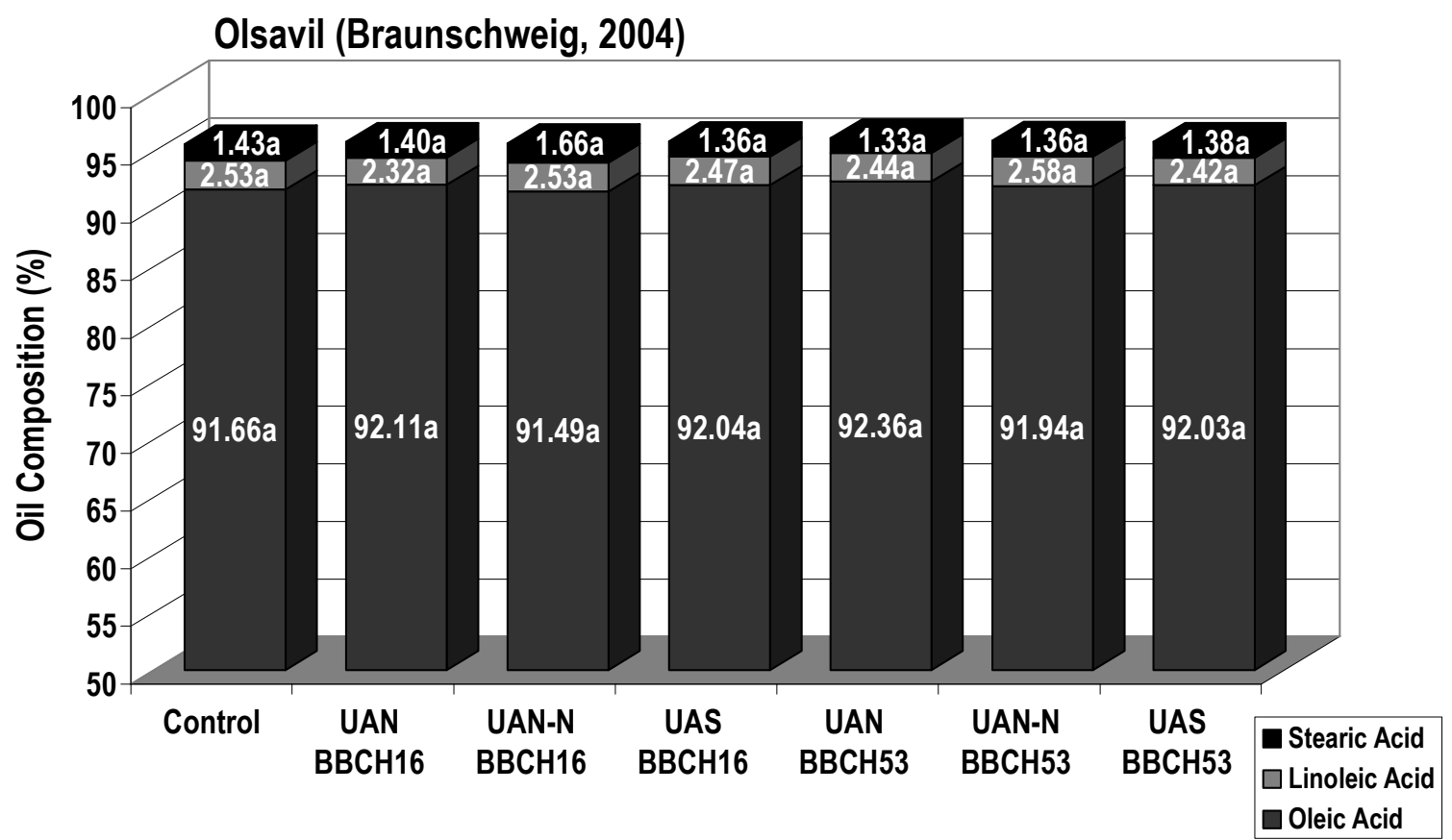

Figure A.6: Influence of liquid ammonium fertilizer on oil composition (\%) of Olsavil at Braunschweig in 2004. UAN: urea ammonium nitrate solution, UAN-N: urea ammonium nitrate solution with nitrification inhibitor, UAS urea ammonium sulphate solution $\mathrm{N}$ concentration: 48 $\mathrm{kgN} / \mathrm{ha}$. 


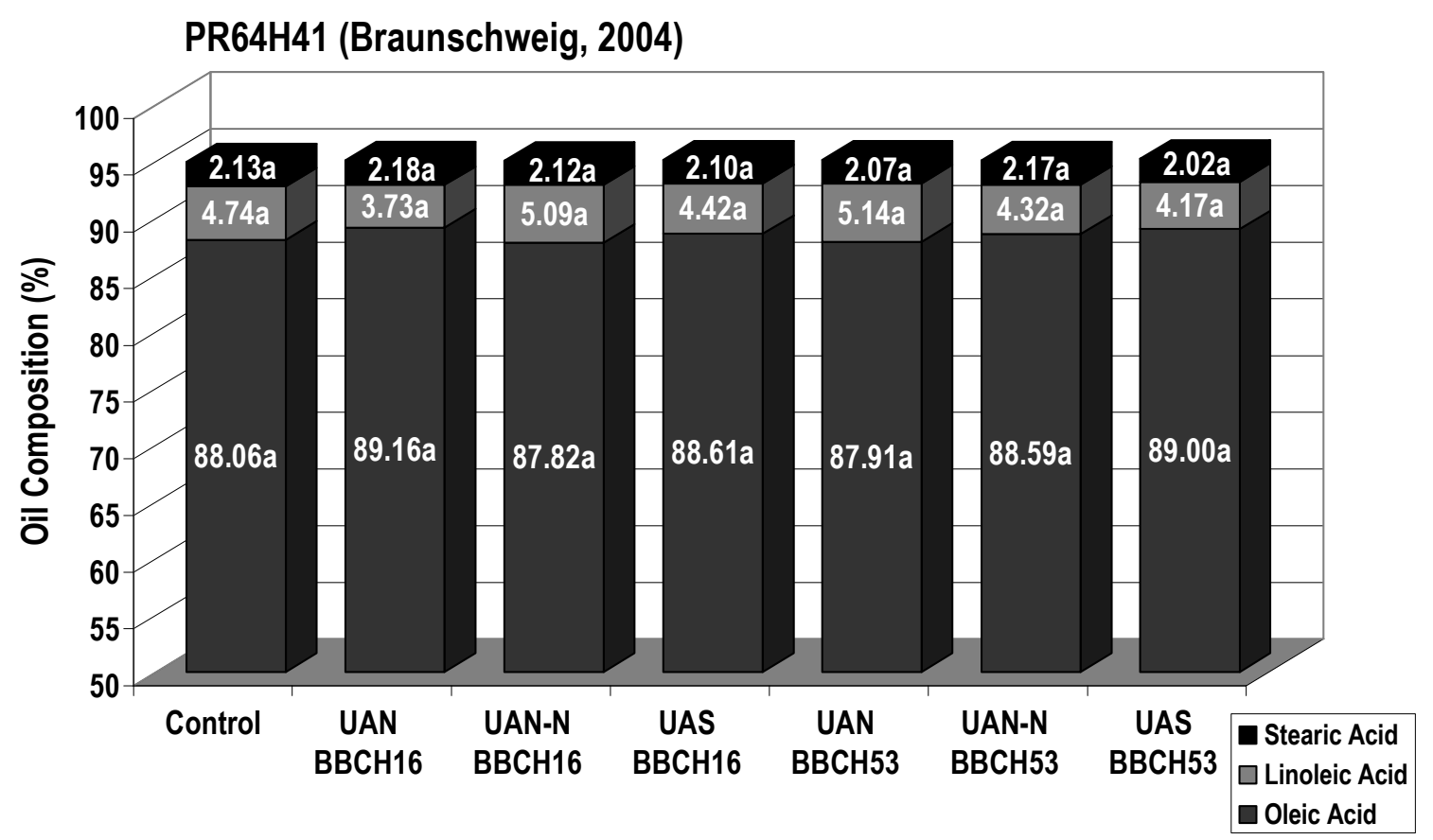

Figure A.7: Influence of liquid ammonium fertilizer on oil composition (\%) of PR64H41 at Braunschweig in 2004.

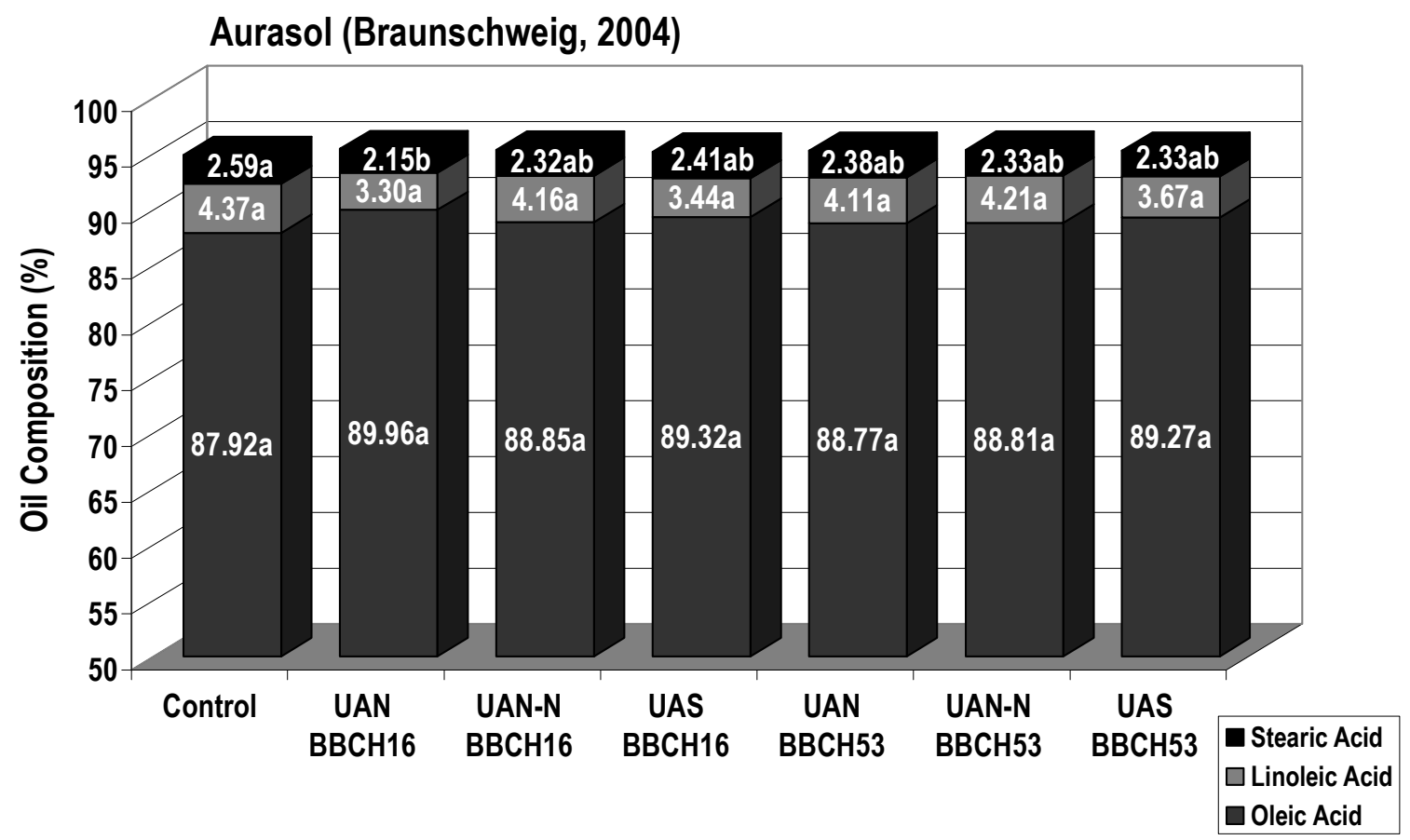

Figure A.8: Influence of liquid ammonium fertilizer on oil composition (\%) of Aurasol at Braunschweig in 2004. 
Table A.28: Influence of liquid ammonium fertilizer and $\mathrm{BION}^{\circledR}$ combination on fungal infection rate (\%) of all varieties at both experiment sites in 2003.

\begin{tabular}{|c|c|c|c|}
\hline & \multicolumn{3}{|c|}{ Fungal Infection Rate (\%) } \\
\hline & OLSAVIL & PR64H41 & AURASOL \\
\hline \multicolumn{4}{|l|}{ BRAUNSCHWEIG } \\
\hline Control & $3.3 a$ & $0.9 a$ & $0.4 a$ \\
\hline${ }^{*} \mathrm{UAN}+\mathrm{BION}{ }^{\circledR} 250 \mathrm{ppm} / \mathrm{BBCH} 16$ & $1.4 a$ & $0.9 a$ & $0.5 a$ \\
\hline $\mathrm{UAN}+\mathrm{BION}^{\circledR} 500 \mathrm{ppm} / \mathrm{BBCH} 16$ & $2.9 \mathrm{a}$ & $3.0 a$ & $5.7 a$ \\
\hline UAN+BION ${ }^{\circledR} 1000 p p m / B B C H 16$ & $0.4 a$ & $7.1 \mathrm{a}$ & $6.8 a$ \\
\hline $\mathrm{UAN}+\mathrm{BION}^{\circledR} 2000 \mathrm{ppm} / \mathrm{BBCH} 16$ & $0.9 a$ & $1.9 a$ & $1.3 a$ \\
\hline \multicolumn{4}{|l|}{ ECKARTSWEIER } \\
\hline Control & $2.1 \mathrm{a}$ & $1.0 \mathrm{a}$ & $1.0 \mathrm{a}$ \\
\hline UAN+BION ${ }^{\circledR} 250 p p m / B B C H 16$ & $9.3 a$ & $5.9 a$ & $3.5 a$ \\
\hline UAN+BION ${ }^{\circledR} 500 p p m / B B C H 16$ & $1.5 a$ & $5.0 \mathrm{a}$ & $1.0 \mathrm{a}$ \\
\hline $\mathrm{UAN}+\mathrm{BION}^{\circledR} 1000 \mathrm{ppm} / \mathrm{BBCH} 16$ & $5.6 a$ & $4.6 a$ & $1.0 \mathrm{a}$ \\
\hline $\mathrm{UAN}+\mathrm{BION}^{\circledR} 2000 \mathrm{ppm} / \mathrm{BBCH} 16$ & $2.1 \mathrm{a}$ & $3.0 \mathrm{a}$ & $2.0 \mathrm{a}$ \\
\hline
\end{tabular}

*UAN: urea ammonium nitrate solution (48kgN/ha at Braunschweig and $50 \mathrm{kgN} / \mathrm{ha}$ at Eckartsweier)

Table A.29: Influence of $\mathrm{BION}^{\circledR}$-liquid ammonium fertilizer combination on yield and quality parameters for Olsavil in preliminary field experiments in 2002 at Braunschweig.

\begin{tabular}{|c|c|c|c|c|c|c|c|c|}
\hline & $\begin{array}{c}\text { Grain } \\
\text { yield } \\
\text { (dt/ha) }\end{array}$ & $\begin{array}{c}\text { Plant } \\
\text { height } \\
\text { (cm) }\end{array}$ & $\begin{array}{l}\text { Head } \\
\text { diam. } \\
(\mathrm{cm}) \\
\end{array}$ & $\begin{array}{c}\text { TSW } \\
\text { (g) }\end{array}$ & Oil (\%) & $\begin{array}{c}18: 1 \\
(\%) \\
\end{array}$ & $\begin{array}{c}18: 2 \\
(\%) \\
\end{array}$ & $\begin{array}{c}18: 0 \\
(\%)\end{array}$ \\
\hline Control & $33.9 \mathrm{a}$ & $166.8 b$ & $17.5 a$ & $63.3 a$ & $53.8 a$ & $92.8 a$ & $2.1 \mathrm{a}$ & $1.2 \mathrm{a}$ \\
\hline UAN+BION ${ }^{\circledR} 10 p p m$ & $32.8 a$ & 171.9ab & $16.5 a$ & $63.0 a$ & $53.1 \mathrm{a}$ & $92.6 a$ & $2.2 \mathrm{a}$ & $1.3 a$ \\
\hline UAN+BION ${ }^{\circledR} 125 p p m$ & $34.9 a$ & 172.0ab & $18.0 a$ & $67.8 a$ & $52.4 a$ & $92.5 a$ & $2.3 a$ & $1.3 a$ \\
\hline UAN+BION ${ }^{\circledR} 250 p p m$ & $33.0 \mathrm{a}$ & 173.4ab & $17.1 \mathrm{a}$ & $65.2 a$ & $53.4 a$ & $92.4 a$ & $2.5 a$ & $1.3 a$ \\
\hline SurfaceN+BION ${ }^{\circledR} 10 p p m$ & $35.8 a$ & $181.0 \mathrm{a}$ & $16.5 a$ & $66.5 a$ & $51.6 a$ & $92.2 a$ & $2.4 a$ & $1.4 a$ \\
\hline SurfaceN+BION ${ }^{\circledR} 125 p p m$ & $29.3 a$ & 171.0ab & $16.9 a$ & $69.0 a$ & $51.9 a$ & $92.2 \mathrm{a}$ & $2.6 a$ & $1.3 a$ \\
\hline SurfaceN+BION ${ }^{\circledR} 250 \mathrm{ppm}$ & $33.6 a$ & $173.5 a b$ & $15.3 a$ & $67.5 a$ & $51.4 a$ & $92.4 a$ & $2.3 a$ & $1.3 a$ \\
\hline Mean & 33.3 & 172.8 & 16.8 & 66.0 & 52.5 & 92.4 & 2.3 & 1.3 \\
\hline $\operatorname{LSD}_{0.05}{ }^{\ddagger}$ & 9.40 & 13.2 & 3.6 & 17.0 & 4.3 & 0.8 & 0.9 & 0.3 \\
\hline
\end{tabular}

Table A.30: Influence of $\mathrm{BION}^{\circledR}$-liquid ammonium fertilizer combination on yield and quality parameters for PR64H61 in preliminary field experiments in 2002 at Braunschweig.

\begin{tabular}{|c|c|c|c|c|c|c|c|c|}
\hline & $\begin{array}{l}\text { Grain } \\
\text { yield } \\
\text { (dt/ha) }\end{array}$ & $\begin{array}{c}\text { Plant } \\
\text { height } \\
(\mathrm{cm}) \\
\end{array}$ & $\begin{array}{l}\text { Head } \\
\text { diam. } \\
(\mathrm{cm}) \\
\end{array}$ & $\begin{array}{c}\text { TSW } \\
\text { (g) }\end{array}$ & Oil (\%) & $\begin{array}{c}18: 1 \\
(\%)\end{array}$ & $\begin{array}{c}18: 2 \\
(\%)\end{array}$ & $\begin{array}{c}18: 0 \\
(\%)\end{array}$ \\
\hline Control & $26.4 a$ & $145.6 a$ & $17.3 a$ & $66.6 a$ & $52.4 a$ & $91.5 a$ & $2.9 \mathrm{~b}$ & $1.5 \mathrm{~b}$ \\
\hline UAN+BION ${ }^{\circledR} 10 p p m$ & $30.5 a$ & $147.7 a$ & $19.1 \mathrm{a}$ & $74.1 \mathrm{a}$ & $51.1 \mathrm{a}$ & 89.5ab & $4.6 a b$ & $1.6 a b$ \\
\hline UAN+BION ${ }^{\circledR} 125 p p m$ & $30.7 a$ & 149.3a & $19.7 a$ & $74.7 a$ & $50.1 a$ & $88.5 b$ & $5.5 a$ & $1.7 a b$ \\
\hline UAN+BION ${ }^{\circledR} 250 p p m$ & $28.3 a$ & $154.0 \mathrm{a}$ & $18.1 \mathrm{a}$ & $70.1 \mathrm{a}$ & $51.0 a$ & $90.2 a b$ & $4.0 a b$ & $1.5 a b$ \\
\hline SurfaceN+BION ${ }^{\circledR} 10 p p m$ & $28.8 a$ & $150.4 a$ & $19.6 a$ & $77.0 \mathrm{a}$ & $47.6 a$ & $89.5 a b$ & $4.5 a b$ & $1.7 a b$ \\
\hline SurfaceN+BION ${ }^{\circledR} 125 p p m$ & $29.4 a$ & 151.0a & $19.3 a$ & $73.2 \mathrm{a}$ & $48.0 a$ & $90.4 a b$ & $3.7 a b$ & $1.7 a b$ \\
\hline SurfaceN+BION ${ }^{\circledR} 250 p p m$ & $22.2 a$ & $143.5 a$ & $22.7 a$ & $80.4 a$ & $46.1 \mathrm{a}$ & $87.9 b$ & $5.8 a$ & $1.9 a$ \\
\hline Mean & 28.0 & 148.8 & 19.4 & 73.7 & 49.5 & 89.7 & 4.4 & 1.6 \\
\hline $\operatorname{LSD}_{0.05}{ }^{\ddagger}$ & 18.7 & 28.0 & 8.1 & 23.5 & 9.0 & 2.5 & 2.2 & 0.4 \\
\hline
\end{tabular}


Table A.31: Influence of $\mathrm{BION}^{\circledR}$-liquid ammonium fertilizer combination on yield and quality parameters for Aurasol in preliminary field experiments in 2002 at Braunschweig.

\begin{tabular}{|c|c|c|c|c|c|c|c|c|}
\hline & $\begin{array}{c}\text { Grain } \\
\text { yield } \\
\text { (dt/ha) } \\
\end{array}$ & $\begin{array}{c}\text { Plant } \\
\text { height } \\
\text { (cm) }\end{array}$ & $\begin{array}{c}\text { Head } \\
\text { diam. } \\
(\mathrm{cm})\end{array}$ & $\begin{array}{c}\text { TSW } \\
\text { (g) }\end{array}$ & Oil (\%) & $\begin{array}{c}18: 1 \\
(\%)\end{array}$ & $\begin{array}{c}18: 2 \\
(\%)\end{array}$ & $\begin{array}{c}18: 0 \\
(\%) \\
\end{array}$ \\
\hline$\overline{\text { Control }}$ & $28.3 a$ & $140.7 a$ & $15.5 a$ & $63.1 \mathrm{a}$ & $50.9 a$ & $85.4 a$ & $7.5 a$ & $2.7 a$ \\
\hline UAN+BION ${ }^{\circledR} 10 p p m$ & $30.7 a$ & $137.9 a$ & $17.8 \mathrm{a}$ & $71.5 a$ & $47.5 a$ & $88.72 a$ & $4.3 a$ & $2.8 a$ \\
\hline UAN+BION ${ }^{\circledR} 125 p p m$ & $31.0 a$ & 136.3a & $18.0 a$ & $74.9 a$ & $48.1 \mathrm{a}$ & $88.8 a$ & $4.1 \mathrm{a}$ & $2.8 a$ \\
\hline UAN+BION ${ }^{\circledR} 250 p p m$ & $35.0 a$ & $144.4 a$ & $16.0 a$ & $69.9 a$ & $50.1 \mathrm{a}$ & $88.5 a$ & $4.4 \mathrm{a}$ & $2.7 a$ \\
\hline SurfaceN+BION ${ }^{\circledR} 10 p p m$ & $30.5 a$ & $144.9 a$ & $15.9 a$ & $73.1 \mathrm{a}$ & $47.7 a$ & $87.3 a$ & $5.4 \mathrm{a}$ & $2.9 a$ \\
\hline SurfaceN+BION ${ }^{\circledR} 125 p p m$ & $33.5 a$ & $141.37 a$ & $16.6 a$ & $77.1 \mathrm{a}$ & $46.1 \mathrm{a}$ & $86.6 a$ & $6.0 \mathrm{a}$ & $2.9 a$ \\
\hline SurfaceN+BION ${ }^{\circledR} 250 p p m$ & $36.0 \mathrm{a}$ & $145.7 a$ & $15.2 a$ & $67.9 a$ & $49.5 a$ & $86.9 a$ & $6.0 a$ & $2.8 a$ \\
\hline Mean & 32.1 & 141.6 & 16.4 & 71.1 & 48.6 & 87.4 & 5.4 & 2.8 \\
\hline $\operatorname{LSD}_{0.05}{ }^{\ddagger}$ & 10.9 & 18.2 & 5.1 & 18.0 & 6.7 & 4.1 & 4.0 & 0.4 \\
\hline
\end{tabular}

Table A.32: Influence of liquid ammonium fertilizer and $\mathrm{BION}^{\circledR}$ combination on oil composition (\%) for all three varieties at both experiment sites in 2003.

\begin{tabular}{|c|c|c|c|c|c|c|}
\hline & \multicolumn{3}{|c|}{ BRAUNSCHWEIG } & \multicolumn{3}{|c|}{ ECKARTSWEIER } \\
\hline & $\begin{array}{c}\text { Oleic } \\
\text { acid (\%) }\end{array}$ & $\begin{array}{l}\text { Linoleic } \\
\text { acid (\%) }\end{array}$ & $\begin{array}{c}\text { Stearic } \\
\text { acid (\%) }\end{array}$ & $\begin{array}{c}\text { Oleic } \\
\text { acid (\%) }\end{array}$ & $\begin{array}{l}\text { Linoleic } \\
\text { acid (\%) }\end{array}$ & $\begin{array}{c}\text { Stearic } \\
\text { acid (\%) }\end{array}$ \\
\hline \multicolumn{7}{|l|}{ OLSAVIL } \\
\hline Control & $89.8 a$ & $2.7 a$ & $1.9 a$ & $91.1 a$ & $2.3 a$ & $1.7 \mathrm{c}$ \\
\hline${ }^{*} \mathrm{UAN}+\mathrm{BION}^{\circledR} 250 \mathrm{ppm}$ & $91.5 a$ & $2.0 \mathrm{~b}$ & $1.5 a$ & $90.2 a$ & $2.5 a$ & $1.9 \mathrm{bc}$ \\
\hline $\mathrm{UAN}+\mathrm{BION}^{\circledR} 500 \mathrm{ppm}$ & $90.9 a$ & $2.1 \mathrm{ab}$ & $1.5 a$ & $89.5 a$ & $2.7 a$ & $2.2 \mathrm{ab}$ \\
\hline $\mathrm{UAN}+\mathrm{BION}^{\circledR} 1000 \mathrm{ppm}$ & $90.2 a$ & $2.4 a b$ & $1.9 a$ & $89.5 a$ & $2.5 a$ & $2.3 a$ \\
\hline $\mathrm{UAN}+\mathrm{BION}^{\circledR} 2000 \mathrm{ppm}$ & $89.7 a$ & $2.6 a$ & $2.0 a$ & $90.1 \mathrm{a}$ & $2.4 a$ & $2.0 \mathrm{ab}$ \\
\hline \multicolumn{7}{|l|}{ PR64H41 } \\
\hline Control & $88.3 a$ & $3.6 a$ & $2.7 a$ & $88.2 a$ & $4.1 \mathrm{a}$ & $2.5 b$ \\
\hline UAN+BION ${ }^{\circledR} 250 p p m$ & $87.9 a$ & $3.8 a$ & $2.6 a$ & $85.9 a$ & $5.2 a$ & $3.1 \mathrm{a}$ \\
\hline UAN+BION ${ }^{\circledR} 500 p p m$ & $88.5 a$ & $3.4 a$ & $2.6 a$ & $86.7 a$ & $4.7 a$ & $2.9 \mathrm{ab}$ \\
\hline $\mathrm{UAN}^{\mathrm{B}} \mathrm{BION}^{\circledR} 1000 \mathrm{ppm}$ & $88.7 a$ & $3.8 a$ & $2.3 a$ & $87.9 a$ & $3.6 a$ & $2.9 \mathrm{ab}$ \\
\hline $\mathrm{UAN}+\mathrm{BION}^{\circledR} 2000 \mathrm{ppm}$ & $88.2 a$ & $3.7 a$ & $2.6 a$ & $87.4 a$ & $4.0 \mathrm{a}$ & $2.8 \mathrm{ab}$ \\
\hline \multicolumn{7}{|l|}{ AURASOL } \\
\hline Control & $88.6 a$ & $3.2 a$ & $3.0 a$ & $87.7 a$ & $4.2 a$ & $2.7 a$ \\
\hline $\mathrm{UAN} \mathrm{BION}^{\circledR} 250 \mathrm{ppm}$ & $88.0 a$ & $3.5 a$ & $3.0 a$ & $86.7 a$ & $4.4 a$ & $3.2 a$ \\
\hline $\mathrm{UAN} \mathrm{BION}^{\circledR} 500 \mathrm{ppm}$ & $87.4 a$ & $4.2 a$ & $2.9 a$ & $85.0 a$ & $5.9 a$ & $3.3 a$ \\
\hline $\mathrm{UAN}^{\mathrm{B} I O N^{\circledR}}{ }^{1000 p p m}$ & $88.3 a$ & $3.4 a$ & $2.9 a$ & $85.3 a$ & $5.5 a$ & $3.3 a$ \\
\hline 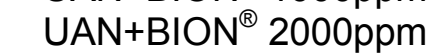 & $88.9 a$ & $2.9 a$ & $2.8 a$ & $87.3 a$ & $4.0 \mathrm{a}$ & $3.1 \mathrm{a}$ \\
\hline
\end{tabular}


Table A.33: Influence of liquid ammonium fertilizer and $\mathrm{BION}^{\circledR}$ combination on oil composition (\%) for all three varieties at both experiment sites in 2004.

\begin{tabular}{|c|c|c|c|c|c|c|}
\hline & \multicolumn{3}{|c|}{ BRAUNSCHWEIG } & \multicolumn{3}{|c|}{ ECKARTSWEIER } \\
\hline & $\begin{array}{c}\text { Oleic } \\
\text { acid (\%) }\end{array}$ & $\begin{array}{l}\text { Linoleic } \\
\text { acid (\%) }\end{array}$ & $\begin{array}{c}\text { Stearic } \\
\text { acid (\%) }\end{array}$ & $\begin{array}{c}\text { Oleic } \\
\text { acid (\%) }\end{array}$ & $\begin{array}{l}\text { Linoleic } \\
\text { acid (\%) }\end{array}$ & $\begin{array}{c}\text { Stearic } \\
\text { acid (\%) }\end{array}$ \\
\hline \multicolumn{7}{|l|}{ OLSAVIL } \\
\hline Control & $91.6 a$ & $2.19 a$ & $1.4 a$ & $91.3 a$ & $2.3 a$ & $1.8 \mathrm{a}$ \\
\hline${ }^{*} \mathrm{UAN}+\mathrm{BION}{ }^{\circledR} 250 \mathrm{ppm} / \mathrm{BBCH} 16$ & $91.9 a$ & $2.43 a$ & $1.4 a$ & $91.3 a$ & $2.1 \mathrm{a}$ & $1.8 a$ \\
\hline UAN+BION ${ }^{\circledR} 500$ ppm/BBCH16 & $92.0 \mathrm{a}$ & $2.35 a$ & $1.4 a$ & $91.0 a$ & $2.4 a$ & $1.8 a$ \\
\hline $\mathrm{UAN}+\mathrm{BION}^{\circledR} 250 \mathrm{ppm} / \mathrm{BBCH} 30$ & $91.9 a$ & $2.51 \mathrm{a}$ & $1.4 a$ & - & - & - \\
\hline $\mathrm{UAN}+\mathrm{BION}^{\circledR} 500 \mathrm{ppm} / \mathrm{BBCH} 30$ & $91.9 a$ & $2.56 a$ & $1.3 a$ & - & - & - \\
\hline \multicolumn{7}{|l|}{ PR64H41 } \\
\hline Control & $88.0 a$ & $4.74 a$ & $2.1 \mathrm{a}$ & $85.8 a$ & $6.3 a$ & $2.8 a$ \\
\hline $\mathrm{UAN}+\mathrm{BION}^{\circledR}$ 250ppm/BBCH16 & $88.9 a$ & $3.89 a$ & $2.2 a$ & $87.1 \mathrm{a}$ & $5.1 \mathrm{a}$ & $2.7 a$ \\
\hline $\mathrm{UAN}+\mathrm{BION}^{\circledR} 500 \mathrm{ppm} / \mathrm{BBCH} 16$ & $88.6 a$ & $4.36 a$ & $2.1 \mathrm{a}$ & $87.6 a$ & $4.4 a$ & $2.8 a$ \\
\hline $\mathrm{UAN}+\mathrm{BION}^{\circledR} 250 \mathrm{ppm} / \mathrm{BBCH} 30$ & $88.5 a$ & $4.52 a$ & $2.2 a$ & - & - & - \\
\hline $\mathrm{UAN}+\mathrm{BION}^{\circledR} 500 \mathrm{ppm} / \mathrm{BBCH} 30$ & $89.2 a$ & $3.79 a$ & $2.1 \mathrm{a}$ & - & - & - \\
\hline \multicolumn{7}{|l|}{ AURASOL } \\
\hline Control & $87.9 a$ & $4.37 a$ & $2.5 a$ & $89.1 a$ & $3.5 b$ & $2.6 a$ \\
\hline UAN+BION ${ }^{\circledR} 250 p p m / B B C H 16$ & $89.5 a$ & $3.54 a b$ & 2.2b & $87.8 b$ & 4.3a & $3.0 a$ \\
\hline $\mathrm{UAN}+\mathrm{BION}^{\circledR} 500 \mathrm{ppm} / \mathrm{BBCH} 16$ & $88.9 a$ & $3.90 \mathrm{ab}$ & $2.4 a b$ & $87.4 b$ & 4.5a & $3.0 a$ \\
\hline $\mathrm{UAN}+\mathrm{BION}^{\circledR} 250 \mathrm{ppm} / \mathrm{BBCH} 30$ & $89.0 a$ & $3.90 \mathrm{ab}$ & 2.3b & - & - & - \\
\hline $\mathrm{UAN}+\mathrm{BION}^{\circledR} 500 \mathrm{ppm} / \mathrm{BBCH} 30$ & $89.4 a$ & $2.88 b$ & 2.4b & - & - & - \\
\hline
\end{tabular}

${ }^{*}$ UAN: urea ammonium nitrate solution $(48 \mathrm{kgN} / \mathrm{ha}$ at Braunschweig and $50 \mathrm{kgN} / \mathrm{ha}$ at Eckartsweier), 


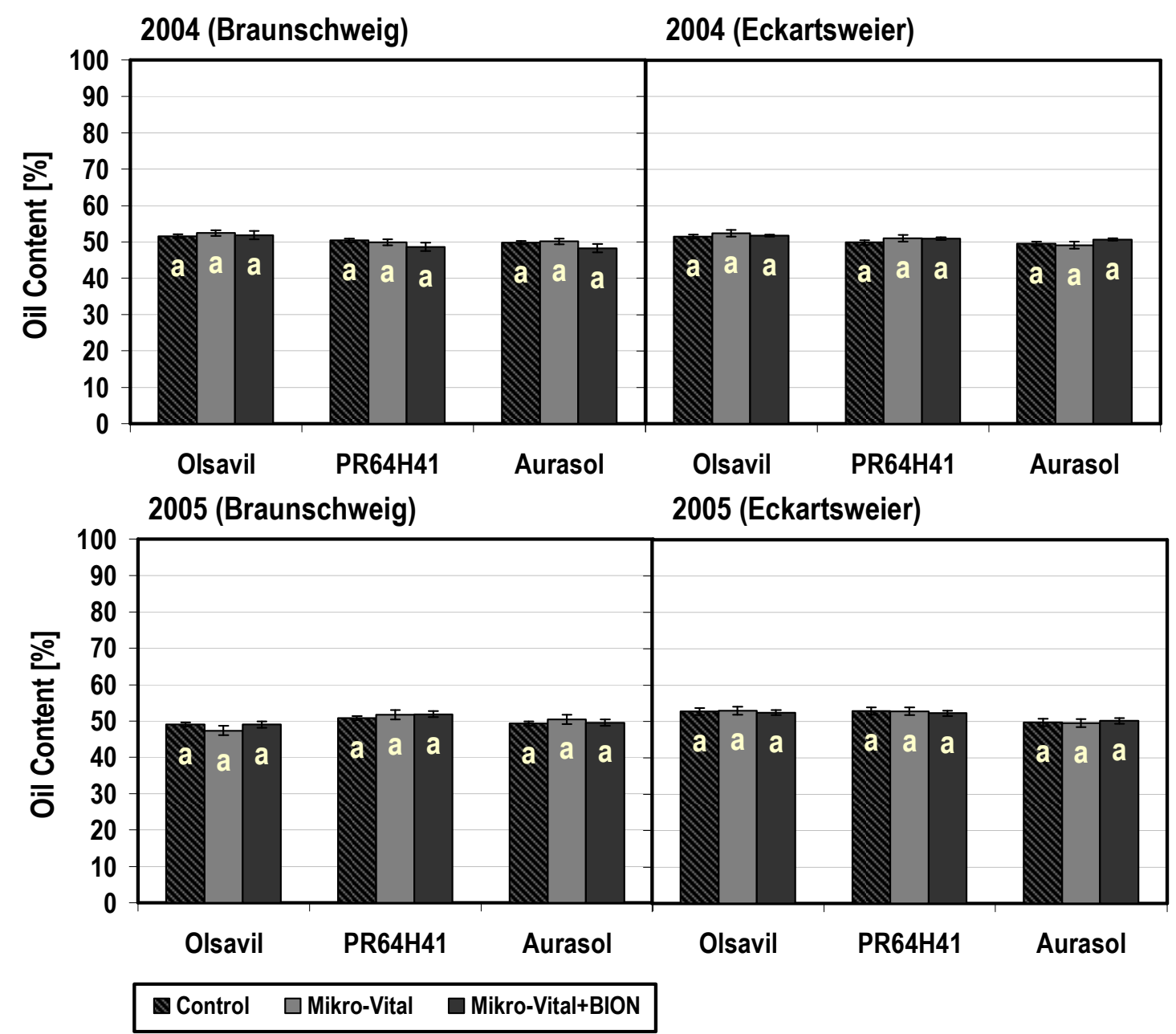

Figure A.9: Influence of Mikro-Vital and its combination with $\mathrm{BION}^{\circledR}$ on oil content (\%) of all varieties at Braunschweig in 2004-2005.

Table A.34: Influence of Mikro-Vital and its combination with $\mathrm{BION}^{\circledR}$ on oil composition (\%) for all three varieties at both experiment sites in 2004.

\begin{tabular}{|c|c|c|c|c|c|c|}
\hline & \multicolumn{3}{|c|}{ BRAUNSCHWEIG } & \multicolumn{3}{|c|}{ ECKARTSWEIER } \\
\hline & $\begin{array}{c}\text { Oleic } \\
\text { acid (\%) }\end{array}$ & $\begin{array}{l}\text { Linoleic } \\
\text { acid (\%) }\end{array}$ & $\begin{array}{c}\text { Stearic } \\
\text { acid (\%) }\end{array}$ & $\begin{array}{c}\text { Oleic } \\
\text { acid (\%) }\end{array}$ & $\begin{array}{l}\text { Linoleic } \\
\text { acid (\%) }\end{array}$ & $\begin{array}{c}\text { Stearic } \\
\text { acid (\%) }\end{array}$ \\
\hline \multicolumn{7}{|l|}{ OLSAVIL } \\
\hline Control & $91.6 a$ & $2.1 \mathrm{a}$ & $1.4 a$ & $91.3 a$ & $2.3 a$ & $1.8 \mathrm{a}$ \\
\hline Mikro-Vital & $91.8 a$ & $2.3 a$ & $1.4 a$ & $91.6 a$ & $2.3 a$ & $1.6 a$ \\
\hline Mikro-Vital+ ${ }^{*} \mathrm{BION}^{\circledR}$ & $91.9 a$ & $2.3 a$ & $1.3 a$ & $91.1 \mathrm{a}$ & $2.1 a$ & $1.7 a$ \\
\hline \multicolumn{7}{|l|}{ PR64H41 } \\
\hline Control & $88.0 a$ & $4.7 a$ & $2.1 a$ & $85.8 a$ & $6.3 a$ & $2.8 a$ \\
\hline Mikro-Vital & $88.5 a$ & $4.1 \mathrm{a}$ & $2.1 \mathrm{a}$ & $87.8 a$ & $4.7 a$ & $2.6 a$ \\
\hline Mikro-Vital+BION $^{\circledR}$ & $87.6 a$ & $4.9 a$ & $2.1 \mathrm{a}$ & $87.3 a$ & $5.1 a$ & $2.6 a$ \\
\hline \multicolumn{7}{|l|}{ AURASOL } \\
\hline Control & $87.9 a$ & $4.3 a$ & $2.5 a$ & $89.1 a$ & $3.5 b$ & $2.6 a$ \\
\hline Mikro-Vital & $88.5 a$ & $3.9 a$ & $2.5 a$ & 88.8ab & $3.4 \mathrm{~b}$ & $2.9 a$ \\
\hline Mikro-Vital+BION ${ }^{\circledR}$ & $88.2 a$ & $3.9 a$ & $2.6 a$ & $87.2 b$ & $4.8 a$ & $2.9 a$ \\
\hline
\end{tabular}

${ }^{*} \mathrm{BION}^{\Theta}$ : applied 125ppm at $\mathrm{BBCH} 16$ growth stage 
Table A.35: Influence of Mikro-Vital and its combination with $\mathrm{BION}^{\circledR}$ on oil composition (\%) for all three varieties at both experiment sites in 2005.

\begin{tabular}{|c|c|c|c|c|c|c|}
\hline & \multicolumn{3}{|c|}{ BRAUNSCHWEIG } & \multicolumn{3}{|c|}{ ECKARTSWEIER } \\
\hline & $\begin{array}{c}\text { Oleic } \\
\text { acid }(\%)\end{array}$ & $\begin{array}{l}\text { Linoleic } \\
\text { acid (\%) }\end{array}$ & $\begin{array}{c}\text { Stearic } \\
\text { acid (\%) }\end{array}$ & $\begin{array}{c}\text { Oleic } \\
\text { acid (\%) }\end{array}$ & $\begin{array}{l}\text { Linoleic } \\
\text { acid (\%) }\end{array}$ & $\begin{array}{c}\text { Stearic } \\
\text { acid (\%) }\end{array}$ \\
\hline \multicolumn{7}{|l|}{ OLSAVIL } \\
\hline Control & $90.4 a$ & $3.6 a$ & $1.5 a$ & $90.8 a$ & $3.1 a$ & $1.7 a$ \\
\hline Mikro-Vital & $90.0 a$ & $3.9 a$ & $1.6 a$ & $91.0 \mathrm{a}$ & $3.0 \mathrm{a}$ & $1.6 a$ \\
\hline Mikro-Vital+ ${ }^{*} \mathrm{BION}^{\circledR}$ & $90.5 a$ & $3.6 a$ & $1.5 a$ & $90.8 a$ & $3.1 \mathrm{a}$ & $1.7 a$ \\
\hline \multicolumn{7}{|l|}{ PR64H41 } \\
\hline Control & $85.2 a$ & $7.1 \mathrm{a}$ & $2.8 a$ & $84.2 a$ & $8.1 a$ & $2.8 a$ \\
\hline Mikro-Vital & $84.9 a$ & $7.4 a$ & $2.8 a$ & $84.8 a$ & $7.5 a$ & $2.8 a$ \\
\hline Mikro-Vital+BION ${ }^{\circledR}$ & $85.1 \mathrm{a}$ & $7.4 a$ & $2.7 a$ & $85.2 a$ & $7.1 \mathrm{a}$ & $2.9 a$ \\
\hline \multicolumn{7}{|l|}{ AURASOL } \\
\hline Control & $84.8 a$ & $7.3 a$ & $3.1 a$ & $86.6 a$ & $5.5 a$ & $3.2 a$ \\
\hline Mikro-Vital & $86.0 a$ & $6.3 a$ & $3.0 \mathrm{a}$ & $84.9 a$ & $6.9 a$ & $3.3 a$ \\
\hline Mikro-Vital+BION $^{\circledR}$ & $85.5 a$ & $6.7 a$ & $3.1 \mathrm{a}$ & $86.1 \mathrm{a}$ & $6.0 a$ & $3.1 \mathrm{a}$ \\
\hline
\end{tabular}

${ }^{*} \mathrm{BION}^{\circledR}$ : applied 125ppm at $\mathrm{BBCH} 16$ growth stage 


\section{ACKNOWLEDGEMENTS}

It would not have been possible to write this thesis without the help and support of the great people around me, to only some of whom I can give particular mention here. I am very thankful to Prof. Dr. Jörg Michael Greef for guiding me through the dissertation process with his most inspiring and creative suggestions and with his outstanding knowledge. As my co-referee, I would like to thank Prof. Dr. Elke Pawelzik for her valuable ideas and quick reading of my thesis. I also thank Prof. Dr. Andreas von Tiedemann for willingly accepting to be my second examiner.

This thesis would not have been possible without the help and patience of my dearest supervisor, Dr. Gerhard Rühl who never accepted less than my best efforts. His support and contribution has been invaluable on both academic and personal level during my complete $\mathrm{PhD}$ and even during my scientific career starting from my internship at the FAL, for which I am extremely grateful.

My special acknowledgement goes to the most friendly and competent support of all scientific collages at the Institute of Crop and Soil Science of JKI. I appreciate very much the help of Barbara Graff and Martina Liehr with the evaluation and organization of my data during the field trials and Christina Methner, Martina Küchental, Dirk Hillegeist, and Bernd Arnemann with the biochemical analyses. My warmest thanks go to Dagmar Strerart and Claudia Lüders for the excellent team work at the laboratory and for their patience and diligence. I also would like to thank Dieter Strauss for his support with the statistical analysis with his friendly attitude.

I would like to acknowledge the financial support of the Agency for Renewable Resources (FNR) that provided the necessary funds for this research.

My warmest thanks go to my collages Andreas Bramm, Martin Kücke, and Frank Höppner who believed in me, motivated and supported me through my PhD. I also would like to thank the lovely Family Häußler as a stepstone in my career and as the starting point of my new life in Germany. They've been a great help and encourage. I still appreciate the grand academic and personal support of my very first mentor Prof. Dr. Turan Saglamtimur of the Cukurova University in Turkey, who encouraged my 'studying abroad' idea, pushed me out, and guided me with his brilliant experiences through my academic career.

I want to thank my family for accepting my choices, for supporting me financially and morally, for bearing my absence from home and choosing a new home for myself in Germany. I would like to thank my friends for the power they gave me, even when I was exhausted and past hope, in particular my dearest friend Güçlü for his 24/7 available motivation speeches and for believing in me more than anyone in my life, also Victor for his great motivation boosts, and Fazi and Çiğdem for keeping me strong and cheerful. Last but definitely not least, I'm thanking my loving partner "Mike, thank you for being there for me at the last and the most stressful stage of my dissertation, for your understanding, for self made food deliveries to my office in the middle of the night, for continuous Red Bull supply when I had to stay awake, and for going through the hardest bit with me." 


\section{Curriculum VitAE}

\begin{tabular}{|c|c|c|}
\hline Personal Data & $\begin{array}{l}\text { Name } \\
\text { Birth } \\
\text { Nationality } \\
\text { Marital status }\end{array}$ & $\begin{array}{l}\text { Burcin Dilci } \\
\text { 28.01.1978 Ankara, Turkey } \\
\text { Turkish } \\
\text { Single }\end{array}$ \\
\hline ScHOOL EdUCATION & $\begin{array}{l}1983-1988 \\
1988-1989 \\
1989-1991 \\
1991-1993 \\
1993-1994\end{array}$ & $\begin{array}{l}\text { Gazipasa Primary School, Kayseri. } \\
\text { Dedeman Elementary School, Kayseri } \\
\text { Central Elementary School, Izmit } \\
\text { Central Gymnasium, Izmit } \\
\text { Askale Gymnasium, Erzurum }\end{array}$ \\
\hline UNIVERSITY EdUCATION & $\begin{array}{c}1994-1998 \\
1999-2002\end{array}$ & $\begin{array}{l}\text { B.Sc. University of Cukurova, Agriculture, } \\
\text { Crop Science, Adana, Turkey } \\
\text { M.Sc. University of Hohenheim, Agricultural } \\
\text { Sciences, „Food Security and Natural } \\
\text { Resource Management in the Tropics and } \\
\text { Subtropics“, Stuttgart, Germany }\end{array}$ \\
\hline Practical TrainING & $\begin{array}{r}1996 \\
1997 \\
1998\end{array}$ & $\begin{array}{l}\text { University of Cukurova, Research Station of } \\
\text { Agricultural Faculty, Adana, Turkey } \\
\text { Bioland, Franz Häußler, Schwörzkirch, } \\
\text { Germany } \\
\text { Federal Agricultural Research Centre, } \\
\text { Institute of Crop and Grassland Science, } \\
\text { Braunschweig, Germany }\end{array}$ \\
\hline EMPLOYMENT & 2008-date & $\begin{array}{l}\text { Research Scientist, Federal Agricultural } \\
\text { Research Centre (FAL), Institute of Crop } \\
\text { and Grassland Science, Braunschweig, } \\
\text { Germany } \\
\text { Research Scientist, Federal Research } \\
\text { Centre for Cultivated Plants - Julius Kuehn } \\
\text { Institute (JKI), Institute of Crop and Soil } \\
\text { Science, Braunschweig, Germany }\end{array}$ \\
\hline
\end{tabular}

